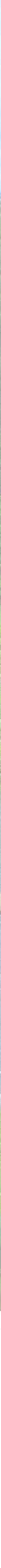

Editors

James Reed

Mirjam Ros-Tonen

Terry Sunderland 


\section{Operationalizing integrated landscape approaches in the tropics}

\section{Editors}

James Reed

Mirjam Ros-Tonen

Terry Sunderland 
(c) 2020 by the Center for International Forestry Research.

All rights reserved.

Content in this publication is licensed under a Creative Commons Attribution 4.0

International (CC BY 4.0), http://creativecommons.org/licenses/by/4.0/

ISBN 978-602-387-138-4

DOI: $10.17528 /$ cifor/007800

Reed J, Ros-Tonen M and Sunderland T. 2020. Operationalizing integrated landscape approaches in the tropics. Bogor, Indonesia: CIFOR.

Photo credits:

Cover $\odot$ Terry Sunderland

Aerial view of mosaic landscape, Gunung Halimun National Park, West Java, Indonesia.

Chapter 1: Aerial view of Nalma village - Mokhamad Edliadi/CIFOR

Chapter 2: Rice field with mountain and houses during cloudy day, Thailand - icon0.com from Pexels

Chapter 3: Afternoon view at Nalma village - Mokhamad Edliadi/CIFOR

Chapter 4: Deforested lands - Tomas Munita/CIFOR

Chapter 5: Peatland forest in RMU concession, Katingan, Central Kalimantan

- Nanang Sujana/CIFOR

Chapter 6: Spiderweb paddies (lingko fields) in Cancar village - Aulia Erlangga/CIFOR

Chapter 7: Aerial view of West Kalimantan - Nanang Sujana/CIFOR

Chapter 8: Shea trees and farming near Chiana, Kassena Nankana District, Ghana - Axel Fassio/CIFOR

Chapter 9: Cattle in Kalomo - Kaala B Moombe/CIFOR

Chapter 10: Fishing boat in protected lake in Empangao - Lucy McHugh/CIFOR

Chapter 11: Forest cover Mbazzi, Mpigi district - John Baptist Wandera/CIFOR

Designed by CIFOR's Digital and Publishing Team

\section{CIFOR}

Jl. CIFOR, Situ Gede

Bogor Barat 16115

Indonesia

$\mathrm{T}+62(251) 8622-622$

$\mathrm{F}+62(251) 8622-100$

E cifor@cgiar.org

\section{cifor.org}

We would like to thank all funding partners who supported this research through their contributions to the CGIAR Fund. For a full list of the 'CGIAR Fund' funding partners please see: http://www.cgiar.org/who-we-are/cgiar-fund/fund-donors-2/

Any views expressed in this publication are those of the authors. They do not necessarily represent the views of CIFOR, the editors, the authors' institutions, the financial sponsors or the reviewers. 


\section{Contents}

Foreword

Acknowledgements vi

Author bios viii

Acronyms xiii

Executive summary $\quad$ xvii

1 Introduction and background 1

James Reed, Mirjam Ros-Tonen and Terry Sunderland

$2 \quad$ Integrated landscape approaches in the tropics 16

James Reed, Amy Ickowitz, Colas Chervier, Houria Djoudi, Kaala B Moombe, Mirjam Ros-Tonen, Malaika Yanou, Elizabeth L Yuliani and Terry Sunderland

3 The role of biodiversity in integrated landscape approaches 32 Joli R Borah, Yves Laumonier, Eric RC Bayala, Houria Djoudi, Davison Gumbo, Kaala B Moombe, Elizabeth L Yuliani and Mathurin Zida

4 Engaging multiple stakeholders to reconcile climate, conservation and development objectives in tropical landscapes

James Reed, Jos Barlow, Rachel Carmenta, Josh van Vianen and Terry Sunderland

5 Theories of change and monitoring and evaluation types for landscape approaches

Colas Chervier, Marie-Gabrielle Piketty and James Reed

6 A methods toolbox for integrated landscape approaches

James Reed, Joli Rumi Borah, Colas Chervier, James Langston, Moira Moeliono, Alida O'Connor, Elizabeth L Yuliani and Terry Sunderland

7 Potential for integration? An assessment of national environment and development policies

Alida O'Connor, Houria Djoudi, Moira Moeliono, Kaala B Moombe and

Freddie Sayi Siangulube

8 Context for landscape approach implementation in the Western Wildlife Corridor Landscape (Northern Chana)

Eric RC Bayala, Houria Djoudi, Mirjam Ros-Tonen and Mathurin Zida

9 Understanding landscape dynamics: A case study from Kalomo District

Kaala B Moombe, Freddie S Siangulube, Bravedo M Mwaanga, Tiza I Mfuni, Malaika P Yanou, Davison J Gumbo, Rays C Mwansa and Gilbert Juunza

10 Kapuas Hulu: A background analysis to implementing integrated landscape approaches in Indonesia

Augusta M Anandi, Elizabeth L Yuliani, Moira Moeliono, Yves Laumonier and Sari Narulita

11 Conclusion and the way forward 


\section{List of figures, tables and boxes}

\section{Figures}

1.1 Ten principles for integrated landscape approaches 5

5.1 Comparison of the three types of evaluation 81

5.2 Example of a generic causal chain for a landscape approach 83

6.1 An overview of the methods described in this chapter, their general purpose and the landscape approach principles and actions to which they apply.

Methods are broadly arranged chronologically but in practice may be iteratively applied as required

6.2 Example of visualization of two possible future scenarios seen by local people and other stakeholders in La Paloma, Uruguay

7.1 National development planning process

7.2 Common landscape approach principles found across each country's national development plans

7.3 Landscape approach principles requiring further action 121

8.1 Spatial distribution of CREMAs

8.2 The Sanyiga Kasena Gavara Kara (SKCK) CREMA 129

$\begin{array}{ll}8.3 & \text { The Builsa Yenning CREMA } \\ 830\end{array}$

8.4 The Moagduri Wuntaluri Kuwosaasi CREMA 130

8.5 Bags of charcoal for sale at the outskirts of the Mole National Park. 135

8.6 Clearing of new farms in Northern Chana (CREMA of Murungu-Mognoré) 135

\begin{tabular}{ll}
9.1 & Location and administrative map of Kalomo District \\
\hline
\end{tabular}

$\begin{array}{ll}9.2 & \text { Initial candidate districts for the COLANDS initiative }\end{array}$

9.3 Rainfall amounts in Kalomo District (15-year period) 156

9.4 Kalomo vegetation 156

9.5 Kalomo land cover/land use (Map A) and distribution of forests (Map B) 160

9.6 Maize production in Kalomo District in metric tonnes (2010-2018) 163

$\begin{array}{lll}\text { 9.7 Dam distribution by the period of construction } & 164\end{array}$

10.1. Situation map, vegetation and study sites in the sub-watersheds Labian-Leboyan and Seriang

\section{Tables}

1.1 Selected global targets and integrated landscape approaches 3

5.1 The most used counterfactual methods $\quad 85$

$\begin{array}{ll}\text { 8.1 Characteristics of CREMAS } & 131\end{array}$

8.2 Preliminary stakeholder inventory in the study area 141

9.1 Prominent policies to manage the African-immigrant settler production systems 154

$\begin{array}{lll}9.2 & \text { Soil features of Kalomo topographical zones } & 157\end{array}$

9.3 Kalomo Hills Local Forest Reserve land cover 161

9.4 Livestock distribution in Kalomo District 161

9.5 Chiefdom hierarchical governance structure and key functions: The case of
Kalomo District

9.6 Key challenges to the implementation of landscape approaches in Kalomo

10.1 Statutory authorities in Kapuas Hulu and their basis in Indonesian legislation 188

\section{Boxes}

8.1 Rosewood between local community livelihoods and export product 134

8.2 Shea: an under-valued source of income 138

9.1 Some key projects/initiatives (see also Chapter 3) 152

9.2 Organizations represented in the implementation of the COLANDS initiative in Kalomo District 


\section{Foreword}

Sectorial approaches to land management have singularly failed to fully integrate the fields of forestry, agriculture, health, infrastructure development, education, etc. This has led to a scattergun approach to solving problems related to both biodiversity conservation and socio-economic development. As a response, integrated landscape approaches have been, under various names, at the forefront of the sustainable development discourse. Such approaches have been advocated as a means of achieving global commitments as well as reconciling oft-competing land uses.

Over the past 20 years, forests and the landscapes in which they occur have been a central focus of the research strategy and actions of the Center for International Forestry Research (CIFOR). While great strides have been made in the "theory" of integrated landscape approaches, evidence of success on the ground remains elusive. Managing landscapes in their entirety is complex, with the need to reconcile the needs and aspirations of multiple stakeholders and their interests.

We need action on the ground to test our theories, and we need to honestly evaluate the impacts of such actions. The COLANDS initiative, funded by the International Climate Initiative (IKI) of the German Federal Ministry for the Environment, Nature Conservation, Building and Nuclear Safety is a real-life attempt at identifying what works at scale in the landscape and, perhaps as importantly, what doesn't. This book, coming around halfway into the implementation of COLANDS, presents a sanguine overview of the differing geographical, social and political contexts of the selected landscapes in each target country - Indonesia, Zambia and Ghana - and identifies the main drivers that have a dynamic influence on the trajectories of change in each. This is a first attempt to describe the opportunities and constraints to landscape-scale integration of differing land uses, negotiating with multiple stakeholders and just what role research organizations such as CIFOR and our partners can play in creating a world characterized by sustainable and self-supporting landscapes.

Only by honest and evidence-based reporting, as presented in this book, will we know if integrated landscape management is truly the answer to the numerous problems facing our contemporary environment and wider society. We have spent many years "talking the talk" - now is the time for "walking the walk".

\section{Robert Nasi}

Director General, CIFOR

Managing Director, CIFOR-ICRAF

Acting Director of Science, CIFOR-ICRAF 


\section{Acknowledgements}

The COLANDS team would like to express its sincere thanks to the individuals, communities and organizations across each of the study sites who graciously gave, and continue to give, their time, energy and knowledge to support and complement COLANDS research activities.

COLANDS Ghana thanks the Forestry Commission of Ghana, our partner in the COLANDS initiative, and all relevant stakeholders we met during a scoping trip that was undertaken in Ghana in 2019 - at both the central level, and at regional and local levels in Northern Ghana. They provided COLANDS with valuable contextual insights informing the COLANDS implementing site in Ghana. In addition, COLANDS Ghana is grateful to Thomas Addoah for his invaluable support during the scoping study.

COLANDS Zambia would like to thank Cosmas Chiiba (District Commissioner for Kalomo), Coy Makaya (Chairman for Kalomo Town Council), the government Heads of Department at provincial level in Choma, and at district level in Kalomo for supporting and facilitating activities under COLANDS. The Zambia team also thanks the Forestry Department in the Ministry of Lands and Natural Resources, Ministry of Chiefs and Traditional Affairs and the Zambia Community-Based Natural Resources Management Forum for leading the stakeholder buy-in of the initiative. COLANDS would like to recognize the leadership of the three Chiefs - Chikanta, Siachitema and Sipatunyana with their community members (headmen, councillors and others), especially in our working villages, for their willingness to dialogue with and support COLANDS. Members of the Consultative Working Group are recognized for their effective participation in planning, data acquisition and reviews of project activities. We would also like to thank the Research Assistants (Jive Mulundano, Mike Simbeleko and Lubomba Bwembelo) for local level coordination, mobilization and generation of information and feedback; and the entire CIFOR Zambia office for planning and implementation of activities.

COLANDS Indonesia wishes to thank the following institutions: the Executive Office of the President of Indonesia and the Government of Indonesia, Ministry of Environment and Forestry of the Republic of Indonesia, Government of West Kalimantan Province and Kapuas Hulu Regency, Riak Bumi NGO, and local communities in our project sites; and the following individuals for their tremendous advice and support: Enda Ginting MSc, Dr. Agus Justianto, Valentinus Heri, Dr. Retno Maryani and Dr. Deden Djaenudin.

We thank CIFOR and COLANDS communications staff for their invaluable editorial and publication support. Special thanks go to Sandra Cordon who worked tirelessly to edit, review, proofread and support coordination of the book; your commitment more broadly with your engagement with COLANDS is greatly appreciated. Special thanks also to Gideon Suharyanto and Vidya Fitrian, who were an incredible support and source of guidance throughout the editing and publishing process. 
The research within this book is part of the CGIAR Research Program on Forests, Trees and Agroforestry (CRP-FTA). This collaborative program aims to enhance the management and use of forests, agroforestry and tree genetic resources across the landscape, from forests to farms. CIFOR leads CRP-FTA in partnership with Bioversity International, CATIE, CIRAD and the International Center for Tropical Agriculture and the World Agroforestry Centre.

We are extremely grateful for funding for this research and book which was provided by the International Climate Initiative (IKI) of the German Federal Ministry for the Environment, Nature Conservation, Building and Nuclear Safety (BMUB) grant 18 IV_084 and the United States Agency for International Development (USAID) Forest and Biodiversity Office. 


\section{Author bios}

Augusta M Anandi is a $\mathrm{PhD}$ candidate at the Amsterdam Institute for Social Science Research (AISSR) of the University of Amsterdam. She is also affiliated with Center for International Forestry Research (CIFOR) and the COLANDS initiative. Her research area is in Indonesia, focusing on customary arrangements, multi-stakeholder platforms and integrated landscape approaches. Augusta holds a Master's degree in environmental policy and management from the University of Adelaide, South Australia.

Jos Barlow is a Professor of Conservation Science at Lancaster University, UK, and a member of the teaching staff on post-graduate programs in the Federal Universities of Pará and Lavras in Brazil. His research examines the impacts of humans on tropical forests, and he is a co-founder of the Sustainable Amazon Network that seeks to use and promote science to find solutions to pressing social and environmental issues. He is executive editor of Journal of Applied Ecology.

Eric RC Bayala is a PhD candidate at the University of Amsterdam where he is affiliated with the Institute for Social Science Research (AISSR). He is also affiliated with the Center for International Forestry Research (CIFOR) through the COLANDS initiative. His research topic is about community engagement in landscape governance and prospects for operationalizing an integrated landscape approach in northern Ghana. He is particularly interested in the decision-making process in CREMAs (Community Resource Management Areas), the perceptions of local stakeholders and multi-stakeholder platforms. Eric holds a Master's degree in Geography (option Rural Geography) from the University of Ouagadougou (Burkina Faso) and a Master's degree in Development (option Protected Area Management) from Senghor University of Alexandria (Egypt).

Joli Rumi Borah is a Postdoctoral Research Fellow at Sunderland Lab, Faculty of Forestry in the University of British Columbia, Canada. Her broad research interests are sustainable management of agricultural landscapes for biodiversity conservation and human well-being and ecosystem services management. Her doctoral work at the University of Sheffield, UK assessed the potential of conservation interventions in effectively managing shifting cultivation for reducing biodiversity loss and carbon emission in Northeast India. Post-PhD, she worked as a Conservation Officer at Royal Society for Protection of Birds (RSPB) that involved providing conservation advice to farmers for sustainable management of the Irish countryside in County Fermanagh, Northern Ireland.

Rachel Carmenta is Tyndall Lecturer in Climate Change and International Development at the University of East Anglia. Her work is at the intersection of environment and development, environmental risk and climate change mitigation and the relationship between place and well-being, focused particularly on the design and social equity of environmental governance.

Colas Chervier is an economist at CIRAD (the French agricultural research and international cooperation organization working for the sustainable development 
of tropical and Mediterranean regions). He specializes in the evaluation of policies/ interventions for natural resource conservation and sustainable management. He is more specifically interested in how economic, fiscal and administrative incentives (e.g. payments for environmental services) can help change the behavior of land users (farmers) and bureaucrats/authorities. He relies on counterfactual and qualitative methods for causal inference and the use of theories of change to analyze the design, the effectiveness and the conditions of effectiveness of such interventions. He is currently interested in applying these methods to the evaluation of landscape and jurisdictional approaches to zero deforestation.

Houria Djoudi is a senior scientist at the Center for International Forestry Research (CIFOR) in Bogor. She has 20 years of work experience in understanding human and ecosystem interaction in different socio-ecological systems in North and West Africa, Central Asia, and South East Asia. Houria's work focuses on socio-ecological systems analysis at the interface of environmental and institutional changes and policy processes. Her work has a strong focus on the questions of equity, particularly on the intersectional and gendered dimensions of conservation and development.

Davison Gumbo is a Technical Advisor for the CIFOR Zambia office based in Lusaka. He holds a PhD in geography from Clark University, USA. Davison's research interests center on contributing to a better understanding of the interface between social and ecological systems within the miombo and other dry forest ecosystems. His scientific work aims to integrate social and ecological sciences for sustainable livelihoods, better management of dry forests, as well as the development of more people-responsive forest and woodland policies.

Amy Ickowitz is a senior scientist at the Center for International Forestry Research (CIFOR) in Bogor, Indonesia where she leads the Sustainable Landscapes and Livelihoods team. She is a development and natural resource economist by training with a PhD in economics from the University of California, Riverside. Most of her recent research is multidisciplinary with a focus on issues of poverty, food insecurity, and malnutrition and the links between all of these and the natural environment. Her current research focuses on the impacts of landscape change on food security and nutrition.

Gilbert Munyati Juunza is a Technical Officer working with the Ministry of Agriculture under the Technical Services Branch, Land Husbandry Section in Kalomo District. During a rich and varied career, he has conceptualized and overseen agriculture land use planning and soil and water conservation of the District. He has also been involved in farm planning for commercial farms and settlement schemes. He is passionate about the use of land capability maps in land use planning for the sustainable use of natural resources.

James Langston is based out of the University of British Columbia, Canada, where he coordinates the Master of International Forestry program and contributes to its research portfolio for the Faculty of Forestry. He completed his PhD in 2019 on the Political Ecology of Spatial Development Initiatives in Indonesia. He continues to work with partners in contested landscapes where his research aims to achieve impact for more equitable and sustainable futures. 
Yves Laumonier has a State Doctoral Biogeography degree from the University of Toulouse, and is an Adjunct Professor in tropical ecology at that university, seconded to CIRAD, Montpellier and the CIFOR research center in Bogor, Indonesia. His focus is on landscape ecology, participatory land-use planning and tropical ecosystems functioning, from mangroves to mountain forests. Yves has been engaged with students in vegetation mapping, ethnobiology, multifunctional landscapes, traditional agroforestry systems in SE Asia for more than 40 years.

Tiza I Mfuni is a researcher in the Center for International Forestry Research' (CIFOR) Sustainable Landscapes and Livelihoods portfolio based in Zambia. Tiza's research interests are in modeling and predicting changes in landscape elements and processes, especially driven by livelihood strategies and climate variability. He is pursuing a Master's degree in Forestry and Wood Science at Stellenbosch University in South Africa and holds a Bachelor's degree in Geomatic Engineering.

Bravedo Mwaanga is a Research Officer at CIFOR Lusaka, Zambia. Bravedo holds a MSc. degree in Global Change Ecology from Bayreuth University, Germany and a Forestry background, BSc. Forestry from Copperbelt University in Zambia. Much of Bravedo's work explores the biophysical, social and the feedback loops existing thereof, across different landscapes surrounding ecological, environmental and societal changes. His work examines interesting aspects of land use changes and how these interact to impact livelihoods at subnational scales: from restoration, woodfuel value chains and feedstock management, conservation, habitat mapping to how local level institutions and practices play out across different landscapes. Much of this work has been practical, or hands-on.

Rays Chileya Mwansa is a second year student at Information and Communications University (ICU) studying for a BSc in Environmental Management System and is also third year law student at National Institute of Public Administration (NIPA). He works within the Forestry Department as District Forestry Officer for Kalomo, Southern Province, Zambia. His work explores sustainable forest management and abatement of climate change. He previously worked for Chaminuka Nature Reserve in Lusaka as Game Park Manager and for Lutheran World Federation in Mayukwayukwa Refugee Resettlement in Kaoma, Western Province as Project Field Officer in charge of Agriculture. He holds a Diploma in Forestry from Zambia Forestry College.

Kaala B Moombe (BSc \& MSc Forestry, University of Stellenbosch, South Africa) is a Senior Researcher at CIFOR Lusaka, Zambia. His current key research interest is in landscape political economy and ecology focusing on contestation / resistance (public and infrapolitics) in the context of the theory and practice of landscape approaches.

Sari Narulita is a GIS and remote sensing specialist at the Center for International Forestry Research (CIFOR) in Bogor, Indonesia. She works on spatial analysis data, mostly in land-use and land-cover change, deforestation, and fragmentation topics. She has experience as a research assistant for the Forest for Invasive Alien Species in South East Asia (FORIS) and also participates in some research in CIFOR, such as: Ecosystem Services Mapping Project in Kapuas Hulu, Financial Flow Mapping, Food Consumption Mapping in Indonesia, Forest and Freshwater Fish Consumption in Nigeria, Land Cover Change in Kapuas Hulu, and fragmentation in West Kalimantan. She holds a Master's 
degree in Natural Resource and Environmental Management and a Bachelor's degree in Forest Resource Conservation and Ecotourism from the IPB University, Indonesia.

Alida O'Connor is a PhD candidate based at the University of British Columbia's Department of Forest and Conservation Sciences in Vancouver, Canada. Alida's work explores the social dimensions of conservation through topics such as community-based conservation, local perceptions and values, and integrated landscape approaches. She holds a Master's degree in Resources, Environment, and Sustainability from the University of British Columbia and a combined Bachelor's in International Development and Environmental Sustainability from Dalhousie University in Halifax, Canada.

Marie Gabrielle Piketty, PhD, economist at CIRAD, works on the governance of sustainable development in forest territories of the Amazon. Her research focuses on private and public governance mechanisms affecting rural development and the sustainable management of natural resources in forest territories. She coordinates the "zero-deforestation" priority (18) of the Challenge Program FTA (Forest Trees and Agroforestry) and is leading the AFD TErrAmaz project aimed at supporting five Amazonian territories in Brazil, Colombia, Ecuador and Peru, in their transition towards zero-deforestation and sustainable development.

James Reed is a researcher at CIFOR, within the theme of Sustainable Landscapes and Livelihoods (SLL). His research focuses on strategies that seek to reconcile conservation and development objectives in the tropics.

Freddie Sayi Siangulube is a $\mathrm{PhD}$ candidate with the Amsterdam Institute for Social Science Research (AISSR) of the University of Amsterdam. His work focuses on multistakeholder platforms (MSPs) as institutions of environmental governance, particularly, MSP processes (rules and regulations) that facilitate successful implementation of integrated landscape approaches in Zambia. Freddie holds a Master's degree from Swedish University of Agricultural Sciences, a Bachelor of Science degree in Forestry from Copperbelt University (Zambia) and a postgraduate diploma in Heritage studies from University of Nairobi (Kenya).

Terry Sunderland is a Professor of Tropical Forestry at the University of British Columbia, Canada and a Senior Research Associate at the Centre for International Forestry Research, Indonesia. Terry is gathering evidence concerning the importance of forests and trees in the attainment of food security, biodiversity conservation and suggests a more integrated approach to land management.

Mirjam Ros-Tonen is associate professor at the Department of Social Geography, Planning \& International Development Studies at the University of Amsterdam. She coordinates projects on integrated landscape approaches, inclusive value chain collaboration, knowledge co-creation, and the mining-farming interface, which she aims to combine into a holistic approach toward inclusive and integrated forest and landscape governance. The current geographical focus of her research is on Ghana, South Africa, Zambia, Burkina Faso and Indonesia, but $\mathrm{PhD}$ supervision has also included research in Cameroon, Kenya and Honduras. Mirjam holds a Master's degree in Human Geography and a PhD in Policy Sciences, based on research on the timber industry in Brazilian Amazonia. 
Josh van Vianen is based in Indonesia and is a Director at Sustainability Tech and Technical Manager at Forest Carbon. Josh works on the application of nascent technologies to large landscape level climate change mitigation and forest conservation projects by developing integrated real time management tools. He holds a Master's degree in Ecology, from the University of Canterbury, New Zealand. His research background covers a range of topics from integrated landscape approaches, to ecosystems services, integrated pest control and plant conservation genetics.

Elizabeth Linda Yuliani is a scientist and has been working in CIFOR since 2000 . Her research interests are ecology, adaptation and resilience of social-ecological systems, wildlife conservation, traditional knowledge and community-based conservation, and governance of protected areas. Most of Linda's field research has been in Indonesia with a special focus on Kapuas Hulu, West Kalimantan where she has worked on various projects since 2004 . She has also carried out research in Jambi and in South and Southeast Sulawesi. She obtained her degree in freshwater ecology from the Bandung Institute of Technology in 1994. She was awarded the British Chevening Award to study for a Master's degree in Ecology and Environmental Management at the University of York where she received her degree in 1999. She is currently a PhD candidate in environmental science at Radboud University Nijmegen in the Netherlands.

Malaika Pauline Yanou is a PhD candidate at the University of Amsterdam at the Institute for Social Science Research (AISSR). Her research focus is on the contribution of local knowledge to implement an integrated landscape approach in Zambia. She holds a MA in International relations and diplomatic affairs at the University of Bologna (Italy) and an MSc in food security and development at the University of Reading (UK). She is interested in decoloniality studies and visual anthropology.

Mathurin Zida is a scientist at CIFOR, within the theme of Sustainable Landscapes and Livelihoods. His research background is transdisciplinary, with a focus on smallholder livelihoods and how they relate to various topics, such as sustainable forest management, collective action, non-timber forest products, climate change, and integrated landscape approaches. 


\section{List of acronyms and abbreviations}

\begin{tabular}{|c|c|}
\hline 7NDP & Seventh National Development Plan 2017-2021 (Zambia) \\
\hline $\mathrm{ADB}$ & Asian Development Bank \\
\hline AFOLU & Agriculture, forestry and other land uses \\
\hline APDS & The forest honeybee collectors' association in Lake Sentarum (Indonesia) \\
\hline ARIES & Artificial intelligence for ecosystem services \\
\hline BAPPEDA & Regional Development Planning Board (Indonesia) \\
\hline BHL & Buruh harian lepas; daily laborers (Indonesia) \\
\hline BIG & Geospatial Information Agency (Indonesia) \\
\hline BKNP & Betung Kerihun National Park (Indonesia) \\
\hline BMUB & $\begin{array}{l}\text { Federal Ministry for the Environment, Nature Conservation, } \\
\text { Building and Nuclear Safety (Germany) }\end{array}$ \\
\hline BPDAS & Watershed Management Authority (Indonesia) \\
\hline BPS & Badan Pusat Statistik, Central Bureau of Statistics (Indonesia) \\
\hline CAGs & Cluster advisory groups (Zambia) \\
\hline $\mathrm{CBBA}^{\circledR}$ & Certification of Capability in Business Analysis ${ }^{\mathrm{TM}}$ \\
\hline CBD & United Nations Convention on Biological Diversity \\
\hline CBM & Community-based monitoring \\
\hline CBNRM & Community-based natural resource management \\
\hline CBNRMF & Community Based Natural Resources Management Forum (Zambia) \\
\hline CCDSP & Chikanta Chiefdom Development Strategic Plan 2012-2016 (Zambia) \\
\hline $\mathrm{CDF}$ & Community Development Fund (Zambia) \\
\hline CDT & Chikanta Development Trust (Zambia) \\
\hline CEC & CREMA Executive Committee (Ghana) \\
\hline CFM & Community forest management \\
\hline CIFOR & Center for International Forestry Research \\
\hline CIRAD & French Agricultural Research Centre for International Development \\
\hline COLANDS & $\begin{array}{l}\text { Collaborating to operationalize landscape approaches for nature, } \\
\text { development and sustainability }\end{array}$ \\
\hline CPCU & District Planning Coordinating Unit (Ghana) \\
\hline $\mathrm{CRB}$ & Community Resources Board (Zambia) \\
\hline CREMA & Community resource management area (Ghana) \\
\hline CRGC & Chikanta Royal Governance Council (Zambia) \\
\hline CRMC & Community Resource Management Committee (Ghana) \\
\hline CSO & Central Statistical Office (Zambia) \\
\hline CSPGs & Cross-sectorial planning groups (Ghana) \\
\hline DASHL & Directorate General of Watershed and Protected Forest (Indonesia) \\
\hline DDCC & District Development Coordinating Committee (Zambia) \\
\hline DFRNMP & $\begin{array}{l}\text { Decentralized forest and other natural resources management project } \\
\text { (Zambia) }\end{array}$ \\
\hline DHS & Demographic and Health Surveys \\
\hline DMTDP & District Medium-Term Development Plans (Ghana) \\
\hline DPMD & Village Community Empowerment Agency \\
\hline DSNP & Danau Sentarum National Park (Indonesia) \\
\hline
\end{tabular}


EPA Environmental Protection Agency (Ghana)

FAO Food and Agriculture Organization of the United Nations

FDMP Forestry development master plan (Ghana)

FIP Forest Investment Program

FLR Forest landscape restoration

FMU Forest management unit (Indonesia)

FORCLIME Forest and Climate Change Program (Indonesia)

FORIG Forestry Research Institute of Ghana

FRL National Forest Reference Level Plan (Ghana)

GHC Ghana cedi

GIS Geographical information systems

GIZ German International Collaboration

GLF Global Landscapes Forum

GMA Game management area (Zambia)

GDP Gross Domestic Product

GPGI Global person generated index

GPS Global positioning system

GRZ Government of the Republic of Zambia

$\mathrm{HoB} \quad$ Heart of Borneo

HRH His Royal Highness (title of address for Chiefs in Zambia)

ICDPs Integrated conservation and development projects

IDR Indonesian rupiah

IFS Improved farming scheme (Zambia)

IKI International Climate Initiative (Germany)

ILA Integrated landscape approach

InVEST Integrated Valuation of Environmental Services and Tradeoffs model

IPBES Intergovernmental Science-Policy Platform on Biodiversity and

Ecosystem Services

IPCC Intergovernmental Panel on Climate Change

ISPO Indonesian Sustainable Palm Oil

ITTO International Tropical Timber Organization

JFM Joint forest management (Zambia)

JKPP Participatory Mapping Network (Indonesia)

KEE Ecosystem Essential Area (Indonesia)

KEHATI Indonesian Biodiversity Foundation

KfW German state-owned development bank

KFR Kalomo Hills Local Forest Reserve (Zambia)

KLHS Strategic environmental assessment (Indonesia)

$\mathrm{KPH} \quad$ Indonesian term for Forest Management Unit

KPP Tourism Management Association (Indonesia)

KSDAE Directorate General of Conservation Natural Resources and Ecosystem

KSTOOLKIT Knowledge Sharing Toolkit

LA Landscape approach

LAC Latin America and the Caribbean

LPFN Landscapes for People, Food and Nature

LSMS Living standards measurement survey 


\begin{tabular}{|c|c|}
\hline LUS & Land usage survey \\
\hline$M \& E$ & Monitoring and evaluation \\
\hline MAB & UNESCO Man and the Biosphere zone \\
\hline MCB & Maize Control Board (Zambia) \\
\hline MCP & Maize Control Policy (Zambia) \\
\hline MESTI & Ministry of Environment, Science, Technology and Innovation (Ghana) \\
\hline MLNR & Ministry of Land and Natural Resources (Ghana) \\
\hline MLNREP & $\begin{array}{l}\text { Ministry of Land, Natural Resources and Environmental Protection } \\
\text { (Zambia) }\end{array}$ \\
\hline MMDAs & Metropolitan, municipal and district assemblies (Ghana) \\
\hline MNDP & Ministry of National Development Planning (Zambia) \\
\hline MNP & Mole National Park (Ghana) \\
\hline MoEF & Ministry of Environment and Forestry (Indonesia) \\
\hline MoFA & Ministry of Food and Agriculture (Ghana) \\
\hline MPs & Members of Parliament \\
\hline MTDP & Medium-Term National Development Policy (Ghana) \\
\hline MTS & Modified Taungya System (Ghana) \\
\hline MWK & Moagduri Wuntanluri Kuwomsaasi CREMA (Ghana) \\
\hline NAZ & National archives of Zambia \\
\hline NBSAP-2 & Zambia's second National Biodiversity Strategy and Action Plan \\
\hline NCCP & National climate change policy (Ghana) \\
\hline NDC & Nationally determined contribution \\
\hline NDPC & National Development Planning Commission (Ghana) \\
\hline NGO & Non-governmental organization \\
\hline NPCC & National policy on climate change (Zambia) \\
\hline NRAC & Northern Rhodesia African Congress \\
\hline NRB & Natural Resources Board (Zambia) \\
\hline NRM & Natural resource management \\
\hline NRP & Native Reserve Policy (Zambia) \\
\hline NSBC & Northern Savanna Biodiversity Conservation project (Ghana) \\
\hline NTFP & Non-timber forest product \\
\hline NTFP-EP & Non-timber forest products exchange program \\
\hline NWR & North-Western Rhodesia \\
\hline NYDF & New York Declaration on Forests \\
\hline PFM & Private forest management (Zambia) \\
\hline PGRC & Plant Genetic Resource Center (Ghana) \\
\hline PHPL & $\begin{array}{l}\text { Directorate General of Sustainable Production Forest Management } \\
\text { (Indonesia) }\end{array}$ \\
\hline PAs & Protected areas \\
\hline PNA & Policy network analysis \\
\hline PSKL & $\begin{array}{l}\text { Directorate General of Social Forestry and Environmental Partnership } \\
\text { (Indonesia) }\end{array}$ \\
\hline QUANSAL & Quantification of saliency \\
\hline $\mathrm{RCCs}$ & Regional coordinating councils (Ghana) \\
\hline RECO & Royal Establishment Council (Zambia) \\
\hline REDD & Reduced emissions from deforestation and forest degradation \\
\hline
\end{tabular}


REDD+ Reducing emissions from deforestation and forest degradation and the role of conservation, sustainable management of forests and enhancement of forest carbon stocks in developing countries

ROZ Republic of Zambia

RPJMN National Medium-Term Development Plan (Indonesia)

RPJPN National Long-Term Development Plan (Indonesia)

RTRW(K) Regional (regency) spatial land-use planning (Indonesia)

RTRWN National spatial planning (Indonesia)

SARI

SBSTA

SCM

SDGs

SFC

Savanna Agricultural Research Institute (Ghana)

SKGK

Subsidiary Body for Scientific and Technological Advice (UNFCCC)

SNA

Synthetic control method

Sustainable development goals

Savannah Fruits Company (Ghana)

SNAP

Sanyiga Kasena Gavara Kara CREMA (Ghana)

SOLVES

Social network analysis

STELLA

TBCAs

National Agricultural Policy (Zambia)

TFCA

$\mathrm{TN}$

TNC

Social values for ecosystem services

Systems thinking, experimental learning laboratory with animation

Transboundary biodiversity conservation areas

Tropical Forest Conservation Act

TNBKDS Betung Kerihun and Danau Sentarum National Park

$\mathrm{UBC}$

UDS

University of British Columbia

UN

University for Development Studies (Ghana)

UNDP

United Nations

UNFCCC United Nations Framework Convention on Climate Change

URPA

USD

UvA

American dollar

VDC

University of Amsterdam

VHR

Village Development Committees

VPC

Very high-resolution images

WDC

WWC

Village Productivity Committee (Zambia)

WWF

Ward development committees (Zambia)

ZIFLP

Western Wildlife Corridor (Ghana)

ZMW

World Wildlife Fund for Nature

Zambia Integrated Forest Landscape Project

Zambian kwacha 


\section{Executive summary}

There is growing commitment worldwide to Integrated Landscape Approaches (ILAs) that aim to achieve sustainable and resilient landscapes based on multi-stakeholder negotiation of trade-offs between potentially competing land uses. Targeting whole landscapes, such approaches are promising pathways toward reconciling global targets related to the Sustainable Development Goals (SDGs), the Aichi Biodiversity Targets, the Paris Climate Agreement, and the Bonn Challenge, with national policy objectives and local realities. Operationalizing integrated landscape approaches is, however, still in its infancy and requires guidance and monitoring. With support of the International Climate Initiative (IKI) of the Federal Ministry for the Environment, Nature Conservation, Building and Nuclear Safety (BMUB), the Collaborating to Operationalise Landscape Approaches for Nature, Development and Sustainability (COLANDS) initiative addresses this knowledge-implementation gap. It does so through multi-stakeholder consultation, building capacity to implement and evaluate integrated approaches to landscape governance, pilot testing of ILAs, and formulating global and national policy recommendations based on the lessons learned. This book describes insights and findings from the first years of COLANDS' activities.

Chapter $\mathbf{2}$ draws on recent literature to address four challenges to the implementation and maintenance of integrated landscape approaches: persistent science-practice-policy gaps in environmental governance; engagement of the private-sector; the dearth of evidence of implementation and effectiveness; and monitoring and evaluation. It calls for the implementation, upscaling, monitoring and evaluation of landscape approaches in varied contexts, building on mixed methods, transdisciplinary research and multiple forms of knowledge. The authors emphasize the need to address power differences and to recognize the heterogeneity of stakeholder and resource user groups, in order to achieve inclusive decision-making and landscape governance.

Biodiversity plays an important role in safeguarding food security, livelihoods and human well-being. Chapter 3 emphasizes the fact that incorporating biodiversity in integrated landscape management strategies is crucial for reconciling conservation and livelihoods in multifunctional landscapes. This requires careful consideration of trade-offs and synergies between biodiversity, ecosystem services and livelihoods at both local and landscape levels. Use of suitable biodiversity indicators, remote sensing, modeling techniques and citizen science programs can facilitate effective monitoring of biodiversity responses to conservation interventions. This can further lead to informed decision-making and sustainable management of landscapes for both biodiversity and livelihoods. The chapter highlights the main biodiversity challenges in the COLANDS countries, Ghana, Zambia and Indonesia.

Navigating the complexity of landscapes and its 'wicked problems' requires governance transformations, multi-stakeholder dialogue facilitated by bridging or boundary organizations, and overcoming disciplinary and administrative 'silos'. Yet, challenges to multi-stakeholder engagement abound: power imbalances, elite capture, a lack of 
political will and high transaction costs. Chapter 4 presents an evidence-based "toolkit" to overcome such challenges. Knowledge co-production, triple-loop learning and seeking consensus in multi-stakeholder platforms; enhancing stakeholders' understanding of landscape dynamics through modeling or scenario building; participatory development of a theory of change; and contextually appropriate incentives for pro-conservation behaviour can stimulate multi-stakeholder engagement in landscape approaches.

Chapter 5 highlights the importance of evaluation to assess the effectiveness and pathways to effectiveness of landscape approaches. Process analysis and impact evaluation can both be used to draw important lessons for the replication of landscape approaches in other contexts. Theories of change can improve the quality and credibility of all types of landscape approach evaluation. In order to allow for generalization, replication or adaptation of early landscape approach experience, such theories of change should integrate local knowledge and perspectives with scientific knowledge and theories. Theories of change are also a useful tool to identify the intervention dimension of landscape approaches and to make decisions about the methods and data to be used.

Building on the principles for integrated landscape approaches, Chapter 6 presents an overview of methods and data that can be used in landscape approaches. The methods described broadly fall under three themes: back-casting (identifying general historical trends), establishing current baseline conditions (stakeholders, networks, perceptions, subjective well-being, and capacity needs), and forecasting to generate projections of potential or desired futures and aid decision-making (rich pictures and scenario visualization, photovoice, and simulation modeling). Selecting methods that fulfil each of these themes can help to develop a more complete understanding of the past, present and future landscape dynamics and help identify potential needs, opportunities and challenges.

The policy contexts in the three countries of implementation and their alignment with the ten principles of integrated landscape approaches are analysed in Chapter 7. Despite differences in contexts and policies, common findings emerge. First, each country's national development plan calls for development that enhances adaptive management (principle 1) to foster a more resilient (principle 9) economy and environment, especially in the face of climate change. Second, the plans recognize multiple land uses (principle 4) and stakeholders (principle 5). These points are fundamental to the landscape approach process. Further, each country's development plan has an element of decentralizing land management rights and responsibilities to different stakeholder groups, but these well-intended policies had yet to be implemented or fell short in practice. In all three countries, there is a need to clarify rights and responsibilities (principle 7), enhance stakeholder capacity (principle 10), and identify common-concern entry points (principle 2) and a negotiated and transparent change logic (principle 6) at all levels from national to local.

Chapters 8-10 depict the contexts for implementing landscape approaches in Ghana, Zambia, and Indonesia. Each of these chapters provide a comprehensive description of the biophysical, socio-economic and governance context in which the landscape approaches will be piloted and documented. The chapters draw on a review of scientific 
and grey literature and scoping studies during which representatives of government agencies, NGOs, and representatives of the local population were interviewed.

The Ghana chapter depicts a savannah landscape in the north of the country marked by irregular rainfall. The Western Wildlife Corridor was chosen as the COLANDS implementation area. This area contains three community resource management areas (CREMAs) where local governance bodies and platforms engage local communities in the governance and management of natural resources, notably near wildlife reserves and national parks. This setting provides an interesting entry point for the implementation of landscape approaches to address the region's challenges related to climate change, conflicts between landscape users, the misfunctioning of management bodies, and the absence of a solid multi-stakeholder platform to facilitate collaboration and concerted decision-making between all key landscape stakeholders.

Located on a high plateau, Kolomo District in the Southern Province of Zambia is a landscape with a cool and dry climate, sandy loam soils, and a natural vegetation consisting of dry forests and woodlands. The Tonga people - the dominant population group - live on the sales of crops (mainly maize), livestock, and fisheries, complemented with the collection of wild fruits, mushrooms and honey, and trade in fuelwood, charcoal and handicrafts. The landscape faces various challenges to which landscape approaches may point to the way forward. Challenges include long-term changes in weather patterns; declining availability of grazing land; conflicts over access to natural resources and absence of conflict management; illegal natural resource use and charcoal production; deforestation; poor coordination between statutory, customary and private policies; incoherent policy guidance; and limited private sector involvement in natural management initiatives. However, enabling policies and stakeholder interest in solving land-use conflicts provide opportunities to implement landscape approaches.

The Indonesia chapter zooms in on Kapuas Hulu regency in West Kalimantan, where COLANDS activities focus on two sub-watersheds of the Kapuas watershed, each with distinct characteristics. Environmental, social, economic and governance challenges prevail in the landscape. These are inadequately addressed due to a complex institutional landscape in which national, provincial, regency and village authorities operate with different approaches and overlapping jurisdictions, responsibilities and budgets. The addition of ill-coordinated bilateral, NGO, public-private and private initiatives further complicates effective action. Yet, the work of NGOs has empowered communities and boosted their negotiation skills; made them aware of land-use and conservation issues; and enhanced their communications and networks. They have also continued or commenced community-based conservation-development initiatives, which can be promising entry points for the implementation of a landscape approach, if strengthened and upscaled to district or sub-watershed level. In parallel, existing discussion platforms could play a role in facilitating the necessary links between community, governmental and civic actors in the landscape for collaboration and mutual support.

Chapter 11 provides a synthesis and indicates the way forward. 

2018; Sachs et al. 2018; Independent Group of Scientists 2019; Zeng et al. 2020). The current COVID-19 pandemic will exacerbate these challenges and has highlighted both the fragility of many of our current operating systems and the dangers of ignoring their interconnectedness (Sunderland 2020).

Sectorial approaches are failing people and nature and many of the above referenced global reports now acknowledge the need for a transformative change instead of "business as usual" (IPBES 2019; IPCC 2019). As such, global policy commitments toward conservation and development increasingly acknowledge that more holistic approaches are required in order to better harmonize the needs of people and planet. Integrated landscape approaches (ILA) are such an example. Indeed, ILAs have been recognized as potential implementation pathways for achieving the SDGs, the Paris Climate Agreement, the Bonn Challenge, and the Aichi and post-2020 biodiversity targets, amongst others (Table 1.1).

As such, ILAs are now central in international dialogues related to biodiversity conservation, livelihoods of marginalized groups, food security and broader development issues as evidenced by the successes of the recent high-profile Global Landscapes Forum (GLF) events ${ }^{1}$. Landscape approaches integrate research, policy and practice concerned with competing land uses to reconcile national level challenges of balancing demands for development and food security with global commitments to curb biodiversity losses and achieve emissions reduction targets.

Such commitments are encouraging, and so are the increased commitments from the private sector to eliminate deforestation and establish green supply chains (e.g. (http:// forestdeclaration.org/; see also Chapter 2 and Ingram et al. 2018). However, such commitments are voluntary and non-legally binding and in practice, markets and states all too often fail to account for the true value of nature, fully acknowledge cross-sectorial interdependencies between ecosystems and human well-being, or plan for the long-term (Clark et al. 2018; Guerry et al. 2015). Often, the types of transformative change required will more conceivably take place at the sub-national level.

This book hopes to offer scholars, practitioners and private sector actors with an interest in landscape approaches, insights from an interdisciplinary group of scientists who combined forces to operationalize landscape approaches for implementation in three countries in the global South - Ghana, Zambia and Indonesia. The rest of this chapter presents a short overview of the characteristics of integrated landscape approaches; what the COLANDS (Collaborating to operationalize landscape approaches for nature, development and sustainability) initiative entails; and why ILAs are needed in the three focus countries. At the end of this chapter, we present a brief outline of the book.

\subsection{Integrated landscape approaches}

Despite lacking consensus on definition, it is generally accepted that integrated landscape approaches are concerned with improving land-use practice, governance 


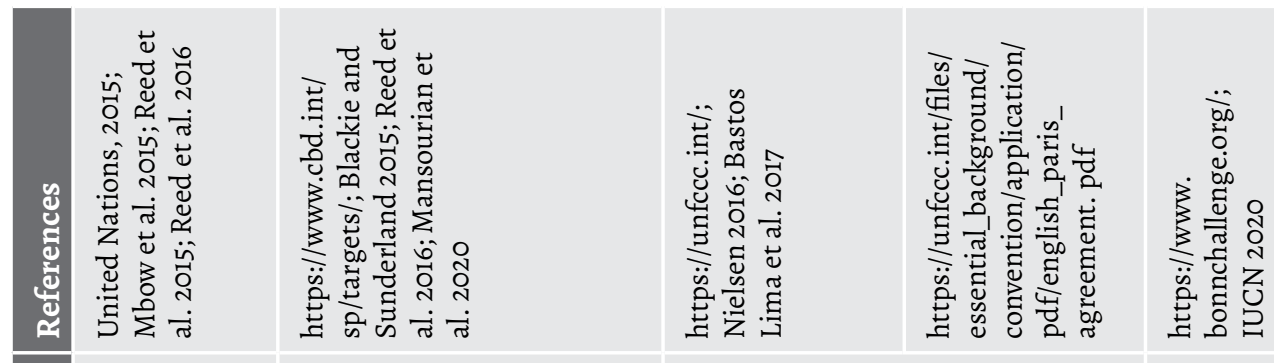

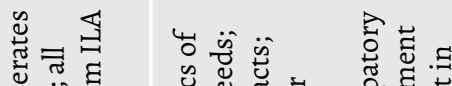

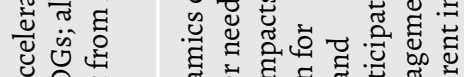

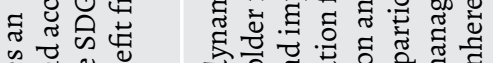

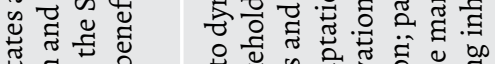

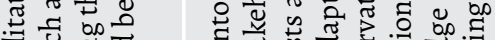

寻

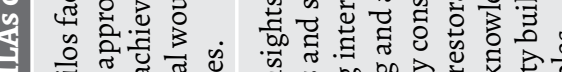

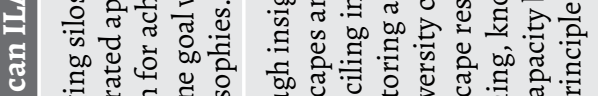

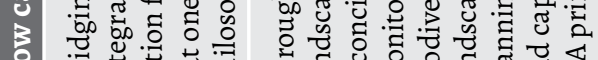

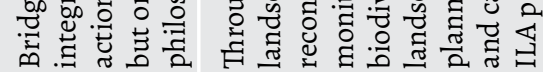

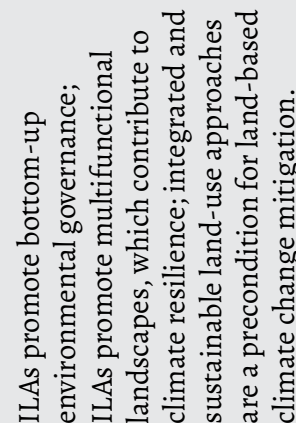
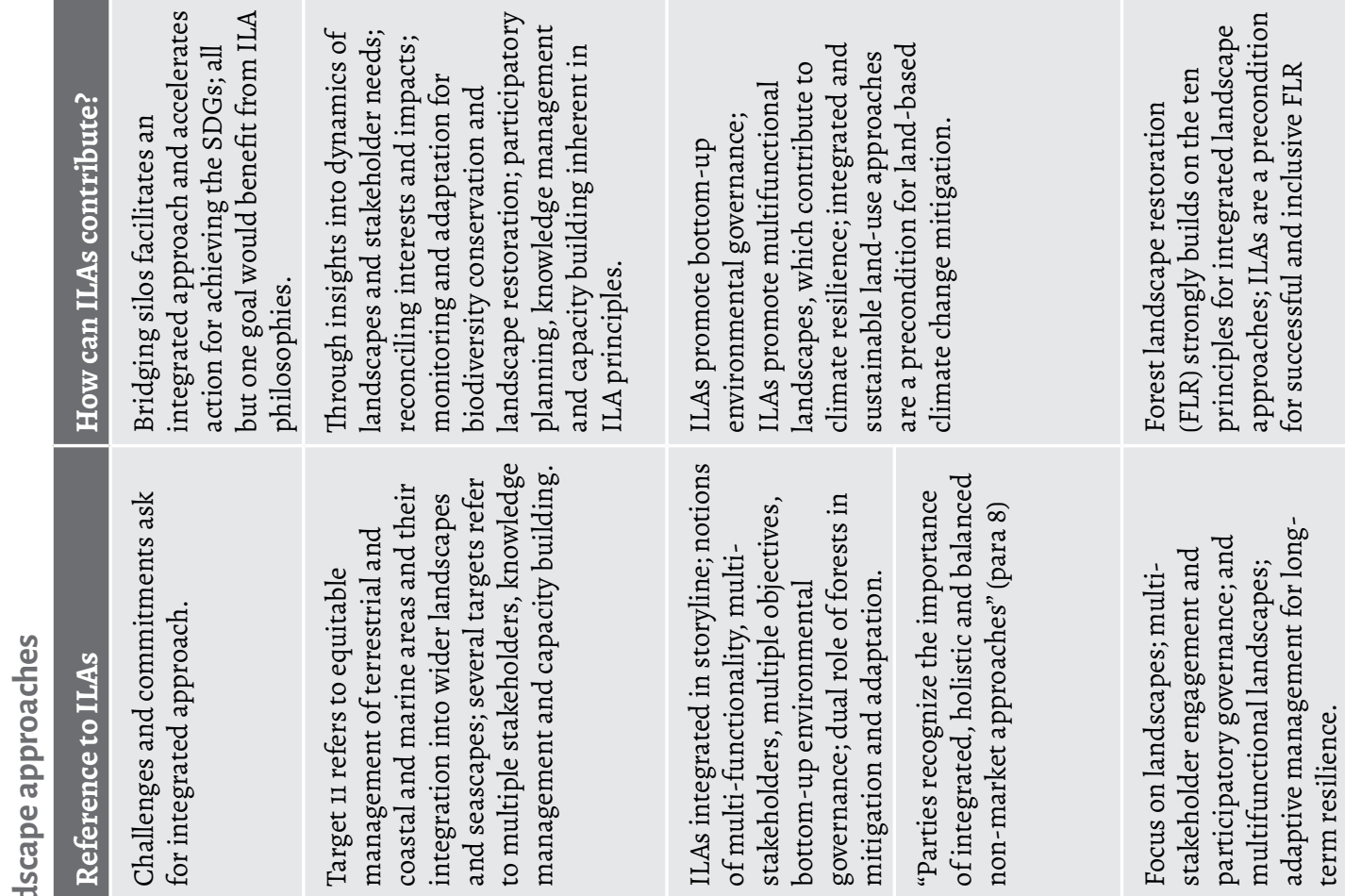

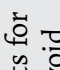

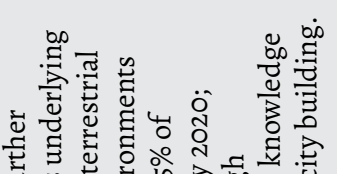
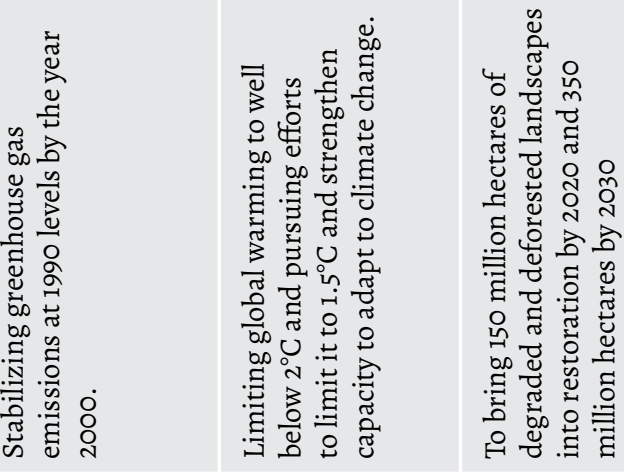

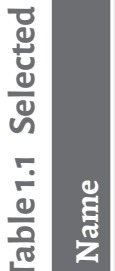

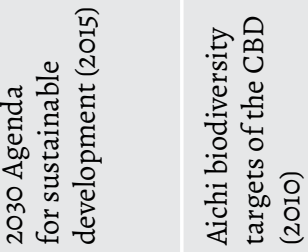

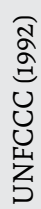

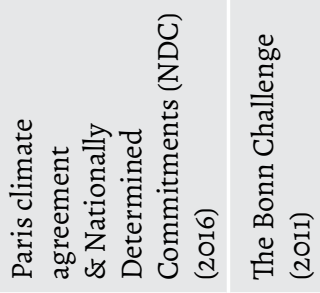


and decision-making in order to reconcile environmental and developmental objectives across scales. Such landscape approaches have gained renewed interest in recent years from the research, policy and donor communities due to the conceptual appeal of better harmonizing traditionally conflicting land-use agendas. For example, the perceived need to significantly enhance food production for a growing and increasingly affluent population has long been considered to be on a collision course with targets that seek to conserve or restore natural habitat for biodiversity (Bahar et al. 2020). Adopting landscape approaches requires explicitly acknowledging such conflicts and incentivizing multiple sector representatives to develop strategies that account for trade-offs and identify more synergistic, sustainable and equitable future landscape trajectories. As such, they represent a potential mechanism for reconciling considerable national-regional-global challenges and targets related to sustainable development and livelihoods, biodiversity conservation, climate resilience, and providing food and nutrition security (Sayer et al. 2013; Minang et al. 2014; Reed et al. 2016; Hanspach et al. 2017; Ros-Tonen et al. 2018; Reed et al. 2019, 2020).

A key distinction between landscape approaches and more sectorial approaches to land management is the transition from a focus on project-oriented actions typically delivered in a short-term, unidirectional and top-down manner toward longer-term process-oriented activities that are devised and negotiated in a collaborative manner. While many landscape approaches have a primary focus on biodiversity conservation (Carmenta et al. 2020; Chapter 3), they are concerned with how conservation efforts impact and are impacted by other land uses and land users within multifunctional systems. As such, contemporary landscape approaches plan for the long-term, place people at the centre, and therefore must be sensitive to issues of representation, power dynamics, rights and access to resources, as well as making connections across sectors and scales that have traditionally not interacted or even been more typically opposed to each other (Chapter 2).

A broad constituency suggests that focusing at the scale of the landscape, rather than a single point of entry such as protected areas, commercial plantations, or agriculture will have considerably more impact and achieve more satisfactory environmental and development outcomes (Chapter 2). However, working at a landscape scale requires guidance and advice and measurement of progress (Chapters 5 and 6). The institutional and policy frameworks for this to take place need to be fully understood and suitably applied to ensure that such integration is actually possible given the many competing claims to land and its associated resources (see Chapter 7).

In recent years, a number of guiding principles for ILAs have been developed (Sayer et al. 2013; Denier et al. 2015; Freeman et al. 2015; Ros-Tonen et al. 2015; Bürgi et al. 2017; Djenontin et al. 2018). Pre-eminent amongst these are the ten principles developed by Sayer et al. (2013). These principles emphasize the need for collective action that brings together multiple stakeholders representing multiple sectors and scales of decisionmaking influence to identify common landscape concerns (see Chapter 6). Through regular dialogue, participatory monitoring and adaptive management, it is expected that enhanced stakeholder capacity and landscape resilience can be achieved (Fig. 1.1). 


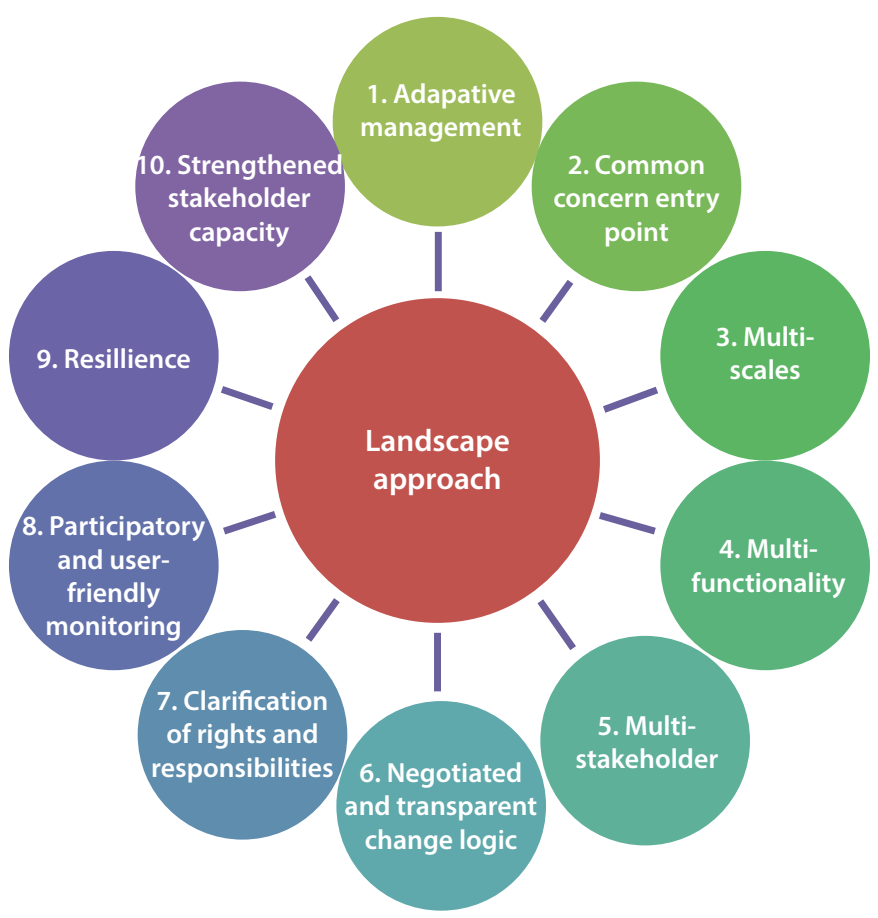

Figure 1.1 Ten principles for integrated landscape approaches.

Source: van Vianen et al. 2015, based on Sayer et al. 2013

Nevertheless, bringing together such a diversity of stakeholders and attempting to find consensus is inherently challenging (Reed et al. 2019) and despite the conceptual appeal of landscape approaches, their application, and particularly the reporting of progress, remains surprisingly nascent (see Chapter 2). While implementation efforts across the tropics have certainly escalated in recent years (Estrada-Carmona et al. 2014; Milder et al. 2014; Hart et al. 2015), there are limited examples in the scientific literature that have applied recognised landscape approach principles (although see Acheampong et al. 2020; Omoding et al. 2020) and reported on their effectiveness in practice through robust evaluation (see Chapter 5). With this in mind, the Center for International Forestry Research (CIFOR) and partners were motivated to address this gap in understanding by applying the conceptual knowledge developed in the last decade (see Chapter 6) to operationalize integrated landscape approaches in three contested tropical landscapes. It is to this initiative Collaborating to Operationalize Landscape Approaches for Nature, Development and Sustainability (COLANDS) that we turn now.

\subsection{The COLANDS initiative}

The development of the COLANDS initiative was rooted in CIFOR's long-standing research programs that had a focus on sustainable landscapes. This program of work contributed to the production of ten principles for landscape approaches (Sayer et al. 
2013), and reviews of the theoretical development (Reed et al. 2016), and implementation of landscape approaches in the tropics (Reed et al. 2017), amongst others. These processes helped to identify suggested principles for landscape approach effectiveness but suggested that, while the theory related to landscape approaches has evolved in recent years, a lack of robust implementation, monitoring and reporting persists. The COLANDS initiative was therefore conceived as an attempt to contribute toward filling the perceived knowledge-implementation gap, with a particular commitment to applying the landscape approach principles and, through learning from implementation, revising the conceptual frameworks accordingly; a double feedback system.

COLANDS is supported by the International Climate Initiative (IKI) of the Federal Ministry for the Environment, Nature Conservation, Building and Nuclear Safety (BMUB) and is a CIFOR-led consortium of partners consisting of the University of British Columbia (UBC), University of Amsterdam (UvA), the French Agricultural Research Centre for International Development (CIRAD), and local and political partners in the countries of implementation. These are: Ghana (University of Development Studies and the Forestry Commission); Zambia (Zambia CBNRM Forum, Forestry Department, and Ministry of Land and Natural Resources); and Indonesia (the indigenous NGO Riak Bumi and CIFOR researchers with a long history of working at the site, and the Executive Office of the President of the Republic of Indonesia) (see Chapters 8, 9 and 10).

In Ghana, COLANDS is implementing landscape level activities within the Western Wildlife Corridor (WWC). With more than $3,700 \mathrm{~km}^{2}$, the WWC stretches from the Mole National Park (MNP) in the South to the Burkina Faso border in the North.

Since 2000, Ghana has been implementing a Collaborative Resource Management Policy promulgated by the Wildlife Division of the Forestry Commission. The objective of this program is to integrate local communities in the governance and management of natural resources. The strategy adopted has been to implement the Community Resource Management Area (CREMA) program, which aims to create appropriate governance structures and instruments that enable communities to sustainably manage natural resources in outside protected wildlife areas (Asare et al. 2013; Robinson and Sasu 2013; Agyare et al. 2015; Baruah et al. 2016; Foli et al. 2018). CREMAs are seen as important mechanisms for the conservation and sustainable use of biodiversity toward the CBD targets. This includes the integrative management of biodiversity along the wildlife corridors that connect protected areas and forest reserves. Despite the innovative approach behind this mechanism, CREMAs have encountered several challenges in the implementation phase (Foli et al. 2018). COLANDS activities will deliver first-hand evidence for CREMAs in the Northern Region and contribute to the understanding of the complex governance interactions at the landscape level. COLANDS will offer crucial insights into how to overcome barriers to an integrative and inclusive participatory process in the implementation of such a collaborative mechanism.

In Zambia, COLANDS activities are undertaken within a collaborative framework involving institutions and personnel from government departments, at both district and national levels. There are several requisite policies, legislation and strategies (e.g. the Forestry Policy of 2014, Forests Act of 2015, National REDD Strategy, Climate Change 
Policy, Decentralization Policy) that are being used in the implementation of a number of natural resource management (NRM), conservation and development programs and projects. Zambia has established an inter-ministerial committee on climate change that coordinates programs and projects in the environmental and natural resources sector. In addition, the work of this committee is supported by the civil society-led Natural Resources Consultative Forum. Several existing institutional frameworks, from national to sub-national levels, support these programs.

Despite the existence of these structures and programs, some challenges exist in the implementation of NRM projects and programs. Institutional interpretation and implementation of policies tend to focus on a single sector and thus exclude other relevant government institutions, thereby weakening outcomes. There is often a mismatch between local level aspirations and the provisions of various projects and programs in the environment and natural resources sector. The adoption of landscape approaches in such settings may allow local communities to better engage in discussions on natural resource use. Despite the specific commitment of the government to achieving decentralized decision-making and governance of resources, capacity challenges at the local level often hinders progress. Through multi-stakeholder processes, COLANDS activities are contributing to addressing such challenges.

Indonesia is one of the world's most biologically diverse countries and is blessed with an abundance of natural resources. However, it is often the unsustainable exploitation of these natural resources and important natural ecosystems that economic development strategies are contingent upon. The barriers to implementing and maintaining an ILA in Indonesia therefore stem from this history of contested land use, and in particular the dichotomy between strategies for natural resource conservation and economic development.

Within the target landscape of Kapuas Hulu Regency, these conflicts are pronounced as land that is important for fulfilling national commitments toward emission reduction targets also has significant economic development potential; for example, for oil palm development. Furthermore, these are also the lands on which Indigenous people rely for their livelihoods. Such overlapping interests generate competing claims for land and conflicts between land uses. Power asymmetries across decision-making scales of influence that typically leave marginalized groups most at risk of the burdens of inequitable policy negotiations further aggravate this (Yuliani et al. 2018). The current Indonesian program and policies on social forestry ${ }^{2}$, the Constitutional Court decision no. 35/2012, which ruled in favour of protecting Indigenous people's rights to manage their customary forests, and the One Map Policy ${ }^{3}$ all provide a unique opportunity for balancing these needs by improving local people's livelihoods and managing landscapes

2 Program Perhutanan Sosial or Social Forestry Programme in Indonesia is one of President Joko Widodo's priorities, aimed to facilitate local communities gaining legal access to the state's forest and use resources sustainably. The program includes various forms, e.g., community forestry, community plantation forest and village forest, implemented under the Ministry of Environment and Forestry Regulation No. 83/2016 on Social Forestry.

3 Kebijakan satu peta or One Map Policy was first announced by former President Yudhoyono, and continued by President Joko Widodo, implemented under the Indonesian Law no. 4/2011 on Geospatial Information and the President's Decree no. 9/2016 on the Acceleration of the One Map Policy. 
more sustainably. However, integration in practice remains a significant challenge. Local and marginalized groups are disempowered from effectively engaging in decisionmaking processes; provincial policy making is weakened by deficiencies in national policy frameworks; and implementation efforts are hindered due to a lack of technical capacity to facilitate collaborative decision-making and conflict resolution.

Across all three countries, COLANDS activities aim to achieve integrated landscape governance, contributing to commitments to the United Nations Framework Convention on Climate Change (UNFCCC) - the Paris goals and associated commitments to Nationally Determined Contributions (NDC); the Convention on Biological Diversity (CBD) biodiversity targets (Blackie and Sunderland 2015); the UN Declaration on the Rights of Indigenous Peoples (Campese et al. 2009; Blomley and Walters 2019); and the Sustainable Development Goals (Reed et al. 2015; Katila et al. 2019). These activities are being delivered through four work packages that are briefly described chronologically below. Nevertheless, in practice, events and challenges (often unpredictable and beyond our control) necessitate iterative planning and therefore a degree of overlap. For example, rapidly escalating socio-political instability in our original country of operation, Burkina Faso, led to a relocation to northern Ghana, social unrest in Zambia required a temporary suspension of activities, and the COVID-19 global pandemic has, and will continue to, significantly constrain our ability to engage at the level we had envisioned.

1. Multi-stakeholder consultation. Strengthened networks of landscape actors and national policy stakeholders are necessary to ensure buy-in to landscape approaches and to facilitate mutual understanding of differing interests among stakeholders. The target landscapes have one or multiple forms of multi-stakeholder platforms in place. These platforms and their members, together with key national level policymakers, are our key target stakeholders. COLANDS teams are convening consultation meetings and working with the target stakeholders to identify challenges and opportunities. Efforts focus on socializing the concepts of landscape approaches and facilitating buy-in from all stakeholders. The resulting stakeholder networks are collaboratively developing mutually agreed contextual frameworks for implementing and testing landscape approaches.

2. Building capacity to implement and evaluate integrated approaches to landscape governance. COLANDS teams are identifying capacity and addressing certain capacity needs of the identified stakeholders, particularly with regard to conflict resolution, participatory planning, and negotiating a shared vision for the future of the landscape. In terms of building local capacity, COLANDS has recruited at least one national $\mathrm{PhD}$ candidate per country, two further PhD candidates, and expanded the capacity of the regional offices with appropriate local recruits. Expertise in indicator development for landscape approaches is being combined with specific landscape stakeholder knowledge to co-produce appropriate sets of landscape metrics to evaluate biophysical, socioeconomic and institutional processes for each of the target landscapes.

3. Pilot testing of integrated landscape approaches. Continuous participatory monitoring enables assessment of the effectiveness of ILAs, revealing important lessons to be documented and shared. Based on this work, the contributions of improved landscape approach implementation for the sustainable supply of forest- 
related goods \& services, biodiversity and poverty alleviation outcomes are being quantified and reported.

4. Global and national policy recommendations. As lessons emerge, they are communicated through all of COLANDS, CIFOR and partners, communications channels, and shared at the national level through workshops, publications and meetings. International events targeted include meetings of the Subsidiary Body for Scientific and Technological Advice (SBSTA), Conference of the Parties of the $\mathrm{CBD}$, and regular engagement at the Global Landscapes Forum (GLF) annual and regional events. CIFOR is an active participant in national and international debates on landscape approaches building on many years of previous work and engagement. COLANDS' further testing of landscape implementation case studies will influence governance at multiple levels, private sector, academia and other landscapescale actors.

The lessons drawn from the work under these four packages will provide the evidence that is urgently needed for the implementation of landscape approaches. These lessons will be extremely valuable for all actors currently designing, implementing and researching landscape approaches - informing those efforts and improving their functionality. In this context, this book describes insights and findings from the first two years of COLANDS' activities, which we hope will serve as a valuable resource for researchers, practitioners and decision-makers with an interest in reconciling environment and development objectives at the landscape scale.

\subsection{Structure and content of the book}

This introductory chapter provides the background and context to the rest of this book by introducing integrated landscape approaches, the COLANDS project, and the contexts of the three countries where the project is being carried out.

Chapter 2 provides a stock take of integrated landscape approaches in the tropics. It addresses four challenges to the implementation and maintenance of integrated landscape approaches: persistent science-practice-policy gaps in environmental governance; engagement by instead of private-sector; the dearth of evidence of implementation and effectiveness; and monitoring and evaluation.

Chapter 3 addresses the importance of incorporating biodiversity in integrated landscape management and of monitoring trade-offs and synergies between biodiversity, ecosystem services and livelihoods. It highlights the use of biodiversity indicators, remote sensing, modeling techniques and citizen science programs for effective monitoring of biodiversity-related responses to conservation interventions. The chapter further highlights the main biodiversity challenges in the COLANDS countries, Ghana, Zambia and Indonesia.

Chapter 4 presents an evidence-based "toolkit" to overcome challenges inherent in multi-stakeholder engagement. Knowledge co-production, triple-loop learning and seeking consensus in multi-stakeholder platforms; enhancing stakeholders' 
understanding of landscape dynamics through modeling or scenario building; participatory development of a theory of change; and contextually appropriate incentives for pro-conservation behaviour are presented as tools for multi-stakeholder engagement in landscape approaches.

Chapter $\mathbf{5}$ highlights the importance of evaluation to assess the effectiveness and pathways to the effectiveness of landscape approaches. It highlights the use of process analysis and impact evaluation to draw important lessons for the replication of landscape approaches in other contexts. It argues for using theories of change to improve the quality and credibility of landscape approach evaluation and to decide on methods and data to be used.

Chapter 6 presents an overview of methods and data that can be used in landscape approaches and their alignment with the principles for integrated landscape approaches. The methods described largely fall under three themes: back-casting (identifying general historical trends), establishing current baseline conditions, and forecasting as an aid in decision-making. These methods can help develop a more complete understanding of the past, present and future landscape dynamics and help identify potential needs, opportunities and challenges.

Chapter 7 explores the policy context in the three countries of implementation and how these relate to the ten principles of integrated landscape approaches. Despite differences in contexts and policies, all plans display alignment with some key principles of landscape approaches. The chapter also identifies principles on which further work needs to be done from national to local level.

Chapters 8-10 depict the contexts for implementing landscape approaches in Ghana, Zambia, and Indonesia. Each of these chapters provide a comprehensive description of the biophysical, socio-economic and governance context in which the landscape approaches will be piloted and documented. The chapters draw on a review of scientific and grey literature and scoping studies during which interviews were held with representatives of government agencies, NGOs, and representatives of the local population.

Chapter 11 provides a synthesis and indicates the way forward.

\section{References}

Acheampong EO, Sayer J, Macgregor C, and Sloan, S. 2020. Application of landscape approach principles motivates forest fringe farmers to reforest Ghana's degraded reserves. Forests 11(4). https://doi.org/10.3390/F11040411.

Agyare AK, Murray G, Dearden P, and Rollins R. 2015. Understanding inter-community performance assessments in community-based resource management at Avu Lagoon, Ghana. Environment, Development and Sustainability 17(6): 1493-1508. https://doi. org/10.1007/s10668-014-9617-7. 
Asare RA, Kyei A. and Mason JJ. 2013. The community resource management area mechanism: A strategy to manage african forest resources for REDD+. Philosophical Transactions of the Royal Society B: Biological Sciences 368(1625). https://doi.org/10.1098/ rstb.2012.0311.

Bahar NH, Lo M, Sanjaya M, Van Vianen J, Alexander P, Ickowitz A, and Sunderland T. 2020. Meeting the food security challenge for nine billion people in 2050: What impact on forests?. Global Environmental Change 62, 102056.

Baruah M, Bobtoya S, Mbile P, and Walters G. 2016. Governance of restoration and institutions: Working with Ghana's Community Resource Management Areas. World Development Perspectives 3: 38-41. https://doi.org/10.1016/j.wdp.2016.11.008.

Bastos Lima MG, Visseren-Hamakers IJ, Braña-Varela J, and Gupta A. 2017. A reality check on the landscape approach to REDD+: Lessons from Latin America. Forest Policy and Economics 78: 10-20. https://doi.org/10.1016/j.forpol.2016.12.013.

Blackie R and Sunderland TCH. 2015. Mapping landscape guidelines and principles to the Aichi target. CIFOR Info Brief (123): 2-5. https://doi.org/10.17528/cifor/005618.

Blomley T. and Walters G. 2019. A Landscape for Everyone: Integrating Rights-based and Landscape Governance Approaches. Gland: IUCN.

Bürgi M, Ali P, Chowdhury A, Heinimann A, Hett C, Kienast F, Mondal MK, Upreti BR, Verburg H. 2017. Integrated landscape approach: Closing the gap between theory and application. Sustainability 9(1371): 1-13.

Campese J, Sunderland T, Greiber T, and Oviedo G, eds. 2009. Rights-based Approaches: Exploring Issues and Opportunities for Conservation. Bogor: CIFOR.

Carmenta R, Coomes DA, DeClerck FAJ, Hart AK, Harvey CA, Milder J, Reed J, Vira B, Estrada-Carmona N. 2020. Characterizing and evaluating integrated landscape initiatives'. One Earth 2(2): 174-187. https://doi.org/10.1016/j.oneear.2020.01.009.

Clark R, Reed J. and Sunderland T. 2018. Bridging funding gaps for climate and sustainable development: Pitfalls, progress and potential of private finance. Land Use Policy 71: 335-346. https://doi.org/10.1016/j.landusepol.2017.12.013.

Denier L, Scherr S, Shames S, Chatterton P, Hovani L, and Stam N. 2015. The Little Sustainable Landscapes Book: Achieving sustainable development through integrated landscape management. Oxford: Global Canopy Programme. https://doi.org/10.1017/ CBO9781107415324.004.

Djenontin INS, Foli S. and Zulu LC. 2018. Revisiting the factors shaping outcomes for forest and landscape restoration in Sub-Saharan Africa: A way forward for policy, practice and research. Sustainability 10(4): 1-34. https://doi.org/10.3390/su10040906.

Estrada-Carmona N, Hart AK, DeClerck FAJ, Harvey CA., and Milder JC. 2014. Integrated landscape management for agriculture, rural livelihoods, and ecosystem conservation: An assessment of experience from Latin America and the Caribbean. Landscape and Urban Planning 129: 1-11. https://doi.org/10.1016/j. landurbplan.2014.05.001.

Foli S, Ros-Tonen MAF, Reed J, and Sunderland T. 2018. Natural resource management schemes as entry points for integrated landscape approaches: Evidence from Ghana 
and Burkina Faso. Environmental Management 62(1): 82-97. https://doi.org/10.1007/ s00267-017-0866-8.

Freeman OE, Duguma LA. and Minang PA. 2015. Operationalizing the integrated landscape approach in practice. Ecology and Society 20(1). https://doi.org/10.5751/ES07175-200124.

GNAFC and FSIN. 2020. Global report on food crises: Joint analysis for better decisions. FSIN. https://reliefweb.int/sites/reliefweb.int/files/resources/WFP-0000114546.pdf.

Guerry, A. D., Polasky, S., Lubchenco, J., Chaplin-Kramer, R., Daily, G. C., Griffin, R. , ... \& Feldman, M. W. (2015). Natural capital and ecosystem services informing decisions: From promise to practice. Proceedings of the National Academy of Sciences, 112(24): $7348-7355$.

Guterres A, Andersen I. and Maruma Mrema E. 2020. Global Biodiversity Outlook 5. Montreal: Secretariat of the CBD.

Hanspach J, Abson DJ, French Collier N, Dorresteijn I, Schultner J, and Fischer J. 2017. From trade-offs to synergies in food security and biodiversity conservation. Frontiers in Ecology and the Environment 15(9): 489-494. https://doi.org/10.1002/fee.1632.

Hart AK, Milder JC, Estrada-Carmona N, Declerck F, Harvey CA, and Dobie P. 2015. Integrated landscape initiatives in practice: Assessing experiences from 191 landscapes in Africa nad Latin America, In Minang PA, van Noordwijk M, Freeman OE, Mbow C, de Leeuw J, Catacutan D, eds. Climate-smart Landscapes: Multifunctionality in Practice. Nairobi: World Agroforestry Centre. 89-102.

Ingram V, van den Berg J, van Oorschot M, Arets E, and Judge L. 2018. Governance options to enhance ecosystem services in cocoa, soy, tropical timber and palm oil value chains. Environmental Management 62(1): 128-142. https://doi.org/10.1007/ s00267-018-0996-7.

Independent Group of Scientists appointed by the Secretary-General 2019. Global Sustainable Development Report 2019: The Future is Now - Science for Achieving Sustainable Development. New York: United Nations. https://sustainabledevelopment.un.org/ content/documents/24797GSDR_report_2019.pdf.

IPBES. 2019. Global Assessment Report on Biodiversity and Ecosystem Services of the Intergovernmental Science-Policy Platform on Biodiversity and Ecosystem Services. Bonn: IPBES secretariat.

IPCC. 2019. Climate Change and Land an IPCC Special Report on climate change, desertification, land degradation, sustainable land management, food security, and greenhouse gas fluxes in terrestrial ecosystems, https://www.ipcc.ch/site/assets/ uploads/sites/4/2020/08/200730-IPCCJ7230-SRCCL-Complete-BOOK-HRES.pdf.

IUCN. 2020. Restore our Future. Bonn challenge. Impact and Potential of Forest Landscape Restoration. Gland: IUCN.

Jenkins M and Schaap B. 2018. Untapped Potential: Forest Ecosystem Services for Achieving SDG 15. UNFF13 Background Analytical Study, United Nations Forum on Forests. https://www.un.org/esa/forests/wp-content/uploads/2018/05/UNFF13_BkgdStudy_ ForestsEcoServices.pdf. 
Katila P, Colfer C, de Jong W, Galloway G, Pacheco P, Winkel G, eds. 2019. Sustainable Development Goals: Their Impacts on Forests and People. Cambridge University Press.

Mansourian S, Parrotta J, Balaji P, Bellwood-Howard I, Bhasme S, Bixler RP, Boedhihartono AK,Carmenta R, Iedd T, de Jong W, et al. 2020. Putting the pieces together: Integration for forest landscape restoration implementation. Land Degradation and Development 31(4): 419-429. https://doi.org/10.1002/ldr.3448.

Mbow C, Beely C. and Dobie P. 2015. How can an integrated landscape approach contribute to the implementation of the sustainable development goals (SDGs) and advance climate-smart landscapes. In PA, van Noordwijk M, Freeman OE, Mbow C, de Leeuw J, Catacutan D, eds. Climate Smart Landscapes: Multifunctionality in Practice. Nairobi: World Agroforestry Centre (ICRAF), 104-116.

Milder JC, Hart AK, Dobie P, Minai J, and Zaleski C. 2014. Integrated Landscape Initiatives for African Agriculture, Development, and Conservation: A RegionWide Assessment. World Development 54: 68-80. https://doi.org/10.1016/j. worlddev.2013.07.006.

Minang PA, van Noordwijk M, Freeman OE, Mbow C, de Leeuw J, and Catacutan D. 2014. Climate Smart Landscapes: Multifunctionality in Practice. Nairobi: World Agroforestry Centre (ICRAF).

Nielsen TD. 2016. From REDD+ forests to green landscapes? Analyzing the emerging integrated landscape approach discourse in the UNFCCC. Forest Policy and Economics 73: 177-184. https://doi.org/10.1016/j.forpol.2016.09.006.

Omoding J, Omoding J, Walters G, Carvalho S, Cracco M, Langoy CD, Kiying KG, Kumar C, Reinhard F, Ssenyonjo E, and Twinomuhangi L. 2020. Implementing a landscape approach in the Agoro-Agu Region of Uganda. Parks 26(1): 99-110. https://doi. org/10.2305/IUCN.CH.2020.PARKS-26-1MM.en.

Reed J, Van Vianen J, and Sunderland T. 2015. From global complexity to local reality: Aligning implementation pathways for the Sustainable Development Goals and landscape approaches. CIFOR Info Brief 129. Bogor. https://doi.org/10.17528/ cifor/005865.

Reed J, Van Vianen J, Deakin EL, Barlow J, and Sunderland T. 2016. Integrated landscape approaches to managing social and environmental issues in the tropics: Learning from the past to guide the future. Global Change Biology 22(7): 2540-2554. https://doi. org/10.1111/gcb.13284.

Reed J, Van Vianen J, Barlow J, and Sunderland T. 2017. Have integrated landscape approaches reconciled societal and environmental issues in the tropics? Land Use Policy 63: 481-492. https://doi.org/10.1016/j.landusepol.2017.02.021.

Reed J, Barlow J, Carmenta R, van Vianen J, Sunderland T. 2019. Engaging multiple stakeholders to reconcile climate, conservation and development objectives in tropical landscapes. Biological Conservation 238, 108229. https://doi.org/10.1016/j. biocon.2019.108229.

Reed J, Ickowitz A, Chervier C, Djoudia H, Moombe K, Ros-Tonen M, Yanoua M, Yuliania L, and Sunderland T. 2020. Integrated landscape approaches in the tropics: A brief stock-take. Land Use Policy 104822. https://doi.org/10.1016/j.landusepol.2020.104822. 
Robinson LW and Sasu KA. 2013. The role of values in a community-based conservation initiative in northern Ghana. Environmental Values 22(5): 647-664. https://doi.org/10.3 197/096327113X13745164553914.

Ros-Tonen MAF, Van Leynseele YPB, Laven A, and Sunderland T. 2015. Landscapes of social inclusion: Inclusive value-chain collaboration through the lenses of food sovereignty and landscape governance. European Journal of Development Research 27(4): 523-540. https://doi.org/10.1057/ejdr.2015.50.

Ros-Tonen MAF, Reed J. and Sunderland T. 2018. From synergy to complexity: The trend toward integrated value chain and landscape governance. Environmental Management 62(1): 1-14. https://doi.org/10.1007/s00267-018-1055-0.

Sachs J, Schmidt-Traub G, Kroll C, Lafortune G, and Fuller G. 2018. SDG Index and Dashboards Report 2018: Global Responsibilities', Global Responsabilities. Implementing the Goals. https://sdgindex.org/reports/sdg-index-anddashboards-2018/.

Sayer, J, Sunderland T, Ghazoul J, Pfund J-L, Sheil D, Meijaard E, Venter M, Boedhihartono AK, Day M, Garcia C, van Oosten C, and Buck LE. 2013. Ten principles for a landscape approach to reconciling agriculture, conservation, and other competing land uses. Proceedings of the National Academy of Sciences of the United States of America 110(21): 8349-56. https://doi.org/10.1073/pnas.1210595110.

Sunderland T. 2020. How our food choices cut into forests and put us closer to viruses. The Conversation, August 2020, pp. 1-7. https://www.downtoearth.org.in/blog/food/ how-our-food-choices-cut-into-forests-and-put-us-closer-to-viruses-72956.

Tauli-Corpuz V, Alcorn J and Molnar A. 2018. Cornered by Protected Areas. Rights and Resources Initiative. https://www.corneredbypas.com/brief.

UN Habitat 2015. Slum almanac 2015 2016. Tracking improvement in the lives of slum dwellers. Nairobi: UN Habitat. https:/unhabitat.org/sites/default/files/downloadmanager-files/Slum\%20Almanac\%202015-2016_PSUP.pdf.

United Nations 2015. Transforming Our World: The 2030 Agenda for Sustainable Development. New York: United Nations Division for Sustainable Development Goals.

van Vianen J, Reed J, and Sunderland T. 2015. From global complexity to local reality: Aligning implementation frameworks with sustainable development goals and landscape. CIFOR Policy Brief, 1, pp. 1-2.

Whitmee S. et al. 2015. Safeguarding human health in the Anthropocene epoch: Report of The Rockefeller Foundation-Lancet Commission on planetary health. The Lancet 386(10007): 1973-2028. https://doi.org/10.1016/s0140-6736(15)60901-1.

World Bank. 2018. Piecing Together the Poverty Puzzle. Washington DC: World Bank. https://doi.org/10.1596/978-1-4648-1330-6.

WWF. 2020. Living planet report 2020. Almond REA, Grooten M, and Petersen T, eds. Gland: WWF. 
Yuliani E. Linda, De Jong EBP, Knippenberg L, Bakara DO, Agus Salim M, and Sunderland T. 2018. Keeping the land: Indigenous communities and the struggle over land use and sustainable forest management in Kalimantan, Indonesia. Ecology and Society 23(4):49.

Zeng Y, Maxwell S, Runting RK, Venter O, Watson JEM, and Carrasco LR. 2020.

Environmental destruction not avoided with the Sustainable Development Goals.

Nature Sustainability 3: 795-798. https://doi.org/10.1038/s41893-020-0555-0. 


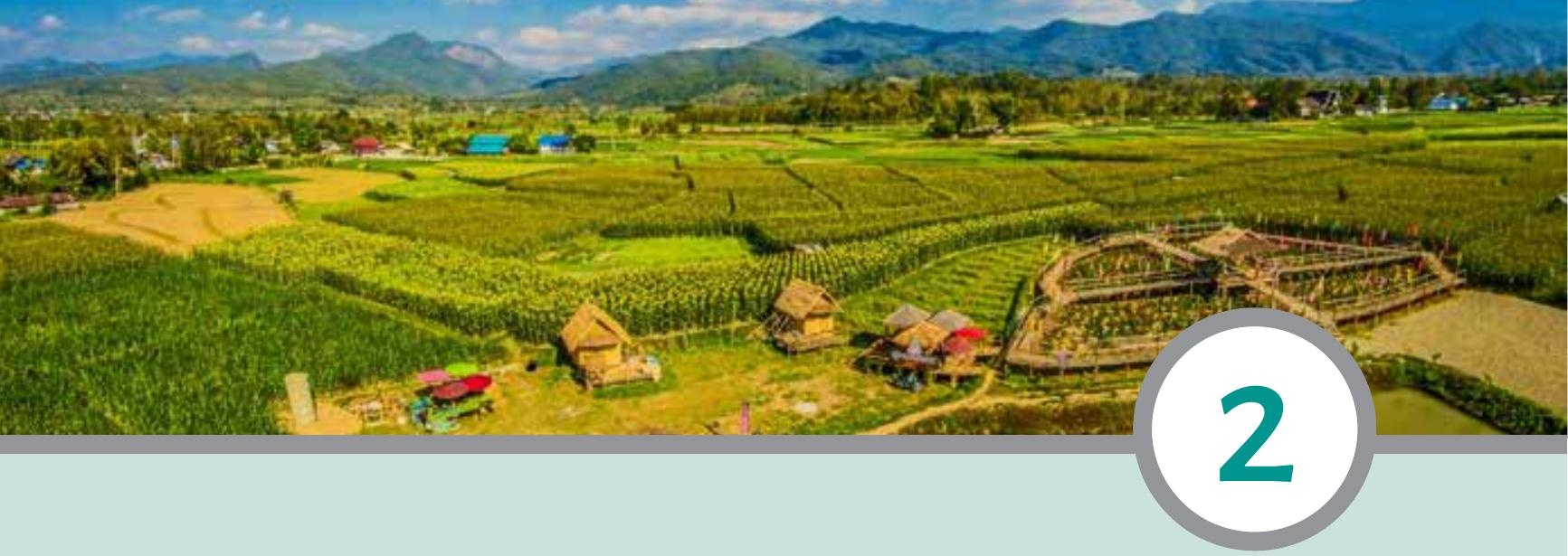

\section{Integrated landscape approaches in the tropics}

\section{A brief stock-take*}

James Reed, Amy Ickowitz, Colas Chervier, Houria Djoudi, Kaala B Moombe, Mirjam Ros-Tonen, Malaika Yanou, Elizabeth L Yuliani and Terry Sunderland

*This is an edited version of an article previously published in Land Use Policy (Reed et al. 2020)

\section{Introduction}

The tropics represent a particular area of concern for conservation and development as they have endured unprecedented levels of environmental degradation, limited development relative to temperate areas, and have high concentrations of extreme poverty and malnutrition (Curtis et al. 2018; Song et al. 2018). The stakes are very high, as the tropics also host a disproportionately large share of global biodiversity with areas vulnerable to climate change (Barlow et al. 2018).

Recent global policy debates acknowledge the need for more integrated solutions that meet human needs and mitigate environmental harm. The Paris climate agreement and Sustainable Development Goals (SDGs) of 2015 explicitly call for more holistic approaches that better integrate the needs of people and planet. At the same time, major conservation organizations and development agencies have extended their modus operandi to better reflect the needs of people in conservation and nature in development (Reed et al. 2016). The private sector has expressed interest in working with landscape actors in attempts to "green" their supply chains, particularly through commitments to emissions reduction or zero deforestation initiatives (Lambin et al. 2018). Therefore, efforts to reconcile multiple - and often competing - claims on land mean that integrated landscape approaches' have become pervasive (Sayer et al. 2013; Reed et al. 2016). 
Below, we draw on recent literature to address four challenges to implementation and maintenance of integrated landscape approaches. First, persistent science-practicepolicy gaps in environmental governance; second, engagement of the private-sector; third, the dearth of evidence of implementation and effectiveness; and last, monitoring and evaluation. The final section discusses the findings and a possible way forward.

\subsection{Environmental governance and bridging science- practice-policy gaps}

One of the challenges facing integrated landscape approaches is the persistent gap between theory and implementation (Jasonoff 1996; Shanley and López 2009; Toomey et al. 2015; Toomey et al. 2017). Recent approaches to environmental governance therefore typically propose a transdisciplinary agenda (Toomey et al. 2015). This requires engaging a broad range of stakeholders from many disciplines, sectors, and scales of organization to collaboratively design and practice more sustainable and equitable landscape management. However, challenges remain and a tendency toward more sectorial approaches persists (Reed et al. 2019; Opdam 2018). There are likely many reasons for this.

The interplay between local institutions and research organizations or government agencies - despite being a prerequisite to effective co-production - is often lacking, as many have neither a history of, nor enthusiasm for, such engagement (Jentoft and McCay 1995). Related to this, the ethos of a landscape approaches may be more conceptually appealing to researchers than to those stakeholders who are more directly impacted by the consequences of crossing jurisdictional boundaries and negotiated land-use decisions and actions (Ros-Tonen et al. 2015; Ros-Tonen et al. 2018). An approach that has the potential to safeguard forests, enhance local well-being, conserve biodiversity and mitigate against the impacts of climate change is an easy sell. However, building awareness of the need to identify (and accept and negotiate) trade-offs is considerably more challenging; it is not unreasonable to suspect that neither landscape inhabitants faced with near-term socio-economic pressures, nor policy-makers faced with shortterm political cycles, will be pleased with the prospect of short-term losses. As former European Council President Jean-Claude Juncker said in reference to political decisionmaking, "we all know what to do, we just don't know how to get re-elected after we've done it."

Understanding the complex political history of land tenure is crucial (Riggs et al. 2016). Landscape approaches should take into account the rights and responsibilities of all stakeholders (Westerink et al. 2017; van Oosten et al. 2019) and include the institutional circumstances that involve a high complexity and heterogeneity of actors and their overlapping, multiple tenure systems and property rights (Mansourian and Sgard 2019). For example, analyses could consider the effect that clarifying or enhancing the tenure rights of local stakeholders has on natural resource management (Robinson et

1 The Economist (2007), “The Quest for Prosperity”, March 15. 
al. 2014; Lawry et al. 2017) or the extent to which local stakeholders are able to assert such rights in decision-making processes and resist the objectives of local elites or private interests (Agrawal et al. 1997; Ribot et al. 2010); and how such transformations might contribute toward national commitments to international sustainability targets. Despite recognition of the need for such analysis, we find limited incorporation in recent landscape approach literature. Indeed, a recently published report on tenure in landscape approaches concludes that refinement of analytical frameworks and organization of in-depth case studies are urgently required (Buck et al. 2019).

There are also challenges associated with the recognition and translation of local knowledge. For example, tacit and context-embedded local knowledge may not be recognized or trusted by holders of codified and expert knowledge in government and research organizations (Berkes 2009; Pfeffer et al. 2013); may not be easily articulated (Reid et al. 2006); or may arise from a different worldview with alternative assumptions, norms and rules (Bonny and Berkes 2008; Arts et al. 2017). The politics of knowledge (Escobar 1998; Goldman and Goldman 2003) that prioritizes expert over local knowledge and sustains mainstream thinking in social networks (Loconto et al. 2018) still tends to be ignored in the literature on integrated landscape approaches, despite evidence of the value of local knowledge on agricultural and environmental interventions (Toderi et al. 2017; Paneque-Galvez et al. 2018).

\subsection{Engaging the private sector}

Recent enthusiasm to engage the private sector in landscape approaches seems to be motivated by two factors: first, a substantial shortfall exists between current investments in the climate and sustainable development agendas, and the amount needed (Clark et al. 2018). Funding is mostly secured from public or philanthropic sources; therefore, closer private sector engagement could motivate contributions to meeting the shortfall. Second, while the private sector has traditionally been associated with the problem, rather than the solution to environmental degradation, this perception may be slowly changing. An alternative viewpoint suggests that publicprivate (-producer) partnerships can facilitate the greening of supply chains, encourage more environmentally sensitive behavior and stimulate "green growth" (Poulton and Macartney 2012). Concerns about failure to secure supply in the near future and to meet recent commitments to remove deforestation from major agricultural commodities' value chains may create a business case for increasing private sector engagement in landscape approaches (Scherr et al. 2017; Ros-Tonen et al. 2018).

Such prospects for green investment create an incentive for landscapes and jurisdictions to engage in sustainable landscape management and landscape certification (Boyd et al. 2018). There is good reason to be skeptical of this agenda and there have been accusations of "greenwashing" due to environmentally destructive actions by private sector actors who nevertheless advocate for sustainability (Pirard et al. 2015). However, with a more informed public demanding better product-sourcing information, increased pressure for companies to reduce supply chain emissions and enhance efficiency, as well as recognition that international products often depend on preserving 
natural capital (and local livelihoods) in source landscapes, there is potential for increased and fruitful collaborations (Arts et al. 2017; Scherr et al. 2017).

Whatever the motivation, we will likely see more examples of public-private and public-private-producer partnerships (Thorpe and Maestre 2015) regardless of who initiates these collaborations. Certainly, an increasing number of companies - Mars, Unilever, Olam, Heineken, The Coca-Cola Company, to name a few - claim to be adopting landscape approaches in their operations and the scientific literature shows an increasing trend toward private-sector involvement in landscape partnerships (Kissinger et al. 2013; Denier et al. 2015; IDH 2017; Scherr et al. 2017; Ros-Tonen et al. 2018).

However, objectives of companies trading international commodities are typically mismatched with recognized principles for landscape approaches. For instance, agribusinesses have a sectorial focus, rely on annual production systems and produce quarterly reports to satisfy shareholders primarily motivated by profit. This contradicts landscape approaches that demand multiple stakeholders engaging across sectors in negotiation processes over long time frames to enhance equity and sustainability (Hart et al. 2015).

Nevertheless, private-sector engagement is often considered crucial to realizing the objectives of climate and sustainable development agendas, as well as the Bonn Challenge and the related New York Declaration on Forests (NYDF) which, respectively, aim to restore 350 million ha of degraded land and eliminate deforestation by 2030 . Integrated landscape approaches have been recognized as a potential pathway to realizing these ambitions and the number of corporate commitments has now reached almost 800 (NYDF assessment partners 2018). Less encouraging, commitments from the soy and beef sectors still lag, as does reliable data (across all sectors) to show evidence of progress toward deforestation commitments (Forestdeclaration.org 2018). Indeed, the latest progress report shows that public and private sector commitments are failing to halt the destruction of natural ecosystems. ${ }^{2}$ However, such commitments, although voluntary and non-binding, can stimulate the kind of transformations in business practices that the fulfillment of the SDGs and NYDF requires - but only if translated to action. Greater support from financial institutions, governments and civil society organizations will be necessary.

Of course, engaging the private sector in environmental governance discussion and practice is neither straightforward nor without its challenges. While companies should feel responsible to more fully engage and cooperate, that should not be considered a panacea or alternative pathway to sustainable development; it is simply one potential component of many potential solutions. Moreover, as private sector initiatives and public-private(-producer) partnerships evolve, government regulation of business activities and the work of watchdogs in monitoring supply-chain activities must play a crucial role. Examples include Trase Earth and the Borneo Atlas, while Forest Trends' Supply Change initiative tracks corporate progress toward voluntary commitments. The application of landscape approaches can also help by facilitating dialogue between

2 https://sdg.iisd.org/commentary/guest-articles/turning-the-new-york-declaration-on-forests-to-new-yorkaction-on-forests/. 
private-sector actors, politicians, and local community members to develop more longterm institutional planning and build trust, empathy and capacity to better negotiate landscape-scale decision-making processes (Langston et al. 2019).

\subsection{Evidence of implementation and first assessments of effectiveness}

A recent global review shows plentiful landscape approaches being implemented worldwide. The Landscapes for People, Food and Nature (LPFN) group identified 428 examples of what it labels 'integrated landscape initiatives': 87 cases in Africa (Milder et al. 2014), 104 in Latin America and the Caribbean (LAC) (Estrada-Carmona et al. 2014), 166 in South and Southeast Asia (Zanzanaini et al. 2017) and 71 in Europe (García-Martín et al. 2016), providing the first global assessment of the characteristics, outcomes and limitations of landscape approaches.

Despite regional variations in motivations, outcomes, and challenges, recognizable patterns emerged; in particular, significant overlap in the findings from Africa and LAC (Hart et al. 2015). For example, four landscape 'domains' remained consistent across continents: nature conservation, farming and agriculture, livelihoods and human well-being, and institutional planning and coordination. In addition, Africa included dimensions of conflict reduction and climate change, while Europe included a cultural heritage dimension. Identified challenges included poor private-sector engagement, concerns over funding for long-term sustainability; lengthy time horizons to determine effectiveness; and (except in Africa) unsupportive or weak policy frameworks. These combined meant that progress and sustainability was often dependent on the impulses of civil society organizations. Nevertheless, there was a widely shared belief that the implementation of integrated landscape initiatives could stimulate more holistic management, consistent with the demands of multifunctional landscapes - particularly with enhanced political and societal support.

Another recent review charted the theoretical development of integrated landscape approaches (Reed et al. 2015; Reed et al. 2016). Insights revealed five key considerations for landscape practitioners: evaluate progress, establish good governance, avoid panaceas, engage multiple stakeholders, embrace dynamic processes. This was supported by the findings of a subsequent review of landscape approach implementation in the tropics that consistently showed community engagement, institutional support, good governance and capacity development were fundamental contributory factors toward the success of landscape approaches (Reed et al. 2017).

Another recent review process developed a typology of integrated landscape initiatives in Latin America and subsequently evaluated their performance (Carmenta et al. 2020). Using data from 104 different examples they found that landscape initiatives varied in their application along a spectrum of high to low integration. The analysis found that integration underscores performance, with those more highly integrated perceived 
to be more effective by project proponents. Beyond these reviews, we found very few independent case studies in the literature that evaluated landscape approaches.

Evaluating landscape approaches has long been considered problematic for at least two reasons. First, stakeholders have different perceptions of success, demonstrated by two recent publications on landscape approaches in the Sangha Tri-national landscape in the northwestern Congo Basin that arrive at different outcomes (Sayer et al. 2016; Clay 2016). There can be multiple reasons for these contrasting outcomes.

One, temporality, is alluded to in both publications. Sayer et al. (2016) acknowledge that the challenges facing the Sangha Region have changed markedly in the last decade and will likely continue to do so; while Clay (2016) emphasizes the need for a nuanced understanding of socio-ecological relationships by considering both historical legacies and future trajectories of change.

Second, there is no common understanding of what constitutes satisfactory evidence of success. Scholars acknowledge that because robust evidence is missing and evaluation methods are not explicit, success is hard to gauge (Sayer et al. 2016; Reed et al. 2017). Although counterfactual impact assessments have been common practice in other sectors (Banerjee and Duflo 2009) and an encouraging body of evidence is developing for conservation and development initiatives (Agol et al. 2014; Ferraro and Hanauer 2014; Baylis et al. 2016), they generally target simple, time-bound and relatively smallscale interventions. Applying such assessments to landscape approaches is problematic because these methods generally require large sample sizes to find statistically sound controls (Sills et al. 2015). Besides, the complexity of landscape approaches, which generally correspond to an aggregation of smaller projects, and the fact that they are long-term, evolving activities, are additional challenges to run such methods. Alternative approaches to determine "success" that take account of complex and longterm processes are needed.

These inherent difficulties in applying robust evaluation methods are combined with the lack of reliable monitoring and evaluation systems. There is certainly no recognized universal standard for monitoring or evaluating performance of landscape approaches. Frameworks or indicators of development have been applied, as will be shown in the next section; the problem is instead associated with lack of implementation or widespread adoption, post-development. This could be due to insufficient financial resources, leading to a knowledge-implementation gap. It could be that implementing actors are reluctant or lack capacity to apply frameworks developed by others. Finally, lacking a universally agreed upon monitoring and evaluation (M\&E) strategy might not be a bad thing; if we agree to look beyond panaceas to address complex challenges (Ostrom et al. 2007) it fits that M\&E strategies should be highly contextualized. Nonetheless, robust (and ideally, participatory) monitoring systems are a fundamental principle of landscape approaches and crucial to identifying trade-offs and synergies as well as informing processes of adaptive management. The next section reviews recent developments in this regard. 


\subsection{Methodological developments in monitoring and evaluation}

To overcome uncertainty in effectiveness and capture the breadth of landscape approaches, we need to move beyond a project mentality focused on outcomes and develop evaluation methods that recognize landscape approaches as long-term endeavors that demand increased attention to complex processes.

Recent literature discussing evaluation of landscape approaches has focused on developing appropriate metrics and indicators. Significant emphasis has been put on attempting to reconcile local stakeholder requirements with broader environmental objectives through local involvement in developing metrics to measure landscape performance - thus, including local stakeholders in broader evaluations (Dietz et al. 2013; Pouw et al. 2017). For example, the landscape measures framework (Buck et al. 2006; Milder et al. 2012) adopts a hierarchical approach of four overarching goals - conservation, production, livelihoods, and institutions - with twenty subcriteria; essentially, 20 questions as indicators to evaluate social and biophysical change. Although the questions themselves are somewhat vague, reflecting the scale and diversity of landscapes, users are encouraged to refine, adapt or elaborate the questionnaire as required to best suit the landscape context and challenges.

The capital assets framework offers potential via its ability to capture both the dynamism of landscapes and the contrasting perceptions of multiple stakeholders. Similar to the landscape measures framework above, this approach, used by Sayer et al. (2007), advocates using social learning in a participatory process of developing simple indicator sets in key asset categories: financial, social, physical, human, and natural capital. In an explicit attempt to sustain stakeholder engagement - and, presumably, alleviate high transaction costs - the capital assets framework encourages continued and open stakeholder dialogue (rather than an over-reliance on expert opinion) throughout the process of conceptualizing, monitoring, and analyzing indicator sets. Analysis of the performance of "individual" assets relative to other assets allows for identification of trade-offs and can stimulate further stakeholder negotiation. Largely similar approaches are applied when assessing resilience or ecosystem service provision within a landscape (see, for example, Resilience Alliance 2010; Potschin and HainesYoung 2016).

Considering other evaluation approaches and principles can help strengthen the identification of metrics and indicators to be monitored. One of these is "systems thinking", which has been proposed as a core principle to evaluate complexity in the evaluation literature (Patton, 2011). Comprehensive landscape monitoring will likely depend on aggregate systems that encompass multiple variables of interest - ideally, with one indicator satisfying multiple objectives. While aggregate systems offer potential (albeit not without their own challenges), a rigorous assessment of a landscape system depends on evaluating not only the individual components, but also how these interact to influence the whole (Levin 1992; Ostrom 2009). 
While there are several potential frameworks and approaches for landscape monitoring and evaluation available, the specific context will largely determine what must be measured and evaluated, and how to do this (see Chapters 5 and 6). An important limiting factor to developing appropriate metrics and methods for causal inference is the lack of data. Practitioners of landscape approaches should investigate publicly available data sources for their landscape of interest. Technological advances have greatly enhanced the ability to monitor land-use cover and change, and recent research also shows the potential for incorporating census, income, health and nutrition data, mobile phone usage and gas stove conversion figures to interpret the social implications of environmental decision-making (Jagger and Rana 2017).

Advances include new data sources at increasingly fine spatial and temporal resolutions, improved algorithms that increase the accuracy of remotely sensed detection (e.g. of fire or rainfall) (Aragao et al. 2008) and the large, open-access platforms that make available prepared data that can be incorporated into new analyses, e.g. Borneo Atlas, Trase, and Global Forest Watch. Added to the burgeoning suite of processed remote sensed data and their repositories (e.g. Maryland's Global Forest Change, NASA's Wed Fire Mapper) are additional sources of geo-referenced data across social, ecological (from biodiversity and carbon, to agricultural yields and soil quality) and economic domains. Examples are YieldGapMap and the World Conservation Monitoring Centre.

Increased use of publicly available spatial and social data sources can alleviate high transaction costs, but an element of 'ground-truthing' and data triangulation through random samples of household data, focus group discussions and semi-structured interviews with key individuals should be incorporated to provide a more complete analysis of landscape dynamics and intervention performance.

\subsection{Discussion and conclusion}

Humanity has made unprecedented social and economic progress in the last century. However, the continued overexploitation of natural resources and the associated impacts of climate change threaten the sustainability of many tropical social-ecological systems. Evidence shows that where sectorial approaches to conservation or development challenges prevail, tensions between conflicting stakeholder objectives persist (Sandker et al. 2009; Carmenta and Vira 2018). There is both a need, and desire, for more holistic approaches to addressing the challenges faced by tropical landscapes. Integrated landscape approaches are among such initiatives. This brief update on the progress of landscape approaches in the tropics reveals that there is considerable enthusiasm for landscape-scale interventions that clearly transcend the research and academic community. The Global Landscapes Forum (GLF) as a knowledge-led platform has successfully provided a convening space for actors that might ordinarily be at odds with one and other, and has a mandate to broaden its reach to engage over one billion people in integrated landscape approaches. Meanwhile, such integrated approaches that aim to link conservation and development concerns are gaining prominence in international conventions related to climate (UNFCCC), biodiversity (CBD), forest restoration (Bonn 
Challenge) and development (SDGs). Clearly, integrated landscape approaches that better considers the needs of multiple stakeholders operating within and outside of the landscape of concern offers potential to develop more equitable management solutions. It is, however, important to recognize that such approaches are not a cure-all for every social and environmental ill, and important gaps in understanding remain.

Challenges for implementation of landscape approaches include accurately conceptualizing what they represent and how they should function - both in terms of the appropriate spatial scale for implementation and the configuration and governance of actors (Clay 2016) and resources (McCall 2016). It is also worth considering the extent to which landscape approaches, in common with other integrated approaches that came before, are more readily marketed than implemented (Pfund 2010). Certainly, the scientific literature points to a lack of evidence of effectiveness (Reed et al. 2017; Sayer et al. 2017). This does not necessarily indicate that landscape approaches are not happening nor effective. Instead, it may be that more localized initiatives (Foli et al. 2018; Ros-Tonen et al. 2018) are not being adequately tested or reported. However, this lack of evidence limits the ability to show where, and under what conditions, landscape approaches are successful (or even feasible) and leaves us with an incomplete understanding of the governance and functioning of such initiatives in practice.

In order to better engage with the realities of complex tropical landscapes, landscape approaches must be long-term and transdisciplinary in nature (Boedhihartono et al. 2018). However, funding for such long-term endeavors is a challenge, with donors traditionally opting to support project cycles of two to three years, and significant challenges associated with bringing together actors from within and across areas of expertise and knowledge (Sayer et al. 2014 and Chapter 4). Questions also remain over how best to engage the private sector and incentivize the political sector. Indeed, there are several elements of landscape approach theory that are, as yet, inadequately supported with robust empirical evidence.

Landscape approaches are conceptually attractive (Chia and Sufo 2015) and offer considerable potential to address socio-economic and environmental trade-offs facing people and nature in complex tropical landscapes. To meet these challenges, landscape approaches must be implemented in varied contexts, up-scaled, monitored, evaluated and documented. The research community has a fundamental role in advancing landscape approaches - both in theory and practice. Transdisciplinary research that learns from multiple and varied knowledge systems should be encouraged and can be supported via tools for scenario-building and theory of change development alongside mixed-methods analyses that capture social perceptions and ecological dynamics. Moreover, the future landscape approach research agenda must more explicitly address power asymmetries (Clay 2016; Ros-Tonen et al. 2018) and recognize the heterogeneity of stakeholder and resource user groups, to stimulate decision-making that is both more integrative and more inclusive of women, youth and other marginalized groups (Hart et al. 2015; Ros-Tonen et al. 2015; Ros-Tonen et al. 2018). The research community can play a role in facilitating these processes and ensuring that integration goes beyond engagement; that muddling through does not imply muddled thinking; and that honest brokerage extends to honest reporting. 


\section{References}

Agol D, Latawiec AE, Strassburg B. 2014. Evaluating impacts of development and conservation projects using sustainability indicators: Opportunities and challenges. Environmental Impact Assessment Review 48: 1-9. https://doi.org/10.1016/j. eiar.2014.04.001.

Agrawal A, Smith RC, Li T. 1997. Community in conservation: Beyond enchantment and disenchantment. Gainesville, Florida, USA: Conservation and Development Forum.

Aragao LEOC, Malhi Y, Barbier N., Lima A, Shimabukuro Y, Anderson L and Saatchi S. 2008. Interactions between rainfall, deforestation and fires during recent years in the Brazilian Amazonia.Philosophical Transactions of the Royal Society B: Biological Sciences 363: 1779-1785. https://doi.org/10.1098/rstb.2007.0026.

Arts B, Buizer M, Horlings L, Ingram V, van Oosten C and Opdam P. 2017. Landscape approaches: A state-of-the-art review. Annual Review of Environment and Resources 42: 439-463.

Banerjee AV and Duflo E. 2009. The experimental approach to development economics. Annual Review of Economics 1: 151-178. https://doi.org/10.1146/annurev. economics.050708.143235.

Barlow J, França F, Gardner TA, Hicks CC, Lennox GD, Berenguer E, Castello L, Economo EP, Ferreira J, Guénard B, et al. 2018. The future of tropical hyperdiverse ecosystems. Nature 559: 517-526

Baylis K, Honey-Rosés J, Börner J, Corbera E, Ezzine-de-Blas D, Ferraro PJ, Lapeyre R, Martin Persson U, Pfaff A and Wunder S. 2016. Mainstreaming impact evaluation in nature conservation. Conservation Letters 9(1): 58-64. https://doi.org/10.1111/ conl.12180.

Berkes F. 2009. Evolution of co-management: Role of knowledge generation, bridging organizations and social learning. Journal of Environmental Management 90(5): 16921702. doi: 10.1016/j.jenvman.2008.12.001.

Boedhihartono AK, Bongers F, Boot RGA, van Dijk J, Jeans H, van Kuijk M, Koster H, Reed J, Sayer J, Sunderland T, et al. 2018. Conservation science and practice must engage with the realities of complex tropical landscapes. Tropical Conservation Science 11: 194008291877957. https://doi.org/10.1177/1940082918779571.

Bonny E and Berkes F. 2008. Communicating traditional environmental knowledge: Addressing the diversity of knowledge, audiences and media types. Polar Record 44(230): 243-253. https://doi.org/10.1017/S0032247408007420.

Boyd W, Stickler C, Duchelle AE, Seymour F, Nepstad D, Bahar, NHA, Rodriguez-Ward D. 2018. Jurisdictional approaches to REDD+ and low emissions development: Progress and prospects. Working Paper June 2018. Washington DC: World Resources Institute.

Buck LE, Milder JC, Gavin T, and Mukherjee I. 2006. Understanding Ecoagriculture: A Framework for Measuring Landscape Performance. Ithaca, NY: Cornell University and Washington DC: Ecoagriculture Partners. https://doi.org/1935-8717.

Buck Scherr SJ, Chami B, Lawrence TJ, Mecham J, Nevers E and Thomas R. 2019. Exploring Property Rights and Tenure in Integrated Landscape Management: A Scoping 
Study from the Landscapes for People, Food, and Nature Network. Washington DC: Landscapes for People, Food, and Nature Network.

Carmenta R, Coomes DA, DeClerck FA, Hart AK, Harvey CA, Milder J, Reed J, Vira B, Estrada-Carmona, N. 2020. Characterizing and evaluating integrated landscape initiatives. One Earth 2(2): 174-187. https://doi.org/10.1016/j.oneear.2020.01.009

Carmenta R and Vira B. 2018. Integration for restoration. Reflecting on lessons learned from the slos of the past. In: Mansourian S and Parrotta J, eds. Forest Landscape Restoration. Integrated Approaches to Support Effective Implementation. London: Routledge. 16-36.

Carmenta, R., Coomes, D. A., DeClerck, F. A., Hart, A. K., Harvey, C. A., Milder, J., ... \& Estrada-Carmona, N. (2020). Characterizing and Evaluating Integrated Landscape Initiatives. One Earth 2(2): 174-187.

Chia EL and Sufo RK. 2015. A situational analysis of Cameroon's Technical Operation Units (TOUs) in the context of the landscape approach: Critical issues and perspectives. Environment, Development and Sustainability 18(4): 951-964. https://doi. org/10.1007/s10668-015-9688-0.

Clark R, Reed J, Sunderland, T. 2018. Bridging funding gaps for climate and sustainable development: Pitfalls, progress and potential of private finance. Land Use Policy 71: 335-346. https://doi.org/10.1016/j.landusepol.2017.12.013.

Clay N. 2016. Producing hybrid forests in the Congo Basin: A political ecology of the landscape approach to conservation. Geoforum 76: 130-141. https://doi.org/10.1016/j. geoforum.2016.09.008.

Curtis B. 2018. Geographical and spatial poverty. In: Cosgrove S and Curtis B, eds. Understanding Global Poverty. Causes, Capabilities and Human Development. Oxfordshire: Taylor \& Francis. 100-124.

Curtis PG, Slay CM, Harris NL, Tyukavina A and Hansen MC. 2018. Classifying drivers of global forest loss. Science 361(6407). 1108-1111. https://doi.org/10.1126/science.aau3445.

Denier L, Scherr S, Shames S, Chatterton P, Hovani L and Stam, N. 2015. The Little Sustainable Landscapes Book: Achieving sustainable development through integrated landscape management. Oxford: Global Canopy Programme. https://doi.org/10.1017/ CBO9781107415324.004.

Dietz T, Bymolt R, Bélemvire A, van der Geest K, de Groot D, Millar D, Obeng F, Pouw N, Rijneveld W, Zaal F. 2013 Participatory Assessment of Development Guidebook. Participatory Assessment of Development. Amsterdam University of Amsterdam.

Escobar A. 1998. Whose knowledge, whose nature? Biodiversity, conservation, and the political ecology of social movements. Journal of Political Ecology 5: 53-82.

Estrada-Carmona N, Hart AK, DeClerck FAJ, Harvey CA and Milder JC. 2014. Integrated landscape management for agriculture, rural livelihoods, and ecosystem conservation: An assessment of experience from Latin America and the Caribbean. Landscape and Urban Planning 129: 1-11.

Ferraro PJ and Hanauer MM. 2014. Quantifying causal mechanisms to determine how protected areas affect poverty through changes in ecosystem services and 
infrastructure. Proceedings of the National Academy of Sciences of the United States of America 111(11): 4332-4337. https://doi.org/10.1073/pnas.1307712111.

Foli S, Ros-Tonen MAF, Reed J and Sunderland T. 2018. Natural resource management schemes as entry points for integrated landscape approaches: Evidence from Ghana and Burkina Faso. Environmental Management 62(1): 82-97. https://doi.org/10.1007/ s00267-017-0866-8.

Forestdeclaration.org 2018. Protecting the World's Forests: Are We on Track? 2018 Progress Assessment of the New York Declaration on Forests Updates on Goals 1-9. (September).

García-Martín M, Bieling C, Hart A and Plieninger T. 2016. Integrated landscape initiatives in Europe: Multi-sector collaboration in multi-functional landscapes. Land Use Policy 58: 43-53. https://doi.org/10.1016/j.landusepol.2016.07.001.

Goldman M and Goldman M. 2003. Partitioned nature, privileged knowledge: Community-based conservation in Tanzania. Development and Change 34(5): 833-862.

Hart AK, Milder JC, Estrada-Carmona N, Declerck F, Harvey CA and Dobie P. 2015. Integrated landscape initiatives in practice: Assessing experiences from 191 landscapes in Africa and Latin America. In: Minang PA, van Noordwijk M, Freeman OE, Mbow C, de Leeuw J and Catacutan D, eds. Climate-smart Landscapes: Multifunctionality in Practice. Nairobi: World Agroforestry Centre. 89-102.

IDH. 2017. Driving business solutions for sustainable landscape. Forum report 8-9 February 2017. Amsterdam. ISH the sustainable trade initiative. https://www. idhsustainabletrade.com/news/idh-forum-driving-business-solutions-sustainablelandscapes/.

Jagger P and Rana P. 2017. Using publicly available social and spatial data to evaluate progress on REDD+ social safeguards in Indonesia. Environmental Science and Policy 76(June): 59-69. https://doi.org/10.1016/j.envsci.2017.06.006.

Jasonoff S. 1996. Is science socially constructed-And can it still inform public policy?. Science and Engineering Ethics 2(3): 263-276.

Jentoft S. and McCay B. 1995. User participation in fisheries management: Lessons drawn from international experiences. Marine Policy 19(3): 227-246. https://doi. org/10.1016/0308-597X(94)00010-P.

Kissinger G, Brasser A and Gross L. 2013. Reducing Risk. Landscape Approaches to Sustainable Sourcing. Washington: EcoAgriculture Partners.

Lambin EF, Gibbs HK, Heilmay R, Carlson KM, Fleck LC, Garrett RD, le Polain de Waroux Y, McDermott CL, McLaughlin D, Newton P, et al. 2018. The role of supplychain initiatives in reducing deforestation. Nature Climate Change 8(2): 109-116. https://doi.org/10.1038/s41558-017-0061-1.

Langston J, Mcintyre R, Falconer K, Sunderland T, van Noordwijk M and Boedhihartono AK. 2019. Discourses mapped by Q-method show governance constraints motivate landscape approaches in Indonesia. PLoS One 14(1), e0211221. https://doi.org/10.1371/ journal.pone.0211221.

Lawry S, Samii C, Hall R, Leopold A, Hornby D and Mtero F. 2017. The impact of land property rights interventions on investment and agricultural productivity in 
developing countries: A systematic review. Journal of Development Effectiveness 9(1): 61-81. https://doi.org/10.1080/19439342.2016.1160947.

Levin SA. 1992. The problem of pattern and scale in ecology: The Robert H. MacArthur award lecture. Ecology 73(6): 1943-1967.

Loconto A, Desquilbet M, Moreau T, Couvet D and Dorin B. 2018. The land sparing - land sharing controversy: Tracing the politics of knowledge. Land Use Policy 96, 103610: 1-13. https://doi.org/10.1016/j.landusepol.2018.09.014.

Mansourian S and Sgard A. 2019. Diverse interpretations of governance and their relevance to forest landscape restoration. Land Use Policy, 104011. https://doi. org/10.1016/j.landusepol.2019.05.030.

McCall MK. 2016. Beyond "Landscape" in REDD+: The Imperative for "Territory"'. World Development 85: 58-72. https://doi.org/10.1016/j.worlddev.2016.05.001.

Meadows DH. 2009. Thinking in systems. A primer. Vermont: Chelasea Green Publishing.

Meinig DW. 1979. The beholding eye. Ten versions of the same scene. In Meinig, DW, ed. The Interpretation of Ordinary Landscapes. New York: Oxford University Press. 33-48.

Milder JC, Buck LE, DeClerck F, Scherr SJ. 2012. Landscape approaches to achieving food production, natural resource conservation, and the millennium development goals. In: Ingram JC, DeCLerck F and Rumbaitis del Rio C, eds. Integrating Ecology and Poverty Reduction. New York, NY: Springer. 77-108.

Milder JC, Hart AK, Dobie P, Minai J, Zaleski C. 2014. Integrated landscape initiatives for African agriculture, development, and conservation: A region-wide assessment. World Development 54: 68-80.

Opdam P. 2018. Exploring the role of science in sustainable landscape management. An introduction to the special issue. Sustainability 10(2), 331: 1-6. doi: 10.3390/su10020331.

Ostrom E. 2009. A general framework for analyzing sustainability of social-ecological systems. Science 325: 419-422. https://doi.org/10.1126/science.1172133.

Ostrom E, Janssen MA, Anderies JM. 2007. Going beyond panaceas. Proceedings of the National Academy of Sciences of the United States of America 104(39): 15176-8. https://doi. org/10.1073/pnas.0701886104.

Paneque-Galvez J, Pérez-Llorente I, Luz IC, Guèze M, Mas J-F, Macía MJ, Orta-Martínez $M$ and Reyes-García V. 2018. High overlap between traditional ecological knowledge and forest conservation found in the Bolivian Amazon. Ambio: A Journal of the Human Environment 47: 908-923. https://doi.org/10.1007/s13280-018-1040-0.

Patton MQ. 2011. Applying Complexity Concepts to Enhance Innovation and Use. New York: Guilford.

Pfeffer K, Baud I, Denis E, Scott D and Sydenstricker-Neto J. 2013. Participatory spatial knowledge management tools. Information, Communication \& Society 16(2): 258-285. https://doi.org/10.1080/1369118X.2012.687393.

Pfund JL. 2010. Landscape-scale research for conservation and development in the tropics: Fighting persisting challenge. Current Opinion in Environmental Sustainability 2(1-2): 117-126. https://doi.org/10.1016/j.cosust.2010.03.002. 
Pirard R, Gnych S, Pacheco P and Lawry S. 2015. Zero-deforestation commitments in Indonesia: Governance challenges. CIFOR Info brief 132. https://doi.org/10.17528/ cifor/005871.

Potschin M and Haines-Young R. 2016. Defining and measuring ecosystem services. In: Potschin M, Fish R and Turner RK, eds. Routledge Handbook of Ecosystem Services. New York/London: Routledge.25-41. https://doi.org/10.1017/CBO9781107415324.004.

Poulton C and Macartney J. 2012. Can public-private partnerships leverage private investment in agricultural value chains in Africa? A preliminary review. World Development 40(1): 96-109. https://doi.org/10.1016/j.worlddev.2011.05.017.

Pouw N, Dietz T, Bélemvire A, de Groot D, Millar D, Obeng F, Rijneveld W, van der Geest K, Vlaminck Z and Zaal F. 2017. Participatory assessment of development interventions. Lessons learned from a new evaluation methodology in Ghana and Burkina Faso. American Journal of Evaluation 38(1): 47-59. https://doi. org/10.1177/1098214016641210.

Reed J, Barlow J, Carmenta R, Van Vianen J and Sunderland T. 2019. Engaging multiple stakeholders to reconcile climate, conservation and development objectives in tropical landscapes. Biological Conservation 238, 108229. https://doi.org/10.1016/j. biocon.2019.108229.

Reed J, Deakin L, Sunderland T. 2015. What are "Integrated Landscape Approaches" and how effectively have they been implemented in the tropics: A systematic map protocol. Environmental Evidence 4(1): 1-7. https://doi.org/10.1186/2047-2382-4-2.

Reed J, Ickowitz A, Chervier C, Djoudi H, Moombe K, Ros-Tonen M, Yanou M, Yuliani $\mathrm{L}$ and Sunderland T. 2020. Integrated landscape approaches in the tropics: A brief stock-take. Land Use Policy, 99, 104822.

Reed J, Van Vianen J, Barlow J and Sunderland T. 2017. Have integrated landscape approaches reconciled societal and environmental issues in the tropics? Land Use Policy. 63: 481-492. https://doi.org/10.1016/j.landusepol.2017.02.021.

Reed J, Van Vianen J, Deakin EL, Barlow J and Sunderland T. 2016. Integrated landscape approaches to managing social and environmental issues in the tropics: Learning from the past to guide the future. Global Change Biology 22(7): 2540-2554. https://doi. org/10.1111/gcb.13284.

Reid WV, Berkes F, Wilbanks TJ and Capistrano D. 2006. Bridging Scales and Knowledge Systems: Concepts and Applications in Ecosystem Assessment. Washington DC: Island Press.

Resilience Alliance. 2010. Assessing resilience in social-ecological systems: Workbook for practitioners. Version 2.0. https://doi.org/10.1007/s11284-006-0074-0.

Ribot JC, Lund JF, Treue T. 2010. Democratic decentralization in sub-Saharan Africa: Its contribution to forest management, livelihoods. Environmental Conservation 37(1): 35-44. https://doi.org/10.1017/S0376892910000329.

Riggs R, Sayer J, Margules C, Boedhihartono AK, Langston J and Sutanto H. 2016. Forest tenure and conflict in Indonesia: Contested rights in Rempek Village, Lombok. Land Use Policy 57: 241-249. https://doi.org/10.1016/j.landusepol.2016.06.002.

Robinson BE, Holland MB and Naughton-treves L. 2014. Does secure land tenure save forests? A meta-analysis of the relationship between land tenure and tropical 
deforestation. Global Environmental Change 29: 281-293. https://doi.org/10.1016/j. gloenvcha.2013.05.012.

Ros-Tonen MAF, Van Leynseele YPB, Laven A and Sunderland T. 2015. Landscapes of social inclusion: Inclusive value-chain collaboration through the lenses of food sovereignty and landscape Governance. European Journal of Development Research 27(4): 523-540. https://doi.org/10.1057/ejdr.2015.50.

Ros-Tonen MAF, Reed J, Sunderland T. 2018. From synergy to complexity: The trend toward integrated value hain and landscape governance. Environmental Management 62(1): 1-14. https://doi.org/10.1007/s00267-018-1055-0.

Sandker M, Campbell BM, Nzooh Z, Sunderland T, Amougou V, Defo L and Sayer J. 2009. Exploring the effectiveness of integrated conservation and development interventions in a Central African forest landscape. Biodiversity and Conservation 18(11): 2875-2892. https://doi.org/10.1007/s10531-009-9613-7.

Sayer J, Campbell B, Petheram L, Aldrich M, Ruiz Perez M, Endamana D, Nzooh Dongmo Z-L, Defo L, Mariki S, Doggart N and Burgess N. 2007. Assessing environment and development outcomes in conservation landscapes. Biodiversity and Conservation 16(9): 2677-2694. https://doi.org/10.1007/s10531-006-9079-9.

Sayer J, Sunderland T, Ghazoul J, Pfund J-L, Sheil D, Meijaard E, Venter M, Boedhihartono AK, Day M, Garcia C, et al. 2013. Ten principles for a landscape approach to reconciling agriculture, conservation, and other competing land uses. Proceedings of the National Academy of Sciences of the United States of America 110(21): 8349-56. https://doi.org/10.1073/pnas.1210595110.

Sayer J, Margules C, Boedhihartono AK, Dale A, Sunderland T, Supriatna J and Saryanthi R. 2014. Landscape approaches; what are the pre-conditions for success? Sustainability Science 10(2): 345-355.

Sayer J, Endamana D, Breuer T, Ruiz-Perez M and Boedhihartono AK. 2016. Learning from change in the Sangha Tri-National landscape. International Forestry Review 18(1): 130-139. https://doi.org/10.1505/146554816819683771.

Sayer JA, Margules C, Boedhihartono AK, Sunderland T, Langston JD, Reed J, Purnomo A, Riggs R, Buck LE, Bruce M,. Campbell BM, Kusters K, et al. 2017. Measuring the effectiveness of landscape approaches to conservation and development. Sustainability Science 12(3): 465-476. https://doi.org/10.1007/s11625-016-0415-z.

Scherr SJ, Shames S and Friedman R. 2017. Business for Sustainable Landscapes. An action agenda for sustainable development. Washington DC: EcoAgriculture Partners.

Shanley P and López C. 2009. Out of the loop: Why research rarely reaches policy makers and the public and what can be done. Biotropica 41(5): 535-544. https://doi.org/10.1111/ j.1744-7429.2009.00561.x.

Sills EO, Herrera D, Kirkpatrick AJ, Brandão Jr A, Dickson R, Hall S, Pattanayak S, Shoch D, Vedoveto M, Young L and Pfaff A. 2015. Estimating the impacts of local policy innovation: The synthetic control method applied to tropical deforestation. PLoS One 10(7), e0132590. https://doi.org/10.1371/journal.pone.0132590.

Song XP, Hansen MC, Stehman SV, Potapov PV, Tyukavina A, Vermote EF and Townshend JR. 2018. Global land change from 1982 to 2016. Nature 560(7720): 639-643. https://doi.org/10.1038/s41586-018-0411-9. 
Thorpe J and Maestre M. 2015. Brokering Development: Enabling Factors for PublicPrivate-Producer Partnerships in Agricultural Value Chains. IFAD and IDS technical report (June): 1-50.

Toderi M, Francioni M, Seddaiu G, Paolo P, Trozzo L and Ottavio PD. 2017. Bottom-up design process of agri-environmental measures at a landscape scale : Evidence from case studies on biodiversity conservation and water protection. Land Use Policy 68: 295-305. https://doi.org/10.1016/j.landusepol.2017.08.002.

Toomey AH et al. 2015. Inter- and Trans-disciplinary Research: A Critical Perspective. GSDR Brief: 1-3.

Toomey AH, Knight AT, Barlow J. 2017. Navigating the Space between Research and Implementation in Conservation. Conservation Letters 10(5): 619-625. https://doi. org/10.1111/conl.12315.

van Oosten C, Runhaar H, Arts B. 2019. Capable to govern landscape restoration? Exploring landscape governance capabilities, based on literature and stakeholder perceptions. Land Use Policy, 104020. https://doi.org/10.1016/j. landusepol.2019.05.039.

Westerink J, Opdam P, Van Rooij S and Steingröver E. 2017. Landscape services as boundary concept in landscape governance: Building social capital in collaboration and adapting the landscape. Land Use Policy. 60: 408-418. https://doi.org/10.1016/j. landusepol.2016.11.006.

Whitmee S, Haines A, Beyrer C, Boltz F, Capon AG, Ferreira de Souza Dias B, Ezeh A, Frumkin H, Gong P, Head P et al. 2015. Safeguarding human health in the Anthropocene epoch: Report of The Rockefeller Foundation-Lancet Commission on planetary health. The Lancet. 386(10007): 1973-2028. https://doi.org/10.1016/s01406736(15)60901-1.

Zanzanaini C, Trần BT, Singh C, Hart A, Milder J and DeClerck F. 2017. Integrated landscape initiatives for agriculture, livelihoods and ecosystem conservation: An assessment of experiences from South and Southeast Asia. Landscape and Urban Planning 165: 11-21. https://doi.org/10.1016/j.landurbplan.2017.03.010. 
The major drivers of biodiversity loss are land-use change, exploitation, pollution, invasion of alien and undesired native species, loss of pollinators and climate change (Díaz et al. 2019). These, in turn, are underpinned by a range of socioeconomic issues such as food and nutrition security (Montoya et al. 2020), livelihoods (Garibaldi et al. 2017), Indigenous rights (Witter and Satterfield 2019) and gender issues (Alvarez and Lovera 2016). This is particularly evident in the tropics, which harbor about two-thirds of the world's biodiversity (Giam 2017; Barlow et al. 2018) and is more pronounced in the subtropical dry forests and woodlands (Miles et al. 2006), where the anthropogenic pressures on the environment have escalated to an unprecedented level (Barlow et al. 2016; Swamy et al. 2018). A strictly conservation focus to address these challenges is limited in scope, as the well-being of the local communities, particularly those who are poor and vulnerable, is inextricably linked to the natural resources in these regions (Swamy et al. 2018; Schleicher et al. 2019). Thus, there is an urgent need for an integrated approach that better acknowledges and reconciles the deeply connected social, environmental, political and economic challenges in the tropics.

Biodiversity is an integral component of such integrated approaches as it contributes both directly and indirectly to food security and human well-being (Cramer et al. 2017). This chapter synthesizes the crucial roles of biodiversity and evaluates ways to conserve and monitor biodiversity within integrated landscape approaches.

\subsection{Why is biodiversity important?}

\subsubsection{Biodiversity and food security}

Biodiversity - that is, the variety of life across genes, species and functional traits - plays an integral role in ensuring food security, livelihoods and human well-being (Cardinale et al. 2012). Globally, 1.6 billion people rely on forests and biodiversity for food and livelihoods (Newton et al. 2020). Biodiversity is critical for safeguarding food and nutrition security, underpinning modern agriculture as well as the livelihoods of millions of forest-proximate communities (Richardson 2010; Sunderland 2011; Broegaard et al. 2017). Biodiversity contributes to food and livelihood security via a number of pathways, which we briefly summarize below.

\section{Forest food}

About one in six people rely on wild food such as wild vegetables and fruits, fungi, honey, edible insects and bushmeat across the world (Vinceti et al. 2013; Vira et al. 2015; Sardeshpande and Shackleton 2019). For instance, local communities use up to 800 species for wild food in Asia and Africa (Bharucha and Pretty 2010), while six million tons of bushmeat is extracted annually from the forests of Africa and South America (Overton et al. 2017; Baudron et al. 2019). Forest foods also provide a safety net to communities during food scarcity (Wunder et al. 2014), signaling the need to manage the interdependence between human needs and biodiversity conservation. 


\section{Nutrition and health}

Biodiversity increases dietary diversity and nutritional quality, especially for local communities (Powell et al. 2015; Rasmussen et al. 2017). Wild foods are important sources of essential fatty acids, iron, zinc, calcium and vitamins (Glew et al. 1997). Deficiency in one or more of these micronutrients is most severe in the developing world, where production is highly dependent on pollinators (Chaplin-Kramer et al. 2014). Bushmeat and fish contribute to $20 \%$ of the protein requirement where other sources of protein are not available (Datta et al. 2008; Naro et al. 2015). In addition, up to $80 \%$ of the population in many developing countries depend on biodiversity for their primary health care (Herndon and Butler 2010). Biodiversity is often the basis for various forms of indigenous medicines that are critical for human survival, especially in developing countries (WHO 2002; Alves and Rosa 2007). Finally, biodiversity loss can also impact human health by increasing the emergence and transmission of infectious diseases (Keesing et al. 2010; Olivero et al. 2017).

\subsection{Livelihood benefits from biodiversity}

Plants and animals harvested from forests contribute significantly to the livelihood strategies of forest-dependent local communities (Delang 2006; Paumgarten and Shackleton 2009), especially in the case of women and the cash poorest (Pouliot and Treue 2013). The contribution of biodiversity to the economy of developing countries has been estimated to be USD 250 billion per annum (Agrawal et al. 2013). Meanwhile, environmental income was found to account for $28 \%$ of total household income in a comparative study across 24 developing countries (Angelsen et al. 2014). For instance, income generated from wild harvest in terms of fuelwood, bushmeat and wild foods was the second biggest contributor to local communities' total annual income in Ghana (Hansen et al. 2015). In Indonesia, 36\% of the total income in indigenous households came from forest resources (Widianingsih et al. 2016). In southern Africa, some poor households derive close to $30 \%$ of their income from forests (Fisher 2004; Jumbe et al. 2008; Mulenga et al. 2012).

\subsection{Adaptation and resilience benefits}

Biodiversity plays a crucial role for resilience and adaptation of people. Ecosystembased adaptation approaches provide cost-effective alternatives for buffering the impacts of climate change, while avoiding the many challenges of hard infrastructure (Jones et al. 2012). Hence, integrated approaches are crucial to capture context-specific, local connections and scale-related challenges between conserving ecosystem services and enhancing the adaptive capacity of people. Most of what is documented as losses and damages to human systems is inherently linked to permanent or temporary disturbances in the biodiversity of ecosystems due to climatic stressors, but studies of loss and damage from climate change tend to overlook the mediating role of biodiversity and ecosystems services to society (van der Geest et al. 2019). A systematic review 
on the impact of climate change on most types of services found that the impact is predominantly negative ( $59 \%$ negative, $24 \%$ mixed, $13 \%$ positive, $4 \%$ neutral), but varied across services. However, very few studies integrated decision-making processes and users, and even fewer studies identified solutions that were robust to uncertainty (Runting et al. 2017). Integrative landscape approaches will help to incorporate this twofold nature of the linkages between ecosystem services and climate change.

\subsection{Ecosystem services from biodiversity}

Biodiversity maintains and enhances multiple ecosystem functions such as primary production, decomposition, nutrient cycling and trophic interactions that support a range of ecosystem services (Cardinale et al. 2012; Lefcheck et al. 2015; Soliveres et al. 2016). The different dimensions of biodiversity such as species richness and abundance, functional diversity (the range of functional traits in species) and phylogenetic diversity (diversity of evolutionary history in species) affect ecosystem services at different spatial and temporal scales (Bennett et al. 2015). For example, species richness can influence ecosystem services such as pollination and pest control whereas abundance can impact biomass production and nutrient cycling (Soliveres et al. 2016). The presence of more species increases the likelihood of an ecosystem to retain a wide range of functional traits. This, in turn, facilitates better ecosystem functioning or provision of services and increases resilience to any potential disturbance compared with communities with fewer species (Brockerhoff et al. 2017).

\subsubsection{Pollination}

Wild pollinators such as bees, butterflies, birds and bats are fundamental to the reproduction and persistence of over $85 \%$ of wild flowering plants globally (Ollerton et al. 2011). Wild pollinators directly affect the productivity of $75 \%$ of globally important crops and are attributed with contributing up to an annual market value of USD 577 billion (Potts et al. 2016). A global study found that pollinator richness increased crop yields across 89 different crop systems (Dainese et al. 2019). Conversely, the absence of pollination can reduce global food production by 5-8\% (Aizen et al. 2009) and risk the nutritional health of up to $56 \%$ of the human population in developing countries (Ellis et al. 2015). However, the diversity and complementarity of functional traits in pollinators is more important than the pollinator species richness, as evidenced in an experimental study in Göttingen, Germany (Fründ et al. 2013). In some parts of the world, for example Africa, with its heterogeneous landscapes and ecosystems, the contribution of animal pollinators to biological diversity remains poorly researched and understood.

\subsubsection{Seed dispersal}

Although many seeds are dispersed by wind, herbivore and frugivore animals also play an important role in seed dispersal. For instance, $68 \%$ of tree species are dispersed by animals in Mexico (Cortés-Flores et al. 2013). Moreover, passage of seeds through the gut of some mammals also enhances seed germination for some species (Campos-Arceiz and Blake 2011). The loss of seed-dispersing species can mean that fruiting trees are 
replaced by wind-dispersed species, leading to homogenization of plant communities (Brodie and Aslan 2012). Thus, seed dispersal by animals contributes significantly to maintaining tree community structure and ecosystem services in the tropics (Markl et al. 2012; Brockerhoff et al. 2017).

\subsubsection{Pest control}

Control of crop pests by their natural enemies such as birds, bats and mammals is an important ecosystem service that supports agriculture (García et al. 2018). Biological pest control is more efficient in complex landscapes with heterogenous habitats where natural pest enemies are diverse and abundant (Chaplin-Kramer et al. 2011). For instance, insectivorous bats and birds play a key role in limiting arthropod abundance and pest outbreaks in diverse agroecological systems (Veres et al. 2013; Martin et al. 2016; Voigt and Kingston 2016). Moreover, natural pest control has always been found to be effective in oil palm landscapes where macaques can potentially regulate rodent populations, with each group feeding up to 3,000 rodents per year, as evidenced in Malaysia (Holzner et al. 2019).

\subsubsection{Biomass production}

Biodiversity promotes primary productivity and its temporal stability at a landscape scale (Oehri et al. 2017). For instance, a synthesis of 67 empirical studies shows that species richness significantly increases biomass production across a range of taxa and ecosystems (Duffy et al. 2017). Conversely, loss of biodiversity from a trophic group can reduce biomass production, resulting in less efficient resource capture, particularly in plants (Cardinale et al. 2012; Liang et al. 2016; Brose and Hillebrand 2016).

\subsubsection{Carbon sequestration}

Forest ecosystems are the largest land carbon sink, accounting for more than half of the carbon stored in terrestrial ecosystems (Hui et al. 2015). The major drivers of carbon accumulation across above- and belowground layers and soil are plant species richness and functional diversity (Lange et al. 2015; Brockerhoff et al. 2017). The estimated monetary value of biodiversity in sequestering carbon is considered to be up to USD 3.1 trillion (Isbell et al. 2017). Thus, biodiversity plays an important role in mitigating climate change by significantly reducing carbon emissions (Chen et al. 2018).

\subsubsection{Nutrient cycling}

Biodiversity influences biogeochemical cycles in myriad ways (Tully and Ryals 2017). For instance, plants sequester carbon, thereby producing soil biodiversity, whereas microorganisms such as bacteria, protozoa, fungi and invertebrate animals decompose organic matter and make nutrients available for plants (van der Heijden et al. 2016). Nitrogen-fixing trees maintain and enhance soil fertility by cycling atmospheric nitrogen, thereby increasing yields (Ajayi et al. 2011). Conversely, decreasing plant and soil diversity can alter decomposition pathways and nutrient cycling (Balvanera et al. 2006; Bender et al. 2016). 


\subsubsection{Ecosystem resilience}

Biodiversity regulates ecosystem resilience by maintaining ecosystem functions and services through a range of mechanisms at species, community and landscape levels (Oliver et al. 2015; Mori et al. 2017). For instance, plant trait diversity maintains resilience in Amazon forests' biomass and thus acts as an insurance against climate change impacts (Sakschewski et al. 2016). Meanwhile, soil biodiversity plays an important role in regulating plant tolerance to stress, thereby also contributing to ecosystem stability (Yang et al. 2018).

\subsubsection{Cultural services}

Cultural services from biodiversity are crucial in enhancing the physical, mental and psychological well-being of human societies (Maller et al. 2006; Abraham et al. 2010; Russell et al. 2013). For instance, ecosystem services from biodiversity provide various health benefits such as lowering blood pressure, relieving stress and mental fatigue, and reducing crime and the tendency for aggressive behavior (Sandifer et al. 2015; Hausmann et al. 2016). Moreover, nature promotes social integration and contributes to the integrity of personal or community identity (Maller et al. 2006). For instance, Indigenous communities often link forest landscapes and biodiversity to tribal identities, kinship, customs and protocols (Gould et al. 2014; Lyver et al. 2017; Yuliani et al. 2018).

\subsection{Managing landscapes for biodiversity and livelihoods}

Effective management of landscapes for both biodiversity and livelihoods requires incorporating biodiversity at the design stage rather than considering it as a response to a conservation initiative. Land management strategies also need to consider the simultaneous interactions between multiple trophic levels and ecosystem services, and potential trade-offs between biodiversity, ecosystem services and livelihoods at both local and landscape scales (Macfadyen et al. 2012). Optimizing synergies and managing trade-offs based on empirical information and adapting management strategies to specific socioeconomic conditions are crucial for maintaining and enhancing both biodiversity and livelihoods in multifunctional landscapes (Kremen and Merenlender 2018).

\subsubsection{Multiple trophic levels and ecosystem services}

Multifunctional landscapes are complex and various ecosystem services interact with and impact these systems simultaneously (O'Farrell and Anderson 2010; RaudseppHearne et al. 2010; Soliveres et al. 2016). Similarly, biodiversity loss occurs across various taxa, and the functional effects of any trophic group may depend on the abundance and diversity of others (Hughes et al. 2016). Therefore, only focusing on a single trophic group or an ecosystem service may lead to underestimating the functional importance of biodiversity and multiple ecosystem services. For instance, an analysis of the relationships between the species richness and abundance of 4,600 taxa and 14 different 
ecosystem services in 150 grasslands shows that high species richness in multiple trophic groups affected ecosystem services more strongly than richness in any individual trophic group (Soliveres et al. 2016). This makes it vital to incorporate simultaneous impacts of any anthropogenic pressure on multiple trophic levels and ecosystem services in effective landscape management strategies.

\subsubsection{Trade-offs between biodiversity and ecosystem services}

A range of trade-offs can occur between biodiversity and ecosystem services and between different ecosystem services (Howe et al. 2014; van der Plas et al. 2018). For instance, trade-offs between agricultural production and biodiversity (Chapin III et al. 2000; Macfadyen et al. 2012) and between carbon storage and other ecosystem services (Goldstein et al. 2012) are well documented. Moreover, the relationships between ecosystem services and biodiversity can also change across landscapes of differing complexity (Birkhofer et al. 2018). For example, a study on the relationship among eight ecosystem services and species richness of five taxonomic groups in cereal farming systems showed that biodiversity increases with increasing landscape complexity, but there was no evidence of a similar positive impact on ecosystem services (Birkhofer et al. 2018). Thus, it is necessary to explicitly incorporate both biodiversity and ecosystem services in landscape management strategies, as promoting one might not necessarily lead to a positive impact on the other (Macfadyen et al. 2012).

\subsubsection{Trade-offs between biodiversity conservation and livelihoods}

Trade-offs between conservation and economic development objectives to ensure livelihoods can potentially be reconciled by targeting management interventions on different components of a landscape (Sayer et al. 2013). However, identification of the optimal allocation of different management options at the landscape scale can also be a challenge (Verhagen et al. 2018). This requires the prioritization of local habitats that are important in providing ecosystem services such as biological pest control (Landis 2017) and pollination services (Garibaldi et al. 2017). For instance, agricultural landscapes can be managed to optimize biodiversity, ecosystem services and livelihoods by incorporating agroforestry, aquaculture, conservation tillage, integrated nutrient management, integrated pest management, crop-livestock integration and water harvesting techniques (Garibaldi et al. 2017).

\subsubsection{Landscape heterogeneity and connectivity}

Landscape composition (proportion of land-use types) and configuration (size, shape and arrangement of land-use patches) play an important role in determining biodiversity in heterogenous landscapes (Duflot et al. 2017; Martin et al. 2019). For example, a review of 49 studies showed that a higher level of landscape configuration (edge density) increased pollinator and natural enemy abundance significantly, leading to improved pollination and pest control across European agroecosystems (Martin et al. 2019). Similarly, an increase in compositional and configurational landscape heterogeneity decreased arthropod abundance in rice cultivation (Dominik et al. 2018), whereas landscape composition had a relatively stronger effect on plant and vertebrate communities (Herrera et al. 2016; Duflot et al. 2017). Therefore, it is crucial to incorporate the impacts of both landscape composition and configuration in land-use planning. 


\subsubsection{Land tenure, rights and social equity}

Since Indigenous communities manage over a quarter of the world's land surface, addressing their tenure, rights and sharing benefits is essential to achieving conservation goals (Garnett et al. 2018). Strengthening stakeholder capacity and facilitating their active involvement in every stage from planning to implementation can contribute significantly in addressing these issues (Zanzanaini et al. 2017). Understanding how different stakeholders benefit from ecosystem services and their preferences for valuing services and how customary institutions are acknowledged by formal institutions are also crucial in evaluating trade-offs and their implications for livelihoods and well-being (Bennett et al. 2015). This facilitates a better understanding of stakeholders' multifaceted perceptions around ecosystem services and thus leads to effectively incorporating those in management systems (Martín-López et al. 2012).

\subsection{Biodiversity monitoring in multifunctional landscapes}

Biodiversity monitoring is key to better understanding how biodiversity responds to drivers of change, its effects on ecosystem services and how to best assess the progress of any conservation intervention (Luque et al. 2018). Setting a frame of reference to track progress and choosing suitable indicators reflecting key aspects of biodiversity response can facilitate objective evaluation of conservation initiatives. Moreover, remote sensing and modeling techniques and community-based monitoring programs can contribute to large-scale data collection, interpretation and informed decision-making with the active participation of local stakeholders.

\subsubsection{Frame of reference to track progress}

The progress of conservation interventions can be evaluated against a clearly specified frame of reference that is either a temporal baseline, i.e. a known biodiversity level at a fixed point in the past or present, or a counterfactual such as an alternative scenario that would have occurred without the intervention (Bull et al. 2014). This frame of reference should be set at an appropriate scale, depending on the context (Mihoub et al. 2017). Although widely used in climate change and restoration assessments, the importance of identifying an appropriate frame of reference to track progress is still largely overlooked in many conservation approaches (Bull et al. 2014), particularly at the landscape scale (Reed et al. 2017).

\subsubsection{Selecting suitable biodiversity indicators}

Biodiversity indicators are widely used tools to monitor and evaluate rates of biodiversity change, habitat condition and the progress in conservation interventions (Mcowen et al. 2016; Bal et al. 2018; Han et al. 2020). A systematic decision framework for indicator selection can make it feasible for land managers and stakeholders to assess biodiversity responses and facilitate effective decision-making (Tzilivakis et al. 2016). This framework can draw from existing international guidelines such as Biodiversity Indicators Partnership (Addison et al. 2018; Rochette et al. 2019). These indicators need to be unambiguously defined and measurable at appropriate scales while also 
considering management effectiveness and budget constraints (Valerio et al. 2016; Bal et al. 2018; Rochette et al. 2019). Moreover, these indicators should include measures to track social outcomes linked to biodiversity such as capacity building and levels of anthropogenic pressures (Mcowen et al. 2016).

\subsubsection{Citizen science programs}

Citizen science, i.e. the practice of engaging the public in a scientific process to produce information that can be used by scientists, decision-makers or the public, is emerging as a powerful tool for tackling conservation challenges (McKinley et al. 2017; Strasser et al. 2019). It can improve conservation efforts by building scientific knowledge through active public participation and by facilitating informed and effective land management decisions and policy-making (Kobori et al. 2016; McKinley et al. 2017). Although most of the existing citizen science programs are currently focused on North America and Europe, various community-based monitoring programs actively operate in Africa and Asia (Chandler et al. 2017). These community-based monitoring (CBM) programs are designed, interpreted and implemented for effective management by local communities (Danielsen et al. 2014). Meanwhile, there is early evidence of the potential for citizen science approaches to improve conservation and development decision-making and outcomes in landscape approaches (Sayer et al. 2015). Citizen science programs can potentially contribute significantly to generating large-scale data on species distribution, species abundance and ecosystem services (Bonney et al. 2016; Chandler et al. 2017), while also creating public awareness, empowering local communities and improving conservation outcomes (McKinley et al. 2017).

\subsubsection{Use of remote-sensing techniques}

Remote-sensing techniques based on high-resolution and multispectral satellite imagery are widely used to monitor biodiversity, ecosystem services and land-use/ land-cover changes at both spatial and temporal scales (Vihervaara et al. 2017; Luque et al. 2018). Moreover, recent technologies from drones and airborne lidar (light detection and ranging) systems generating very high-resolution (VHR) images can improve biodiversity monitoring and ecosystems at both local and regional scales (Guo et al. 2017). Novel techniques to estimate species richness and compositional turnover ( $\beta$-diversity) from airborne or satellite remote sensing can help provide faster and more effective biodiversity monitoring (Rocchini et al. 2018). Increasing the availability and accessibility of processed remotely sensed and geo-referenced data sources at fine spatial and temporal resolutions through open access databases can be particularly useful (Reed et al. 2020).

\subsubsection{Use of modeling and predictions}

Landscape ecological modeling can contribute significantly to our understanding of socioeconomic drivers of land use change and their impact in multifunctional landscapes (Synes et al. 2016). Moreover, social-ecological models can be useful tools for evaluating trade-offs between conserving biodiversity and multiple ecosystem services and providing temporal and spatial projections of future scenarios that can facilitate better decision-making (Mori et al. 2017). For instance, ecosystem services models that 
incorporate biodiversity conservation, such as the Integrated Valuation of Environmental Services and Tradeoffs (InVEST) model (Nelson et al. 2009; see also Chapter 6) can be effective in incorporating the complexity of interacting ecosystem services at multiple scales and generating future land use scenarios for informing policy (Swayne et al. 2010).

\subsection{Biodiversity assessment in the three landscapes}

\subsubsection{Western Wildlife Corridor landscape, Northern Ghana}

\section{Fauna and floristic biodiversity}

The North Ghanaian savannah that hosts the Western Wildlife Corridor (WWC) is generally described as an area rich in wildlife and floristic biodiversity. Indeed, the forest reserves found there are important refuges for many species of mammals, primates, reptiles, birds and rodents, among others (Husseini et al. 2015; Owusu-Ansah 2018).

In terms of floristic biodiversity, the woody species encountered in the area are mainly Vitellaria paradoxa, Combretum spp., Acacia spp., Anogeissus leiocarpa, Afzelia africana, Burkea africana, Isoberlinia doka, Terminalia spp., Adansonia digitata, Boscia senegalensis, Calotropis procera, Lannea microcarpa, Acacia goumaensis, Acacia polycanta, Tamarindus indica, Balanites aegyptiaca, Anonna senegalensis, Bombax spp., Diospyros mespiliformis, Parkia biglobosa, Pterocarpus erinaceus, forming most of the woody savannas. Forest galleries border the main rivers and host species such as Danielia oliveri, Terminalia spp., Anogeissus leiocarpa and Khaya senegalensis (Bouché 2007; Husseini et al. 2015; Owusu-Ansah 2018; see also Chapter 8).

\section{Importance, constraints and measures of biodiversity conservation}

Compared to the high forest zone of Ghana, the savanna ecological zone is timber-poor and hence is not suitable for commercial timber production. However, it still plays a key role in meeting the socioeconomic, cultural and other ecosystem services needs of people (Asase and Oteng-Yeboah 2012). The savanna woodlands ecosystem comprises multifunctional areas that can contribute to reducing rural poverty, supporting the local economy and maintaining biological diversity (IUCN 2012). They provide important regulating, provisioning and cultural services, and are a critical refuge for native biodiversity. In terms of provisioning services, this ecosystem produces about $70 \%$ of Ghana's total supply of firewood and charcoal (World Bank 2002). It shelters several Ghanaian staples, including root tubers such as yam, cereals such as millets, assorted vegetables and nuts. Savanna bushmeat (e.g. rodents, antilopes, reptiles) is estimated to provide $12 \%$ of rural people's protein intake, while it is is also a source of income (Ibid.). With its large tracts of grasslands, the WWC hosts most of Ghana's livestock population, significantly contributing to the protein needs of the country. Other useful ecosystem services include medicinal plants, roofing grasses and fencing poles. The savanna woodlands also have beneficial effects on the local climate and constitute a natural barrier to the desiccating harmattan winds from the Sahara, helping to maintain a favorable microclimate for agricultural production in the south. 
Shea trees (Vitellaria paradoxa) are indigenous to the landscape and are important for the regulation services within the agroforestry system and for the livelihood of people, particularly women (Anang et al. 2011). The fruits are harvested by women to produce shea butter or shea kernel, which are consumed locally, but increasingly marketed as a global commodity in recent years. However, this ecosystem is facing pressure, as shea trees are being lost to indiscriminate charcoal production as a response to the increasing urban demand (Lurimuah 2011; Dapilah et al. 2019). In addition, with the global demand increasing and the lack of investment in the shea value chain, the transformation of the shea nut has negative impacts as it is energy intensive and therefore fuelwood is often harvested in large quantities for this purpose (Jibreel et al. 2013; Jasaw et al. 2017).

African rosewood (Pterocarpus erinaceus) occurs in the Northern Region, particularly within the catchment area of the Mole and Bui National Parks. Recent botanical surveys carried out in northern Ghana estimate the abundance of the African rosewood species to be 82 trees per 40 ha (Ghana Shea Landscape REDD+ Project Concept Note 2017). The exploitation of this species is subject to many conflicts and a heated debate in the area, as demand from international timber markets (China) is increasing (Treanor 2015). To curb overexploitation, a ban was placed on exports in 2012 but was later lifted as salvage permits were given during the construction of a major road network and hydropower station in the Northern Region in 2013, which led again to overexploitation and the subsequent reintroduction of the ban in January 2014. The species was not targeted for local illegal chain-sawed lumber until the surge in demand in 2013 (Dumenu and Bandoh 2016). There is potential to support the development and management of rosewood as a high-value source of revenue. In terms of sustainable management of the biodiversity of both shea and rosewood ecosystems, understanding their ecological characteristics and dynamics including species abundance, distribution, mortality and regeneration patterns is crucial (Dumenu and Bandoh 2016).

As in other drylands regions, threats to biodiversity in the area come from climate change, land degradation and deforestation. Thus, the survival of indigenous land varieties of important food crops and an increasing number of medicinal plant species is being threatened. High levels of human and animal pressure on natural resources, uncontrolled bush fires, agricultural expansion, deforestation and the replacement of indigenous varieties with imported ones are the most cited threats to biodiversity in the region (Mensah et al. 2016). Those issues are exacerbated by the changing climate, with a higher seasonal variability and more extreme events expected in the future. Consequently, many wild species such as elephants, for example, are restricted to a few protected areas. Because of high human impact, elephant migration is now essentially nonexistent in both the eastern and western corridors. However, the existence of a third, lesser known corridor has been revealed between Mole National Park and Bontioli in Burkina Faso through the Gbele Resource Reserve (Bouché 2007).

For many years, the biodiversity efforts of the government were concentrated in the Ghanaian humid zone, and the first draft of the National Biodiversity Strategy and Action Plan neither included the different ethnic and cultural perspectives of the savanna zone nor addressed land degradation issues in the northern savanna regions. Meanwhile, more awareness and efforts are needed to address the biodiversity loss in 
the Northern Region. Indeed, inadequate relevant information has been pointed out as a drawback to the implementation of the National Biodiversity Strategy for Ghana (Hackman 2014).

In situ biodiversity efforts such as those undertaken by the Plant Genetic Resource Center (PGRC), which operates under the auspices of the Ministry of Environment, Science and Technology (MEST) and is based at Bunso, have a basic assignment to collect, conserve, characterize and document plant genetic resources in the country. Besides its ex situ/in vivo facilities, the PGRC maintains an arboretum that contains timber species, medicinal plants, non-timber species and fruit trees. The PGRC works with other institutions related to the northern savannah landscape, such as the Savanna Agricultural Research Institute (SARI) and NGOs working with communities to preserve biological resources and natural habitats, including sacred groves.

In the face of the multiple threats affecting biodiversity conservation, economic incentives through livelihood support activities have been promoted by numerous projects as instruments for natural resource and biodiversity conservation at the fringes of protected areas (Ekpe et al. 2014).

\subsubsection{Kalomo District, Zambia}

Zambia is well endowed with natural resources and biological diversity (GRZ 2015a) that are an importance source of food, nutrition and vitamins, especially to rural households. As elsewhere, human activities have led to unprecedented levels of biodiversity loss in the last few decades (Hanks 2019). Consequently, one of the goals of Zambia's second National Biodiversity Strategy and Action Plan (NBSAP-2) is to "address the underlying drivers of biodiversity loss by mainstreaming biodiversity across government and society" (GRZ 2015a, p. 32). This is underpinned by several policies designed to stem biodiversity loss in affected sectors (GRZ 2015a).

The major drivers of biodiversity loss in Zambia are various, including economic; policy and regulatory; social, environmental, cultural and demographic; political; scientific; and technological. Agriculture, whether subsistence or commercial, remains one of the main drivers of not only habitat loss but also biodiversity loss. The annual deforestation rate in Zambia is 276,021 ha per annum or $6 \%$ of the total forest cover (GRZ et al. 2016) and this has a tremendous impact on biodiversity. Relatedly, practices such as intensive mono-cropping, burning of bush areas for land preparation, use of synthetic fertilizers, and the associated poor disposal of herbicides and insecticides further contribute to the loss of biodiversity.

Government structures are weakly empowered and supported in reducing biodiversity loss due to insufficient resources. Further, conflicting mandates among institutions that issue provisions that adversely affect biodiversity; for example, trade policies in the external sector that allow duty-free importation of fishing gear and the issuing of mining operation licenses by the Ministry of Mines and Minerals Development in protected areas (Matakala et al. 2015) impede progress. In addition, biodiversity management is hampered by low investment in and funding of human resources and physical infrastructure. Key biodiversity sectors such as forestry, wildlife and fisheries 
that fall under environmental and natural sectors are lowly prioritized and hence get a low share of the national budget. Actual allocations for environmental protection have over the years been less than 50\% of the budgeted amounts (GRZ 2015b).

Lately, a rise in invasive alien species has been noted and they too are contributing to biodiversity loss. Among the invasive species in Zambia are the water hyacinth (Kafue weed), Salvinia molesta (Kariba weed), and Tithonia diversifolia (Mabeta et al. 2018). The Lantana camara, a weed, and Toona ciliata are posing serious threats to forestry plantations in the Copperbelt Province as well as near the Victoria Falls in the Livingstone area (GRZ et al. 2016).

Biodiversity loss in Zambia is increasing, due to a host of drivers wherein economic drivers are the largest contributor. Further compounded by emerging issues such as climate change, invasive alien species and mining, they collectively pose serious threats for sustainable biodiversity management in Zambia. Improved extension services and more integrated decision-making can increase awareness and capacity on the diffusion of technologies that increase efficiency and productivity, such as conservation agriculture, and reduced utilization of water, fertilizers and pesticides or other inputs that adversely affect biodiversity.

\subsubsection{Kapuas Hulu Regency, West Kalimantan, Indonesia}

Located in the northeastern part of West Kalimantan Province and bordering Sarawak (Malaysia), Kapuas Hulu Regency $\left(31,162 \mathrm{~km}^{2}\right)$ is one of the last rainforest frontiers of Borneo and the hydrological powerhouse of the whole province. Very remote until the 1980s, it now has a long history of collaboration on transboundary management and conservation between Malaysia and Indonesia. Starting in 1993, transboundary biodiversity conservation areas (TBCAs) were delineated, several biodiversity expeditions were financed by the International Tropical Timber Organization (ITTO 1998), and more recently, there has been involvement in transnational cooperation under the Heart of Borneo (HoB) initiative (Wulffraat et al. 2017).

With $73 \%$ of forest cover in 2019 (Laumonier et al. 2020a), the region is biodiversity rich. However, competing perspectives over land exist between local government agencies (planning bureau, forestry, watershed, agriculture, national park authorities, fisheries, tourism), local communities, local NGOs and the private sector. The current land use has been influenced by several issues of unclear or even ambiguous regulations and conflicting recommendations made by institutions related to natural resource management, tenurial conflicts, exclusion of ecosystem services in land-use planning processes and the agenda of large-scale businesses. Those issues have impacts on forest clearance and biodiversity loss and are threatening local communities' livelihoods and cultural identity (Shantiko et al. 2013). In the pursuit of development, land allocated for alternative use to forestry has increased by more than $19 \%$ in the revised spatial plan of 2011 (PERDA Kabupaten Kapuas Hulu 2014).

Indigenous communities still manage land using traditional practices, i.e. swidden agriculture to grow crops such as paddy, maize, cassava, tubers and vegetables. The agricultural land acquired by clearing forest or secondary forest is systematically left 
to lie fallow for a period after paddy rice is harvested. Perennial crops, mainly rubber, provide a ready source of cash income and are often grown to supplement other crops such as pepper, fruits and illipe (tengkawang) nuts. The forest is essential for the people in Kapuas Hulu, especially for food (meat, fruits and vegetables), medicines and traditional crafts (baskets and mats). In general, although economic activities in the district and rural areas are emerging, subsistence activities still play a central role, for instance, food provisioning from fallows, fishing and the gathering of forest products. In the south, many communities are involved in environmentally devastating illegal gold mining operations near almost all rivers.

The diversity of ecosystems and their importance for the conservation of Borneo's biodiversity led to the establishment of two national parks in Kapuas Hulu (an unusual situation for Indonesia): Betung Kerihun National Park, which has a variety of lowland, hill and mountain forest ecosystems; and Danau Sentarum National Park, the only remaining extensive wetlands in Borneo with a unique ecosystem of interconnecting seasonal lakes, peat swamps and periodically inundated freshwater swamp forests (Giesen 2000; see also Chapter 10). To curb the massive illegal logging occurring in the area in the 1990s and up until 2003, and also to secure the hydrological power function of the Kapuas River Basin $\left(98,700 \mathrm{~km}^{2}\right)$ for the rest of the province, the local government declared the regency a 'conservation regency' in 2003. More recently, a World Wide Fund for Nature initiative advocated the establishment of a biodiversity corridor between the two parks (Widmann et al. 2012). Furthermore, the whole regency was registered as an official UNESCO Man and the Biosphere (MAB) zone in 2018.

The complex geomorphology and biophysical characteristics of the Kapuas River Basin brought about a high diversity of habitats and vegetation types. The Kapuas originates from the mountain range in the east, descends westward into flat lowlands less than $50 \mathrm{~m}$ in elevation to reach its delta near the provincial capital city of Pontianak, 900 $\mathrm{km}$ away (MacKinnon et al. 1996). This low inclination resulted in the formation of a floodplain, wetlands and lakes in the upstream part of the river, surrounded by the mountain ranges of the Betung-Kerihun-Upper Kapuas mountains in the north, the Muller Mountains in the east, and the towering sandstone Madi Plateau in the south. With mean annual precipitation of $4231 \mathrm{~mm}$ (range 2863-5517) (WorldClim 2018), the entire region has a very humid climate, but prolonged droughts can occur, often during El Niño years. The wetlands of the Danau Sentarum system receive approximately $25 \%$ of the annual flood flow of the Kapuas River during the wet season. Conversely, $50 \%$ of the downstream flow during the dry season originates in these wetlands (Klepper 1994). Hidayat et al. (2017) used a combination of satellite remote sensing and observations from field campaigns to study the hydrological dynamics of the Kapuas Basin.

For ecology and biodiversity assessments, the Danau Sentarum National Park area has received far greater attention compared with the rest of the regency. Since the 1990s, it has been an active research site for ecologists researching flora and vegetation (several swamp forest types, from forests that are periodically inundated with freshwater to deep peat swamp forests; Kerangas and Kerapah), fauna (fish, crocodiles, birds, proboscis monkeys and endangered Bornean orangutans), as well as human resource use (honey, fisheries, turtles, rattan, timber), culture, and social and environmental economics (see 
review by Aglionby 2010). In contrast, all the rest of the regency, including the other national park, Betung Kerihun, has received very little attention besides the original transboundary expeditions and baseline fauna and flora data (Soedjito 1999; ITTO 2013). The number of tree species in the lowlands and hills is estimated to be around 1200 , encompassing at least 120 species of dipterocarp, numerous palms and orchids, which are replaced at higher altitude with the 'Montane rainforest of the Müller- and Upper Kapuas Mountains' floristic region (Raes 2009). The fauna of the lowlands and hills is also very diverse, with 300 species of birds (25 endemic to Borneo), at least 180 fish species and at least 54 mammals (including 8 primates: Bornean orangutan, Müller's Bornean gibbon, white-fronted surili, maroon leaf monkey, southern pig-tailed macaque, crab-eating macaque, Sunda slow loris and Horsfield's tarsier) (Aglionby 2010). All the southern hills and mountains had never been surveyed until recently (Weihreter 2014; Labrière et al. 2015; Boissière et al. 2017; Laumonier et al. 2020b).

Ongoing development has introduced changes and brought new pressures, which have influenced the long-established interactions between the people and their landscape. Oil palm plantations have expanded across West Kalimantan in recent years. They are now advancing toward Kapuas Hulu, with the establishment of oil palm plantations spreading from the west of the regency, reaching the 'biodiversity corridor' between the two national parks in the north, and spreading into the south (Yuliani 2010; Leonald and Rowland 2016). The potential impact of the growth of oil palm plantations on biodiversity and ecosystem functions presents a significant challenge for the regency, which is faced with the need to mitigate the impacts of economic development and of maintaining ecosystem services, preserving the environmental and social functions that they provide.

As a designated conservation district and MAB zone, the regency government of Kapuas Hulu made commitments to conserve its natural resources. However, the challenge will be to ensure that this can be done while creating economic development opportunities that contribute to poverty alleviation and support the needs of the local population. The landscape approach implemented for two of its watersheds (see Chapter 10) will facilitate this process.

\section{Conclusion}

Biodiversity plays an important role in safeguarding food security, livelihoods and human well-being. Thus, incorporating biodiversity into integrated landscape management strategies is crucial for reconciling conservation and livelihoods in multifunctional landscapes. This requires careful consideration of trade-offs and synergies between biodiversity, ecosystem services and livelihoods at both local and landscape levels. Use of suitable biodiversity indicators, remote sensing and modeling techniques, and citizen science programs can facilitate effective monitoring of a biodiversity response to conservation interventions. This can further lead to informed decision-making and the sustainable management of landscapes for both biodiversity and livelihoods. 


\section{References}

Abraham A, Sommerhalder K and Abel T. 2010. Landscape and well-being: A scoping study on the health-promoting impact of outdoor environments. International Journal of Public Health 55: 59-69.

Addison PFE, Carbone G and McCormick N. 2018. The Development and Use of Biodiversity Indicators in Business: An Overview. Gland, Switzerland: IUCN. vi + 16pp.

Aglionby J. 2010. Danau Sentarum National Park, Indonesia: A historical overview. Borneo Research Bulletin 41: 20-35.

Agrawal A, Cashore B, Hardin R, Shepherd G, Benson C and Miller D. 2013. Economic contributions of forests. Background paper prepared for the United Nations Forest on Forests (UNFF), 10th Session, Istanbul, Turkey. (http://citeseerx.ist.psu.edu/viewdoc/ download?doi=10.1.1.269.2378\&rep=repi\&type=pdf).

Aizen MA, Garibaldi LA, Cunningham SA and Klein AM. 2009. How much does agriculture depend on pollinators? Lessons from long-term trends in crop production. Annals of Botany 103: 1579-88.

Ajayi OC, Place F, Akinnifesi FK and Sileshi GW. 2011. Agricultural success from Africa: The case of fertilizer tree systems in southern Africa (Malawi, Tanzania, Mozambique, Zambia and Zimbabwe). International Journal of Agricultural Sustainability 9: 129-36.

Alvarez I, and Lovera S. 2016. New times for women and gender issues in biodiversity conservation and climate justice. Development 59: 263-5.

Alves RR. and Rosa IM. 2007. Biodiversity, traditional medicine and public health: where do they meet? Journal of Ethnobiology and Ethnomedicine 3(1): 14.

Anang BT, Akuriba M and Alesane A. 2011. Charcoal production in Gushegu District, Northern Region, Ghana: Lessons for sustainable forest management. International Journal of Environmental Sciences 1: 1944-1953.

Angelsen A, Jagger P, Babigumira R, Belcher B, Hogarth NJ, Bauch S, Börner J, SmithHall C and Wunder S. 2014. Environmental income and rural livelihoods: A globalcomparative analysis. World Development 64:S12-S28.

Asase A, Oteng-Yeboah AA. 2012. Plants used in Wechiau Community Hippopotamus Sanctuary in Northwest Ghana. Journal of Ethnobotany Research $\&$ Applications 10: 605- 618.

Bal P, Tulloch AI, Addison PF, McDonald-Madden E and Rhodes JR. 2018. Selecting indicator species for biodiversity management. Frontiers in Ecology and the Environment 16: 589-98.

Balvanera P, Pfisterer AB, Buchmann N, He J-S, Nakashizuka T, Raffaelli D and Schmid B. 2006. Quantifying the evidence for biodiversity effects on ecosystem functioning and services: Biodiversity and ecosystem functioning/services. Ecology Letters 9: $1146-56$.

Barlow J, França F, Gardner TA, Hicks CC, Lennox GD, Berenguer E, Castello L, Economo EP, Ferreira J, Guénard B, et al. 2018. The future of hyperdiverse tropical ecosystems. Nature 559: 517-26. 
Barlow, J, Lennox GD, Ferreira J, Berenguer E, Lees AC, Nally RM, Thomson JR, Ferraz SF de B, Louzada J, Oliveira VHF, et al. 2016. Anthropogenic disturbance in tropical forests can double biodiversity loss from deforestation. Nature 535: 144-7.

Barnosky AD, Matzke N, Tomiya S, Wogan GOU, Swartz B, Quental TB, Marshall C, McGuire JL, Lindsey EL, Maguire KC, et al. 2011. Has the Earth's sixth mass extinction already arrived? Nature 471: 51-7.

Baudron F, Tomscha SA, Powell B, Groot JCJ, Gergel SE and Sunderland T. 2019. Testing the various pathways linking forest cover to dietary diversity in tropical landscapes. Frontiers in Sustainable Food Systems 3:97. https://doi.org/10.3389/fsufs.2019.00097.

Bender SF, Wagg C and van der Heijden MGA. 2016. An underground revolution: Biodiversity and soil ecological engineering for agricultural sustainability. Trends in Ecology \& Evolution 31: 440-52.

Bennett EM, Cramer W, Begossi A, Cundill G, Díaz S, Egoh BN, Geijzendorffer IR, Krug $\mathrm{CB}$, Lavorel S, Lazos E, et al. 2015. Linking biodiversity, ecosystem services, and human well-being: Three challenges for designing research for sustainability. Current Opinion in Environmental Sustainability 14: 76-85.

Bharucha $\mathrm{Z}$ and Pretty J. 2010. The roles and values of wild foods in agricultural systems. Philosophical Transactions of the Royal Society B: Biological Sciences 365: 2913-26.

Birkhofer K, Andersson GKS, Bengtsson J, Bommarco R, Dänhardt J, Ekbom B, Ekroos J, Hahn T, Hedlund K, Jönsson AM, et al. 2018. Relationships between multiple biodiversity components and ecosystem services along a landscape complexity gradient. Biological Conservation 218: 247-53.

Boissière $M$, Herold $M$, Atmadja $S$ and Sheil D. 2017. The feasibility of local participation in Measuring, Reporting and Verification (PMRV) for REDD+. PLoS ONE 12(5): e0176897.

Bonney R, Phillips TB, Ballard HL and Enck JW. 2016. Can citizen science enhance public understanding of science? Public Understanding of Science 25: 2-16.

Bouché P. 2007. Northern Ghana elephant survey, Pachyderm 42(42): 58-69.

Brockerhoff EG, Barbaro L, Castagneyrol B, Forrester DI, Gardiner B, GonzálezOlabarria JR, Lyver PO, Meurisse N, Oxbrough A, Taki H, et al. 2017. Forest biodiversity, ecosystem functioning and the provision of ecosystem services. Biodiversity and Conservation 26:3005-35.

Brodie JF and Aslan CE. 2012. Halting regime shifts in floristically intact tropical forests deprived of their frugivores. Restoration Ecology 20: 153-7.

Broegaard RB, Rasmussen LV, Dawson N, Mertz O, Vongvisouk T and Grogan K. 2017. Wild food collection and nutrition under commercial agriculture expansion in agriculture-forest landscapes. Forest Policy and Economics 84: 92-101.

Brondizio ES, Settele J, Díaz S and Ngo HT. 2019. Global assessment report on biodiversity and ecosystem services of the Intergovernmental Science-Policy Platform on Biodiversity and Ecosystem Services. Bonn, Germany: IPBES Secretariat.

Brose U and Hillebrand H. 2016. Biodiversity and ecosystem functioning in dynamic landscapes. Philosophical Transactions of the Royal Society B: Biological Sciences 371:20150267. 
Bull JW, Gordon A, Law EA, Suttle KB and Milner-Gulland EJ. 2014. Importance of baseline specification in evaluating conservation interventions and achieving no net loss of biodiversity: No net loss and baseline specifications. Conservation Biology 28: 799-809.

Campos-Arceiz A and Blake S. 2011. Megagardeners of the forest - the role of elephants in seed dispersal. Acta Oecologica 37: 542-53.

Cardinale BJ, Duffy JE, Gonzalez A, Hooper DU, Perrings C, Venail P, Narwani A, Mace GM, Tilman D, Wardle DA, et al. 2012. Biodiversity loss and its impact on humanity. Nature 486: 59-67.

Chandler M, See L, Copas K, Bonde AMZ, López BC, Danielsen F, Legind JK, Masinde S, Miller-Rushing AJ, Newman G, et al. 2017. Contribution of citizen science towards international biodiversity monitoring. Biological Conservation 213: 280-294.

Chapin III FS, Zavaleta ES, Eviner VT, Naylor RL, Vitousek PM, Reynolds HL, Hooper DU, Lavorel S, Sala OE, Hobbie SE, et al. 2000. Consequences of changing biodiversity. Nature 405: 234-42.

Chaplin-Kramer R, Dombeck E, Gerber J, Knuth KA, Mueller ND, Mueller M, Ziv G and Klein AM. (2014). Global malnutrition overlaps with pollinator-dependent micronutrient production. Proceedings of the Royal Society B: Biological Sciences 281(1794), 20141799.

Chaplin-Kramer R, O'Rourke ME, Blitzer EJ and Kremen C. 2011. A meta-analysis of crop pest and natural enemy response to landscape complexity: Pest and natural enemy response to landscape complexity. Ecology Letters 14: 922-32.

Chen S, Wang W, Xu W, Wang Y, Wan H, Chen D, Tang Z, Tang X, Zhou G, Xie Z, et al. 2018. Plant diversity enhances productivity and soil carbon storage. Proceedings of the National Academy of Sciences of the United States of America 115: 4027-32.

Cortés-Flores J, Andresen E, Cornejo-Tenorio G and Ibarra-Manríquez G. 2013. Fruiting phenology of seed dispersal syndromes in a Mexican neotropical temperate forest. Forest Ecology and Management 289: 445-54.

Cramer W, Egea E, Fischer J, Lux A, Salles J-M, Settele J and Tichit M. 2017. Biodiversity and food security: from trade-offs to synergies. Regional Environmental Change 17: 1257-9.

Dainese M, Martin EA, Aizen MA, Albrecht M, Bartomeus I, Bommarco R, Carvalheiro LG, Chaplin-Kramer R, Gagic V, Garibaldi LA, et al. 2019. A global synthesis reveals biodiversity-mediated benefits for crop production. Science Advances 5(10):eaaxo121.

Danielsen F, Jensen PM, Burgess ND, Altamirano R, Alviola PA, Andrianandrasana $\mathrm{H}$, Brashares JS, Burton AC, Coronado I, Corpuz N, et al. 2014. A multicountry assessment of tropical resource monitoring by local communities. BioScience 64: $236-51$.

Dapilah F, Nielsen J $\emptyset$ and Akongbangre JN. 2019. Peri-urban transformation and shared natural resources: the case of shea trees depletion and livelihood in Wa municipality, Northwestern Ghana. African Geographical Review 38(4): 374-389. 
Datta A, Anand MO and Naniwadekar R. 2008. Empty forests: Large carnivore and prey abundance in Namdapha National Park, north-east India. Biological Conservation 141: 1429-35.

Delang CO. 2006. The role of wild food plants in poverty alleviation and biodiversity conservation in tropical countries. Progress in Development Studies 6: 275-86.

Díaz S, Settele J, Brondízio E, Ngo H, Guèze M, Agard J, Arneth A, Balvanera P, Brauman $\mathrm{K}$, Butchart S, et al. 2019. Summary for policymakers of the global assessment report on biodiversity and ecosystem services of the Intergovernmental Science-Policy Platform on Biodiversity and Ecosystem Services. IPBES secretariat, Bonn, Germany. 56 pages. https://doi.org/10.5281/zenodo.3553579

Dominik C, Seppelt R, Horgan FG, Settele J and Václavík T. 2018. Landscape composition, configuration, and trophic interactions shape arthropod communities in rice agroecosystems. Journal of Applied Ecology 55: 2461-72.

Duffy JE, Godwin CM and Cardinale BJ. 2017. Biodiversity effects in the wild are common and as strong as key drivers of productivity. Nature 549: 261-4.

Duflot R, Ernoult A, Aviron S, Fahrig L and Burel F. 2017. Relative effects of landscape composition and configuration on multi-habitat gamma diversity in agricultural landscapes. Agriculture, Ecosystems \& Environment 241: 62-9.

Dumenu WK, Bandoh WN. 2016. Exploitation of African rosewood (Pterocarpus erinaceus) in Ghana: A situation analysis, Ghana Journal of Forestry 32: 1-15.

Ekpe EK, Hinkle CR, Quigley MF and Owusu EH. 2014. Natural resource and biodiversity conservation in Ghana: the use of livelihoods support activities to achieve conservation objectives, International Journal of Biodiversity Science, Ecosystem Services $\&$ Management 10(4): 253-261. https://doi.org/10.1080/21513732.2014.971056.

Ellis AM, Myers SS and Ricketts TH. 2015. Do pollinators contribute to nutritional health? PLOS ONE 10:e114805.

Fisher M. 2004. Household welfare and forestry dependence in Southern Malawi. Environmental and Development Economics 9: 135-154.

Fründ J, Dormann CF, Holzschuh A and Tscharntke T. 2013. Bee diversity effects on pollination depend on functional complementarity and niche shifts. Ecology 94: 2042- 54 .

García D, Miñarro M and Martínez-Sastre R. 2018. Birds as suppliers of pest control in cider apple orchards: Avian biodiversity drivers and insectivory effect. Agriculture, Ecosystems \& Environment 254: 233-43.

Garibaldi LA, Gemmill-Herren B, D'Annolfo R, Graeub BE, Cunningham SA and Breeze TD. 2017. Farming approaches for greater biodiversity, livelihoods, and food security. Trends in Ecology \& Evolution 32: 68-80.

Garnett ST, Burgess ND, Fa JE, Fernández-Llamazares Á, Molnár Z, Robinson CJ, Watson JEM, Zander KK, Austin B, Brondizio ES, et al. 2018. A spatial overview of the global importance of indigenous lands for conservation. Nature Sustainability 1: 369-74.

Ghana Shea Landscape REDD+ Project Concept Note. 2017. Ghana. United Nations Development Programme (UNDP) and Ministry of Finance, Ghana. https://www. 
greenclimate.fund/sites/default/files/document/16460-ghana-shea-landscape-reddproject.pdf.

Giam X. 2017. Global biodiversity loss from tropical deforestation. Proceedings of the National Academy of Sciences of the United States of America 114: 5775-7.

Giesen W. 2000. Flora and Vegetation of Danau Sentarum: Unique Lake and Swamp Forest Ecosystem of West Kalimantan. Borneo Research Bulletin 31: 89-122.

Glew RH, Vanderjagt DJ, Lockett C, Grivetti LE, Smith GC, Pastuszyn A and Millson M. 1997. Amino acid, fatty acid, and mineral composition of 24 indigenous plants of Burkina Faso. Journal of Food Composition and Analysis 10: 205-17.

Goldstein JH, Caldarone G, Duarte TK, Ennaanay D, Hannahs N, Mendoza G, Polasky S, Wolny S and Daily GC. 2012. Integrating ecosystem-service tradeoffs into land-use decisions. Proceedings of the National Academy of Sciences of the United States of America 109: 7565-70.

Gould RK, Ardoin NM, Woodside U, Satterfield T, Hannahs N and Daily GC. 2014. The forest has a story: cultural ecosystem services in Kona, Hawai'i. Ecology and Society 19(3): 55 .

GRZ. 2015a. Zambia's second national biodoversity strategy and action plan 2015-2020 (NBSAP-2). Lusaka, Zambia: Government of the Republic of Zambia.

GRZ. 2015b. Report of the Auditor General on Sustainable Management of Fish Resources in Natural Waters. Lusaka, Zambia: Government of the Republic of Zambia.

GRZ, FAO and Government of Finland. 2016. Biodiversity Report for Integrated Land Use Assessment Phase II (ILUA II). Technical Report Series.

Guo X, Coops NC, Tompalski P, Nielsen SE, Bater CW and John Stadt J. 2017. Regional mapping of vegetation structure for biodiversity monitoring using airborne lidar data. Ecological Informatics 38: 50-61.

Hackman KO. 2014. The state of biodiversity in Ghana: Knowledge gaps and prioritization. International Journal of Biodiversity and Conservation 6(9): 681-701.

Han X, Gill MJ, Hamilton H, Vergara SG and Young BE. 2020. Progress on national biodiversity indicator reporting and prospects for filling indicator gaps in Southeast Asia. Environmental and Sustainability Indicators 5.100017.

Hanks DJ. 2019. Consumplation. The action of looking thoughtfully at a consumption and anthropogenic impacts on the environment. MSc thesis, University of Alberta.

Hansen CP, Pouliot M, Marfo E, Obiri BD and Treue T. 2015. Forests, timber and rural livelihoods: implications for social safeguards in the Ghana-EU voluntary partnership agreement. Small-scale Forestry 14: 401-22.

Hausmann A, Slotow R, Burns JK and Di Minin E. 2016. The ecosystem service of sense of place: benefits for human well-being and biodiversity conservation. Environmental Conservation 43: 117-27.

Herndon CN and Butler RA. 2010. Significance of Biodiversity to Health: Biodiversity and Health. Biotropica 42: 558-560.

Herrera JM, Salgueiro PA, Medinas D, Costa P, Encarnação C and Mira A. 2016. Generalities of vertebrate responses to landscape composition and configuration 
gradients in a highly heterogeneous Mediterranean region. Journal of Biogeography 43: 1203-14.

Hidayat H, Teuling A, Vermeulen B, Taufik M, Kastner K, Geertsema T, Bol D, Hoekman D, Haryani G, Van Lanen H. 2017. Hydrology of inland tropical lowlands: The Kapuas and Mahakam wetlands. Hydrology and Earth System Sciences 21(5): 2579-2594.

Holzner A, Ruppert N, Swat F, Schmidt M, Weiß BM, Villa G, Mansor A, Mohd Sah SA, Engelhardt A, Kühl H, et al. 2019. Macaques can contribute to greener practices in oil palm plantations when used as biological pest control. Current Biology 29:R1066-R1067.

Hooper DU, Adair EC, Cardinale BJ, Byrnes JEK, Hungate BA, Matulich KL, Gonzalez A, Duffy JE, Gamfeldt L, et al. 2012. A global synthesis reveals biodiversity loss as a major driver of ecosystem change. Nature 486: 105-8.

Howe C, Suich H, Vira B and Mace GM. 2014. Creating win-wins from trade-offs? Ecosystem services for human well-being: A meta-analysis of ecosystem service trade-offs and synergies in the real world. Global Environmental Change 28: 263-75.

Hughes FMR, Adams WM, Butchart SHM, Field RH, Peh KS-H and Warrington S. 2016. The challenges of integrating biodiversity and ecosystem services monitoring and evaluation at a landscape-scale wetland restoration project in the UK. Ecology and Society 21(3):10.

Hui D, Deng Q Tian H and Luo Y. 2015. Climate change and carbon sequestration in forest ecosystems. In Chen W-Y, Suzuki T and Lackner M, eds. Handbook of Climate Change Mitigation and Adaptation. New York: Springer. 1-40.

Husseini R, Baatuuwie B and Issifu H. 2015. Natural forest reserves in the Northern region of Ghana: description and management status. Research journal's Journal of forestry 2(6).

International Tropical Timber Organization (ITTO). 1998. Borneo Biodiversity Expedition 1997. Yokohama, Japan.

International Tropical Timber Organization (ITTO). 2013. Promoting biodiversity conservation in Betung Kerihun National Park (BKNP) as the trans-boundary ecosystem between Indonesia and the state of Sarawak Malaysia, (Phase III). Yokohama, Japan.

Isbell F, Gonzalez A, Loreau M, Cowles J, Díaz S, Hector A, Mace GM, Wardle DA, O'Connor MI, Duffy JE, et al. 2017. Linking the influence and dependence of people on biodiversity across scales. Nature 546: 65-72.

IUCN 2012. Livelihoods and Landscapes Strategy. Results and reflections. Gland, Switzerland: International Union for Conservation of Nature (IUCN). https://portals.iucn.org/ library/sites/library/files/documents/2012-055.pdf.

Jasaw GS, Saito O, Gasparatos A, Shoyama K, Boafo YA and Takeuchi K. 2017. Ecosystem services trade-offs from high fuelwood use for traditional shea butter processing in semi-arid Ghana. Ecosystem services 27: 127-138.

Jibreel MB, Mumuni E, Al-Hassan S, Baba NM. 2013. Shea butter and its processing impacts on the environment in the Tamale Metropolis of Ghana. International Journal of Development and Sustainability 2(3): 2008-2019. 
Johnson CN, Balmford A, Brook BW, Buettel JC, Galetti M, Guangchun L and Wilmshurst JM. 2017. Biodiversity losses and conservation responses in the Anthropocene. Science 356: $270-5$.

Jones HP, Hole DG and Zavaleta ES. 2012. Harnessing nature to help people adapt to climate change. Nature Climate Change 2: 504-9.

Jumbe CBL, Bwalya SM and Husselman M. 2008. Contribution of Dry Forests to Rural Livelihoods and the National Economy in Zambia. In Managing the Miombo Woodlands of Southern Africa, Technical Annex No. 1. Washington DC: The World Bank, Sustainable Development Department, Environmental, and Natural Resources Management Unit, Africa Region.

Keesing F, Belden LK, Daszak P, Dobson A, Harvell CD, Holt RD, Hudson P, Jolles A, Jones KE, Mitchell CE, et al. 2010. Impacts of biodiversity on the emergence and transmission of infectious diseases. Nature 468: 647-52.

Klepper O. 1994. A hydrological model of the Upper Kapuas river and the Kapuas lakes. Consultancy report for Asian Wetland Bureau/PHPA, for the UK-Indonesia Tropical Forest Management Project, Sub-project 5 Conservation. Bogor, Indonesia: Asian Wetland Bureau (Wetlands International).

Kobori H, Dickinson JL, Washitani I, Sakurai R, Amano T, Komatsu N, Kitamura W, Takagawa S, Koyama K, et al. 2016. Citizen science: A new approach to advance ecology, education, and conservation. Ecological Research 31: 1-19.

Kremen C and Merenlender AM. 2018. Landscapes that work for biodiversity and people. Science 362:eaau6020.

Labrière N, Laumonier Y, Locatelli B, Vieilledent G and Comptour M. 2015. Ecosystem services and biodiversity in a rapidly transforming landscape in northern Borneo. PloS one 10(10): e0140423.

Landis DA. 2017. Designing agricultural landscapes for biodiversity-based ecosystem services. Basic and Applied Ecology 18: 1-12.

Lange M, Eisenhauer N, Sierra CA, Bessler H, Engels C, Griffiths RI, Mellado-Vázquez PG, Malik AA, Roy J, Scheu S, et al. 2015. Plant diversity increases soil microbial activity and soil carbon storage. Nature Communications 6:6707.

Laumonier Y, Simamora T, Manurung A, Narulita S, Pribadi U, Simorangkir A, Shantiko B. 2020a. Sentinel landscapes initiative: Stocktake and baseline data analysis for future landscape management and monitoring in West Kalimantan, FTA Working Paper 5. Bogor, Indonesia: CIFOR.

Laumonier Y, Hadi DP, Pribadi UA, Narulita S. 2020b. Kapuas Hulu Ecological Vegetation Map 1:50000. Available at: https://doi.org/10.17528/CIFOR/DATA.00202. Bogor, Indonesia: CIFOR.

Lefcheck JS, Byrnes JEK, Isbell F, Gamfeldt L, Griffin JN, Eisenhauer N, Hensel MJS, Hector A, Cardinale BJ and Duffy JE. 2015. Biodiversity enhances ecosystem multifunctionality across trophic levels and habitats. Nature Communications 6:6936.

Leonald L and Rowland D. 2016. Drivers and effects of agrarian change in Kapuas Hulu Regency, West Kalimantan, Indonesia. In: Deakin EL, Kshatriya M, Sunderland TCH, 
eds. Agrarian Change in Tropical Landscapes. Bogor, Indonesia: CIFOR. Indonesia https://doi.org/10.17528/cifor/005867.

Liang J, Crowther TW, Picard N, Wiser S, Zhou M, Alberti G, Schulze E-D, McGuire AD, Bozzato F and Pretzsch H. 2016. Positive biodiversity-productivity relationship predominant in global forests. Science 354(6309):aaf8957.

Luque S, Pettorelli N, Vihervaara P and Wegmann M. 2018. Improving biodiversity monitoring using satellite remote sensing to provide solutions towards the 2020 conservation targets. Methods in Ecology and Evolution 9: 1784-6.

Lurimuah S. 2011. The economic and environmental effects of commercial charcoal production in the Upper West Region of Ghana, MSc Thesis, School of Graduate Studies, Kwame Nkrumah University of Science and Technology, Kumasi (http://hdl. handle.net/123456789/2177).

Lyver PO, Timoti P, Gormley AM, Jones CJ, Richardson SJ, Tahi BL and Greenhalgh S. 2017. Key Māori values strengthen the mapping of forest ecosystem services. Ecosystem Services 27: 92-102.

Mabeta J, Mweemba B and Mwitwa J. 2018. Key drivers of biodiversity loss in Zambia. BIOFIN Policy Brief \# 3. http://www.biodiversityfinance.net/sites/default/files/ content/knowledge_products/BIOFIN\%2OZM\%20PB\%20\%233-Drivers\%20of\%20 biodiversity\%2oloss\%20in\%20Zambia.pdf.

Macfadyen S, Cunningham SA, Costamagna AC and Schellhorn NA. 2012. Managing ecosystem services and biodiversity conservation in agricultural landscapes: are the solutions the same? Journal of Applied Ecology 49: 690-4.

MacKinnon K, Hatta G, Halim H. and Maigalik A. 1996. The ecology of Indonesia series. Volume III-The ecology of Kalimantan, Indonesia, Borneo. Periplus pub. Cambridge: CUP.

Maller C, Townsend M, Pryor A, Brown P and St Leger L. 2006. Healthy nature healthy people: 'contact with nature' as an upstream health promotion intervention for populations. Health Promotion International 21: 45-54.

Markl JS, Schleuning M, Forget PM, Jordano P, Lambert JE, Traveset A, Wright SJ and Böhning-Gaese K. 2012. Meta-analysis of the effects of human disturbance on seed dispersal by animals: Human effects on animal seed dispersal. Conservation Biology 26: $1072-81$.

Martin EA, Dainese M, Clough Y, Báldi A, Bommarco R, Gagic V, Garratt MPD, Holzschuh A, Kleijn D, Kovács-Hostyánszki A, et al. 2019. The interplay of landscape composition and configuration: New pathways to manage functional biodiversity and agroecosystem services across Europe. Ecology Letters 22: 1083-94.

Martin EA, Seo B, Park C-R, Reineking B and Steffan-Dewenter I. 2016. Scale-dependent effects of landscape composition and configuration on natural enemy diversity, crop herbivory, and yields. Ecological Applications 26: 448-62.

Martín-López B, Iniesta-Arandia I, García-Llorente M, Palomo I, Casado-Arzuaga I, Amo DGD, Gómez-Baggethun E, Oteros-Rozas E, Palacios-Agundez I, Willaarts B, et al. 2012. Uncovering ecosystem service bundles through social preferences. PLoS ONE 7:e38970. 
Matakala PW, Misael K and Jochen S. 2015. Zambia national strategy to reduce emissions from deforestation and forest degradation (REDD+). Harare, Zambia: Forestry Department, Ministry of Lands Natural Resources and Environmental Protection, FAO, UNDP, and UNEP, GRZ.

McKinley DC, Miller-Rushing AJ, Ballard HL, Bonney R, Brown H, Cook-Patton SC, Evans DM, French RA, Parrish JK, Phillips TB, et al. 2017. Citizen science can improve conservation science, natural resource management, and environmental protection. The role of citizen science in biological conservation. Biological Conservation 208: 15-28.

Mcowen CJ, Ivory S, Dixon MJR, Regan EC, Obrecht A, Tittensor DP, Teller A and Chenery AM. 2016. Sufficiency and suitability of global biodiversity indicators for monitoring progress to 2020 targets: Sufficiency and suitability of biodiversity indicators. Conservation Letters 9: 489-94.

Mensah R, Effah AK, Attua EM, Chimsah FA, Boakye-Danquah J, Sackey I .2016. Biodiversity of woody species and their utilization in a Savannah ecological zone of Northern Ghana. Journal of Biodiversity and Environmental Sciences (JBES) 8(3): 22-45.

Mihoub J-B, Henle K, Titeux N, Brotons L, Brummitt NA and Schmeller DS. 2017. Setting temporal baselines for biodiversity: The limits of available monitoring data for capturing the full impact of anthropogenic pressures. Scientific Reports 7: 41591.

Miles L, Newton AC, DeFries RS, Ravilious C, May I, Blyth S, Kapos V and Gordon JE. 2006. A global overview of the conservation status of tropical dry forests. Journal of biogeography 33(3): 491-505.

Montoya D, Gaba S, de Mazancourt C, Bretagnolle V and Loreau M. 2020. Reconciling biodiversity conservation, food production and farmers' demand in agricultural landscapes. Ecological Modelling 416: 108889.

Mori AS, Lertzman KP and Gustafsson L. 2017. Biodiversity and ecosystem services in forest ecosystems: A research agenda for applied forest ecology. Journal of Applied Ecology 54: 12-27.

Mulenga B, Richardson R and Tembo G. 2012. Non-Timber Forest Products and Rural Poverty Alleviation in Zambia. Working Paper No. 62. Lusaka, Zambia: Indaba Agricultural Policy Research Institute.

Naro E, Mero EL, Naro E, Kapfo K, Wezah K, Thopi K, Rhakho K, Akami L, Thopi L, Chirhah M, et al. 2015. Project hunt: An assessment of wildlife hunting practices by local community in Chizami, Nagaland, India. Journal of Threatened Taxa 7: 7729-43.

Nelson E, Mendoza G, Regetz J, Polasky S, Tallis H, Cameron DR, Chan KM, Daily GC, Goldstein J, Kareiva PM, et al. 2009. Modeling multiple ecosystem services, biodiversity conservation, commodity production, and tradeoffs at landscape scales. Frontiers in Ecology and the Environment 7: 4-11.

Newbold T, Hudson LN, Hill SLL, Contu S, Lysenko I, Senior RA, Börger L, Bennett DJ, Choimes A, Collen B, et al. 2015. Global effects of land use on local terrestrial biodiversity. Nature 520: 45-50.

Newton P, Kinzer AT, Miller DC, Oldekop JA and Agrawal A. 2020. The number and spatial distribution of forest-proximate people globally. One Earth 3:363-70. 
Oehri J, Schmid B, Schaepman-Strub G and Niklaus PA. 2017. Biodiversity promotes primary productivity and growing season lengthening at the landscape scale. Proceedings of the National Academy of Sciences of the United States of America 114: 10160-5.

O'Farrell PJ and Anderson PM. 2010. Sustainable multifunctional landscapes: A review to implementation. Current Opinion in Environmental Sustainability 2: 59-65.

Oliver TH, Heard MS, Isaac NJB, Roy DB, Procter D, Eigenbrod F, Freckleton R, Hector A, Orme CDL, Petchey OL, et al. 2015. Biodiversity and resilience of ecosystem functions. Trends in Ecology \& Evolution 30: 673-84.

Olivero J, Fa JE, Real R, Márquez AL, Farfán MA, Vargas JM, Gaveau D, Salim MA, Park D and Suter J. 2017. Recent loss of closed forests is associated with Ebola virus disease outbreaks. Scientific Reports 7: 1-9.

Ollerton J, Winfree R and Tarrant S. 2011. How many flowering plants are pollinated by animals? Oikos 120: 321-6.

Overton J, Davis S, Nguluka L, Nsende E, Sompa B, Simukonda C and Lindsey P. 2017. The Illegal bushmeat trade in the greater Kafue Ecosystem, Zambia: Drivers Impacts and Solutions. FAO http://www.fao.org/3/a-bc610e.pdfand.

Owusu-Ansah N. 2018. Assessing How Collaborative Resource Management Impacts Victims Perspectives on Wildlife Crop Raids. Journal of Natural Resources and Development 08: 115-124.

Paumgarten F and Shackleton CM. 2009. Wealth differentiation in household use and trade in non-timber forest products in South Africa. Ecological Economics 68: 2950-9.

Peraturan Daerah (PERDA) Kabupaten Kapuas Hulu 2014. (Regional Regulation (PERDA) on the Kapuas Hulu District Spatial Plan for 2014 - 2034). Kapuas Hulu District Spatial Plan 2014-2034. Bupati Kapuas Hulu, Putussibau, Indonesia. https://peraturan.bpk. go.id/Home/Details/51239/perda-kab-kapuas-hulu-no-1-tahun-2014.

Potts SG, Imperatriz-Fonseca V, Ngo HT, Aizen MA, Biesmeijer JC, Breeze TD, Dicks LV, Garibaldi LA, Hill R, Settele J, et al. 2016. Safeguarding pollinators and their values to human well-being. Nature 540: 220-9.

Pouliot M and Treue T. 2013. Rural people's reliance on forests and the non-forest environment in West Africa: Evidence from Ghana and Burkina Faso. World Development 43: 180-93.

Powell B, Thilsted SH, Ickowitz A, Termote C, Sunderland T and Herforth A. 2015. Improving diets with wild and cultivated biodiversity from across the landscape. Food Security 7: 535-54.

Raes N. 2009. Borneo: A quantitative analysis of botanical richness, endemicity and floristic regions based on herbarium records. PhD thesis National Herbarium Nederland, Leiden University.

Rasmussen LV, Watkins C and Agrawal A. 2017. Forest contributions to livelihoods in changing agriculture-forest landscapes. Forest Policy and Economics 84:1-8.

Raudsepp-Hearne C, Peterson GD and Bennett EM. 2010. Ecosystem service bundles for analyzing tradeoffs in diverse landscapes. Proceedings of the National Academy of Sciences of the United States of America 107: 5242-7. 
Reed J, Ickowitz A, Chervier C, Djoudi H, Moombe K, Ros-Tonen M, Yanou M, Yuliani $\mathrm{L}$ and Sunderland T. 2020. Integrated landscape approaches in the tropics: A brief stock-take. Land Use Policy 99: 104822.

Reed J, van Vianen J, Barlow J and Sunderland T. 2017. Have integrated landscape approaches reconciled societal and environmental issues in the tropics? Land Use Policy 63: 481-92.

Richardson RB. 2010. Ecosystem services and food security: Economic perspectives on environmental sustainability. Sustainability 2:3520-48.

Rocchini D, Luque S, Pettorelli N, Bastin L, Doktor D, Faedi N, Feilhauer H, Féret J-B, Foody GM, Gavish Y, et al. 2018. Measuring $\beta$-diversity by remote sensing: A challenge for biodiversity monitoring. Methods in Ecology and Evolution 9: 1787-98.

Rochette A-J, Akpona JDT, Akpona HA, Akouehou GS, Kwezi BM, Djagoun CAMS, Habonimana B, Idohou R, Legba IS, Nzigidahera B, et al. 2019. Developing policyrelevant biodiversity indicators: Lessons learnt from case studies in Africa. Environmental Research Letters 14:035002.

Runting RK, Bryan BA, Dee LE, Maseyk FJ, Mandle L, Hamel P, Wilson KA, Yetka K, Possingham HP and Rhodes JR. 2017. Incorporating climate change into ecosystem service assessments and decisions: A review. Global Change Biology 23: 28-41.

Russell R, Guerry AD, Balvanera P, Gould RK, Basurto X, Chan KMA, Klain S, Levine J and Tam J. 2013. Humans and nature: How knowing and experiencing nature affect well-being. Annual Review of Environment and Resources 38: 473-502.

Sakschewski B, von Bloh W, Boit A, Poorter L, Peña-Claros M, Heinke J, Joshi J and Thonicke K. 2016. Resilience of Amazon forests emerges from plant trait diversity. Nature Climate Change 6: 1032-6.

Sandifer PA, Sutton-Grier AE and Ward BP. 2015. Exploring connections among nature, biodiversity, ecosystem services, and human health and well-being: Opportunities to enhance health and biodiversity conservation. Ecosystem Services 12: 1-15.

Sardeshpande M and Shackleton C. 2019. Wild edible fruits: A systematic review of an under-researched multifunctional NTFP (non-timber forest product). Forests 10: 467.

Sayer J, Margules C, Bohnet I, Boedhihartono A, Pierce R, Dale A and Andrews K. 2015. The role of citizen science in landscape and seascape approaches to integrating conservation and development. Land 4: 1200-12.

Sayer J, Sunderland T, Ghazoul J, Pfund J-L, Sheil D, Meijaard E, Venter M, Boedhihartono AK, Day M, Garcia C, et al. 2013. Ten principles for a landscape approach to reconciling agriculture, conservation, and other competing land uses. Proceedings of the National Academy of Sciences of the United States of America 110: 8349- 56.

Schleicher J, Zaehringer JG, Fastré C, Vira B, Visconti P and Sandbrook C. 2019. Protecting half of the planet could directly affect over one billion people. Nature Sustainability 2: 1094-6.

Shantiko B, Fripp E, Taufiqoh T, Heri T and Laumonier Y. 2013. Socio-economic considerations for land-use planning; The case of Kapuas Hulu, West Kalimantan. Working Paper 120. Bogor, Indonesia: CIFOR. 
Soedjito H. 1999. Flora dan fauna Taman Nasional Betung Kerihun, Kalimantan Barat (Flora and Fauna of Bentung Kerihun National Park, West Kalimantan). Jakarta: WWF Indonesia - PHPA - LIPI - ITTO. iii-88. ISBN 979-95102-2-8.

Soliveres S, van der Plas F, Manning P, Prati D, Gossner MM, Renner SC, Alt F, Arndt H, Baumgartner V, Binkenstein J, et al. 2016. Biodiversity at multiple trophic levels is needed for ecosystem multifunctionality. Nature 536: 456-9.

Strasser B, Baudry J, Mahr D, Sanchez G. and Tancoigne É. 2019. "Citizen science"? Rethinking science and public participation. Science \& Technology Studies 32: 52-76.

Sunderland TCH. 2011. Food security: Why is biodiversity important? International Forestry Review 13: 265-74.

Swamy L, Drazen E, Johnson WR and Bukoski JJ. 2018. The future of tropical forests under the United Nations Sustainable Development Goals. Journal of Sustainable Forestry 37: 221-56.

Swayne DA, Yang W, Voinov AA, Rizzoli A and Filatova T, eds. 2010. Multi-Scale Modelling of Ecosystem Services-an Iterative Approach. International Congress on Environmental Modelling and Software Modelling for Environment's Sake. International Environmental Modelling and Software Society (iEMSs) Fifth Biennial Meeting. July 5 - 8 2010. Ottawa. Canada. http://www.iemss.org/iemss2010/index. php?n=Main. Proceedings.

Synes NW, Brown C, Watts K, White SM, Gilbert MA and Travis JMJ. 2016. Emerging opportunities for landscape ecological modelling. Current Landscape Ecology Reports 1: $146-67$.

Treanor NB. 2015. China's Hongmu Consumption Boom: Analysis of the Chinese Rosewood Trade and Links to Illegal Activity in Tropical Forested Countries. Forest Trends Report Series, Forest Trade and Finance. Washington: Forest Trends.

Tully K and Ryals R. 2017. Nutrient cycling in agroecosystems: Balancing food and environmental objectives. Agroecology and Sustainable Food Systems 41: 761-98.

Tzilivakis J, Warner DJ, Green A, Lewis KA and Angileri V. 2016. An indicator framework to help maximise potential benefits for ecosystem services and biodiversity from ecological focus areas. Ecological Indicators 69: 859-72.

Valerio F, Basile M, Balestrieri R, Posillico M, Di Donato S, Altea, T and Matteucci G. 2016. The reliability of a composite biodiversity indicator in predicting bird species richness at different spatial scales. Ecological Indicators 71: 627-35.

van der Geest K, de Sherbinin A, Kienberger S, Zommers Z, Sitati A, Roberts E and James R. 2019. The impacts of climate change on ecosystem services and resulting losses and damages to people and society. In Mechler R, Bouwer LM, Schinko T, Surminski $\mathrm{S}$ and Linnerooth-Bayer J, eds. Loss and Damage from Climate Change: Concepts, Methods and Policy Options. Cham: Springer International Publishing. 221-36.

van der Heijden MG, de Bruin S, Luckerhoff L, van Logtestijn RS and Schlaeppi K. 2016. A widespread plant-fungal-bacterial symbiosis promotes plant biodiversity, plant nutrition and seedling recruitment. The ISME Journal 10: 389-99.

van der Plas F, Ratcliffe S, Ruiz-Benito P, Scherer-Lorenzen M, Verheyen K, Wirth C, Zavala MA, Ampoorter E, Baeten L, Barbaro L, et al. 2018. Continental mapping 
of forest ecosystem functions reveals a high but unrealised potential for forest multifunctionality. Ecology Letters 21: 31-42.

Veres A, Petit S, Conord C and Lavigne C. 2013. Does landscape composition affect pest abundance and their control by natural enemies? A review. Agriculture, Ecosystems $\mathcal{\delta}$ Environment 166: 110-7.

Verhagen W, van der Zanden EH, Strauch M, van Teeffelen AJA and Verburg PH. 2018. Optimizing the allocation of agri-environment measures to navigate the trade-offs between ecosystem services, biodiversity and agricultural production. Environmental Science \& Policy 84: 186-96.

Vihervaara P, Auvinen A-P, Mononen L, Törmä M, Ahlroth P, Anttila S, Böttcher K, Forsius M, Heino J, Heliölä J, et al. 2017. How essential biodiversity variables and remote sensing can help national biodiversity monitoring. Global Ecology and Conservation 10: 43-59.

Vinceti B, Ickowitz A, Powell B, Kehlenbeck K, Termote C and Cogill B. 2013. The contribution of forests to sustainable diets. Page 30. International Conference on Forests for Food Security and Nutrition. Rome. 13-15 May 2013.

Vira B, Agarwal B, Jamnadass R, Kleinschmit D, McMullin S, Mansourian S, Neufeldt H, Parrotta JA, Sunderland T and Wildburger C. 2015. 1. Forests, trees and landscapes for food security and nutrition. In Vira B, Wildburger C and Mansourian S, eds. Forests and Food: Addressing Hunger and Nutrition Across Sustainable Landscapes. Open Book Publishers. Cambridge. United Kingdom. 9-26.

Voigt CC and Kingston T, eds. 2016. Bats in the Anthropocene: Conservation of Bats in a Changing World. Cham: Springer International Publishing.

Weihreter E. 2014. Traditional knowledge, perceptions and forest conditions in a Dayak Mentebah community, West Kalimantan, Indonesia. Working Papers Series $n^{\circ} 156$. Bogor, Indonesia: Center for International Forestry Research (CIFOR).

WHO. 2002. World Health Organization Traditional medicine strategy 2002-2005. http://whqlibdoc.who.int/hq/2002/WHO_EDM_TRM_2002.1.pdf.

Widianingsih N, Theilade I and Pouliot M. 2016. Contribution of forest restoration to rural livelihoods and household income in Indonesia. Sustainability 8: 835.

Widmann P, Tjiu A, Putera MH, Syahirsyah and Wulffraat S. 2012. Connecting diversity: People and nature of Labian-Leboyan corridor in the Indonesian Heart of Borneo. Jakarta: WWF Indonesia.

Witter R and Satterfield T. 2019. The ebb and flow of indigenous rights recognitions in conservation policy: Indigenous rights recognitions in conservation policy. Development and Change 50: 1083-1108.

World Bank 2002. Project appraisal document on a proposal grant from the Global Environmental Facility Trust Fund in the amount of SDR 6.0 million to the Republic of Ghana for a northern savanna biodiversity biodiversity conservation project. Report No: 21 847-GH. http://documents1.worldbank.org/curated/ en/566881468774676876/pdf/multiopage.pdf.

WorldClim. 2018. Global Climate Data. Available at: https://worldclim.org/. 
Wulffraat S, Greenwood C, Faisal KF, Sucipto D, Chan H, Beukeboom H, Soulisa N and Kinasih A. 2017. The Environmental Status of Borneo 2016 Report. Jakarta, Indonesia: Heart of Borneo Programme.

Wunder S, Börner J, Shively G and Wyman M. 2014. Safety nets, gap filling and forests: A global-comparative perspective. World Development 64:S29-S42.

Yang G, Wagg C, Veresoglou SD, Hempel S and Rillig MC. 2018. How soil biota drive ecosystem stability. Trends in Plant Science 23: 1057-67.

Yuliani EL, de Jong EB, Knippenberg L, Bakara DO, Salim MA and Sunderland T. 2018. Keeping the land: Indigenous communities' struggle over land use and sustainable forest management in Kalimantan, Indonesia. Ecology \& Society 23(4).

Yuliani EL, Indriatmoko Y, Salim MA, Farid IZ, Muhajir M, Prasetyo LB, Heri V. 2010. Biofuel policies and their impacts on local people and biodiversity: A case study in Danau Sentarum. Borneo Research Bulletin 41: 109-144.

Zanzanaini C, Trần BT, Singh C, Hart A, Milder J and DeClerck F. 2017. Integrated landscape initiatives for agriculture, livelihoods and ecosystem conservation: An assessment of experiences from South and Southeast Asia. Landscape and Urban Planning 165: 11-21. 
 climate, conservation and development objectives in tropical landscapes}

James Reed, Jos Barlow, Rachel Carmenta, Josh van Vianen and Terry Sunderland

"This is an edited version of an article previously published in the journal Biological Conservation (Reed et al. 2019)

\section{Introduction}

This chapter can be considered an evidence-based "toolkit" for engaging multiple stakeholders. We hope it is of practical use to researchers and practitioners involved in landscape decisionmaking - and that those involved in complex landscape management continue to record and share their experiences to improve the evidence of what works.

Despite the appeal and increasing prominence of integrated landscape approaches, empirical evidence is limited for the performance or process related to the operationalization and outcomes in practice (Estrada-Carmona et al. 2014; Reed et al. 2017; Sayer et al. 2016). Further, very few assessments have explored the specific challenges facing these initiatives.

We address this knowledge gap by combining our experiences from a comprehensive systematic review (Reed et al. 2016); consultation workshops (Cairns Australia May 2012; Lake Eacham, Australia, June 2015; Bogor, Indonesia, July 2018, amongst others); to practical experience in leading multi-scale social and ecological research networks in the Amazon (Gardner et al. 2013) and Mekong delta (Sunderland et al. 2012) amongst others; and the evolving literature on social-ecological systems and landscape approaches. The aim is to learn from the successes and failures of previous attempts at 
integrating conservation and development, and to understand why the integration of multiple stakeholders remains problematic. We identify a number of constraints and opportunities facing attempts to engage multiple stakeholders in tropical landscapes that we have broadly categorized below.

\subsection{Navigating complexity}

Landscapes are often highly complex social-ecological systems; they hold poorly understood ecological interactions responding to both fast and slow drivers of change (Fischer et al. 2015), and the impacts of multiple - and often contradictory - socioeconomic institutions (Carmenta and Vira 2018). Political, environmental, social and commercial interactions at the landscape scale further amplify system complexity and, therefore, the degree of difficulty for investigation, management and disentanglement (Demek 1978; Mollinga 2010). This complexity is exacerbated by the expanding spatial scales at which contemporary socio-economic interactions take place (Carrasco et al. 2017; Hull and Liu 2018; Liu et al. 2013).

One approach to managing complexity is framing it as a "wicked problem" (Balint et al. 2011; Defries and Nagendra 2017), which means a satisfactory conclusion is unattainable because any given "solution" will generate new challenges (Rittel and Webber 1973). This should not, however, discourage research that attempts to provide solutions that are "better" than previous solutions - although "better" is subjective and open to (mis) interpretation (Carmenta et al. 2017). That is, what is good for one set of stakeholders may not be good for others.

Meanwhile, centralized management is increasingly considered a poor fit for complex systems where issues need to be addressed simultaneously at various scales (Berkes 2004; Hodge 2007; Kremen et al. 2000) and hybrid governance arrangements are increasingly common (Kozar et al. 2014; Viana et al. 2016). Therefore, researchers and practitioners must not simply ask at which scale should land-use decision-making, policies and management structures be conceived and implemented, but they must also consider how institutions, sectors and policies interact and integrate, and determine the processes that will enhance recognition, understanding and adequate amelioration of conflicted aspirations and preferences. This is particularly relevant in landscapes of rapid change and transformation, such as the agricultural forest frontiers of the global South.

A systemic approach to dealing with complexity suggests that navigating, not solely managing or planning for complexity, is preferable (Armitage et al. 2009; Sayer et al. 2016). The inherent complexity of landscapes makes formal management and planning problematic; therefore, an element of "muddling through" will always be necessary (Chazdon et al. 2017; Lindblom 1959; Sayer et al. 2008). Still, developing institutions that can accommodate diverse stakeholders with conflicting interests is challenging and hints at what Brown (2003) termed a case of institutional misfit. Greater fluidity of actors and institutional interplay across sectors and scales may require changes to both top-down and bottom-up governance structures to minimize scale conflicts (Foli et al. 2018 Olsson et al. 2006; Young 2002). 
Shifting to alternative governance arrangements is far from straightforward: entrenched power structures, institutional stickiness and socio-political inertia are hard to break down (Brockhaus and Angelsen 2012). Governance transformations often require political will and a political window of opportunity (Folke et al. 2005) that may be opened by a pressing environmental concern (problem-driven) or an administration that seeks a problem to justify change (politically-driven) (Kingdon and Thurber 1984). Olsson et al. (2006) suggest that "key leaders and shadow networks can prepare a system for change by exploring alternative system configurations and developing strategies for choosing from among possible futures". Effective network building that integrates actors from across disciplines and sectors can improve our understanding of system-wide dynamics and enhance our "ability to exploit economies of scale in shared resources and technical expertise" (Barlow et al. 2011, p.4). Yet effectively bridging disciplinary divides and linking science with action has, at best, been only partially successful (Brown 2003; Clark et al. 2011). One strategy is to build networks with a shared thematic or geographic focus (Gardner et al. 2013). However, overcoming entrenched differences requires careful, dedicated facilitation and long-term engagement, and may only be possible within a favorable political economy.

A potentially powerful approach to facilitate dialogue, enhance links between disciplines and navigate the 'space' between science and policy (c.f. Toomey et al. 2016) involves adding boundary, or bridging, organizations (Cash et al. 2006; Cash and Moser 2000; Clark et al. 2011; Guston 2001). Boundary organizations fulfill the complex task of considering the objectives of, and being accountable to, actors from across social-ecological system boundaries, while aiming for impartiality (Guston 2001) and co-production of knowledge and social order (Jasonoff 1996a, 1996b). Boundary organizations can link global research and environmental objectives with national commitments and local socio-economic and cultural realities. They support dialogue between experts and decision-makers by facilitating open communication, mutual understanding of problems and proposed solutions, and mediating conflicts (Cash et al. 2003). Their value, therefore, depends on the production of salient, credible and legitimate 'boundary objects' (i.e. maps, reports, protocols) that are sufficiently adaptable (to different viewpoints) and robust (to maintain identity) to satisfy the intentions of multiple parties (Cash et al. 2003; Star and Griesemer 1989). Recent evidence has demonstrated the incorporation of boundary organizations across a range of countries and contexts (Clark et al. 2011; Mollinga 2010; Pohl et al. 2010; Polsky and Cash 2005; Reyers et al. 2015). However, ascertaining effectiveness of such incorporation remains challenging (Clark et al. 2011) and the inclusion of boundary organizations will not automatically lead to positive change if they lack credibility or legitimacy, or are embedded in unfavorable political economy contexts (Graham and Mitchell 2016).

\subsection{Overcoming siloed thinking}

Many efforts to improve conservation and development outcomes highlight the critical importance of meaningful and long-term local stakeholder engagement (Bürgi et al. 2017; Sayer et al. 2013). For example, recent reviews of landscape approaches found 
community engagement in decision-making, and inclusion of people-based strategies, to be the most significant contributing factor to successful outcomes (Reed et al. 2017, Carmenta et al. 2020). Similarly, an assessment of a long-term landscape approach in the Sangha Trinational landscape in the Congo Basin found that participants considered multi-stakeholder processes vital to enhance the capacity to share and comprehend complex challenges (Sayer et al. 2016 p.137). These examples are further supported by assertions from the literature, which stress the value of community engagement and empowerment to the long-term sustainability of joint conservation and development interventions (Ostrom 1990; Persha et al. 2011).

Despite conceptual recognition and growing evidence of the importance of bridging sectoral and disciplinary divides in decision-making, practical progress remains slow (Agrawal and Gibson, 1999; Lund 2015; Ribot et al. 2010; Carmenta and Vira 2018) with scant reporting on the means of implementation or methods for evaluation (Stenseke 2009; Bixler et al. 2016). The following constraints complicate integration and the practical implementation of integrated approaches.

First, attempts to balance the objectives of multiple stakeholders are often hindered by "the political process of decision-making, differing values and norms, and power imbalances" (Defries and Nagendra 2017). A lack of incentives for real change can result in "elite capture" or the further marginalization of some of the most vulnerable people (Viana et al. 2016). Participation can also fail due to the reluctance of local stakeholders themselves to engage in what may be perceived as a divisive, threatening, or burdensome intervention (Cheng et al. 2006; Green et al. 2018). Second, practical advances have failed as stakeholder engagement is often only a box-ticking exercise to satisfy project or donor demands (Enengel et al. 2011; German et al. 2007; Castella et al. 2014). Finally, multi-stakeholder engagement processes have high transaction costs (Enengel et al. 2011) also borne by local stakeholders. Thus, effective - and sustainable engagement is likely to occur only if the long-term rewards are perceived as potentially outweighing initial short-term gains, or costs associated with investments/compliance.

Overcoming these issues means recognizing that multiple stakeholder engagement is much more than simply supporting or empowering local communities. Increasingly, the concept of knowledge co-production that integrates communities of knowledge with communities of action is seen to have significant potential for confronting the kinds of "wicked problems" presented by social-ecological systems (Cash et al. 2003). Engagement platforms must confront issues of inequity, avoid elite capture and encourage democratic forms of co-governance. Context is also important; imbalances of power are often seen as detrimental to multi-stakeholder dialogue, yet there may be instances when asymmetrical power relationships could help promote the agendas of marginalized groups (Hendriks 2009; Moeliono et al. 2014). However, ethically, and to maintain accordance with UN declarations (e.g. Declaration on Human Rights and Declaration on the Rights of Indigenous People) attempts should be made to dissolve power asymmetries such that power is evenly distributed with decisions negotiated fairly in order to encourage co-productive governance arrangements. 
Although working effectively across disciplinary and sectoral divides is fraught with difficulty (Sandbrook et al. 2013), previous experiences provide valuable lessons. One key insight is that interdisciplinarity can be enhanced via multiple pathways. For example, multi-stakeholder fora can be incentivized through triple loop learning (i.e. not only questioning if we are doing things right but also understanding if we are doing things right, and how to know what is the right thing to do) (Biggs et al. 2011) and seeking consensus on problem definition objectives, and solutions (Blackstock 2007). Developing a robust theory of change in a participatory manner can be useful in this regard (Qiu et al. 2018; Sayer et al. 2016; see also Chapter 5). Generating a shared understanding amongst stakeholders of their respective requirements or objectives and the implications of actions can help to highlight potential areas of synergy and also enhance empathy and trust amongst participants. Diverse collectives could then develop, built on an acknowledgement of the interdependency of actions and the need to collectively work towards an agreed outcome (Steyaert and Jiggins 2007).

Previous attempts at working across disciplines have also shown the importance of ensuring public consultation venues are accessible to all stakeholders (or legitimate representatives) (Sessin-Dilascio et al. 2016); negotiations are held in a common language (Bennett and Dearden 2014); and strategies developed to enable equitable participation of all concerned stakeholders, including women and marginalized groups (Ling et al. 2009). There must be genuine potential for collective development of alternative pathways. Independent facilitation and support from external agencies - whether political, technical, or financial - can inspire more effective stakeholder engagement (Balint and Mashinya 2006; Sayer et al. 2016). Commitments must be longterm, as capacity building can be a lengthy process, demanding up to 20 years of external support. ${ }^{1,2}$ Nor does external support guarantee enhanced equity; in one study, internal capacity was shown to exist before externally induced programs disrupted equitable stakeholder engagement (Guillaume 2017). A robust baseline or pilot study to determine contextual nuance, social norms and behaviors can therefore be valuable. Encouragingly, some donors have recognized this and offer seed money for such initiatives.

Effective engagement processes that are adapted to specific contexts, structured in an accessible manner and cognizant of historic or potential conflict and power hierarchies should be encouraged. Furthermore, the dynamism of complex ecosystems and associated stakeholders means that system shocks and fluctuations will inevitably occur, increasing the susceptibility to uncertainty and risk over time (Cooke and Kothari 2001; Smith 2008). Engagement structures must be an iterative process of periodically informing, evaluating and updating knowledge and objectives to stimulate feedback (Carpenter and Gunderson 2001; Folke et al. 2005; Gunderson et al. 2001) with methods to assess both the satisfaction of participants (Enengel et al. 2011) and the effectiveness of governance platforms (Bixler et al. 2016; Hassenforder et al. 2016; Kusters et al. 2018).

1 https://forestsnews.cifor.org/51411/a-promising-but-uncertain-future-for-tenure-rights-devolution?fnl=en

2 Jennie Barron (IWMI/SLU) presentation: Feasibility of green water management and rainwater harvesting in drylands. Falkenmark Symposium - Achieving SDG in Africa: Scaling green-blue revolution. World Water Week 2017. 


\subsection{Incentivizing behavioral change at the local level}

Effectively engaging stakeholders to integrate climate, conservation and development goals will be influenced by the application of appropriate incentive structures designed to reduce the overexploitation of natural resources (Fischer et al. 2012). Determining the "right" or "best" incentives in complex landscapes with multiple stakeholders requires consideration of many issues. Furthermore, transitions to sustainability demands interventions across scales and sectors, including off-site interventions (e.g. changing diet preferences, redistribution, reducing consumption of processed foods and waste in GDP-rich countries) (Martin et al. 2018; Tilman and Clark 2014).

Incentive effectiveness is highly dependent on the socio-economic, cultural and political context, and an adequate incentive in one landscape - or for one group - may be inappropriate or insufficient elsewhere (Luttrell et al. 2013; Newton et al. 2013). Incentive structures targeted at either the individual (e.g. direct cash payments) or community level (e.g. investment in health services or education) will generate variable responses depending on context (e.g. the impact on motivations for behavioral change) (Muradian et al. 2013). This raises questions about the equitable distribution and appropriateness of incentive structures (Dietz et al. 2003; Ostrom et al. 1999).

Incentives for pro-conservation behavior can take many forms, from providing financial compensation to clarifying property or access rights, to addressing issues of equity, health, infrastructure, or power asymmetries of class or gender (Carmenta et al. 2020). Again, context is important; for example, market-based incentives rely on market forces to incentivize behavioral change and may therefore be biased toward middle-income actors with good market access.

One approach to incentives involves providing alternative livelihood options that reduce threats to the natural resource base (Roe et al. 2015); for example, encouraging seaweed farming as an alternative to artisanal fishing (Hill et al. 2011). However, the effectiveness in delivering positive outcomes for conservation or ecosystem services remains poorly understood, largely because the impact of such projects is rarely evaluated (Ferraro and Pattanayak 2006; Sainsbury et al. 2015). Indeed, a recent review of alternative livelihood projects found that less than 20 percent of studies sufficiently analyzed or evaluated project impacts, while fewer than 10 percent resulted in positive conservation outcomes (Roe et al. 2015). A similar lack of evidence of effectiveness is found when examining the impact of alternative livelihood projects on socio-economic outcomes in Ghana (Hilson and Banchirigah 2009) and Africa more broadly (Wicander and Coad 2015). As with compensatory incentives, alternative livelihood strategies must be carefully contextualized. For example, livelihood options for a bushmeat hunter (Chaves et al. 2017), may involve more than simply a financial or environmental consideration as a hunter may command a certain social respect within the community that he is reluctant to relinquish (John Fa, personal communication). Nevertheless, when applied effectively, alternative livelihood programs can empower local communities, enhance local agency and reduce threats to local biodiversity (Lotter and Clark 2014; Roe 2015). 


\subsubsection{Perverse incentives}

Research has illustrated the perils of perverse incentives - that is, well-intended proconservation incentives that have the paradoxical effect of accelerating natural resource depletion, or crowding out intrinsic motivations (Ferraro and Kramer 1995; Langholz 1999; Wunder 2001). Perverse incentives may occur when the opportunity costs of ecosystem conservation are underappreciated and the financial returns for the end users from ecosystem conversion are greater (or perceived as greater) than those generated from conservation. Rudimentary cost-benefit analysis may not account for the broader implications of conserving, or converting. The challenge is to develop a more nuanced understanding of the complex interactions between people, nature and institutions and then attempt to identify which incentive structure will likely deliver optimal outcomes for the highest number of stakeholders, to achieve more winners and fewer losers (Sayer et al. 2014).

\subsubsection{Modeling approaches}

One strategy to facilitate forecasting is via simulation models, which have long been a feature of joint conservation and development discourse (Holling and Chambers 1973; Sayer and Campbell 2004; Walters 1986; Wu and Hobbs 2002). Rather than attempting to predict the future, their value is in generating potential outcomes that enable a better understanding of social-ecological system function. Participatory modeling can make explicit the assumptions and preferences of a diversity of participants, thereby enabling more transparent decision-making processes (Holling and Chambers 1973; Sayer et al. 2016; Wu and Hobbs 2002). Importantly, it can support better understanding of the bio-physical and socio-economic processes within the landscape, and how these interact (Musacchio 2009; O'Farrell and Anderson 2010b). Coupled with participatory historical trend analysis - consulting inhabitants to collect historical landscape information - it can be particularly effective for identifying patterns of change. Understanding both ecological processes derived from landscape configuration and function, as well as structural hierarchies, social conflicts, and political agendas, can strengthen measures for safeguarding natural resources and enhance the efficacy of collaborative decisionmaking (Marlier et al. 2013).

However, many modeling approaches have shortfalls, with projections characterized by a high degree of uncertainty (Prestele et al. 2016), and seldom capturing real world complexity. Most models retain a large number of assumptions, the parameters are subject to modeler bias and - particularly for long-term projections - are limited to the known or anticipated variables of the time. For example, a model designed today to forecast future forest cover in Indonesia for the next 30 years would certainly include oil palm production as an independent variable - something that might not have been the case 30 years previously and would (as we now know) have represented a significant oversight.

Nevertheless, participatory modeling has been shown to be extremely effective in enhancing stakeholder discussion, helping to illustrate potential synergies or trade-offs and stimulating development of innovative solutions. For example, Castella et al. (2014) describe the use of a boundary object (in the form of a 3D model representing a Laotian 
village landscape) to encourage local stakeholder participation in land-use planning. The model enabled those stakeholders lacking the capacity to adequately convey landscape features or interpret GIS maps to maintain an active role in scenario visualizing. Model outputs (as GIS maps) were then coupled with simple cost-benefit analyses (with locally determined parameters) so that community members could iteratively negotiate potential outcomes and ultimately, influence decision-making processes (Sayer et al. 2007).

\subsection{Enhancing engagement to address complex challenges}

Governance that seeks to reconcile climate, conservation and development agendas must first reconcile disconnects across scales, sectors, and disciplines such that the grand theories of international policy and academia more closely align with messier local realties (Barlow et al. 2018; Boedhihartono et al. 2018). We have identified important opportunities for future research and practice.

First, greater recognition of the need to navigate complex challenges, as opposed to applying rigid management and log-frame approaches, should be encouraged. Careful construction of multi-stakeholder dialogue fora enlisting the support of boundary organizations and independent facilitation that applies established principles (Brouwer et al. 2016) offers potential (Larsen et al. 2018).

Second, the sustainability of multi-stakeholder engagement will be enhanced through the development of inclusive and transparent theories of change that identify desired outcomes and measurable process indicators (Qiu et al. 2018 and see Chapter 5). Including local communities and policymakers in the design and subsequent implementation and monitoring can bring to light trade-offs and synergies early in the process and iteratively inform adaptive co-governance. Academia, donors and scientific journals increasingly recognize the value and potential impact of incorporating citizen science, indigenous knowledge and other non-traditional Western science approaches in social-ecological system research design and application (Ban et al. 2018; Mistry and Berardi 2016).

Third, greater effort is needed in evaluating the process and impact of multi-stakeholder engagement. This means rather than merely monitoring social and biophysical indicators, attention must be paid to the functioning and contribution of the governance platform itself (Bixler et al. 2016; Kusters et al. 2018).

Finally, incentives that reward pro-conservation behavior must be encouraged. Incentives are often fundamental to influencing perceptions, actions and outcomes and can therefore lead to positive and negative or perverse changes. Engaging stakeholders in forecasting exercises and role-playing games can position actors in unfamiliar roles and decision-making environments, simultaneously building knowledge, capacity and empathy. 
While the challenges and opportunities identified here may have independent and collective value in terms of moving toward operationalizing landscape approaches and closing knowledge-practice gaps, obstacles to progress remain and new challenges will undoubtedly arise. Innovations in theory, developing new and further development of existing tools, and greater understanding of the precise functioning of landscape approaches must be encouraged. Crucially, the evidence base must continue to be developed with robust monitoring of the biophysical, social and governance processes within the landscape; this is vital to keep pace with unprecedented global environmental change, and ensure multiple stakeholder engagement remains effective.

\section{References}

Agrawal A and Gibson CC. 1999. Enchantment and disenchantment: The role of community in natural resource conservation. World development 27(4): 629-649. https://doi.org/10.1016/S0305-750X(98)00161-2

Armitage DR, Plummer R, Berkes F, Arthur RI, Charles AT, Davidson-Hunt IJ, ... McConney P. 2009. Adaptive co-management for social-ecological complexity. Frontiers in Ecology and the Environment 7(2): 95-102. https://doi.org/10.1890/070089.

Balint PJ and Mashinya J. 2006. The decline of a model community-based conservation project: Governance, capacity, and devolution in Mahenye, Zimbabwe. Geoforum 37(5): 805-815. https://doi.org/10.1016/j.geoforum.2005.01.011.

Balint PJ, Stewart RE, Desai A, and Walters LC. 2011. Wicked Environmental Problems: Managing Uncertainty and Conflict. Washington, DC: Island Press.

Ban NC, Frid A, Reid M, Edgar B, Shaw D and Siwallace P. 2018. Incorporate indigenous perspectives for impactful research and effective management. Nature Ecology 8 Evolution 2(11), 1680. https://doi.org/10.1038/s41559-018-0706-0.

Barlow J, Ewers RM, Anderson L, Aragao LEOC, Baker TR, Boyd E ... Gardner TA. 2011. Using learning networks to understand complex systems: case study of biological, geophysical and social research in the Amazon. Biological Reviews 86(2): 457-474. https://doi.org/10.1111/j.1469-185X.2010.00155.x.

Barlow J, França F, Gardner T, Hicks C, Lennox G, Berenguer E, ... Graham N. 2018. The future of tropical hyperdiverse ecosystems. Nature 559: 517.

Bennett N and Dearden P. 2014. Why local people do not support conservation: Community perceptions of marine protected area livelihood impacts, governance and management in Thailand. Marine Policy 44: 107-116. https://doi.org/10.1016/j. marpol.2013.08.017.

Berkes F. 2004. Rethinking community-based conservation. Conservation Biology 18(3): 621-630. https://doi.org/10.1111/j.1523-1739.2004.00077.x.

Biggs D, Abel N, Knight AT, Leitch A, Langston A and Ban NC 2011. The implementation crisis in conservation planning: Could "mental models" help ? Conservation Letters 4(3):169-183. https://doi.org/10.1111/j.1755-263X.2011.00170.x.

Bixler RP, Johnson S, Emerson K, Nabatchi T, Reuling M, Curtin C, ... Grove JM. 2016. Networks and landscapes: A framework for setting goals and evaluating performance 
at the large landscape scale. Frontiers in Ecology and the Environment 14(3): 145-153. https://doi.org/10.1002/fee.1250.

Blackstock KL 2007. Operationalising sustainability science for a sustainability directive? Reflecting on three pilot projects. Geographical Journal 173(4): 343-357.

Boedhihartono AK, Bongers F and Boot RGA. 2018. Conservation science and practice must engage with the realities of complex tropical landscapes. Tropical Conservation Science 11: 1-7. https://doi.org/10.1177/1940082918779571.

Brockhaus M and Angelsen A. 2012. Seeing REDD+through 4Is: A political economy framework. Analysing REDD+: challenges and choices. Bogor, Indonesia: Center for International Forestry Research. 15-30.

Brouwer H, Woodhill A, Hemmati M. and Verhoosel K. 2016. The MSP Guide - How to Design and Facilitate Multi-stakeholder Partnerships. Rugby, Warwickshire: Practical Action Publishing.

Brown K. 2003. Integrating conservation and development: A case of institutional misfit Frontiers in Ecology and the Environment 1(9): 479-487.

Bürgi M, Ali P, Chowdhury A, Heinimann A, Hett C, Kienast F, ... Verburg PH. 2017. Integrated landscape approach : Closing the gap between theory and application Sustainability, 9(8), 1371. https://doi.org/10.3390/su9081371

Carmenta R, Zabala A, Daeli W, and Phelps J 2017. Perceptions across scales of governance and the Indonesian peatland fires. Global Environmental Change 46: 50-59. https://doi.org/10.1016/j.gloenvcha.2017.08.001.

Carmenta R and Vira B. 2018. Integration for restoration. Reflecting on lessons learned from silos of the past. In Mansourian S and Parrotta J, eds. Forest Landscape Restoration: Integrated Approaches to Support Effective Implementation. Abingdon, Oxon and New York: Routledge, 16-36.

Carmenta R, Coombes DA, DeClerk FAJ, Hart AK, Harvey CA, Milder J, Reed J, Vira B and Estrada-Carmona N. 2020. Characterizing and evaluating integrated landscape initiatives. One Earth. 2(2): 174-187. https://doi.org/10.1016/j.oneear.2020.01.009.

Carpenter SR, and Gunderson LH. 2001. Coping with collapse: Ecological and social dynamics in ecosystem management. BioScience 51(6): 451-457.

Carrasco LR Chan J, Mcgrath FL and Nghiem LTP. 2017. Biodiversity conservation in a telecoupled world. Ecology and Society 22(3).

Cash DW, Adger WN, Berkes F, Garden P, Lebel L and Olsson P. 2006. Scale and crossscale dynamics: Governance and information in a multilevel world. Ecology and Society $11(2)$.

Cash DW, Clark WC, Alcock F, Dickson NM, Eckley N, Guston DH, ... Mitchell RB. 2003. Knowledge systems for sustainable development. Proceedings of the National Academy of Sciences 100(14).

Cash DW and Moser SC. 2000. Linking global and local scales: Designing dynamic assessment and management processes. Global Environmental Change 10(2): 109-120.

Castella JC, Bourgoin J, Lestrelin G and Bouahom B. 2014. A model of the sciencepractice-policy interface in participatory land-use planning: Lessons from Laos. Landscape Ecology 29(6): 1095-1107. https://doi.org/10.1007/s10980-014-0043-x. 
Chaves WA, Valle DR, Monroe MC, Wilkie DS, Sieving KE and Sadowsky B. 2017. Changing wild meat consumption: An experiment in the Central Amazon, Brazil. Conservation Letters 11(2), e12391. https://doi.org/10.1111/conl.12391.

Chazdon RL, Brancalion PHS, Lamb D, Laestadius L, Calmon M and Kumar C. 2017. Policy perspective: A policy-driven knowledge agenda for global forest and landscape restoration. Conservation Letters 10(1): 125-132. https://doi.org/10.1111/conl.12220

Cheng AS and Mattor KM. 2006. Why won't they come? Stakeholder perspectives on collaborative national forest planning by participation level. Environmental Management 38(4): 545-561. https://doi.org/10.1007/s00267-005-0124-3.

Christensen J. 2004. Win-win illusions. Conservation in Practice 5(1): 12-19.

Clark WC, Tomich TP, van Noordwijk M, Guston D, Catacutan D, Dickson NM, and McNie E. 2011. Boundary work for sustainable development: Natural resource management at the Consultative Group on International Agricultural Research (CGIAR). Proceedings of the National Academy of Sciences. 13(17): 4615-4622. https://doi. org/10.1073/pnas.0900231108.

Cooke B. and Kothari U. 2001. Participation: The New Tyranny? London: Zed Books.

Defries R. and Nagendra H. 2017. Ecosystem management as a wicked problem. Science 270: $265-270$.

Demek J. 1978. The landscape as a geosystem. Geoforum 9(1), 29-34.

Dietz T, Ostrom E and Stern PC. 2003. The struggle to govern the commons. Science, 302(5652): 1907-1912.

Enengel B, Penker M, Muhar A, Williams R. 2011. Benefits, efforts and risks of participants in landscape co-management: An analytical framework and results from two case studies in Austria. Journal Environmental Management 92(4): 1256-1267. https://doi.org/10.1016/j.jenvman.2010.12.005.

Estrada-Carmona N, Hart AK, DeClerck FAJ, Harvey CA and Milder JC. 2014. Integrated landscape management for agriculture, rural livelihoods, and ecosystem conservation: an assessment of experience from Latin America and the Caribbean. Landsc Urban Plan 129: 1-11.

Ferraro PJ, and Kramer RA. 1995. A framework for affecting household behavior to promote biodiversity conservation. Environmental and Natural Resources Policy and Training (EPAT) Project Little Rock, AR/Arlington, VA: Winrock International Environmental Alliance.

Ferraro PJ, and Pattanayak SK. 2006. Money for nothing? A call for empirical evaluation of biodiversity conservation investments. PLoS Biol 4(4), e105. https://doi.org/10.1371/ journal.pbio.0040105.

Fischer J, Dyball R, Fazey I., Gross C, Dovers S, Ehrlich R, ... Borden RJ. 2012. Human behavior and sustainability. Frontiers in Ecology and Environment 10: 153-160. https:// doi.org/10.1890/110079.

Fischer J, Gardner TA, Bennett EM, Balvanera P, Biggs R, Carpenter S. ... Tenhunen J. 2015. Advancing sustainability through mainstreaming a social-ecological systems perspective. Current Opinion in Environmental Sustainability 14: 144-149. https://doi. org/10.1016/j.cosust.2015.06.002. 
Foli S, Ros-Tonen M, Reed J, Sunderland T. 2018. Natural resource management schemes as entry points for integrated landscape approaches: Evidence from Ghana and Burkina Faso. Environmental Management 62(1): 82-97. https://doi.org/10.1007/s00267017-0866-8.

Folke C, Hahn T, Olsson P, Norberg J. 2005. Adaptive Governance of social-ecological systems. Annual Review of Environmental Resources 30: 441-473. https://doi.org/10.1146/ annurev.energy.30.050504.144511.

Gardner TA, Ferreira J, Barlow J, Lees AC, Parry L, Vieira ICG, ... Cardoso TM. 2013. A social and ecological assessment of tropical land uses at multiple scales: The Sustainable Amazon Network. Philosophical Transactions of the Royal Society of London. Series B, Biological Sciences 368(1619), 20120166. https://doi.org/10.1098/rstb.2012.0166.

German L, Mansoor H, Alemu G, Mazengia W, Amede T, Stroud A. 2007. Participatory integrated watershed management: Evolution of concepts and methods in an ecoregional program of the eastern African highlands. Agricultural Systems 94(2): 189-204. https://doi.org/10.1016/j.agsy.2006.08.008.

Graham A and Mitchell CL. 2016. The role of boundary organizations in climate change adaptation from the perspective of municipal practitioners. Climatic Change 381-395. https://doi.org/10.1007/s10584-016-1799-6.

Green JMH, Fisher B, Green RE, Makero J, Platts PJ, Robert N, ... Balmford A. 2018. Local costs of conservation exceed those borne by the global majority. Global Ecology and Conservation, 14, e00385. https://doi.org/10.1016/j.gecco.2018.e00385.

Guillaume E. 2017. A case study on inclusiveness in forest management decision-making mechanisms: A comparison of certified and non-certified forests in the Republic of the Congo. International Forestry Review 19(2): 145-157.

Gunderson, L, Holling CS, Peterson G, Pritchard L. 2001. Resilience. In: Mooney H and Canadell J, eds. Encyclopedia of Global Environmental Change 2.

Guston DH. 2001. Boundary Organizations in Environmental Policy and Science: An Introduction, Science, Technology \& Human Values 26(4):): 399-408.

Hassenforder E, Pittock J, Barreteau O, Daniell KA and Ferrand N. 2016. The MEPPP Framework: A Framework for Monitoring and Evaluating Participatory Planning Processes. Environmental Management 57(1): 79-96. https://doi.org/10.1007/s00267015-0599-5.

Hendriks CM. 2009. Deliberative governance in the context of power. Policy and Society 28(3): 173-184. https://doi.org/10.1016/j.polsoc.2009.08.004.

Hill NAO, Rowcliffe JM and Koldewey HJ. 2011. The interaction between seaweed farming as an alternative occupation and fisher numbers in the Central Philippines. Conservation Biology 26(2): 324-334. https://doi.org/10.1111/j.1523-1739.2011.01796.x

Hilson G, and Banchirigah SM. 2009. Are Alternative Livelihood Projects Alleviating Poverty in Mining Communities? Experiences from Ghana. The Journal of Development Studies 45(2): 172-196. https://doi.org/10.1080/00220380802553057.

Hodge ID. 2007. The governance of rural land in a liberalised world. Journal of Agricultural Economics 58(3): 409-432. 
Holling CS, and Chambers R. 1973. Resource science: the nurture of an infant. BioScience 23(1): 13-20.

Hull V, and Liu J. 2018. Telecoupling: A new frontier for global sustainability. Ecology and Society 23(4), art41. https://doi.org/10.5751/ES-10494-230441.

Jasonoff S. 1996a. Is science socially constructed-And can it still inform public policy? Science and Engineering Ethics 2(3), 263-276.

Jasonoff S. 1996b. Beyond epistemology-Relativism and engagement in the politics of science. Social Studies of Science 26(2): 393-418.

Kingdon JW and Thurber JA. 1984. Agendas, alternatives and public policies. Boston: Little, Brown.

Kozar R, Buck LE, Barrow EG, Sunderland TCH, Catacutan DE, Planicka C, ... Willemen L. 2014. Toward viable landscape governance systems: What works? Washington DC: EcoAgriculture Partners.

Kremen C, Niles J, Dalton M, Daily GC, Ehrlich PR, Fay J. ... Guillery R. 2000. Economic Incentives for Rain Forest Conservation Across. Science 288: 1828-1833.

Kusters K, Buck L, Graaf M de, Minang P, van Oosten C, Zagt R. 2018. Participatory planning, monitoring and evaluation of multi-stakeholder platforms in integrated landscape initiatives. Environmental Management 62(1): 170-181. https://doi. org/10.1007/s00267-017-0847-y

Langholz J. 1999. Exploring the effects of alternative income opportunities on rainforest use: Insights from Guatemala's Maya Biosphere Reserve. Society and Natural Resources 12(2): 139-149. https://doi.org/10.1080/089419299279803

Larsen Rasmus K, Osbeck M, Dawkins E, Tuhkanen H, Nguyen H, Nugroho A, ... Wolvekamp, P. 2018. Hybrid governance in agricultural commodity chains: Insights from implementation of 'No Deforestation, No Peat, No Exploitation' (NDPE) policies in the oil palm industry. Journal of Cleaner Production 183:544-554. https://doi. org/10.1016/j.jclepro.2018.02.125

Lindblom CE. 1959. The science of "muddling through." Public Administration Review (19)2: 79-88.

Ling C, Hanna K and Dale A. 2009. A Template for Integrated Community Sustainability Planning. Environmental Management 44(2), 228-242. https://doi.org/10.1007/s00267009-9315-7.

Liu J, Hull V, Batistella M, Defries R, Dietz T, Fu F, ... Naylor R. 2013. Framing Sustainability in a Telecoupled World. Ecology and Society, 18(2).

Lotter W. and Clark K. 2014. Community involvement and joint operations aid effective community involvement and joint operations aid effective anti-poaching in Tanzania. Parks 20: 19-28.

Lund JF. 2015 Paradoxes of participation: The logic of professionalization in participatory forestry. Forest Policy and Economics 60: 1-6. https://doi.org/10.1016/j. forpol.2015.07.009.

Luttrell C, Loft L, Gebara MF, Kweka D, Brockhaus M and Angelsen A. 2013. Who Should Benefit from REDD + ? Rationales and Realities. Ecology and Society 18(4). 
Marlier ME, Defries RS, Voulgarakis A, Kinney PL, Randerson T, Shindell DT, ... Faluvegi G. 2013. El Niño and health risks from landscape fire emissions in southeast Asia. Nature Climate Change 3: 131-136. https://doi.org/10.1038/nclimate1658.El.

Martin A, Coolsaet B, Corbera E, Dawson NM. 2018. Land use intensification: the promise of sustainability and the reality of trade-offs. In K. Schreckenberg, G. Mace, \& M. Poudyal (eds.), Ecosystem Services and Poverty Alleviation: Trade-offs and governance. Taylor \& Francis Group.

Mistry BJ and Berardi A. 2016. Bridging indigenous and scientific knowledge. Science 352(6291): 1274-1276.

Moeliono M, Gallemore C, Santoso L, Brockhaus M, Di Gregorio M. 2014. Information networks and power: Confronting the "wicked problem " of REDD + in Indonesia. Ecology and Society 19(2).

Mollinga PP. 2010. Boundary work and the complexity of natural resources management, Crop Science 50:S-1-S-9. https://doi.org/10.2135/cropsci2009.10.0570

Muradian R, Arsel M, Pellegrini L, Adaman F, Aguilar B, Agarwal B, ... Urama K. 2013. Payments for ecosystem services and the fatal attraction of win-win solutions. Conservation Letters 6(4): 274-279. https://doi.org/10.1111/j.1755-263X.2012.00309.x

Musacchio LR. 2009. The scientific basis for the design of landscape sustainability: a conceptual framework for translational landscape research and practice of designed landscapes and the six Es of landscape sustainability. Landscape Ecology 24(8): 9931013. https://doi.org/10.1007/s10980-009-9396-y.

Newton P, Agrawal A, Wollenberg L. 2013. Enhancing the sustainability of commodity supply chains in tropical forest and agricultural landscapes. Global Environmental Change-Human and Policy Dimensions 23(6): 1761-1772. https://doi.org/10.1016/j. gloenvcha.2013.08.004.

O'Farrell PJ, and Anderson PML. 2010. Sustainable multifunctional landscapes: A review to implementation. Current Opinion in Environmental Sustainability 2(1-2), 59-65. https://doi.org/10.1016/j.cosust.2010.02.005.

Olsson P, Gunderson LH, Carpenter SR, Ryan P, Lebel L, Folke C, Holling CS. 2006. Shooting the rapids: Navigating transitions to adaptive governance of socialecological systems. Ecology and Society 11(1).

Ostrom E. 1990. Governing the commons: The evolution of institutions for collective action. Cambridge: Cambridge University Press.

Ostrom E, Burger J, Field CB, Norgaard RB, and Policansky D. 1999. Revisiting the commons: Local lessons, global challenges. Science 284(5412): 278-282.

Persha L, Agrawal A, Chhatre A. 2011. Social and ecological synergy: local rulemaking, forest livelihoods, and biodiversity conservation. Science 331(6024): 1606-1608. https://doi.org/10.1126/science.1199343.

Pohl C, Rist S, Zimmermann A, Fry P, Schneider F, Speranza CI, ... Wiesmann U. 2010. Researchers' roles in knowledge co-production: experience from sustainability research in Kenya, Switzerland, Bolivia and Nepal, Science and Public Policy 37: 267281. https://doi.org/10.3152/030234210X496628 
Polsky C, and Cash D. 2005. Drought, climate change, and vulnerability: the role of science and technology in a multi-scale, multi-stressor world. In Drought and water crises: science, technology, and management issues. New York: Marcel Dekker. 215-245.

Prestele R, Alexander P, Rounsevell MDA, Calvin K, Doelman J and Eitelberg DA. 2016. Hotspots of uncertainty in land-use and land-cover change projections: a global-scale model comparison. Global Change Biology 22(12):3967-3983. https://doi.org/10.1111/ gcb.13337.

Qiu J, Game ET, Tallis H, Olander LP, Glew L, Kagan, J. S., ... Weaver SK. 2018. EvidenceBased causal chains for linking health, development, and conservation Actions. BioScience 68(3). https://doi.org/10.1093/biosci/bix167.

Reed J, Barlow J, Carmenta R, van Vianen J, Sunderland T, 2019. Engaging multiple stakeholders to reconcile climate, conservation and development objectives in tropical landscapes. Biological Conservation 238: 108229.

Reed J, Vianen J van, Deakin EL, Barlow J, Sunderland T. 2016. Integrated landscape approaches to managing social and environmental issues in the tropics: learning from the past to guide the future. Global Change Biology 22(7). https://doi.org/10.1111/ gcb.13284.

Reed J, Vianen J van, Barlow J, Sunderland T. 2017. Have integrated landscape approaches reconciled societal and environmental issues in the tropics? Land Use Policy, 63, 481-492. https://doi.org/10.1016/j.landusepol.2017.02.021.

Reyers B, Nel JL, Farrell PJO, Sitas N, Nel DC. 2015. Navigating complexity through knowledge coproduction: Mainstreaming ecosystem services into disaster risk reduction, Proceedings of the National Academy of Sciences 112(24). https://doi. org/10.1073/pnas.1414374112.

Ribot JC, Lund JF and Treue T. 2010. Democratic decentralization in sub-Saharan Africa: its contribution to forest management, livelihoods. Environmental Conservation, 37(1), 35-44. https://doi.org/10.1017/S0376892910000329.

Rittel H, and Webber M. 1973. Dilemmas in a general theory of planning. pdf. Policy Sciences (4): 155-169.

Roe D. (Ed). 2015. Conservation, crime and communities. London.

Roe D, Booker F, Day M, Zhou W, Allebone-Webb S, Hill NAO, ... Sunderland TC H. 2015. Are alternative livelihood projects effective at reducing local threats to specified elements of biodiversity and/or improving or maintaining the conservation status of those elements? Environmental Evidence 4(1): 1-22. https://doi.org/10.1186/s13750-0150048-1.

Sainsbury K, Burgess ND, Sabuni F, Howe C, Puis E, Killenga R, Milner-gulland E J. 2015. Exploring stakeholder perceptions of conservation outcomes from alternative income generating activities in Tanzanian villages adjacent to Eastern Arc Mountain forests. Biological Conservation 191: 20-28. https://doi.org/10.1016/j.biocon.2015.06.001.

Sandbrook C, Adams WM, Buscher B, Vira B. 2013. Social research and biodiversity conservation. Conservation Biology 27(6): 1487-1490. https://doi.org/10.1111/cobi.12141.

Sayer JA, and Campbell, BM. 2004. The science of sustainable development: local livelihoods and the global environment. Cambridge: Cambridge University Press. 
Sayer JA, Margules C, Boedhihartono AK, Sunderland T, Langston JD, Reed J, ... Sayer JA. 2016. Measuring the effectiveness of landscape approaches to conservation and development. Sustainability Science. https:/doi.org/10.1007/s11625-016-0415-z.

Sayer J, Bull G, Elliott C. 2008. Mediating Forest Transitions: 'Grand Design' or 'Muddling Through 6(4):320-327.', Conservation and Society.

Sayer J, Campbell B, Petheram L...... Burgess N. 2007. Assessing environment and development outcomes in conservation landscapes. Biodiversity and Conservation 16(9): 2677-2694.

Sayer J, Endamana, D, Boedhihartono, AK, Breuer T. 2016. Learning from change in the Sangha Tri-National landscape. International Forestry Review 18: 130-139.

Sayer J, Margules C, Boedhihartono AK, Dale A, Sunderland T, Supriatna J, Saryanthi R. 2014. Landscape approaches; what are the pre-conditions for success? Sustainability Science 10(2): 345-355.

Sayer J, Sunderland T, Ghazoul J, Pfund JL, Sheil D, Meijaard E. ... Buck LE. 2013. Ten principles for a landscape approach to reconciling agriculture, conservation, and other competing land uses. Proceedings of the National Academy of Sciences of the United States of America 110(21): 8349-8356.

Sessin-Dilascio K, Centro I. and Irvine KN. 2016. The dynamics of co-management and social capital in protected area management - The Cardoso Island State Park in Brazil. World Development (February). https://doi.org/10.1016/j.worlddev.2014.11.004

Smith J. 2008. A critical appreciation of the "bottom-up" approach to sustainable water management: embracing complexity rather than desirability. Local Environment 13(4): $353-366$.

Star SL. and Griesemer J. (n.d.) Institutional ecology,translations' and boundary objects: Amateurs and professionals in Berkeley's Museum of Vertebrate Zoology, 1907-39. Social Studies of Science 19(3): 387-420.

Stenseke M. 2009. Local participation in cultural landscape maintenance:

Lessons from Sweden. Land Use Policy 26(2): 214-223.. https://doi.org/10.1016/j. landusepol.2008.01.005.

Steyaert P. and Jiggins J. 2007. Governance of complex environmental situations through social learning: a synthesis of SLIM's lessons for research, policy and practice. Environmental Science and Policy 10: 575-586. https://doi.org/10.1016/j. envsci.2007.01.011.

Sunderland TCH, Sayer J, Hoang M-H. 2012. Evidence-based conservation: lessons from the lower Mekong. London: Routledge.

Tilman D, and Clark M. 2014. Global diets link environmental sustainability and human health. Nature 515(7528): 518-522. https://doi.org/10.1038/nature13959

Toomey AH, Knight AT and Barlow J. 2016. Navigating the space between research and implementation in conservation. Conservation Letters 10(5): 619-625. https://doi. org/10.1111/conl.12315.

Viana C, Coudel E, Barlow J, Ferreira J, Gardner T, Parry L. 2016. How does hybrid governance emerge? Role of the elite in building a Green Municipality in the Eastern 
Brazilian Amazon, Environmental Policy and Governance 350: 337-350. https://doi. org/10.1002/eet.1720.

Walters C. 1986. Adaptive Management Of Renewable Resources. New York: Macmillan Publishers Ltd.

Wicander S and Coad. 2015. Learning our lessons: a review of alternative livelihood projects in Central Africa. IUCN.

$\mathrm{Wu}$ J. and Hobbs R. 2002. Key issues and research priorities in landscape ecology: An idiosyncratic synthesis. Landscape Ecology 17(4): 355-365. Retrieved from http://www. scopus.com/inward/record.url?eid=2-s2.0-0036033445\&partnerID=40\&md5=4194751f ad4ef5e8c6dfb2731fbcb89c.

Wunder S. 2001. Poverty alleviation and tropical forests-What scope for synergies? World Development 29(11): 1817-1833. https://doi.org/10.1016/S0305-750X(01)00070-5

Young OR. 2002. Institutional Interplay: The environmental consequences of cross-scale interactions. In: Ostrom E, Dietz T, Dolsak N, Stern PC, Stonich S and Weber EU, eds. The Drama of the Commons. Committee on the Human Dimensions of

Global Change, National Research Council. Washington: National Academy Press. 263-291. 

This, and the following chapter, are aimed at providing guidance for landscape approach proponents to make informed decisions about the evaluation approach and methods they will use. To do so, this chapter provides an overview of the main types of evaluation that are likely to be needed in a diversity of cases. Therefore, this guide is not meant to be prescriptive but rather to be used as a decision-making tool for practitioners. The following chapter then documents a selection of methods that broadly correspond to the evaluation approaches. Neither chapter is meant to equip landscape approach promoters with all the necessary knowledge to implement each method but rather to provide enough information about pros and cons and above all the domain of applicability of each approach or tool so that they are able to make decisions about which one to use. Implementing these approaches and tools can be then undertaken in collaboration with an evaluation expert.

\subsection{Main types of landscape approach evaluation: comparison and complementarity}

Before designing any data collection plan for monitoring and evaluation purposes, landscape approach managers and/or promoters need to make decisions regarding the evaluation question they target and subsequently the type of evaluation they want to use. In this section, we identify three suitable types of evaluation for landscape approaches and show that each of them emphasizes a particular evaluation question.

The first type of evaluation corresponds to performance monitoring tools, which consider the evolution of key variables and compares the level reached by each of them relative to a standard/target value. Thus, the evaluation question deals with the best indicators and corresponding targets to be defined in order to reflect the sustainability of a landscape/jurisdiction. Most of the available tools focus on quite long-term outcomes (e.g. IDH-the sustainable trade initiative's Verified Sourcing Areas $^{1}$ and European Forest Institute's Terpercaya initiative ${ }^{2}$ ) but some of them also deal with intermediary outcomes and conditions/determinants for sustainability (e.g. the landscapes rating tool developed by the Certification of Capability in Business Analysis $\left.^{\mathrm{TM}}-\mathrm{CBBA} \circledast\right)^{3}$. These tools provide relevant information to consumers, traders and investors willing to purchase or invest in sustainably produced commodities or to make green investments. This kind of information can also be used as criteria to target incentives, such as fiscal transfers, aimed at accelerating transitions towards sustainability. A clear advantage of this type of evaluation is that it is relatively straightforward in terms of design, once the spatial boundaries of the landscape have been defined. However, these tools are not helpful to answer questions such as how or why the value of these indicators change.

1 https:/www.idhsustainabletrade.com/landscapes/verified-sourcing-areas/.

2 http://www.euredd.efi.int/documents/15552/460846/The+Terpercaya+Initiative+Briefing+6_WEB.pdf/.

3 https:/www.iiba.org/certification/iiba-certifications/ccba/. 
The two other types of evaluation understand effectiveness as the extent to which a given intervention or a group of interventions achieve(s) its/their intended outcomes. These approaches place significant emphasis on causality between purposive actions and outcomes, and thus apply to situations where changes in outcomes are intentional, i.e. the result of interventions. These approaches are particularly useful for decisionmakers who are interested in improving current models of landscape approaches, and possibly replicate and scale them up (as is often the case with contemporary landscape approaches).

The second type of evaluation is usually called impact evaluation. It aims to assess the additional impact of landscape approaches or conservation policies targeting a landscape on generally rather long-term outcomes (e.g. deforestation, well-being, revenues, etc.). In other words, it is helpful to understand if the intervention did make a difference over the medium/long term. This type of approach generally relies on counterfactual methods, which compare the outcomes of a policy in intervention sites with outcomes in "control" sites with similar observable characteristics. Control sites are selected to provide credible information on what would have happened to intervention sites if they had not received the intervention (which is the counterfactual outcome). Impact evaluation has been applied to landscape-scale analysis, particularly focused on assessing deforestation, following different methodologies such as the matching and synthetic control method (Cisneros et al. 2015; Sills et al. 2015; see also Table 5.1). Such counterfactual approaches are considered to be statistically robust, although their capacity to provide evidence for the underlying mechanism and impact pathways is often presented as limited. Using heterogeneity analysis (differential impact according to initial conditions) or assessing the impact of the intervention on intermediary outcomes have proved particularly informative (Chervier et al. 2017; Cisneros et al. 2015; Hanauer and Canavire-Bacarreza, 2015). It is worth noting, however, that finding appropriate counterfactuals for such evaluation objects implemented at large (landscape) scale remains difficult, particularly because of the small pool of potential controls (Roopsind et al. 2019; Sayer et al. 2017).

The third type of evaluation puts emphasis on why an intervention works and in what context. An example of such evaluation of processes is the evaluation of underlying processes of jurisdictional REDD+ with the aim to identify challenges, pitfalls and in turn improve outcomes (Ravikumar et al. 2015; Rodriguez-Ward et al. 2018; Sanders et al. 2017). These studies provide evidence for the influence of various governance interventions on landscape approach outcomes. Evidence for causal mechanisms is based on the triangulation of various data sources, including in particular semistructured interviews with a large number of stakeholders and relevant secondary data. However, empirical knowledge about how landscape approaches work in practice and under what conditions remain scarce.

Figure 5.1 illustrates the differences between these three types of evaluation, but also demonstrates the potential for complementarity by combining them. It shows that each of them tends to focus more intensively on a specific aspect of the evaluation (in bold red lines). While monitoring tools would focus on the definition of indicators and monitoring their change, impact evaluation would focus more specifically on causality 

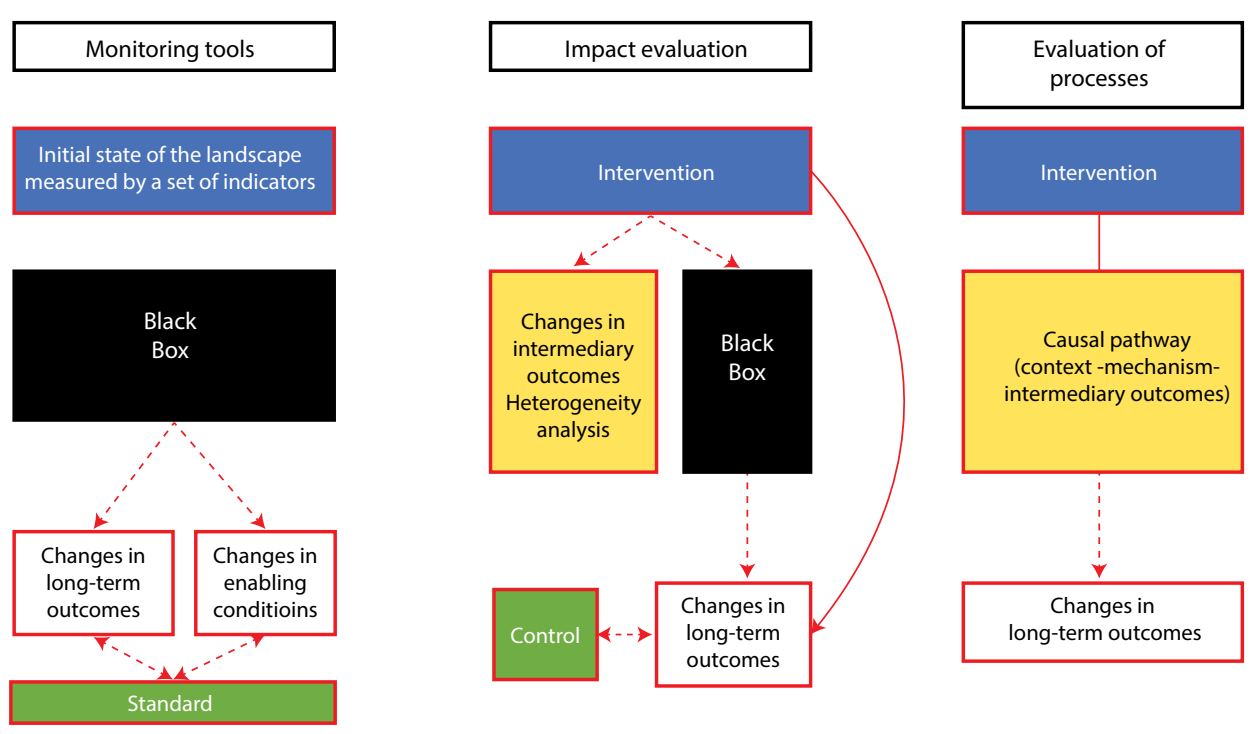

Figure 5.1 Comparison of the three types of evaluation.

between an intervention and long-term outcomes and evaluation of governance processes on disentangling causal pathways. The suggestion is thus to combine these types of evaluation in order to have a comprehensive and robust evaluation of landscape approaches.

\subsection{Building a theory of change for the evaluation of landscape approaches}

There is a wide consensus in the evaluation literature regarding the importance of using theories of change to evaluate interventions (Astbury and Leeuw 2010; Leeuw and Donaldson 2015), particularly for complex interventions (Rey et al. 2012). A theory of change in evaluation generally articulates causal linkages between interventions and their desired effects. The use of theories of change improves all three types of evaluation (Margoluis et al. 2013; Miteva et al. 2012). For example, the use of theories in impact evaluation would improve the definition of the counterfactual and would help generalize the results. In this section, we present four key steps that are necessary to build and then use a theory of change for evaluation purpose.

\subsubsection{Design a causal chain}

A theory of change describes the causal sequences of effects associated with the implementation of landscape approaches. Several studies and reports attempt to define generic causal chains for landscape or jurisdictional approaches based on extended empirical knowledge gained from studying and implementing them (Hovani et al. 2018; Sayer et al. 2017). In particular, The Nature Conservancy produced a generic Theory of Change for jurisdictional programs that clearly articulates intermediary outcomes 
showing "how improved cross-sector collaboration can translate into improved landscape performance" and define enabling and hindering conditions for a number of causal links (Hovani et al. 2018; Leeuw and Donaldson 2015).

There is a need to extend this work and we suggest that doing so would require combining two types of theories (Leeuw et al. 2015). Participatory methods are generally encouraged to build a causal chain because they enable implementing agents to tailor the design to the specificities of local conditions (Barret et al. 2018; Qiu et al. 2018). The resulting "bottom-up theories" allow capturing stakeholders' and practitioners' perception of how things are supposed to unfold as a result of the implementation of landscape approaches. Evaluation experts argue that it is useful to combine bottomup theories with knowledge from formal research and theorizing in order to draft meaningful theories of change. It allows putting into perspective the subjective insights provided by the professionals involved in these interventions and incorporating a broader knowledge base.

Figure 5.2 shows an example of a generic causal chain for a landscape approach that is based on a review of the empirical and grey literature on environmental governance theories and landscape and jurisdictional approaches.

\subsubsection{Identify the evaluation object, the intervention}

A theory of change should clearly identify the intervention(s) that are supposed to bring about change. In the context of landscape approaches, the intervention dimension is broadly defined as: a range of multi-stakeholder interventions, initiatives, programs applied at sub-national/landscape levels in order to achieve lasting, landscape-wide improvements to natural resource management by catalyzing collaborative action of a group of stakeholders working with local government to institutionalize improved landuse governance and practice (Hovani et al. 2018; Paoli et al. 2016). Landscape approach interventions typically focus on strengthening local capacity and governance by building actor networks, improving accountability, investing in knowledge development, etc. (see Chapter 1).

We suggest that, in any landscape engaged in a landscape approach, such coherent systems of interventions can be identified. To be coherent, these actions and changes must have been designed in relation to one another, i.e. as contributions to the achievement of a common goal or a set of interrelated sustainability goals. This implies that these goals have been formally conceptualized and can thus be identified.

Identifying the intervention dimension of landscape approaches is particularly challenging as landscape and actor complexity (i.e. multiple and often conflicting actors and actions across systems, sectors and scales) make it difficult to define intervention capacities, limits and dimensions. Indeed, landscape approaches may encompass multiple interventions that spread across multiple sectors and institutional scales. Furthermore, they span over long-time periods and are characterized by the emergence of new goals and interventions during the implementation phase (Sayer et al. 2017). A causal chain, even if built retrospectively, is a good way to describe such a system of interventions and justify the coherence between its components (Craig et al. 2008). 


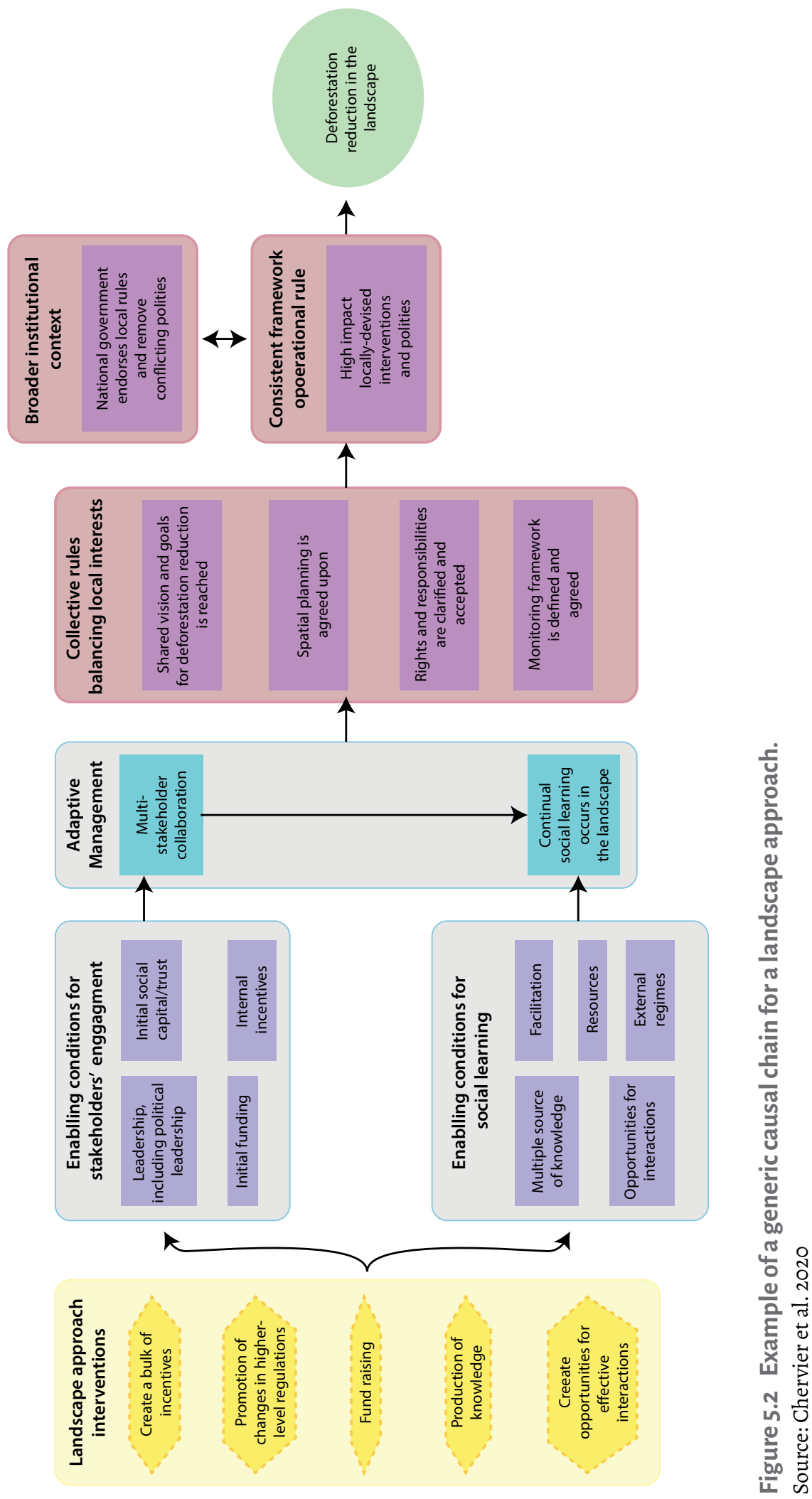




\subsubsection{Scope the amount of data needed}

Data collection requirements can make evaluation relatively expensive, especially in contexts where reliable data is not readily available. It is thus necessary to find compromises between what is desirable in terms of development of knowledge and information, what existing data is already available and accessible, and what additional data collection is feasible provided the limited resources generally allocated to evaluation.

Program theories are generally composed of a significant number of links and boxes and would thus require a gigantic amount of data to be informed exhaustively. Landscape approach leaders or promoters will generally need to prioritize what indicators and what causal links are the most important to be informed. Doing so will narrow down the evaluation (causal links to be informed) and so the monitoring (variables to be monitored) needs. However, careful consideration needs to be given to the selection process such that the indicators selected can adequately capture the full range (or as close to the full range) of potential intervention impacts (Agol et al. 2014).

Besides, the type of causal inference method chosen (see Section 3.4) might necessitate collecting data outside the target landscape. This would be the case if landscape approach promoters want to use counterfactual methods to demonstrate the impact of landscape approaches. Such collection of data in 'control' sites can be viewed as a waste of resources. However, with-without comparison remains the least biased way to measure impact. Adjusting the design of outcome variables and covariates so that they can easily be extracted from available data sources such as remote sensing and census data can help pull the costs down.

\subsubsection{Choose the appropriate method(s) for causal inference}

Theories of change help making hypotheses about causal linkages associated with the effects of landscape approaches. In turn, landscape approach managers and promoters might be interested in providing evidence for these causal links. They would then face decisions regarding which method to use.

Quasi-experimental design is often viewed as the best possible option for providing evidence for causal links, when experimental design is not possible, which will typically be the case for landscape approaches. There are plenty of quasi-experimental methods available, including matching, difference in differences, instrumental variable, discontinuity analysis, and the synthetic control method (EC Evalset Sourcebook ${ }^{4}$; Sills et al. 2015; see Table 5.1 for a selection). Selecting the most appropriate method will depend on the evaluation setting and more specifically on the availability of appropriate data and the number of treated units (landscapes where the landscape approach is implemented) and control units (landscapes not engaged in a landscape approach). Table 5.1 summarizes three counterfactual methods that are mostly used to evaluate landscape or jurisdictional approaches.

4 https://ec.europa.eu/regional_policy/sources/docgener/evaluation/guide/evaluation_sourcebook.doc 
Table 5.1 The most used counterfactual methods.

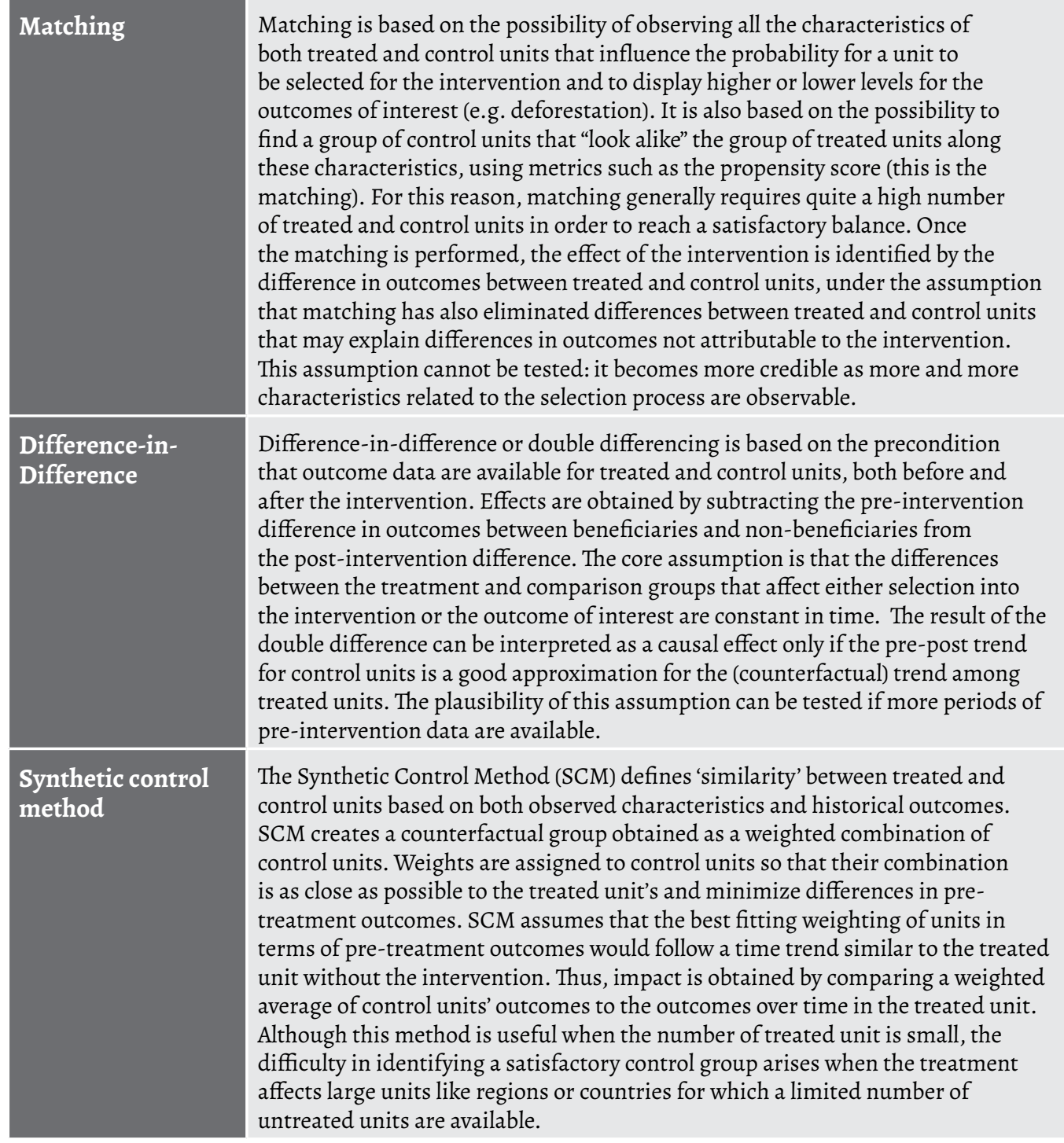

Source: Drawing from the EC Evalset Sourcebook and Sills et al. 2015

It can also happen that quantitative methods are not applicable (the local context does not create the right empirical setting, poor availability of data and high cost of new data collection). In this case, qualitative methods for causal inference such as process tracing can be used.

"Process tracing involves the examination of "diagnostic" pieces of evidence within a case that contribute to supporting or overturning alternative explanatory hypotheses. A central concern is with sequences and mechanisms in the unfolding of hypothesized causal processes. The researcher looks for the observable implications of hypothesized explanations, often examining at a finer level of detail or a lower level of analysis than that initially posited in the relevant theory. The goal is to establish whether the events or processes within the case fit those predicted by alternative explanations."

(Bennett 2010, p. 208) 


\section{Conclusion}

In this chapter, we highlighted the importance of combining various types of evaluation of landscape approaches. Practitioners should not only consider monitoring tools, but also assess the effectiveness and pathways to effectiveness of landscape approaches, using process analysis or impact evaluation. This will allow practitioners and policymakers to draw important lessons for the replication of landscape approaches in other contexts.

We believe that the use of theories of change would improve the quality and credibility of all types landscape approach evaluation. In order to allow for generalization, replication or adaptation of early landscape approach experience, such theories of change should integrate local knowledge and perspectives with scientific knowledge and theories. Theories of change are also a useful tool to identify the intervention dimension of landscape approaches and to make decisions about the methods and data to be used (see next chapter).

\section{References}

Agol D Latawiec AE and Strassburg BB. 2014. Evaluating impacts of development and conservation projects using sustainability indicators: Opportunities and challenges. Environmental Impact Assessment Review 48, 1-9.

Astbury B and Leeuw FL. 2010. Unpacking black boxes: Mechanisms and theory building in evaluation. American Journal of Evaluation 31, 363-381. https://doi. org/10.1177/1098214010371972

Barret D, Blundo Canto G, Dabat M-H, Devaux-Spatarakis A, Faure G, Hainzelin E, Mathé S, Temple L, Toillier A and Triomphe B. 2018. ImpresS methodological guide. Methodological guide to ex post evaluation of agricultural research in developing countries. CIRAD.

Bennett A. 2010. Process tracing and causal inference. In Brady HE and Collier D, eds. Rethinking Social Inquiry: Diverse Tools, Shared Standards. Lanham MD: Rowman \& Littlefield Publishers.

Boyd W, Stickler C, Duchelle AE, Seymour F, Nepstad D, Bahar NHA and RodriguezWard D. 2018. Jurisdictional approaches to REDD+ and low emissions development: Progress and prospects. Working Paper. Washington DC: World Resources Institute.

Chervier C, Le Velly G and Ezzine-de-Blas D, 2017. When the implementation of payments for biodiversity conservation leads to motivation crowding-out: A case study from the cardamoms forests, Cambodia. Ecological Economics 156: 499-510.

Chervier C, Picketty M-G and Reed J. 2020. A tentative theory of change to assess the effectiveness of jurisdictional approaches to reduced deforestation. Frontiers in Forests and Global Change. https://doi.org/10.3389/ffgc.2020.498151.

Cisneros E, Zhou SL and Börner J. 2015. Naming and shaming for conservation: Evidence from the Brazilian Amazon. PLOS ONE 10, e0136402. https://doi.org/10.1371/journal. pone. 0136402 . 
Craig P, Dieppe P, Macintyre S, Michie S, Nazareth I and Petticrew M. 2008. Developing and evaluating complex interventions: The new Medical Research Council guidance. BMJ 337, a1655.

DeFries R and Rosenzweig C. 2010. Toward a whole-landscape approach for sustainable land use in the tropics. Proceedings of the National Academy of Sciences 107, 19627-19632. https://doi.org/10.1073/pnas.1011163107.

Estrada-Carmona N, Hart AK, DeClerck FA, Harvey CA and Milder JC. 2014. Integrated landscape management for agriculture, rural livelihoods, and ecosystem conservation: An assessment of experience from Latin America and the Caribbean. Landscape and Urban Planning 129, 1-11.

García-Martín M, Bieling C, Hart A and Plieninger T. 2016. Integrated landscape initiatives in Europe: Multi-sector collaboration in multi-functional landscapes. Land Use Policy 58, 43-53.

Hanauer MM, Canavire-Bacarreza G. 2015. Implications of heterogeneous impacts of protected areas on deforestation and poverty. Philosophical Transactions of the Royal Society B: Biological Sciences 370(1681), 20140272. https://doi.org/10.1098/rstb.2014.0272

Hovani L, Cortez R, Hartanto H, Thompson I, Fishbein G, Madeira EM and Adams J. 2018. The Role of Jurisdictional Programs in Catalyzing Sustainability Transitions in Tropical Forest Landscapes. Arlington VA: The Nature Conservancy.

Leeuw FL and Donaldson SI. 2015. Theory in evaluation: Reducing confusion and encouraging debate. Evaluation 21: 467-480. https://doi.org/10.1177/1356389015607712.

Margoluis R, Stem C, Swaminathan V, Brown M, Johnson A, Placci G, Salafsky N and Tilders I. 2013. Results chains: A tool for conservation action design, management, and evaluation. Ecology and Society 18 (3). https://doi.org/10.5751/ES-05610-180322

Milder JC, Hart AK, Dobie P, Minai J and Zaleski C. 2014. Integrated landscape initiatives for African agriculture, development, and conservation: A region-wide assessment. World Development 54, 68-80.

Miteva DA, Pattanayak SK and Ferraro J. 2012. Evaluation of biodiversity policy instruments: what works and what doesn't? Oxford Review of Economic Policy 28: 69-92. https://doi.org/10.1093/oxrep/grsoo9.

Noss RF. 1983. A regional landscape approach to maintain diversity. BioScience 33: $700-706$.

Paoli GD, Palmer B, Schweithelm J, Limberg G and Green L. 2016. Jurisdictional Approaches to Reducing Palm Oil Driven Deforestation in Indonesia. Scoping Study of Design Considerations and Geographic Priorities. Bogor, Indonesia: Daemeter.

Qiu J, Game ET, Tallis H, Olander LP, Glew L, Kagan JS, Kalies EL, Michanowicz D, Phelan J, Polasky S, Reed J, Sills EO, Urban D and Weaver SK. 2018. Evidence-based causal chains for linking health, development, and conservation actions. BioScience 68: 182-193. https://doi.org/10.1093/biosci/bix167.

Ravikumar A, Larson A, Duchelle A, Myers R and Tovar JG. 2015. Multilevel governance challenges in transitioning towards a national approach for REDD+: Evidence from 23 subnational REDD+ initiatives. International Journal of the Commons 9(2). 
Reed J, van Vianen J, Barlow J and Sunderland T. 2017. Have integrated landscape approaches reconciled societal and environmental issues in the tropics? Land Use Policy 63: 481-492. https://doi.org/10.1016/j.landusepol.2017.02.021.

Reed J, Van Vianen J, Deakin EL, Barlow J and Sunderland T. 2016. Integrated landscape approaches to managing social and environmental issues in the tropics: learning from the past to guide the future. Global Change Biology 22: 2540-2554. https://doi. org/10.1111/gcb.13284.

Rey L, Brousselle A and Dedobbeleer N. 2012. Logic analysis: Testing program theory to better evaluate complex interventions. Canadian Journal of Program Evaluation 26(3): 61-89.

Rodriguez-Ward D, Larson AM and Ruesta HG. 2018. Top-down, bottom-up and sideways: The multilayered complexities of multi-level actors shaping forest governance and REDD+ arrangements in Madre de Dios, Peru. Environmental Management. 62(1): 98-116. https://doi.org/10.1007/s00267-017-0982-5.

Roopsind A, Sohngen B and Brandt J. 2019. Evidence that a national REDD+ program reduces tree cover loss and carbon emissions in a high forest cover, low deforestation country. Proceedings of the National Academy of Sciences 116: 24492-24499. https://doi. org/10.1073/pnas.1904027116

Sanders AJP, Hyldmo HDS, Prasti H RD, Ford RM, Larson AM and Keenan RJ. 2017. Guinea pig or pioneer: Translating global environmental objectives through to local actions in Central Kalimantan, Indonesia's REDD+ pilot province. Global Environmental Change 42: 68-81. https://doi.org/10.1016/j.gloenvcha.2016.12.003.

Sayer JA, Margules C, Boedhihartono AK, Sunderland T, Langston JD, Reed J, Riggs R, Buck LE, Campbell BM, Kusters K, et al. 2017. Measuring the effectiveness of landscape approaches to conservation and development. Sustainability Science 12: 465-476. https://doi.org/10.1007/s11625-016-0415-z.

Sills EO, Herrera D, Kirkpatrick AJ, Brandão A, Dickson R, Hall S, Pattanayak S, Shoch D, Vedoveto M, Young L and Pfaff A. 2015. Estimating the impacts of local policy innovation: The synthetic control method applied to tropical deforestation. PLoS ONE 10, e0132590. https://doi.org/10.1371/journal.pone.0132590.

Zanzanaini C, Trần BT, Singh C, Har, A, Milder J and DeClerck F. 2017. Integrated landscape initiatives for agriculture, livelihoods and ecosystem conservation: An assessment of experiences from South and Southeast Asia. Landscape and Urban Planning 165: 11-21. https://doi.org/10.1016/j.landurbplan.2017.03.010. 

This toolbox has been developed as an attempt to provide guidance to implementers of integrated landscape approaches (ILAs) who seek to utilize previously published principles for landscape approaches (Sayer et al. 2013) (see Chapter 1). However, it is important to first note some caveats to its potential application. First, we strongly recommend that users of this toolbox first read and consider the preceding chapter in this volume that encourages the consideration and selection of an evaluation approach prior to designing research methods. Designing a clear theory of change and prioritizing the causal links can help relevant stakeholders to make decisions about the extent to which they should adjust the implementation and management of an ILA - and should help to inform the selection of research methods.

Second, questions and hypotheses related to land-use management are specific to each landscape - context is key - and therefore, the methods described here are in no way intended to be either prescriptive or exhaustive. We acknowledge that there are many other methods to select from that may be more or less appropriate than those described below (likewise, those described below may not be relevant in every context), and that the specific landscape context (and evaluation approach) will help to inform the selection of methods. Therefore, we selected the tools that we feel could apply in a broad range of contexts because they inform and are closely related to the theory of ILAs and ILA principles (Sayer et al. 2013, Reed et al. 2016). Finally, this toolbox was developed in the context of the IKI-funded Center for International Forestry Research (CIFOR) initiative 'Collaborating to operationalize landscape approaches for nature, development and sustainability' (COLANDS) and therefore, the methods are designed to guide implementation activities in a context-specific way, while also seeking to facilitate consistency in application across sites and subsequent cross-site comparison and analysis.

The methods described are based on an important underlying assumption that landscape approaches are primarily concerned with improving the governance and sustainable and equitable use of land and natural resources within a target landscape. As such, there is an emphasis on methods that will help to both enhance stakeholder engagement and capacity and also contribute to monitoring and evaluation protocols that can, in turn, influence the processes of adaptive management. We specifically hope that these methods will help build an understanding of the institutional, socio-economic and biophysical characteristics of each landscape. The suggested methods can be applied to generate a historical characterization of the landscape, current challenges associated with land use and natural resource management, and potential future landscape trajectories of change - as perceived by those that influence, are affected by, or have an interest in land-use decision-making. A further assumption is that operationalization of landscape approaches will benefit from the acknowledgement and use of previously formulated landscape approach principles proposed by Sayer et al. (2013).

Therefore, we draw from these 10 principles to suggest the specific principles that are fundamental to the various stages of implementing a landscape approach. We then describe how and why certain methods might be useful for developing a more holistic understanding of the landscape system that encompasses the institutional, biophysical and socio-economic context. Finally, we propose a toolbox of methods that can be 


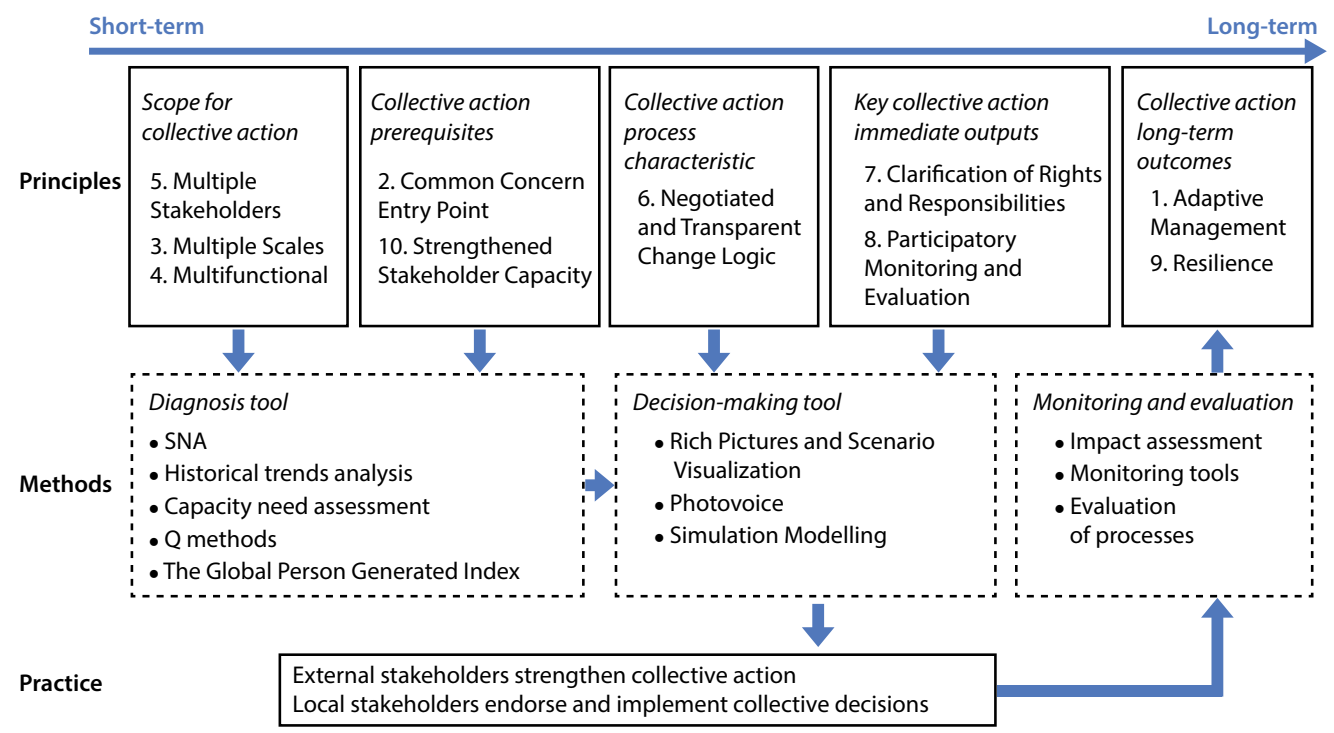

Figure 6.1 An overview of the methods described in this chapter, their general purpose and the landscape approach principles and actions to which they apply. Methods are broadly arranged chronologically but in practice may be iteratively applied as required.

applied in the implementation of landscape approaches. While some of the methods will hold relevance for the biophysical dimension, this is not a primary focus of this chapter as these are described elsewhere in this volume (see Chapter 3). It is anticipated that applying the methods described here can then inform subsequent stages of process, how this feeds back to the theory of the conceptualization of landscape approaches and inform future policy development (see Fig 6.1).

\subsection{Ten principles for landscape approaches}

While all of the 10 landscape approach principles (Sayer et al. 2013) hold practical (and technical) value for implementing agents, we suggest that certain principles will require greater focus, dependent on the phase of implementation. Furthermore, contextual application of the principles has shown that some principles are critical for process guidance, while others relate to outcomes (Omoding et al. 2020). For example, identifying a common concern amongst stakeholders (principle 2) will be fundamental to achieving long-term engagement in the process and therefore is necessarily an early stage activity. Meanwhile, principles of adaptive management (principle 1) are reliant on responding to a certain level of application and monitoring (principle 8) and therefore, become a more prominent concern at a later stage of the implementation process. Below, we identify the principles we consider to be of more immediate concern and that will provide the structure for the identification of the methods toolbox described later in the chapter. 
Nevertheless, as articulated (Sayer et al. 2013), the 10 principles are not deemed to be a prescriptive approach to landscape management. Rather, they are considered a loose guiding framework to be most valuable when considerately applied to a given context such that users are "able to draw on the principles in ways that meet the particular needs of the problems they are confronting" (Sayer et al. 2013, p.8355). We therefore recommend introducing the 10 principles to stakeholders within the particular landscape of interest and encouraging a deliberative process of negotiation to select, amend and refine the guiding framework to best meet the contextual needs. However, prior to this, implementing agencies should conduct scoping and baseline studies to identify key partners and establish a characterization of the landscape and the associated challenges therein. Where possible, we recommend that such activities should aim to make use of existing, affordable and reusable data sources rather than investing heavily in primary data collection at the outset. Furthermore, implementing agencies should be cognizant of the data preferences of local institutions and national government ministries and where appropriate aim to use consistent or complementary sources. We suggest the activities to characterize the landscape fall broadly within the categories outlined below.

\subsection{Institutional context}

Environmental governance and local socio-economic development in the global South often ensue in the context of an increasingly complex political economy. Forces of economic globalization and global environmental change have increased the level of interaction and interdependency of actions between previously distinct, and often conflicting, land-use sectors and actors (Brondizio et al. 2009). Landscapes are complex, diverse and dynamic, and therefore the extent to which such interaction exists will vary. However, within all landscapes there will be a degree of multi-level interaction of institutions representing public, private and civil sectors. Landscape approaches should attempt to understand and convey the linkages and interplay between institutions operating across the vertical, horizontal, and diagonal spectrum. Furthermore, landscape approaches should then seek to go beyond the depiction of interacting institutions and attempt to draw actors together so that governance challenges and responses can be discussed, translated, negotiated, and reformulated to influence more positive social-ecological outcomes (Cash et al. 2006; Mansourian et al. 2020).

Institutional challenges manifest across decision-making levels of influence and spatial and temporal scales of outcome. For example, national policy design may be maladapted to local policy development or realities, while mismatches often occur between human action and biophysical processes (Cash et al. 2006). Generating a thorough understanding of the institutional context will therefore aid the process of implementation at the landscape scale. Such an improved understanding can be achieved via a number of processes. Firstly, identifying and establishing political partners at multiple levels that are committed to engaging in landscape approaches will increase the likelihood of achieving the political will necessary to influence policies 
conducive to sustainable, equitable landscape prosperity. Secondly, identifying bridging organizations that can close the vertical and horizontal institutional gaps that hinder better coordinated governance and integrated landscape planning efforts. Finally, conducting desk-based policy analysis (see Chapter 7), and field-based policy and network analysis (see below) can generate an understanding of the existing governance structures and social networks that shape policy and decision-making. These activities may also help explain the uptake (or lack thereof) and influence of policies in practice (full description in toolbox below).

\subsection{Socio-economic context}

Landscapes are complex, dynamic social-ecological systems. Consequently, multiple socio-economic factors (i.e. demographics, employment, health, culture, etc.) influence landscape form and function. Recognizing these factors and the local political economy are therefore crucial for understanding the priorities of people within a landscape, and the impacts of natural resource management and decision-making on human well-being and landscape dynamics.

There are many pre-existing socio-economic data sources available that can be used as a basis for understanding a landscape's socio-economic context. For example, the Living Standards Measurement Survey (LSMS) is a household survey program that partners with national statistical offices to design and implement multi-topic household surveys (http://surveys.worldbank.org/lsms). Other sources include census data and the Demographic and Health Surveys (DHS) (https://dhsprogram.com/) program, both providing country-wide and region-specific data. Another useful resource is Gapminder Data, which provides free access to the datasets used by the data visualization tool, Gapminder World (https://www.gapminder.org/data/). The site has a wide range of datasets available for topics such as health, education, land use, population, economy, as well as related sub-indicators.

Utilizing existing data sources, such as the aforementioned examples, can enhance the feasibility and replicability of data collection and evaluation within a landscape. Further, available data collected on a recurring basis is useful for identifying socio-economic indicators that can be monitored over time. That being said, objective indicators must be paired with subjective methods of data collection from the outset of the process of implementing landscape approaches. Social considerations, particularly in natural resource management, are often characterized by objective, externally defined, and easily quantifiable indicators. Though these indicators are useful, they fail to capture the complex and multidimensional nature of well-being that can vary from site to site and from one stakeholder group to another (Milner-Gulland et al. 2014; Satterfield et al. 2013; Sterling et al. 2017). Moreover, they ignore subjective well-being indicators that determine how people perceive their quality of life (McGregor and Pouw, 2017).

A context-specific understanding of what people perceive to be important to wellbeing and what they prioritize in their landscape is critical information for the early 
stages of operationalizing landscape approaches. Yet, it is important to recognize that perceptions among different stakeholders on priorities might differ and should therefore be continuously revisited as needs and priorities may shift over time. Evidence suggests perceptions, particularly of good governance and social impacts, are strong predictors of local support for natural resource management initiatives (Bennett 2016; Bennett et al. 2019). This underscores the importance of using a suite of methods to produce a more holistic understanding of the socio-economic context. In this document we introduce several interdisciplinary methods for this purpose.

\subsection{Biophysical context}

Integrated landscape approaches are particularly concerned with developing equitable, just and sustainable solutions for land and natural resource management. It is therefore imperative for implementing agencies to generate an understanding of the landscape components and configurations, how stakeholders perceive these, and what their expectations are for future landscape change, as well as to develop a system whereby such changes can be monitored and assessed.

Biodiversity, i.e. the variety of life across genes, species and functional traits, plays an integral role in human well-being by providing food, medicine, non-timber forest products (NTFPs), food security and nutrition, and overall livelihood strategies (Broegaard et al. 2017). Therefore, biodiversity is a key component of integrated landscape approaches and should be incorporated at the design stage rather than considering it as a response alone. Landscape management strategies also need to consider the simultaneous interactions between multiple trophic levels and ecosystem services and potential trade-offs between biodiversity, ecosystem services and livelihoods at both local and landscape scales (Macfadyen et al. 2012).

Biodiversity monitoring is crucial in understanding biodiversity responses to drivers of change, their effects on ecosystem services and assessing the progress of such integrated landscape approaches (see Chapter 3). Setting a frame of reference to track progress and choosing suitable indicators reflecting key aspects of biodiversity response will facilitate objective evaluation of the performance of landscape approaches.

Moreover, remote sensing, scenario modeling techniques and community-based monitoring programs can contribute to large-scale data collection, interpretation, and informed decision-making. Strengthening stakeholder capacity and facilitating their active involvement in every stage - from planning to implementation - can contribute significantly in biodiversity assessments (Zanzanaini et al. 2017). Understanding how different stakeholders benefit from ecosystem services and their preferences for valuing services is also crucial in evaluating trade-offs and their implications for livelihoods and well-being (Bennett et al. 2015). This will facilitate a better understanding of stakeholders' multifaceted perceptions toward ecosystem services and will lead to effectively incorporating those in land management strategies (Ahamadd et al. 2019; Martín-López et al. 2012). 


\subsection{Methods toolbox}

The methods described below are neither prescriptive, nor exhaustive, but are intended to provide an overview of established methods that can support the implementation phase of ILAs. That is, they are mostly concerned with bringing together diverse stakeholders to help enhance the collective understanding of past, present and future social-ecological dynamics and land-use change. Where appropriate we link the methods with associated principles for landscape approaches as described by Sayer et al. (2013) and reminded above. Selection of methods should be informed by the evaluation approach applied (see Chapter 5 ). We do not detail biodiversity associated methods as they are described elsewhere in this volume (see Chapter 3 ).

\subsection{Diagnostic tools}

\subsubsection{Stakeholder analysis}

Landscape approaches are premised on processes of negotiation and decisionmaking that aim for equitable and sustainable land and natural resource management (van Oosten et al. 2014). Identifying stakeholders, learning about their rights and responsibilities, their interests and influence is thereby a first step in landscape approaches. A stakeholder is defined as an individual, group, institution or aggregation, or levels in society with an interest in a particular resource/process/service/intervention and affecting or being affected by those (Freeman et al. 2010). Stakeholders are typically those who are interested in or affected by policies, decisions, and actions of the system (Burger 2011). The term thus includes policy makers, planners and administrators in government and other organizations, people with ties to the land, and commercial and subsistence user groups (Grimble et al. 1995). For example, in watershed management, stakeholders may be viewed in a continuum, ranging from upstream to downstream, from local to national or even the international funding agencies at the global institutional level (Pulhin 2014).

Recognizing the wide range of the continuum and stakeholder classification, it is important to apply a classification that fits the local multi-level governance of decisionmaking, involving de facto and de jure rights and power, and informal and formal institutions. There are numerous stakeholder classifications as described by Stanghellini (2010). In the COLANDS Indonesia case (Chapter 10) for example, we applied the classification by Kusumanto et al. (2005) as a first step to identify relevant stakeholders: on-site, off-site, and supra-site stakeholders. This classification was modified from primary-secondary stakeholders (ODA, 1995), combined with proximity attribute (Colfer et al. 1999; Driscoll and Starik 2004). Having this classification in mind prior to data collection also helps to formulate appropriate interview questions and better understand the stories shared by respondents, for example related to power structure, rights, and responsibilities.

- On-site stakeholders are those who live in the concerned area, use or manage the land according to local or customary rules, often do not have legal rights or authority 
to make decisions, but are directly affected by any decisions on the area made by others. Stakeholders within this group will vary by landscape but might include: indigenous people (with different sub-groups e.g. customary leaders, administrative leaders, elites, marginalized), and in some cases could also include transmigrants, and plantation workers.

- Off-site stakeholders are those who do not live in the concerned area, but possess legal rights or authority to make decisions over the area. Various sectors of government at multiple levels represent this group.

- Supra-site stakeholders are those who live further from the concerned area, whose livelihoods are not affected by any decisions, do not have legal rights or authority on the area but have concerns/interests and have the potential to influence decisions and often function as mediators between the on-site and off-site stakeholders. Belonging to this group are typically donors, research institutions, NGOs, and the private sector.

Identifying stakeholders might not be sufficient to understand the dynamics. A second step in stakeholder analysis might be to understand the relationships between stakeholders. One method is the network analysis explained below. Another, more participatory approach, is asking stakeholders to indicate the importance of, and relation to, other stakeholders and drawing, for instance, a Venn diagram. This approach and subsequent analysis is useful to understand the reasons behind perceptions of stakeholder relations. Another method to understand relations is to ask stakeholders how close their relationship is to other stakeholders where 'close' needs to be defined together. Using a simple 1-5 score the results can be drawn in a spider diagram (for more details see Moeliono et al. 2020).

\subsubsection{Network analysis}

Landscape approaches aim to improve communication and reconcile conservation and development needs between multiple stakeholders and actors (principle 5) and across multiple scales (principle 3). Conducting a network analysis in the early stages of operationalizing landscape approaches can be an important tool for understanding the current social network in the landscape and the associated power dynamics and relationships. This insight would provide important baseline information including who has the most influence in the landscape and the diversity of knowledge being shared by, and with, whom. Conducting a network analysis at different periods throughout the process will be a powerful tool for visualizing how the network changes over time. However, it also comes with challenges, as we will address below.

\section{Social network analysis}

Across disciplines, it is common to categorize actors within a study or project (Prell et al. 2009). However, categorization does little to inform us on how these actors interact with one another and the impacts of these relationships. Social network analysis (SNA) is a method used to quantitatively and qualitatively analyze the social connections between individuals, subgroups, and larger social systems (Kowalski and Jenkins 2015; Scott 
and Carrington 2011). SNA is based on graph theory, in which actors are represented by the points on a graph, and their social relations are represented by the lines (Scott and Carrington 2011). To generate this information, a network of actors must be identified. Possible methods to identify actors include stakeholder analysis (see above) and key informant interviews. This is followed by the creation of a tool (questionnaire, survey, semi-structured interview script) to survey individuals in the network and identify what kind of relationships and knowledge flows between them. Once this data is collected it is entered into a software mapping tool to illustrate the network. There are a number of software options available, many of which can be found at the Knowledge Sharing Toolkit website (KSTOOLKIT 2018).

The relationships can then be analyzed for structural patterns that illustrate the functionality of the larger network. For example, actors sharing a strong tie are more likely to trust one another, share similar views, and influence each another (Prell et al. 2009). Conversely, a weak tie is characterized by less frequent communication, typically between two dissimilar actors, and acts as a pathway for the flow of new information. This is beneficial for sharing diverse knowledge and perspectives, however actors sharing weak ties are less likely to trust one another and the relationship is more fragile (Prell et al. 2009). Other network patterns include centralization, where one or few individuals hold the majority of ties with others in the network, and homophily, a network where similar actors are drawn to each other (Prell et al. 2009), for example related to rights to land.

There is an emerging body of work applying SNA to natural resource management studies (Kowalski and Jenkins 2015; Moeliono et al. 2014; Prell et al. 2009; Riggs et al. 2018). Power arrangements influence local conservation and development outcomes, and in order to achieve conservation objectives and effectively engage with this structure, the distribution of power must first be understood (Langston et al. 2019). This is particularly relevant for evaluating the overall process.

\section{Policy network analysis}

Similar to a SNA, Policy Network Analysis (PNA) is a tool for analyzing the structure of governance and to understand the role of these structures in policy processes and outcomes. A PNA is designed to analyze the relationships between a network of actors, specifically actors defined as involved in a specific policy domain, ranging from legislative parties, government ministries, business associations, labor unions, professional societies, and public interest groups (Rhodes 2006). Exploring the exchange and pooling of resources within a policy network can reveal how a network limits or enables participation in policy making and implementation.

\section{Network analysis challenges}

The focus of a network analysis is the relationship between actors in a specific network. Thus, one challenge before undertaking the actual survey is identifying the network to be studied and to define the boundaries. This is a particularly complex problem as everybody in the landscape, and often beyond, is an actor having some influence 
on outcomes, either directly or indirectly. Defining the boundaries is therefore an important first step, either as perceived by actors themselves or based on our theoretical understanding of the landscape (Wasserman and Faust 1994). In policy network analysis, boundaries are typically set by a policy. Thus, members of the network are all actors who are directly or indirectly involved in the particular policy, for example the development planning process.

Capturing the complexities of a network is both the purpose and the challenge of this method. It is common for network analyses to show the interactive processes between actors but fail to elaborate on power relations and functional relations (Ndeinoma et al. 2018). Another important consideration while conducting a network analysis is defining 'actors' as individual stakeholders or as a member of an organizational stakeholder (government, private sector, etc). It is also important to recognize that actors may be marginalized, such as indigenous communities. In some cases, certain actors may selfexclude themselves not wanting visibility in a network due to the possible illegal nature of their engagement, the current political climate, or due to a specific interest whereby it is more advantageous for the actor to influence policy from a hidden position. Identifying these 'ghosts' in the landscape is a particular challenge. Furthermore, actors may be intermittently present in the landscape, varying seasonally, or only be in the network a few times a year, yet have a large impact. Relatedly, it is optimal for the person conducting the analysis to be a respected and trusted person in the landscape. It is critical the interviewee trusts the interviewer and has little to lose by answering honestly. Trust and familiarity may also help when scheduling interviews with people in high ranking positions (i.e. traditional leaders, members of government, industry representatives, etc.).

Finally, sharing the results of the analysis can provoke conflict among local actors if they perceive the structure of the network differently to the results of the exercise, or if the results indicate controversial positionality. This can be a benefit and a challenge depending on the mediation and facilitation of the process. Benefits of the process of constructing the actor network are a shared understanding of who actually influences landscape conservation and development processes.

\subsubsection{The Global Person Generated Index (GPGI)}

The Global Person Generated Index (GPGI) is one example of a tool that enables people to articulate their own definition of well-being, or what they need to live 'a good life'. This tool is relevant to landscape approaches as it is able to capture the priorities and perspectives of multiple stakeholders (principle 5). Responses can be used to identify common concerns (principle 2) and diverging perspectives within and across stakeholder groups as well as informing medium-long term activities such as establishing a negotiated and transparent change logic (principle 6).

The GPGI originates from the Patient Generated Index, which was designed to assess health-related quality of life (Camfield and Ruta 2007). GPGI builds on this by collecting information on subjective well-being, which allows participants to share their own assessment of their life circumstance. The GPGI consists of three stages (Rasolofoson et al. 2018). In the first stage, the participant(s) are asked to identify five domains 
that are most important to their lives (e.g. family, employment, health, etc.). In stage two, the participants rate their satisfaction with each domain from o (very bad) to 4 (very good). In stage three, participants score each domain according to its relative importance in their life. This information is valuable for capacity needs assessment purposes (see below) and developing a baseline for tracking social changes over time. To elicit responses specific to perceptions of the impact of an intervention on well-being, a fourth stage can be added, where participants again score the impact of the intervention (Rasolofoson et al. 2018). The GPGI process can be repeated to monitor change in perceptions and priorities over time.

The GPGI can be utilized on its own, or combined with other methods, such as an interview or household survey. However, due to the subjective nature of the GPGI, it is difficult to test the validity of the results. The GPGI is best used in conjunction with other methods to provide a more holistic approach to evaluating social impacts.

\subsubsection{Capacity needs assessment}

A frequently cited reason for the failure of community-based conservation projects is a lack of local capacity to achieve project objectives and implement good governance (Smith and Walpole 2005; Linkie et al. 2007). Furthermore, the literature on attempts to integrate conservation and development objectives frequently refers to the need to promote a more equitable representation of stakeholders and ensure that those previously underrepresented have the capacity to meaningfully engage in decisionmaking (German et al. 2007). Therefore, capacity development should be a fundamental component of any strategy focusing on the scale of an entire landscape (principle 10).

Capacity is the overall ability of the individual or group to perform their responsibilities (Stephen and Triraganon, 2009). It depends not only on the capabilities of the people, but also on the overall size of the task, the resources which are needed to perform them, and the framework within which they are discharged. Meanwhile, capability is the knowledge, skills and attitudes of the individuals, separately or as a group, and their competence to undertake the responsibilities assigned to them (Stephen and Triraganon, 2009).

There are numerous examples of existing capacity development strategies and so rather than add to these, we provide here a brief overview of the key steps and considerations. Various international organizations have developed tools for capacity building needs assessment (e.g. Kay et al. 2004; UNDP, 2008; Stephen and Triraganon, 2009). These tools share similar principles that capacity development is "not a one-off intervention but an iterative process of design-application-learning-adjustment" (UNDP, 2008). Capacity is not something that can be built through blueprint activities with specific timeframes and strict budgets and the capacity needs will often emerge during the course of a project rather than at the beginning, which relates to continuous and adaptive learning (principle 1 ). Capacity development, therefore, is an organic process which involves experimentation and learning as it proceeds. The Food and Agriculture Organization (FAO) uses the term "capacity development" to emphasize that it is a process rather than a blueprint (Kay et al.2004). 
While there are some differences in the proposed methodologies for conducting capacity assessments, many share key characteristics and most emphasize the need to find a good balance between being scientifically robust and sufficiently adaptable to a range of contexts. There is also consistency in the idea that a capacity development process should encompass a series of interlinked steps.

The steps defined by FAO (Kay et al. 2004) and IUCN (Stephen and Triraganon 2009) appear to be the most aligned with the objectives of landscape approaches (i.e. initiatives that are not merely development projects).

The steps are summarized below:

- Where are we now? Identification of the existing and latent capacities.

- Where do we want to go? Identification of what capacity is required to achieve the intended goals.

- How do we get there? Identification of capacity gaps, and development of plan to fill the gaps including identification of other potential institutions to contribute in the capacity building.

\subsubsection{Stakeholder perception analysis - Q methodology}

Q methodology is a blend of quantitative and qualitative techniques to help understand people's framing of human values and the perspectives on a given topic or issue that ultimately shape decision-making and behaviour (Webler et al. 2009). Q is particularly relevant for landscape approaches as it is considered useful for revealing stakeholder perceptions on policy appraisal, land-use management alternatives, critical reflection and conflict resolution (Mukherjee et al. 2018); all potential challenges for landscape approach 'users'. The principal aim of $Q$ methodology is to uncover the diversity of perspectives on a given topic amongst a selected group of stakeholders and how these are embedded in the language (discourse) they use. In the context of landscape approaches, the application of $Q$ method could therefore help identify consensus or divergence of perspectives related to pressing land use concerns (principle 2) or identification of influential actors in the landscape (principle 5), amongst others.

A Q study consists of four stages - research design, data collection, analysis and interpretation (Zabala et al. 2018). The first stage involves identifying the spectrum of potential perspectives on the topic of interest, with information drawn from as many sources as available (i.e. print, interviews and expert consultation); this process should be documented. From this spectrum of perspectives, the researchers then select a representative sample of perspectives (the $Q$ set) that a (typically non-random) group of respondents (the P sample) will then subjectively rank (typically from most agree through to most disagree). Consideration must be carefully given to the formulation of the question of interest, the $Q$ set, and the $P$ sample, in order to ensure the full range of divergent positions a person could take on the issue is captured. The statements that make up the $Q$ set should be short, stand-alone (not double-loaded) statements that are easily comprehensible but, depending on the topic of interest can have 'excess meaning' (i.e. they are not factual statements and so can be interpreted slightly differently by different sorters) (Brown 1980; Webler et al. 2009). Unlike other methods, a large sample 
size is not necessary to elicit powerful findings (Sandbrook et al. 2013), however findings cannot be extrapolated to broader populations (Zabala et al. 2018).

Stage two, referring to data collection sees the respondents (P sample) rank and sort the $Q$ set into categories typically demarcated by quansal (QUANtification of SALiency) units (Webler et al. 2009). Respondent choices are 'self-referential' using internal yardsticks based on personal values and beliefs, but placement of the $Q$ statements is guided by a 'condition of instruction' - typically the extent to which they most agree or most disagree (Webler et al. 2009, Zabala et al. 2018). The resultant grid (the $Q$ sort) usually takes a bell-shaped distribution with statements of lowest saliency clustered in the middle of the bell and statements of highest salience at the outer extremes (Brown et al. 2008; Zabala et al. 2018). Data collection is typically performed face-to-face but can also be performed online.

Each respondent generates one $\mathrm{Q}$ sort and the sum of $\mathrm{Q}$ sorts are then statistically analyzed (stage three) to reveal patterns in the way the respondents form opinions on the subject of interest. Analysis of the $Q$ sorts is performed through multivariate data reduction techniques that entails reducing the data to the main shared perspectives (factors), through processes of extraction and rotation (see Brown, 1980; Zabala et al. 2018). Two key results describe each factor and the relation between each factor and each respondent and item (Zabala et al. 2018). There are a number of software packages available to perform $Q$ analysis (Schmlock 2014; Zabala 2014).

The final stage (interpretation) involves interpreting the factors and developing the suite of social perspectives. This results from a combination of the item scores, qualitative data collected during the $Q$ sort, and the researchers understanding of the case and respondent views. This stage is thus completed by examining the areas of consensus and divergence across the shared perspectives.

Results from Q-methodology can provide transparency on the diverse underlying narratives of sustainability, natural resource management, and development issues. Enhanced understanding of stakeholder perceptions enables decision-makers to achieve more legitimacy and buy-in to interventions aimed at addressing social-ecological challenges. Decision-makers that strategically account for consensus and divergence in stakeholder perspectives will be better equipped to boldly contest, or to collaborate with the influential actors in the landscape (Ravikumar et al. 2018). Beyond, there is inherent value in exposing diverse views for better collaborative problem framing by scientists aiming to be honest brokers. Landscape approach practitioners must not overlook or discount those with different perceptions and narratives when trying to make progress toward more inclusive or sustainable development. Illuminating previously unforeseen perspectives of least and most resistance to landscape approach interventions can enable more rigorous theories of change.

\subsubsection{Historical trends analysis}

Historical trends analysis relies on local actors or community recollection to outline important past events and drivers of change to identify underlying patterns and socialecological impacts and help predict potential future outcomes. Historical trends analysis 
is therefore useful for engaging multiple stakeholders (principle 5) to identify common concerns (principle 2), feed into theories of change (principle 6) and enhance resilience of future landscape trajectories (principle 9).

A diversity of representatives that are familiar with different aspects of the landscape can be brought together in a focus group discussion-like setting to discuss drivers of change and social-ecological impacts. Participants should be selected strategically for their likely held knowledge of place and of issues. This requires selecting participants of adequate diversity, representing the different facets of the local society. Groups should reflect the diversity of household incomes in landscape, include both women and men, and be culturally appropriate. The aim is to establish some consensus on the discussion outputs. The first step is to build a historical timeline for the landscape, including social, environmental and political events that occurred within the village and at higher scales. Timelines do not have to be defined but can be open to the locally perceived time scales of influence. Participants can therefore offer information on what they felt was relevant to the discussion. The next step is to ask participants to identify key events that have had an impact on natural resources, and whether the impact was positive or negative. This question should be repeated for life in the village, asking which events have brought positive and negative changes to people's lives. Quality of life can be defined with locals through their perspectives. A final step is to then ask participants of their future expectations for the landscape and which institutions they expect to have influence on future conservation and development outcomes. Historical trends analysis can be supplemented and/or triangulated by capturing secondary historical information of relevance through, for example, public records, past studies or surveys.

\subsection{Decision-support tools}

\subsubsection{Rich pictures and scenario visualization}

Rich pictures encourage people to prepare simple drawings that allow them to represent their knowledge, values, and potential scenarios for a landscape (Boedhihartono 2012). Rich pictures are particularly useful for engaging multiple stakeholders (principle 5), understanding the multi-functionality (principle 4) of a landscape and identifying common concern entry points (principle 2), which can later inform a negotiated and transparent change logic (principle 6) and strengthen stakeholder capacity (principle 10).

Participatory mapping is one example of a method that uses rich pictures.

Broadlyspeaking, participatory mapping is the creation of maps by local participants. This is an adaptable tool that can be used to elicit a wide range of information. For example, maps can be used to visualize areas of high dependence or cultural significance to specific stakeholder groups, as well as where they travel, what for, and how often (Chambers 2006). Additionally, participatory mapping can be used for scenario development which can be a powerful tool for building shared visions of desired future situations. Sletto et al. (2009) describe the process as important as the completed map itself. Asking stakeholders to negotiate a shared vision can raise issues of identity, social relations, overlapping boundaries, and competing objectives. With this in mind, independent facilitation can be valuable to carefully, and impartially, guide this process. 


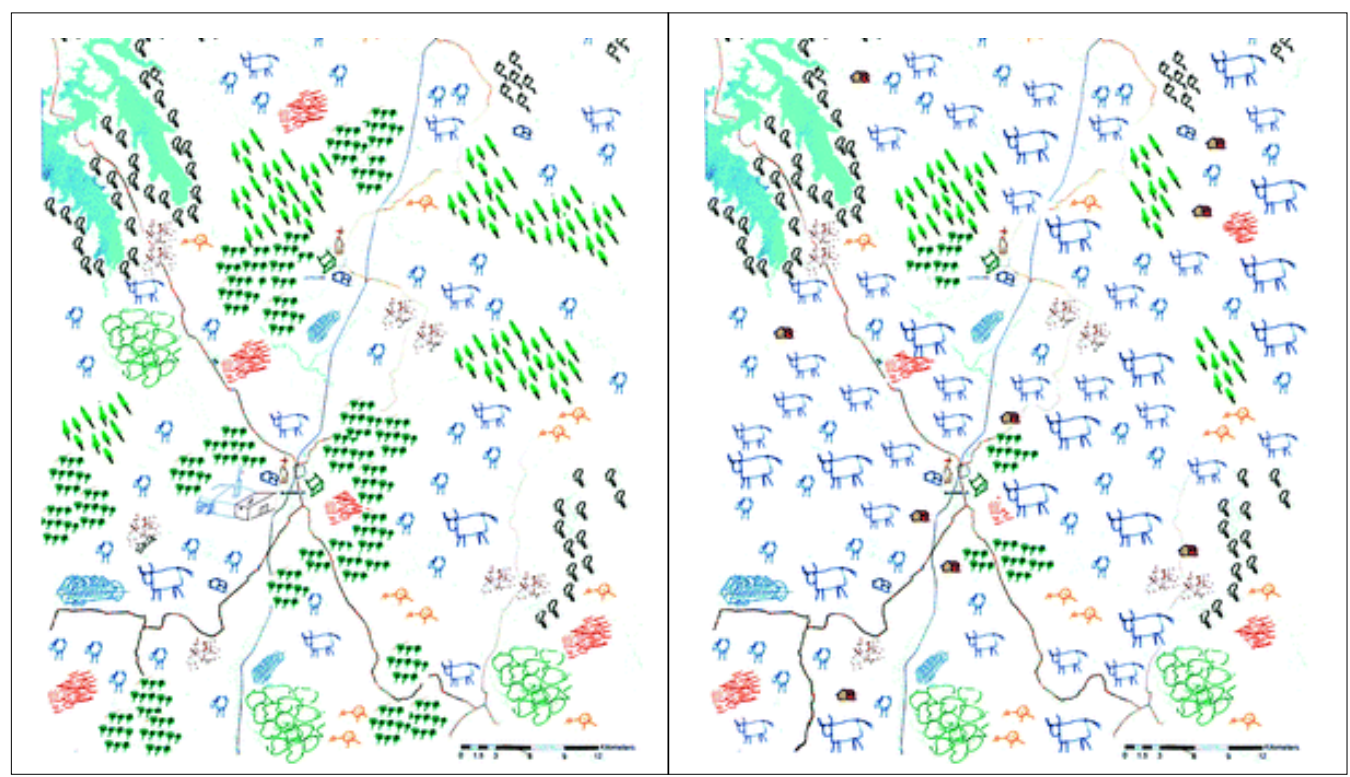

Figure 6.2 Example of visualization of two possible future scenarios seen by local people and other stakeholders in La Paloma, Uruguay.

Source: Reprinted/adapted by permission from Springer Nature (Boedhihartono and Sayer 2012)

The choice of method for building scenarios should be appropriate to the capacities of the participants. Scenarios can be developed using simple visual techniques, such as participatory mapping, or more technical approaches using simulation modeling (see below), depending on the context (Sandker et al. 2010; Collier et al. 2011; Boedhihartono, 2012). Scenarios based initially upon drawings and later formalized with models were used as a basis for a long-term initiative to monitor the performance of a Congo basin forest landscape (Endamana et al. 2010). Asubonteng et al. (2020) used previously cut out symbols representing land uses present in the landscape, which participants arranged on a base map of the landscape to design their desired landscapes. Scenarios for best-case and worst-case future situations can be used to encourage debate about conservation decision-making, and for building consensus on desirable future situations as the basis for theories of change (see Chapter 5). Figure 6.2 an example of visualization of two possible future scenarios seen by local people and other stakeholders in La Paloma, Uruguay. Participants were asked to illustrate their preferred balance between mixed crops, plantations, cattle grazing and forest. These visualizations helped exchange information, reduce tensions and move toward an acceptable compromise at the landscape scale. For more examples like this, see Boedhihartono 2012.

\subsubsection{Photovoice}

Photovoice is another example of a participatory visual method. Photovoice enables participants to capture and share aspects of their environment through photographs and/or video. The method was created to (1) enable people to record and reflect their community's strengths and concerns; (2) to promote critical dialogue and knowledge about important community issues through large and small group discussions of 
photographs; and (3) to reach policymakers (Wang and Burris 1997, p.370). Photovoice is highly flexible and can be used to visualize answers to specific questions or broader topics. For example, Bennett and Dearden (2013) used photovoice to visualize the social and ecological changes in coastal communities on the Andaman Coast of Thailand; Berbés-Blázquez (2012) used photovoice to assess ecosystem services and well-being in Costa Rica; and Masterson et al. (2018) used the method as a scoping exercise and deep learning tool to assess interlinkages between well-being and socio-ecological change and power dynamics in knowledge co-production in Kenya and South Africa.

\subsubsection{Simulation modeling}

Simulation modeling can be an effective way of creating and analyzing a formal abstraction of a social-ecological system to predict its performance in the real world (Sandker et al. 2010; Sandker et al. 2012). Simulation modeling can be used to assess alternative performance outcomes by varying the parameters of the model; its stocks and flows and the weights they are given. It can help users understand whether, under what conditions, and in which ways desired or perverse outcomes might be achieved (Collier et al. 2011). Sandker et al. (2007) used STELLA dynamic modeling software (Isee systems, 2012) in Malinau district, North Kalimantan, Indonesia. The model was created through an iterative participatory process involving government officials, local communities and researchers from CIFOR. The model draws upon a variety of available data sources to simulate a range of potential scenarios for impacts of oil palm expansion in the landscape. Models have limited power to make accurate predictions of complex outcomes of land-use change but in this case were used to promote dialogue on different possible trajectories of change (Sandker et al. 2008). The involvement of district officials created an opportunity for scientists engaging in long-term conservation activities in the landscape to discuss potential risks and benefits of oil palm development, for example, with decision-makers, and moderate raised expectations to ensure that local communities were central to the conservation and development debate, and therefore informed adaptive management (principle 1).

When considering the impacts of biophysical changes on landscape dynamics, the application of ecosystem service mapping tools offers potential. The online, open access tool InVEST (Integrated tool to Value Ecosystem Services and their Trade-offs) is an integrated and spatially distributed model that enables users to analyze the impacts of land-cover change on the provision of ecosystem services. Developed by the Natural Capital Project ${ }^{1}$ the tool predicts future ecosystem service provision in biophysical or monetary value outputs (Crossman et al. 2013) and has been widely applied in varying contexts (Swetnam et al. 2011). Importantly, the tool can be used to assess potential future ecological trade-offs. Nelson et al. (2009) used InVEST to assess three stakeholder-defined scenarios of future land use. By combining models for ecosystem services, biodiversity conservation and commodity market values, they were able to quantify potential future trade-offs arising from increasing one or other of the model inputs. Furthermore, they were able to speculate the degree to which potential trade-

1 http://www.naturalcapitalproject.org/InVEST.htmls. 
offs might be moderated by future policy interventions - particularly payments for ecosystem services.

While InVEST is especially useful for biophysical mapping and evaluating socioeconomic and ecological trade-offs, it fails to account for social (particularly nonmonetary) values of ecosystem services, or "cultural services". A new tool, SOLVES (Social Values for Ecosystem Services), enables quantified and spatially explicit measures of social values to be incorporated into ecosystem service assessments. The publicly available GIS tool developed by the US Geological Survey uses a 12-point index to allow users to assess and map social values in relation to landscape metrics such as topography, distance to roads or water, and land cover - therefore improving the ability to assess trade-offs amongst ecosystem services and the social perception of their value (Sherrouse et al. 2011). Bagstad et al. (2016) used SOLVES in collaboration with another biophysical modeling tool, ARIES (Artificial Intelligence for Ecosystem Services) to map ecosystem service hot/cold spots in the Southern Rocky Mountains with public perceptions of areas of natural value. The analysis enabled the identification of areas of potential synergy or conflict between locations of ecosystem service value and the areas valued by local residents, thus benefitting resource managers, land planners and policymakers.

While model projections are characterized by a high degree of uncertainty (Prestele 2016) and rarely capture real world complexity (Reed et al. 2019), the process of bringing together multiple stakeholders (principle 5) to build the model and negotiate alternative scenarios (principle 6) can help to clarify roles and responsibilities (principle 7) and build capacity (principle 9) to enhance resilience (principle 9) to future environmental and social disturbance (Trosper 2003) and provide important decision-making support for policy development (Reed et al. 2019).

\section{Conclusion}

This methods paper and toolbox details those methods that we feel can inform the implementation of ILAs and may hold relevance across a range of contexts. Nevertheless, it is important to re-emphasize that the above is not intended to be an exhaustive list of methods and tools for integrated landscape approaches. The methods described will likely be of greater value when used in combination and when appropriate, iteratively. Each of the methods holds individual value, but we recognize an added value in using a suite of methods (see e.g. Asubonteng et al. 2020). The methods described can be broadly associated with three themes: back-casting (and identifying general historical trends), establishing current baseline conditions, and forecasting to generate projections of potential or desired futures and aid decision-making. As such, selecting methods that fulfil each of these themes can help to develop a more complete understanding of the past, present and future landscape dynamics and help identify potential needs, opportunities and challenges. 


\section{References}

Ahammad R, Stacey N and Sunderland T. 2019. Use and perceived importance of forest ecosystem services in rural livelihoods of people in Bangladesh. Ecosystem Services 35: 87-98.

Asubonteng KO, Ros-Tonen M, Baud I and Pfeffer K. 2020. Envisioning the future of mosaic landscapes: Actor perceptions in a mixed cocoa-oil palm area in Ghana. Environmental Management 62(1): 1-19. https://doi.org/10.1007/s00267-020-01368-4.

Bagstad KJ, Reed JM, Semmens DJ, Sherrouse BC and Troy A. 2016. Linking biophysical models and public preferences for ecosystem service assessments: A case study for the Southern Rocky Mountains. Regional Environmental Change 16(7): 2005-2018.

Bennett NJ. 2016. Using perceptions as evidence to improve conservation and environmental management. Conservation Biology 30(3): 582-592.

Bennett NJ and Dearden P. 2013. A picture of change: Using photovoice to explore social and environmental change in coastal communities on the Andaman Coast of Thailand. Local Environment 18(9): 983-1001.

Bennett NJ, Di Franco A, Calò A, Nethery E, Niccolini F, Milazzo M and Guidetti P. 2019. Local support for conservation is associated with perceptions of good governance, social impacts, and ecological effectiveness. Conservation Letters 12:e12640. https://doi. org/10.1111/conl.12640.

Berbés-Blázquez M. 2012. A participatory assessment of ecosystem services and human well-being in rural Costa Rica using photo-voice, Environmental Management 49(4): 862-875.

Boedhihartono AK. 2012. Visualizing Sustainable Landscapes: Understanding and Negotiating Conservation and Development Trade-offs Using Visual Techniques. Gland, Switzerland: IUCN.

Boedhihartono AK and Sayer J. 2012. Forest landscape restoration: Restoring what and for whom?. In Stanturf J, Lamb D and Madsen P, eds. Forest landscape Restoration. Dordrecht: Springer Vol 15. 309-323.

Broegaard RB, Rasmussen LV, Dawson N, Mertz O, Vongvisouk T and Grogan K. 2017. Wild food collection and nutrition under commercial agriculture expansion in agriculture-forest landscapes. Forest Policy and Economics 84: 92-101.

Brondizio ES, Ostrom E and Young OR. 2009. Connectivity and the governance of multilevel social-ecological systems: the role of social capital. Annual Review of Environment and Resources 34: 253-278.

Brown SR. 1980. Political Subjectivity: Applications of Q Methodology in Political Science. London: Yale University Press.

Brown SR, Durning DW and Selden SC. 2008. Q methodology. In: Yang K and Miller GJ (eds.), Handbook of Research Methods in Public Administration (2nd ed.). New York: CRC Press. 721-763.

Burger J. 2011. Science and stakeholders: A synthesis. In Burger J (d) Stakeholders and Scientists. New York, NY: Springer. 427-442. 
Camfield L and Ruta D. 2007. Translation is not enough: Using the Global Person Generated Index (GPGI) to assess individual quality of life in Bangladesh, Thailand, and Ethiopia. Quality of Life Research 16: 1039-1051.

Carmenta R, Coomes DA, DeClerck FA, Hart AK, Harvey CA, Milder J, Reed J, Vira B and Estrada-Carmona N. 2020. Characterizing and evaluating integrated landscape initiatives. One Earth 2(2): 174-187.

Cash DW, Adger WN, Berkes F, Garden P, Lebel L, Olsson P, Pritchard L and Young O. 2006. Scale and cross-scale dynamics: Governance and information in a multilevel world. Ecology and Society 11(2), 8.

Chambers R. 2006. Participatory mapping and geographic information systems: Whose map? Who is empowered and who disempowered? Who gains and who loses? The Electronic Journal of Information Systems in Developing Countries 25(1): 1-11.

Colfer CJP, Prabhu R, Günter M, McDougall C and Porro NM. 1999. Who counts most? Assessing human well-being in sustainable forest management Bogor, Indonesia: CIFOR.

Collier N, Campbell BM, Sandker M, Garnett ST, Sayer J and Boedhihartono AK. 2011. Science for action: The use of scoping models in conservation and development. Environmental Science \& Policy 14: 628-638.

Crossman ND, Burkhard B, Nedkov S, Willemen L, Petz K, Palomo I, Drakoud EG, Martín-Lopez B, McPhearsong T, Boyanova K, et al. 2013. A blueprint for mapping and modelling ecosystem services. Ecosystem Services 4: 4-14.

Driscoll C and Starik M. 2004. The primordial stakeholder: Advancing the conceptual consideration of stakeholder status for the natural environment. Journal of Business Ethics 49: 55-73.

Endamana D, Boedhihartono A, Bokoto B, Defo L, Eyebe A, Ndikumagenge C, Nzooh Z, Ruiz-Perez M, Sayer J. 2010. A framework for assessing conservation and development in a Congo Basin forest landscape. Tropical Conservation Science 3: 262-281.

Freeman RE, Harrison JS, Wicks AC, Parmar BL and De Colle S. 2010. Stakeholder theory: The state of the art. Cambridge University Press: Cambridge.

Freeman OE, Duguma LA and Minang PA. 2015 Operationalizing the integrated landscape approach in practice. Ecology and Society 20(1):12.

German L, Mansoor H, Alemu G, Mazengia W, Amede T and Stroud A. 2007. Participatory integrated watershed management: Evolution of concepts and methods in an ecoregional program of the eastern African highlands. Agricultural Systems 94(2): 189-204.

Grimble R, Chan MK, Aglionby J and Quan J, 1995. Trees and trade-offs: A stakeholder approach to natural resource management. Gatekeeper SeriesNo. 52. London, UK: IIED.

Hobbs R. 1997. Future landscapes and the future of landscape ecology. Landscape and Urban Planning 37: 1-9.

Isee Systems. 2012. Stella: IThink, version 10: system thinking for business. https://www. iseesystems.com/store/products/ithink.aspx. 
Kay M, Franks T and Tato S. 2004. Capacity Needs Assessment Methodology and Processes. Rome: Food and Agriculture Organization (FAO).

Kowalski AA and Jenkins LD. 2015. The role of bridging organizations in environmental management: Examining social networks in working groups. Ecology and Society $20(2): 16$.

KSTOOLKIT 2018. Knowledge Sharing Toolkit. http://www.kstoolkit.org/social_ network_analysis. Accessed March 28, 2019.

Kusumanto T, Yuliani EL, Macoun P, Indriatmoko Y and Adnan H. 2005. Learning to adapt: Managing forests together in Indonesia. Bogor, Indonesia: CIFOR, YGB, PSHK-ODA. .

Langston JD, Riggs RA, Sayer JA, Margules C and Boedhihartono AK. 2019. Science embedded in local forest landscape management improves benefit flows to society. Frontiers in Forests and Global Change 2(3): 1-13. https://doi.org/10.3389/ffgc.2019.00003

Linkie M, Smith RJ, Zhu YU, Martyr DJ, Suedmeyer B, Pramono J and Leader-Williams N. 2008. Evaluating biodiversity conservation around a large Sumatran protected area. Conservation Biology 22(3): 683-690.

Macfadyen SS, Cunningham A, Costamagna AC and Schellhorn, NA. 2012. Managing ecosystem services and biodiversity conservation in agricultural landscapes: Are the solutions the same? Journal of Applied Ecology 49: 690-694.

Mansourian S, Parrotta J, Balaji P, Bellwood-Howard I, Bhasme S, Bixler RP, Boedhihartono K, Carmenta R, Jedd T, de Jong W, et al. 2020. Putting the pieces together: Integration for forest landscape restoration implementation. Land Degradation \& Development 31(4): 419-429.

Martín-López B, Iniesta-Arandia I, García-Llorente M, Palomo I, Casado-Arzuaga DG, Amo D, Gómez-Baggethun E, Oteros-Rozas E, Palacios-Agundez I, Willaarts B, et al. 2012. Uncovering ecosystem service bundles through social preferences.PLoS ONE 7(6), e 38970.

Masterson VA., Mahajan SL and Tengö, M. 2018. Photovoice for mobilizing insights on human well-being in complex social-ecological systems. Ecology and Society 23(3):13.

McGregor JA and Pouw N. 2017. Towards an economics of well-being. Cambridge Journal of Economics 41(4): 1123-1142.

Milner-Gulland EJ, McGregor JA, Agarwala M, Atkinson G, Bevan P, Clements T,Homewood D, Kumpel N, Lewis J, et al. 2014. Accounting for the impact of conservation on human well-being. Conservation Biology 28: 1160-1166.

Moeliono M, Brockhaus M, Gallemore C, Dwisatrio B, Maharani CD, Muharrom E and Pham TT. 2020. REDD+ in Indonesia: A new mode of governance or just another project?. Forest Policy and Economics 121, 102316. https://doi.org/10.1016/j. forpol.2020.102316.

Moeliono M, Gallemore C, Santoso L, Brockhaus M and Di Gregorio M. 2014. Information networks and power: Confronting the "wicked problem" of REDD+ in Indonesia. Ecology and Society 19(2):9. 
Mukherjee N, Zabala A, Huge J, Nyumba TO, Adem Esmail B and Sutherland WJ. 2018. Comparison of techniques for eliciting views and judgements in decision-making. Methods in Ecology and Evolution 9(1): 54-63.

Ndeinoma A, Wiersum KF and Arts B. 2018. The governance of indigenous natural products in Namibia: A policy network analysis. Environmental Management 62(1): 29- 44 .

Nelson E, Mendoza G, Regetz J, Polasky S, Tallis H, Cameron DR, Chan KMA, Daily GC, Goldstein J, Kareiva PM, et al. 2009. Modeling multiple ecosystem services, biodiversity conservation, commodity production, and tradeoffs at landscape scales. Frontiers in Ecology and the Environment 7(1): 4-11.

ODA 1995. Guidance note on how to do stakeholder analysis of aid projects and programmes. London: ODA. https://sswm.info/sites/default/files/reference attachments/ODA\%201995\%20Guidance\%20Note\%20on\%20how\%20to\%20do\%20 a\%20Stakeholder\%20Analysis.pdf.

Omoding J, Walters G, Andama E, Carvalho S, Colomer J, Cracco M, Eilu G, Kiyingi G, Kumar C, Langoya CD, et al. 2020. Analysing and applying stakeholder perceptions to Improve protected area governance in Ugandan conservation landscapes. Land 9(6), 207. https://doi.org/10.3390/land9060207.

Prell C, Hubacek K and Reed M. 2009. Stakeholder analysis and social network analysis in natural resource management. Society and Natural Resources 22(6): 501-518.

Prestele R, Alexander P, Rounsevell MD, Arneth A, Calvin K, Doelman J, Eitelberg DA, Engström K, Fujimori S, Hasegawa T, et al. 2016. Hotspots of uncertainty in land-use and land-cover change projections: A global-scale model comparison. Global Change Biology 22(12): 3967-3983.

Pulhin JM. 2014. Stakeholder analysis as a tool in integrated watershed management. Agriculture and Development Notes 5: 1-4.

Rasolofoson RA, Nielsen MR and Jones JP. 2018. The potential of the Global Person Generated Index for evaluating the perceived impacts of conservation interventions on subjective well-being. World Development 105: 107-118.

Ravikumar A, Larson AM, Myers R and Trench T. 2018. Inter-sectoral and multilevel coordination alone do not reduce deforestation and advance environmental justice: Why bold contestation works when collaboration fails. Environment and Planning C: Politics and Space 36(8): 1437-1457.

Reed J, Van Vianen J, Deakin EL, Barlow J and Sunderland T. 2016. Integrated landscape approaches to managing social and environmental issues in the tropics: Learning from the past to guide the future. Global Change Biology 22(7): 2540-2554.

Reed J, Barlow J, Carmenta R, van Vianen J and Sunderland, T. (2019). Engaging multiple stakeholders to reconcile climate, conservation and development objectives in tropical landscapes. Biological Conservation 238, 108229.

Rhodes RAW. 2006. Policy network analysis.In: Moran M, Rein M and Goodin RE (eds.) The Oxford Handbook of Public Policy. The Oxford Handbooks of Political Science. Oxford: OUP. 423-445. 
Riggs R, Langston J, Margules C, Boedhihartono A, Lim H, Sari D, Sururi Y and Sayer J. 2018. Governance challenges in an Eastern Indonesian forest landscape. Sustainability 10(1), 169.

Ros-Tonen MAF, Reed J and Sunderland T. 2018. From synergy to complexity: The trend toward integrated value chain and landscape governance. Environmental Management 62(1): 1-14.

Sandbrook CG, Fisher JA and Vira B. 2013. What do conservationists think about markets? Geoforum 50: 232-240.

Sandker M, Suwarno A and Campbell BM. 2007. Will forests remain in the face of oil palm expansion? Simulating change in Malinau, Indonesia. Ecology and Society 12(2).

Sandker M, Campbell B and Suwarno A. 2008. What are participatory scoping models? Ecology and Society 13(1): r2.

Sandker M, Campbell BM, Ruiz-Perez M, Sayer JA, Cowling R, Kassa H and Knight AT, 2010. The role of participatory modelling in landscape approaches to reconcile conservation and development. Ecology and Society 15(2): 13.

Sandker M, Ruiz-Perez M and Campbell BM. 2012. Trade-offs between biodiversity conservation and economic development in five tropical forest landscapes. Environmental Management 50: 633-644.

Satterfield T, Gregory R, Klain S, Roberts M and Chan KM. 2013. Culture, intangibles and metrics in environmental management. Journal of Environmental Management 117: 103-114.

Sayer J, Sunderland T, Ghazoul J, Pfund J., Sheil D, Meijaard E, Venter M, Boedhihartono AK, Day M, Garcia C, et al. C. 2013. Ten principles for a landscape approach to reconciling agriculture, conservation, and other competing land uses. Proceedings of the National Academy of Science 110(21): 8349-8356.

Sherrouse BC, Clement JM and Semmens DJ. 2011. A GIS application for assessing, mapping, and quantifying the social values of ecosystem services. Applied Geography 31(2): 748-760.

Schmolck P. 2014. PQMethod Software (Version 2.35). http://schmolck.org/qmethod/.

Scott J and Carrington PJ. 2011. The SAGE Handbook of Social Network Analysis. Thousand Oaks: SAGE Publications.

Sletto BI, Hale CR, Middleton BR, Nygren A, Rodríguez I and Schroeder R. 2009. "We drew what we imagined" participatory mapping, performance, and the arts of landscape making. Current Anthropology 50(4): 443-476.

Smith RJ and MJ Walpole. 2005. Should conservationists pay more attention to corruption? Oryx 39: 251-256.

Stanghellini PSL. 2010. Stakeholder involvement in water management: The role of the stakeholder analysis within participatory processes. Water Policy 12: 675-694.

Stephen P and Triraganon R. 2009. Strengthening voices for better choices: A capacity needs assessment process. Gland, Switzerland: IUCN.

Sterling EJ, Filardi C, Toomey A, Sigouin A, Betley E, Gazit N, Newell J, Albert S, Alvira D, Bergamin N, et al. 2017. Biocultural approaches to well-being and sustainability indicators across scales. Nature Ecology \& Evolution 1(12): 1798-1806. 
Sunderland TCH, Sayer J and Hoang TMH. (eds.). 2012. Evidence-Based Conservation: Lessons from the Lower Mekong. London: Routledge.

Swetnam RD, Fisher B, Mbilinyi BP, Pantaleo KT, Munishi PKT, Willcock S, Ricketts T, Mwakalila S, Balmford A, Burgess ND, et al. 2011. Mapping socio-economic scenarios of land cover change: A GIS method to enable ecosystem service modelling. Journal of Environmental Management 92(3): 563-574.

Trosper RL. 2003. Resilience in pre-contact Pacific Northwest social ecological systems. Conservation Ecology 7(3).

UNDP 2008. Capacity Assessment Methodology: User's Guide. Capacity Development Group Bureau for Development Policy. New York: UNDP.

van Oosten C, Gunarso P, Koesoetjahjo I and Wiersum, F. 2014. Governing forest landscape restoration: Cases from Indonesia. Forests 5: 1143-1162.

Wang C and Burris MA. 1997. Photovoice: Concept, methodology, and use for participatory needs assessment. Health Education and Behavior 24(3):369-387.

Wasserman S and Faust K. 1994. Social Network Analysis: Methods and Applications (Vol. 8). Cambridge: Cambridge University Press.

Webler T, Danielson S and Tuler S. 2009. Using Q Method to Reveal Social Perspectives in Environmental Research. Greenfield MA: Social and Environmental Research Institute.

Zabala, A. 2014. Q method: A package to explore human perspectives using $Q$ methodology. The R Journal (6(2): 163-173.

Zabala A, Sandbrook C and Mukherjee N. 2018. When and how to use Q methodology to understand perspectives in conservation research. Conservation Biology 32(5): 1185-1194.

Zanzanaini CBT, Tran C, Singh A, Hart J, Milder J and DeClerck FA. 2017. Integrated landscape initiatives for agriculture, livelihoods and ecosystem conservation: An assessment of experiences from South and Southeast Asia. Landscape and Urban Planning 165: 11-21. 


\subsection{Ghana}

We reviewed the objectives of Ghana's Medium-Term National Development Policy Framework for the period 2018-2021. We discuss several policies and natural resource management schemes that promote development objectives and their potential to support a landscape approaches.

\subsubsection{Key findings}

Ghana's Medium-Term National Development Policy Framework (2018-2021) Agenda for Jobs: Creating Prosperity and Equal Opportunity for All is the sixth in a series of policy frameworks designed to guide Ghana's development (NDPC 2017). The framework is coordinated by the National Development Planning Commission (NDPC), responsible for synthesizing development priorities identified through a multilevel process (see Figure 7.1). At the district level, metropolitan, municipal and district assemblies (MMDAs) are responsible for the preparation and submission of district-level development plans. MMDAs are a platform for community members, non-governmental organizations (NGOs) and traditional authorities to identify community needs and planning priorities (NDPC 2017). Next, the regional coordinating councils (RCCs) harmonize district-level plans into regional development plans and submit them to the NDPC for formulation of the national plan. The NDPC is also required to establish and utilize cross-sectorial planning groups (CSPGs) consisting of representatives of the NDPC, relevant sector ministries, and public- and private-sector institutions and organizations. CSPGs are expected to convene at least once every 3 months and to work together on cross-sectorial development issues (NDPC 2017).

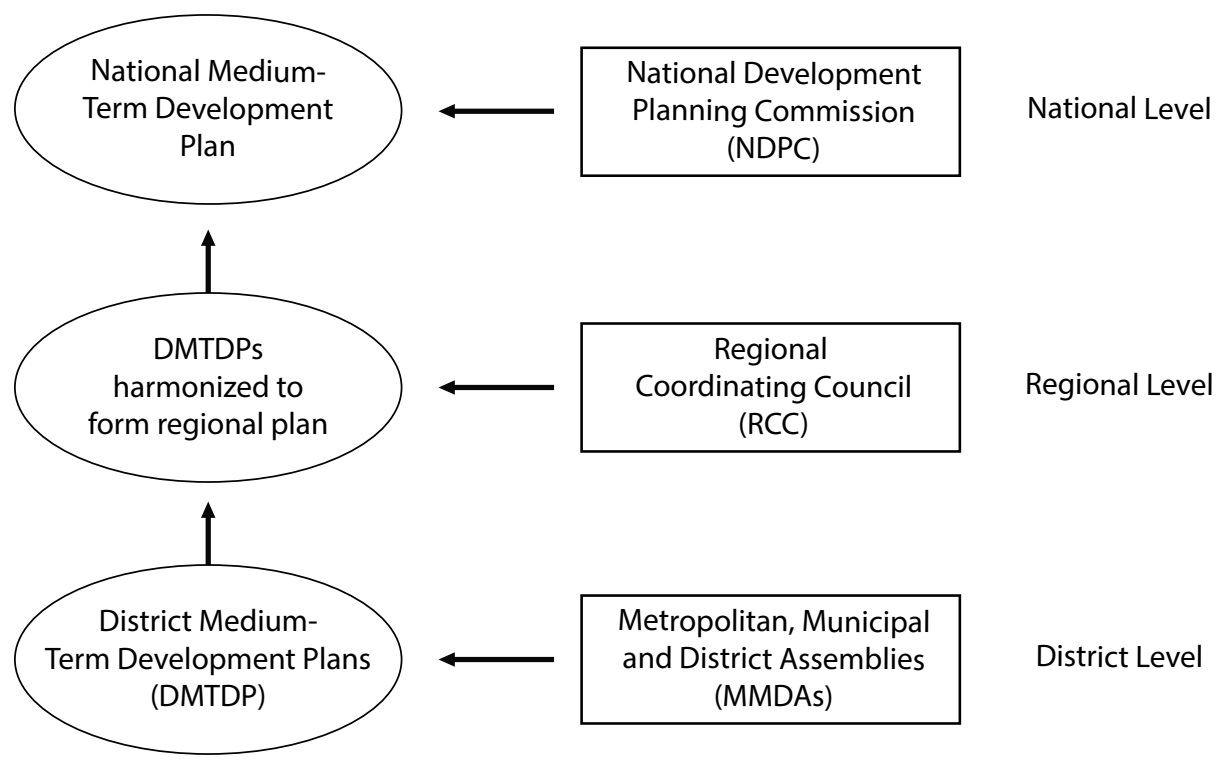

Figure 7.1 National development planning process.

Source: Adapted from NDPC (2017) 
In Ghana, urbanization is outpacing development, and this challenge is reflected in the priorities outlined in the most recent Medium-Term National Development Policy Framework. The strategic areas of the policy framework include: restoring the economy, transforming agriculture and industry, strengthening social protection and inclusion, revamping socioeconomic infrastructure and reforming public delivery institutions (NDPC 2017). The plan cites falling demand for traditional exports, unstable global commodity prices (gold, cocoa, oil), an underperforming agriculture and manufacturing sectors as key contributors to revenue shortfalls and an incapacity to implement past development plans (NDPC 2017). The policy framework calls attention to commercial production of oil and gas as an emerging opportunity for the country. In collaboration with the private sector, oil exploration is expected to accelerate in the Voltaian, Keta and Accra Basins (NDPC 2017). The Voltaian Basin alone covers approximately $40 \%$ of the country's land mass (CBD 2016).

It is evident that Ghana's policy framework is geared toward large-scale, near-term development, which raises questions regarding environmental impacts and related socio-economic reverberations. Concerns surrounding future development plans stem from Ghana's past and present challenges around competing land uses. A growing population, agricultural expansion, intensification of cocoa and oil palm, illegal timber harvesting, and illegal small-scale mining (commonly known as galamsey) have increased social tensions, contaminated water sources, and degraded land and biodiversity (CBD 2016; NDPC 2017; UNDP 2018). The national policy framework acknowledges the need to reconcile conservation and development needs and outlines a number of focus areas for the 2018-2021 time frame. For example, the framework commits to ensuring the Environmental Protection Agency (EPA) and the Petroleum Commission work together on environmentally sound exploration and production of oil and gas. Other focus areas include restoring degraded land, improving land administration and management, expanding protected areas and increasing resilience to climate change (NDPC 2017).

Several contemporary policies support these broad objectives in Ghana. For instance, the National Environmental Policy of 2014 aims to integrate environmental consideration in sectorial, structural and socioeconomic planning at all levels (MLNR 2016). The National Climate Change Policy (NCCP) was launched in 2014 to guide Ghana toward a climateresilient economy through low-carbon growth (NDPC 2017). A pillar of the national climate change agenda is Ghana's REDD+ Strategy (Forestry Commission 2016) and the supporting National Forest Reference Level (FRL) plan. The FRL plan will serve as the baseline for monitoring emissions reductions from REDD+ activities aimed at reducing emissions from deforestation and forest degradation (National REDD+ Secretariat 2017).

The Forest and Wildlife Policy of 2012 regulated by the Ministry of Lands and Natural Resources (MLNR) marked a shift in policy focus from timber to conservation. The policy calls for sustainable conservation and development of forest and wildlife resources to sustain socioeconomic and cultural benefits, while fulfilling Ghana's commitments to international agreements and conventions (MLNR 2012; Adom 2017). Relatedly, the Forestry Development Master Plan (FDMP) (2016-2036) seeks to transform the forestry sector by implementing the objectives of the Forest and Wildlife Policy and the National Climate Change Policy. The plan intends to follow an ecosystem-based strategy that 
considers the interactions between government, organizations, industry, traditional authorities and landowners (MLNR 2016).

Two natural resource management schemes that embody the above policies are the Modified Taungya System (MTS) and the community resource management areas (CREMAs). The MTS is a co-management reforestation arrangement between the Ghana Forestry Commission and local communities (Foli et al. 2018). The scheme is a legally binding land lease that recognizes farmers as co-owners of forest plantations until tree crops mature (after around 3 years) (Acheampong et al. 2016). During this time, farmers can intercrop food crops and receive $100 \%$ of the proceeds. They are also entitled to $40 \%$ of tree revenues once the trees have matured after three years (Acheampong et al. 2016; Foli et al. 2018).

The second scheme, CREMAs, was initiated in the early 2000 s by the Wildlife Division of the Forestry Commission to sustainably manage natural resources outside of protected areas, in turn, reducing pressure on wildlife and forest reserves (Foli et al. 2018). In exchange for sustainable management, communities are granted rights to the economic benefits derived from natural resources within the CREMAs. Today, there are approximately 30 CREMAs across the country (Foli et al. 2018). The passage of the pending Wildlife and Resources Management Bill would help mainstream CREMA and community participation in wildlife and forest resource management into Ghana's institutional framework.

Despite the apparent progress in recent policy development, barriers to implementing these policies and natural resource management schemes persist. As a member of the Convention on Biological Diversity (CBD), Ghana developed the National Biodiversity Strategy (NBSAP) to oversee the sustainable use of biological resources (CBD 2016). The NBSAP report credits the national development agenda with capturing biodiversity issues, but identifies a serious lack of coordination across sectors, particularly at the national level. The report describes a case where a farmer illegally cultivated parts of a wildlife reserve, causing conflict with the Forestry Commission. Yet, the same farmer received a district farming award from the Ministry of Food and Agriculture, and the farm was used as an agricultural demonstration site (CBD 2016, 32). The Ministry of Environment, Science, Technology and Innovation (MESTI), Ministry of Lands and Natural Resources (MLNR) and the Ministry of Food and Agriculture (MoFA) were supposed to establish an environmental desk at their respective ministries to enhance cross-sectorial coordination and prevent cases such as the farmer described above. However, due to a lack of resources and coordinating capacity, the MoFA was the only ministry with an environmental desk at the time of the report (CBD 2016).

A lack of coordinating capacity across sectors is further challenged by a national spatial planning system that has largely operated in isolation from development planning. Acheampong and Ibrahim (2016) describe how 'socio-economic' is treated as separate from 'spatial', leading to two distinct planning systems with different institutional frameworks and policies, further dividing and complicating land-use plans. A need for coordination across sectors and stakeholder groups has become the prevailing narrative throughout the literature assessing Ghana's policies and development objectives (Mensah 2005; CBD 2016; NDPC 2017; UNDP 2018; Government of Ghana 2019). 


\subsubsection{The potential for landscape approaches in Ghana}

When applying the 10 principles of the landscape approach (see Sayer et al. 2013) to the key findings of Ghana's national policy review, two clear gaps emerge: a need to strengthen stakeholder capacity (Principle 10), and a need to negotiate a transparent change logic (Principle 6) across sectors. In order to establish a transparent change logic that is understood and endorsed across sectors and stakeholder groups, identifying common concern entry points (Principle 2 ) and clarifying rights and responsibilities (Principle 7) is needed. The objectives of the Medium-Term National Development Policy (MTDP) framework are focused on restoring the economy, with an emphasis on oil and gas. With large-scale natural resource extraction on the horizon, effective cross-sectorial and multi-stakeholder collaboration is crucial if Ghana is to concurrently fulfil its environmental commitments.

A review of the Medium-Term National Development Policy Framework process revealed there are existing platforms that could be leveraged to enhance stakeholder engagement. For example, the metropolitan, municipal and district assemblies (MMDAs) are designed as a platform for multiple stakeholders (Principle 5) to identify community needs and development priorities. The cross-sectorial planning groups (CSPGs), required to convene at least once every 3 months, also have potential for multi-stakeholder collaboration. As we discussed, there are many policies that support integration of development and conservation objectives (i.e. National Environmental Policy, Forestry Development Master Plan, REDD+, The Forest and Wildlife Policy, etc.) and encourage multifunctional (Principle 4) landscapes; the challenge is ensuring that these policies are enacted.

Although policies and platforms are in place to facilitate improved collaboration across sectors and stakeholder groups, rectifying these issues at the national scale is an enormous undertaking. Foli et al. (2018) assessed some locally embedded natural resource management initiatives in Ghana and Burkina Faso that showed potential to be entry points for integrated landscape approaches. The study found Ghana's CREMAs scheme met most of the desired criteria for operationalizing landscape approaches and showed potential to be scaled up for far-reaching landscape governance (Foli et al. 2018). A commitment to upscale CREMAs could be an excellent opportunity to work toward the aforementioned landscape approach principles.

\subsection{Zambia}

The review focused on Zambia's current development plan (The $7^{\text {th }}$ National Development Plan (7NDP)) and several policies designed to accomplish development objectives. Three key themes were identified: diversification, decentralization and integration. This summary will touch on each, followed by an overview of the related opportunities and constraints for operationalizing landscape approaches within Zambia's current policy climate. 


\subsubsection{Key findings}

Zambia's development is challenged by a vulnerable economy, amplified by the need to meet the demands of a growing population. Between 2006 and 2016, Zambia's population rapidly increased from 11.8 million to 15.9 million (MNDP 2017), with mounting pressure on natural resources for food, wood fuel, infrastructure and income. Informal settlements and expansion of agricultural land have led to the encroachment of game management areas, national parks and forest reserves (GRZ 2006, 2015a; Mabeta et al. 2018). The 7NDP (2017-2021) aims to alleviate these stresses by working toward a resilient economy that enables opportunities for both rural and urban dwellers.

Diversification: Presently, the Zambian economy is heavily dependent on mining and agriculture, both of which are vulnerable to external shocks such as fluctuating market prices and hard-hitting environmental shocks exacerbated by climate change (MNDP 2017). For these reasons, a priority of the 7NDP is establishing a diverse economy, resilient to external shocks. Agriculture, mining and tourism have been prioritized for their high growth potential. Focus has been placed on increasing the productivity of smallholder farmers and the agro-diversification of crops, fisheries, livestock and forestry products (MNDP 2017). To mitigate the effects of climate change, the 7NDP promotes the adoption of climate-smart agriculture techniques such as agroforestry, conservation farming, crop rotation and organic fertilizers (MNDP 2017).

Diversifying agricultural production and the other priority sectors will require significant infrastructure development and investment in small-scale producer groups. Challenges surrounding land tenure, lack of transport and reliable energy threaten production and dissuades investors and long-term investment in land by smallholders. Another challenge is the high cost of taxes and fees (licensing, inspections, impact assessments), preventing long-term investment and proving unaffordable for smallholder producers (MNDP 2017; Mabeta et al. 2018).

Decentralization: The decentralization policy is key to the implementation of the 7NDP, but implementation is contingent on the enactment of the recently (2018) amended Public Finance Act. The policy's objective is to devolve central government authority and resources to provincial, district and subdistrict levels. The policy is supported by a number of existing policies and laws encouraging governance at multiple scales such as the Registration and Development of Villages Act (GRZ 1971). Another example is the Urban and Regional Planning Act of 2015, which established guidelines for multisector and multi-level governance for integrated urban and regional planning (GRZ 2015b). Other examples include the Forestry Policy (2014) and Forests Act (2015), which decentralize forest management through Community Forest Management (CFM), Joint Forest Management (JFM) and Private Forest Management (PFM) (GRZ 2017). To be effective, all of these policies require collaboration with multiple sectors, actors and levels of government, underscoring the importance of integration.

Integration: The 7NDP departs from the prevailing top-down sectorial approach toward a new vision of multisectorial integration. The plan introduced several new coordination mechanisms. The cluster advisory groups (CAGs), composed of sectors 
sharing common objectives, are an example. Prior to the 7NDP officially adopting an integrated approach, several policies, strategies and structural changes were already reflecting this shift and could be utilized to help achieve 7NDP objectives. For instance, the Second National Biodiversity Strategy and Action Plan (NBSAP-2), formulated by the Ministry of Lands, Natural Resources and Environmental Protection (MLNREP) to implement the goals of the Convention on Biological Diversity (CBD) matched CBD targets with groupings of ministries across sectors responsible for their completion (GRZ 2015a). Another notable shift toward integration is the harmonization of the Second National Agricultural Policy (SNAP) and the National Policy on Climate Change (NPCC) (GRZ 2013).

\subsubsection{The potential for landscape approaches in Zambia}

The policy trends outlined reveal favorable conditions for operationalizing landscape approaches. Impressive first steps have been made that align with the 10 principles of the landscape approach (see Sayer et al. 2013). For example, the 7NDP's focus on diversification, specifically through integration, signals Zambia's commitment to adaptive management (Principle 1) and resilience (Principle 9) to external shocks.

Further, national strategies such as the 7NDP and NBSAP-2 recognize the many stakeholders (Principle 5) and land uses (Principle 4) shaping Zambia's landscape. Each of these key development strategies identifies cross-sectorial groups that need to work together, which links to Principle 2 (Common concern entry point) and Principle 7 (Clarify rights and responsibilities). However, for policies constructed at the national level to be successfully realized, they will need to be renegotiated at the provincial, district and ward levels. This ties into Principle 6 (Negotiated and transparent change logic).

Decentralization is a focal point across many of Zambia's strategies and policies. However, the devolution of power means that more people are given more responsibilities, drawing attention to an ongoing struggle in Zambia -lack of capacity. Without the technical capacity, fiscal capacity and necessary skills, it is difficult for people to step into new roles and make the most of the rights they are given. All the national strategies in the review cited lack of capacity as a major roadblock to the success of previous plans. Consequently, this has resulted in unfulfilled potential of well-intended acts and policies. One of the greatest consequences of lack of capacity is the inability to monitor and evaluate and share information (Principle 8). Without monitoring and evaluation, it is difficult to learn and adapt (Principle 1) and understand changes at multiple scales (Principle 3), which ultimately reduces resilience (Principle 9).

Strengthening stakeholder capacity is simultaneously the biggest challenge and the best opportunity for operationalizing landscape approaches in Zambia, especially since capacity building takes time and Zambia is facing pressure to develop rapidly. A lack of capacity makes it difficult to operationalize landscape approaches, as nearly all the other principles depend on it. At the same time, this underscores how impactful investing in Principle 10 (Strengthened stakeholder capacity) could be. 


\subsection{Indonesia}

The review focused on Indonesia's current development approach and several policies and plans designed to accomplish environmental and developmental objectives. The Indonesian Sustainable Palm Oil (ISPO) policy, One Map policy, and the Social Forestry policy were selected for a more in-depth analysis of Indonesian policy in practice. These policies were selected based on their alignment with the goals of the current National Development Plan, as well as many of the objectives of a landscape approach. Consequently, these examples provide valuable insights into the potential challenges and opportunities for operationalizing landscape approaches in Indonesia.

\subsubsection{Key findings}

Indonesia's development is guided by the National Long-Term Development Plan (RPJPN) for the period 2005-2025. The RPJPN is broken into four, 5-year stages, referred to as the National Medium-Term Development Plans (RPJMN). The most recent MediumTerm Development Plan for the period 2015-2019 identified an inclusive green economy as the pathway forward for development (LSE 2015). Establishing a green economy requires overcoming Indonesia's long-standing challenges with transparency, inclusion and regulation, which have created a dichotomy between conservation and development and forest and non-forest areas. This has manifested into the exploitation of natural resources, extreme biodiversity loss and the marginalization of vulnerable groups.

In Indonesia, planning processes tend to fall into one of three streams: national spatial planning (RTRWN), development planning (RPJPN) and strategic environmental assessment (KLHS). The KLHS is meant to underpin spatial planning and development to ensure sustainable land use, but evidence of this in practice remains scarce. For example, RTRWN is supported by Law 26/2007 which stipulates that provincial and local land-use policy should be formulated based on the region's environmental carrying capacity (Ardiansyah et al. 2015). Yet, ongoing deforestation and peatland degradation clearly indicate a discrepancy between policy and practice.

In addition to the horizontal disconnect across sectors and planning streams, a vertical disconnect also exists. Decentralization in Indonesia is supported by a number of laws and policies devolving rights and responsibilities from central to local government (i.e. Law 32/2004 on Regional Administration, Law 33/2004 on Fiscal Balance between Central and Regional Governments, Law 23/2014 on the Village). Decentralization is important for giving local governments the authority to address their context-specific needs, but these decentralized roles and responsibilities must be clearly defined. Further, a lack of coordination and communication has resulted in policies issued at the national scale contradicting those formed by provincial and local governments and adat (customary) law (Pisani 2014; Ardiansyah et al. 2015).

When analyzing the ISPO, Social Forestry and One Map policies, these vertical and horizontal disconnects become even more apparent. For example, the ISPO is a policy adopted by the Ministry of Agriculture with the aim of improving the competitiveness of palm oil on the global market, meet greenhouse gas reduction targets and adhere to 
biodiversity conservation policies (ISPO 2013). While the policy was made mandatory in 2014 for all oil palm plantations, smallholders were given until 2020 to comply (Jelsma and Schoneveld 2016). Yet, to date, less than $1 \%$ of smallholders are certified under ISPO (Jong 2018). ISPO certification requirements are difficult to meet for smallholders who manage their land without formal boundaries, have no proof of land ownership and have poor access to extension services. This shows a vertical disconnect between ISPO requirements designed at the national scale and on-the-ground realities. ISPO also illustrates a horizontal disconnect. Oil palm plantations for biofuel production are exempt from ISPO certification. Indonesia has one of the most ambitious biofuel blending targets in the world, predicated on the expansion of oil palm plantations and conflicting with the National Action Plan to Reduce Greenhouse Gas Emissions (RANGRK) and other environmental policies (Anderson et al. 2016; Artati et al. 2019).

A closer look at the Social Forestry policy and One Map policy reveals a similar story. The One Map policy aims to reconcile land-use conflicts through a single, unified map. The policy has reportedly reconciled 85 maps managed by 19 government agencies across the country (Gokkon 2018). However, there are criticisms of the One Map policy and public participation. Communities often do not have access to mapping tools, but some have received support from the Participatory Mapping Network (JKPP). These maps were rejected by the Geospatial Information Agency (Badan Informasi Geospasial or BIG), because of the use of a less accurate GPS receiver, but the 'standard' device was much more expensive (Shahab 2016). This begs the question: for whom and at what scale is this policy accessible? And what will these 'reconciled' maps look like on the ground? It should be noted that Social Forestry maps will be included in the One Map database, at the behest of President Joko Widodo's Social Forestry policy.

Social Forestry aims to devolve legal access to state forest land to improve land rights, support livelihoods and achieve conservation outcomes through five different social forestry schemes (Fisher et al. 2018). The Social Forestry program is regulated by Social Forestry decree P83/2016 and administered through the Forestry Agency. The policy is legally mandated by the MoEF and thus regulated by forestry laws. However, Social Forestry falls under the category of land use, meaning it is also bound by laws on villages, land, spatial planning and the national and regional development plans (Moeliono et al. 2017). This has made the program difficult to navigate and regulate. In addition, the Social Forestry permitting process is expensive and requires technical and fiscal capacity to map forest boundaries and provide the required documentation. Again, this highlights the vertical disconnect between policy and implementation.

\subsubsection{The potential for landscape approaches in Indonesia}

A number of landscape approach principles (see Sayer et al. 2013) are reflected in Indonesia's national policies and plans. Indonesia's National Medium-Term Development Plan acknowledges multiple land uses (Principle 4) and the need to reconcile development and conservation objectives to enhance resilience (Principle 9) and climate change adaptation (Principle 1) through the development of an inclusive green economy. To make this goal a reality, changes are needed to improve transparency, enhance regulation and prevent the exclusion of marginalized groups. 


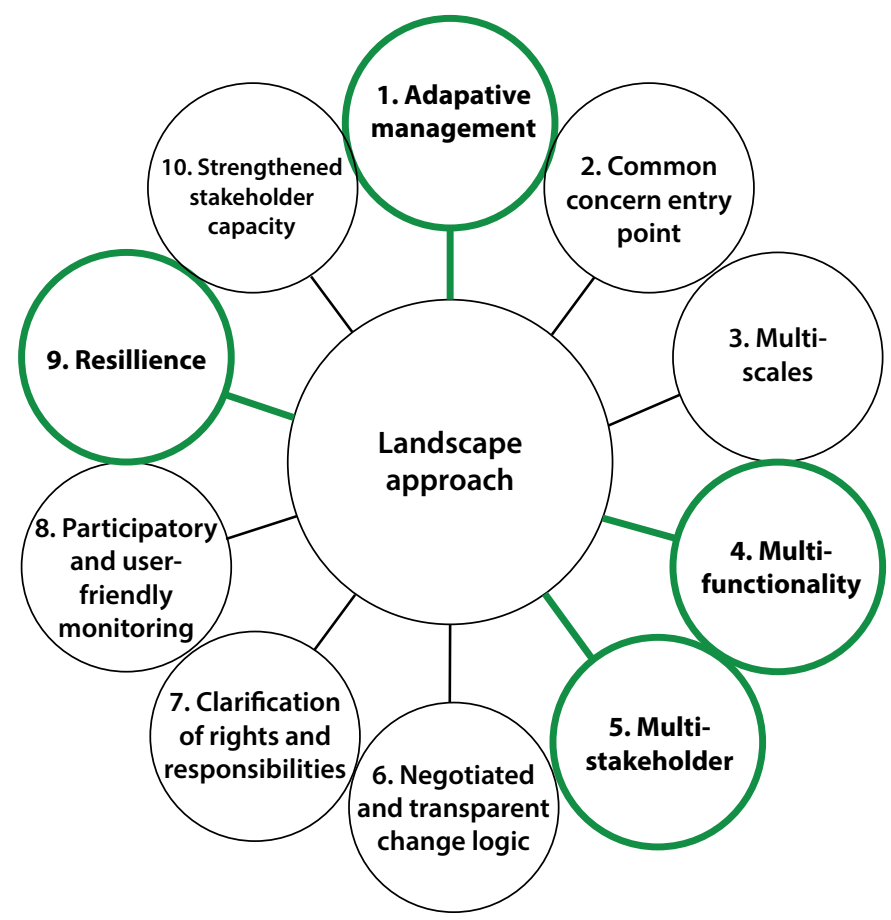

Figure 7.2 Common landscape approach principles found across each country's national development plans.

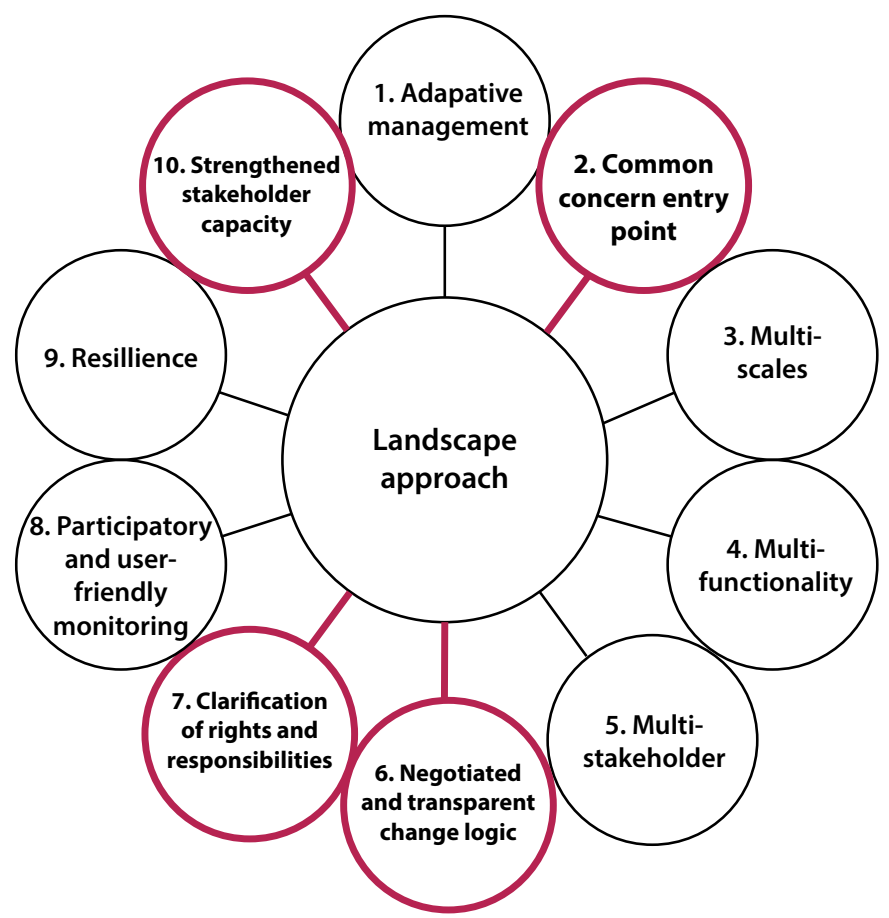

Figure 7.3 Landscape approach principles requiring further action. 
The three policies discussed have sought to address these challenges. For example, the ISPO policy had potential to act as a regulatory framework for sustainable palm oil production. The One Map policy was designed to improve transparency and clarify land rights (Principle 7). One Map also recognizes the multifunctionality (Principle 4) and multiple stakeholders across a landscape (Principle 5). Finally, the Social Forestry policy aims to give rights and responsibilities (Principle 7) to communities in hopes of fostering community forest management that increases stakeholder capacity (Principle 10) and allows the integrated management of multiple land uses (Principle 4).

However, as the discussion of the three policy examples revealed, national policy has seldom led to implementation at the local scale. The ISPO requirements proved inaccessible for smallholders, although with the appropriate support, smallholder groups have the potential to significantly impact conservation and development outcomes. Moreover, the objectives of the policy contradicted those from other sectors. In the case of the One Map policy, technical capacity was a limiting factor for the participation of communities. Finally, the Social Forestry policy's goal to devolve rights to communities was overshadowed by top-down and rigidly structured requirements for each Social Forestry scheme and permitting process.

A closer look at these policies and the barriers to their implementation offers valuable insights into potential constraints and opportunities for operationalizing landscape approaches in Indonesia. These challenge areas are where landscape approach principles could be of greatest assistance. Particularly identifying common concern entry points (Principle 2), clarifying rights and responsibilities (Principle 7) and enhancing stakeholder capacity (Principle 10) are particularly need to move forward. Meanwhile, adopting landscape approaches that engages multiple stakeholders (Principle 5) to identify a negotiated and transparent change logic (Principle 6) would offer significant potential to enhance Indonesian policy performance and ensure that policy development is more representative of national and local concerns and practices.

\section{Concluding remarks}

Although the context and policies in each country were vastly different, common findings emerged (Figures 7.2 and 7.3). First, each country's national development plan called for development that enhances adaptive management (Principle 1) to foster a more resilient (Principle 9) economy and environment, especially in the face of climate change. This is fundamental to the process of implementing landscape approaches. The plans recognize multiple land uses (Principle 4) and stakeholders (Principle 5); again, very much in line with landscape approach thinking. Further, each country's development plan had an element of decentralizing land management rights and responsibilities to different stakeholder groups. However, peer-reviewed papers and project reports showed that in many cases, these well-intended policies had yet to be implemented, or fell short in practice.

Overall, there is a need to clarify rights and responsibilities (Principle 7), enhance stakeholder capacity (Principle 10), identify common concern entry points (Principle 2) 
and to find a negotiated and transparent change logic (Principle 6) that resonates at not just the national level, but at regional and local levels too. We suggest that a greater commitment to these principles and the adoption of landscape approaches holds potential for each of the countries to aid delivery of their respective environment and development objectives.

\section{References}

Acheampong RA and Ibrahim A. 2016. One nation, two planning systems? Spatial planning and multi-level policy integration in Ghana: mechanisms, challenges and the way forward. Urban Forum 27(1): 1-18.

Acheampong E, Insaidoo TF and Ros-Tonen MAF. 2016. Management of Ghana's modified taungya system: Challenges and strategies for improvement. Agroforestry Systems 90(4): 659-74.

Adom D. 2017. Challenges to the efficacy of forestry and wildlife policies in Ghana for environmental protection: A review. African Journal of Agricultural Research 12(39): $2858-76$.

Anderson ZR, Kusters K, McCarthy J and Obidzinski K. 2016. Green growth rhetoric versus reality: Insights from Indonesia. Global Environmental Change 38: 30-40.

Ardiansyah F, Marthen AA and Amalia N., 2015. Forest and land-use governance in a decentralized Indonesia: A legal and policy review. Occasional Paper 132. Bogor, Indonesia: CIFOR.

Artati Y, Jaung W, Juniwaty KS, Andini S, Lee SM, Segah H and Baral H. 2019. Bioenergy Production on degraded land: Landowner perceptions in Central Kalimantan, Indonesia. Forests 10(2): 99-110.

[CBD] Convention on Biological Diversity. 2016. National Biodiversity Strategic Action Plan 2016. Republic of Ghana. Ministry of Environment, Science, Technology, and Innovation. Accra. November 2016. Accessed 20 November 2019. https://www.cbd. int/countries/?country=gh.

Fisher MR, Moeliono M, Mulyana A, Yuliani EL, Adriadi A, Judda J and Sahide MAK. 2018. Assessing the new social forestry project in Indonesia: recognition, livelihood and conservation? International Forestry Review 20(3): 346-61.

Foli S, Ros-Tonen MAF, Reed J and Sunderland T. 2018. Natural resource management schemes as entry points for integrated landscape approaches: Evidence from Ghana and Burkina Faso. Environmental Management 62(1): 82-97.

Forestry Commission. 2016. Ghana REDD + Strategy 2016-2035. Accra. Accessed 19 November 2019. https:/www.fcghana.org/userfiles/files/REDD+/Ghana\%20 REDD+\%20Strategy.pdf.

Gokkon B. 2018. One Map to rule them all: Indonesia launches unified land-use chart. Mongabay Series: Jokowi Commitments. Accessed 5 February 2019. https://news. mongabay.com/2018/12/one-map-to-rule-them-all-indonesia-launches-unifiedland-use-chart/. 
[GRZ] Government of the Republic of Zambia. 2017. National Investment Plan to Reduce Deforestation and Forest Degradation (2018-2022). Ministry of Lands and Natural Resources. Accessed 5 January 2019. https://www.climateinvestmentfunds.org/sites/ cif_enc/files/meeting-documents/zambia_final_investment_plan_fip.pdf.

[GRZ] Government of the Republic of Zambia. 2015a. Zambia's Second National Biodiversity Strategy and Action Plan (NBSAP-2) 2015-2025. Ministry of Lands, Natural Resources and Environmental Protection. Lusaka, Zambia. Accessed 5 January 2019. https:// www.cbd.int/doc/world/zm/zm-nbsap-v2-en.pdf.

[GRZ] Government of the Republic of Zambia. 2015b. Urban and Regional Planning Act. Lusaka, Zambia. Accessed 5 January 2019. http://www.parliament.gov.zm/sites/ default/files/documents/acts/The\%20Urban\%20and\%20Regional\%20Planning\%20 \%20Act\%2C\%202015.pdf.

[GRZ] Government of the Republic of Zambia. 2013. The Harmonization of the National Agriculture Policy (NAP) and the National Policy on Climate Change (NPCC) of the Government of the Republic of Zambia. Final Report. The Ministry of Agriculture and Livestock (MAL) and the Ministry of Lands, Natural Resources and Environmental Protection (MLNREP). Accessed 5 January 2019. http://www.fao.org/docrep/o18/ aq666e/aq666e.pdf.

[GRZ] Government of the Republic of Zambia. 2006. Republic of Zambia: Vision 2030. Lusaka, Zambia: Government of the Republic of Zambia.

[GRZ] Government of the Republic of Zambia. 1971. Chapter 289 The Registration and Development of Villages Act. Accessed 10 January 2019. http://www.parliament.gov.zm/ sites/default/files/documents/acts/Registration\%20and\%20Development\%20of\%20 Villages\%20Act.pdf.

Government of Ghana. 2019. Ghana: Voluntary National Review Report on the Implementation of the 2020 Agenda for Sustainable Development. National Development Planning Commission. Accra. June 2019. Accessed 20 November 2019. https:// sustainabledevelopment.un.org/content/documents/23420Ghanas_VNR_report_ Final.pdf.

[ISPO] Indonesian Sustainable Palm Oil. 2013. Accessed 5 November 2019. http://www. ispo-org.or.id/index.php?lang=en.

Jelsma I and Schoneveld GC. 2016. Towards more sustainable and productive independent oil palm smallholders in Indonesia: Insights from the development of a smallholder typology. Working Paper 210. Bogor, Indonesia: CIFOR.

Jong HN. 2018. Small farmers not ready as Indonesia looks to impose its palm oil sustainability standard on all. Mongabay. Accessed 5 January 2019. https://news.mongabay. com/2018/04/small-farmers-not-ready-as-indonesia-looks-to-impose-its-palm-oilsustainability-standard-on-all/.

[LSE] London School of Economics and Political Science. 2015. Indonesia-National Medium Term Development Plan. Grantham Research Institute on Climate Change and the Environment. Accessed 25 September 2019. https:/www.climate-laws.org/ geographies/indonesia/policies/national-medium-term-development-plan-20152019-rpjmn-2015-2019. 
Mabeta J, Mweemba B and Mwitwa J. 2018. Zambia Policy Brief\#3: Key drivers of biodiversity loss in Zambia. Biodiversity Finance Initiative (BIOFIN). Accessed 25 September 2019. http:/www.biodiversityfinance.net/sites/default/files/content/knowledge_products/ BIOFIN\%20ZM\%2OPB\%20\%233-Drivers\%20of\%2obiodiversity\%2oloss\%20in\%20 Zambia.pdf.

Mensah, J. 2005. Problems of district medium-term development plan implementation in Ghana: The way forward. International Development Planning Review 27(2): 245-70.

[MLNR] Ministry of Lands and Natural Resources. 2016. Forestry Development Master Plan (2016-2036). Accra: MLNR, Republic of Ghana. Accessed 20 November 2019. https:// www.fcghana.org/userfiles/files/MLNR/FDMP\%20Final\%20(2).pdf.

[MLNR] Ministry of Lands and Natural Resources. 2012. Forest and Wildlife Policy. Accra: MLNR, Republic of Ghana. Accessed 20 November 2019. https://www.documents. clientearth.org/wp-content/uploads/library/2012-01-o1-ghana-forest-and-wildlifepolicy-2012-ext-en.pdf.

[MNDP] Ministry of National Development Planning. 2017. The Seventh National Development Plan 2017-2021. Zambia: Ministry of National Development Planning. Lusaka, Zambia. Accessed 25 September 2019. http://extwprlegsi.fao.org/docs/pdf/ zam170109.pdf.

Moeliono M, Pham TT, Bong IW, Wong GY and Brockhaus M. 2017. Social Forestry -why and for whom? A comparison of policies in Vietnam and Indonesia. Forest and Society 1(2): $1-20$.

[NDPC] National Development Planning Commission. 2017. Medium-Term National Development Policy Framework. An Agenda for Jobs: Creating prosperity and equal opportunity for all. 2018-2021. Volume 1: Policy Framework. National Development Planning Commission, Government of Ghana. Accessed 5 October 2020. https://s3us-west-2.amazonaws.com/new-ndpc-static1/CACHES/PUBLICATIONS/2018/08/23/ Medium-term+Policy+Framework-Final+June+2018.pdf.

National REDD+ Secretariat. 2017. Ghana's national forest reference level. Accra, Ghana. Accessed 25 November 2019. https://redd.unfccc.int/files/ghana_national_reference level_01.01_2017_for_unfccc-yaw_kwakye.pdf.

Pisani E. 2014. Indonesia in pieces. The downside of decentralization. Foreign Affairs 93(4): $142-152$.

Sayer J, Sunderland T, Ghazoul J, Pfund J.L, Sheil D, Meijaard E, Venter M, Boedhihartono A.K, Day M, Garcia, C and Van Oosten C. 2013. Ten principles for a landscape approach to reconciling agriculture, conservation, and other competing land uses. Proceedings of the National Academy of Sciences USA 110(21): 8349-56.

Shahab N. 2016. Indonesia One Map Policy. Open Government Partnership. Accessed 5 September 2019. https:/www.opengovpartnership.org/sites/default/files/casestudy_Indonesia_One-Map-Policy.pdf.

[UNDP] United Nations Development Programme. 2018. Northern Ghana Human Development Report. Bridging the Poverty Gap and Fostering Socioeconomic Transformation and Empowerment to Contribute to Human Development for All. Accessed 25 November 2019. https://www.gh.undp.org/content/dam/ghana/docs/Reports/UNDP_NG_ HDR\%20Report_\%202018_GC_Online.pdf. 


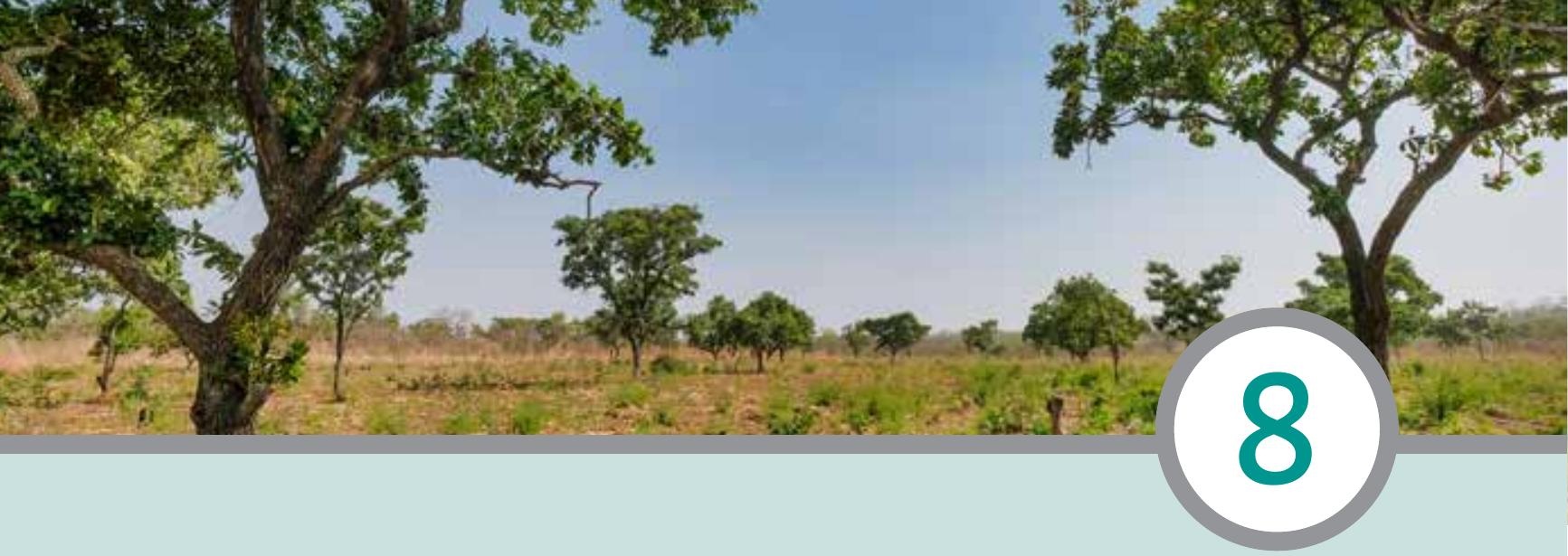

\section{Context for landscape approach implementation in the Western Wildlife Corridor Landscape (Northern Ghana)}

Eric RC Bayala, Houria Djoudi, Mirjam Ros-Tonen and Mathurin Zida

\section{Introduction}

West African forest and savannah ecosystems contain important biodiversity that provides numerous goods and services to local people. However, these landscapes are increasingly under enormous anthropogenic pressures, leading to habitat fragmentation and the concomitant loss of biological diversity. Climate change further constrains the conservation of natural resources (Dimobe 2017) and associated challenges of food insecurity and poverty have made the sustainable management of tropical landscapes an urgent priority (Reed et al. 2016; Barlow et al. 2018). Indeed, one of the major challenges of the $21^{\text {st }}$ century is to overcome conflicts between biodiversity conservation, food production and livelihoods (Ouko 2018).

Since the 1970s, several initiatives such as biosphere reserves and communitybased natural resource management (CBNRM) have been used worldwide to simultaneously address the challenge of biodiversity conservation and poverty alleviation, while putting local communities at the centre of decision-making (Clay 2016; Ouko 2018; Green 2016). In Ghana, this is reflected in the establishment 
of Community Resource Management Areas (CREMAs). These 32 CREMAs ${ }^{1}$, spread throughout 26 districts of the country, are managed under a community governance regime, involving community institutions, the district assembly and other local administrative structures (Agyare et al. 2015; IUCN 2017; Foli et al. 2018; Murray et al. 2018). The concept was developed in the 2000 s as an alternative to the exclusive and centralized model of wildlife governance and as a means to reduce pressure on national parks and wildlife reserves (Foli et al. 2018). The scheme has been applauded for empowering local communities around protected areas in governing their landscapes, in the hope that they will actively contribute to reconciling conservation objectives with those related to their livelihoods (Agyare et al. 2015). However, like any CBNRM scheme, the Ghanaian model also faces constraints related to the plurality of actors with diverse interests, objectives, perceptions and expectations (Agyare et al. 2015). Sectorial interventions persist, particularly among those in charge of agriculture, livestock, mining and natural resource management, thus increasing conflicts over the use of landscape resources (Foli et al. 2018). These constraints compromise the achievement of conservation and development outcomes and inclusive governance (Agyare et al. 2015).

Sectorial approaches are considered insufficient to address complex social, environmental, economic and political challenges in the current context of strong growth in demand for food and natural resources (Godfray et al. 2010; Foley et al. 2011; Tscharntke et al. 2012; Green 2016). Hence, the call for integrated and adaptive landscape approaches as a solution for landscape management (Reed et al. 2016). Such an approach requires enhanced collaboration between local government, populations, and other stakeholders involved in the landscapes of concern (Lindsay 2018). Indeed, the success of landscape approaches is closely linked to inclusive and participatory negotiation between the various stakeholders and the involvement of rural communities (Reed et al. 2017).

With a view to operationalizing this approach, the Center for International Forestry Research, through its COLANDS initiative (Collaborating to Operationalize Landscape Approaches for Nature, Development and Sustainability), has targeted Ghana, Zambia and Indonesia as research sites. This chapter presents and analyzes the Ghanaian context, based on a review of scientific and grey literature; a scoping study during which we interviewed representatives of government agencies, NGOs, as well as representatives of the local population; and considering the ten landscape approach principles by Sayer et al. (2013) as a guiding conceptual framework. We pay attention, respectively, to the general, biophysical and socioeconomic characteristics of the study site (Sections 8.1-8.3), local governance structures, including the CREMA system (Section 8.4), and both the potential and the limitations of existing multi-stakeholder platforms (Section 8.5 ). Section 8.6 concludes the chapter.

1 Ghana has thirty-two CREMAs. Twenty-four of these are certified for devolution of authority and responsibility for natural resource management, and are fully operational. Eight are at various stages of development and have not yet received their certificates of devolution. The CREMAs are located in about twenty six districts in seven regions of Ghana (IUCN, 2017). 


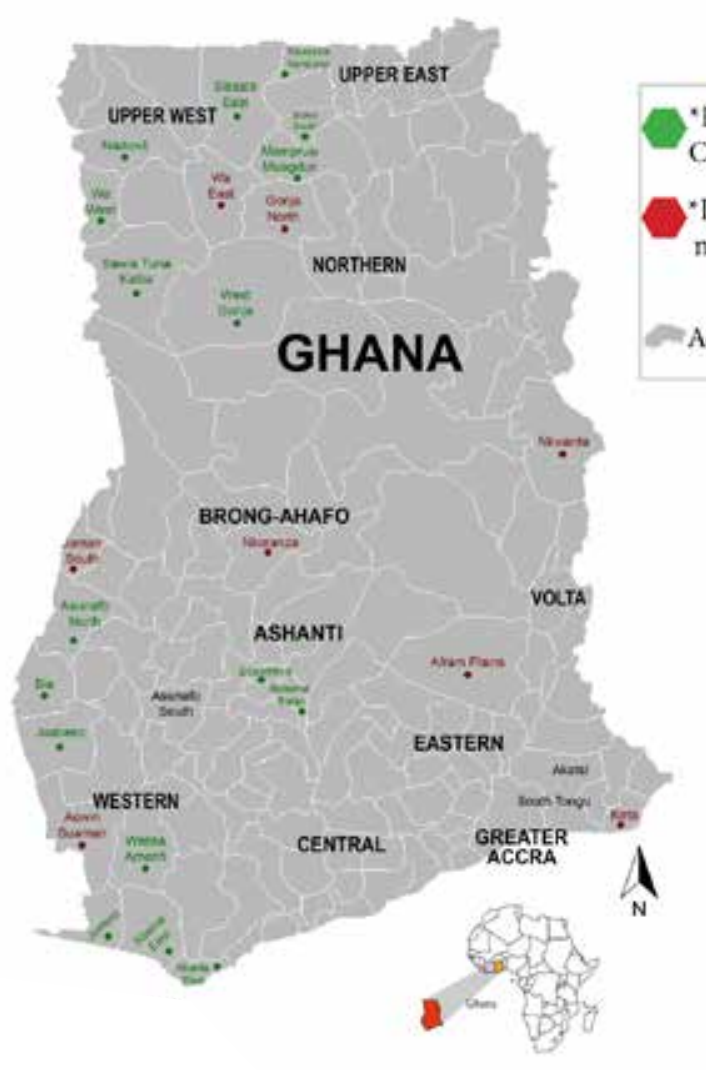

Figure 8.1 Spatial distribution of CREMAs

Source: Adapted from Agyare (2017) and taken from IUCN (2017)

\subsection{The Western Wildlife Corridor}

\subsubsection{General information and CREMA setting}

The Western Wildlife Corridor (WWC) in the north of Ghana was selected as the focal landscape of the COLANDS initiative, based on the presence of CREMAs, multiple stakeholders in the landscape, and potentially conflicting uses of landscape resources. The WWC is a vast ecosystem covering approximately $3,713 \mathrm{~km}^{2}$, stretching from the Ranch de Nazinga wildlife reserve (Burkina Faso) in the North to the Mole National Park (Ghana) in the South. With a length of $104 \mathrm{~km}$, it is essentially comprised of natural forests, some of which are classified as forest reserves under the jurisdiction of the Ghana Forestry Commission. The Corridor was established through the implementation of the Northern Savanna Biodiversity Conservation (NSBC) project. This project, implemented by the World Bank/Global Environmental Facility, aimed to improve the environment, livelihoods and health in the northern savanna zone of Ghana through the conservation and sustainable use of natural resources. The global environmental objective was to identify, monitor and conserve key components of the biodiversity of the northern savanna zone. The WWC is one of the two corridors-along with the 


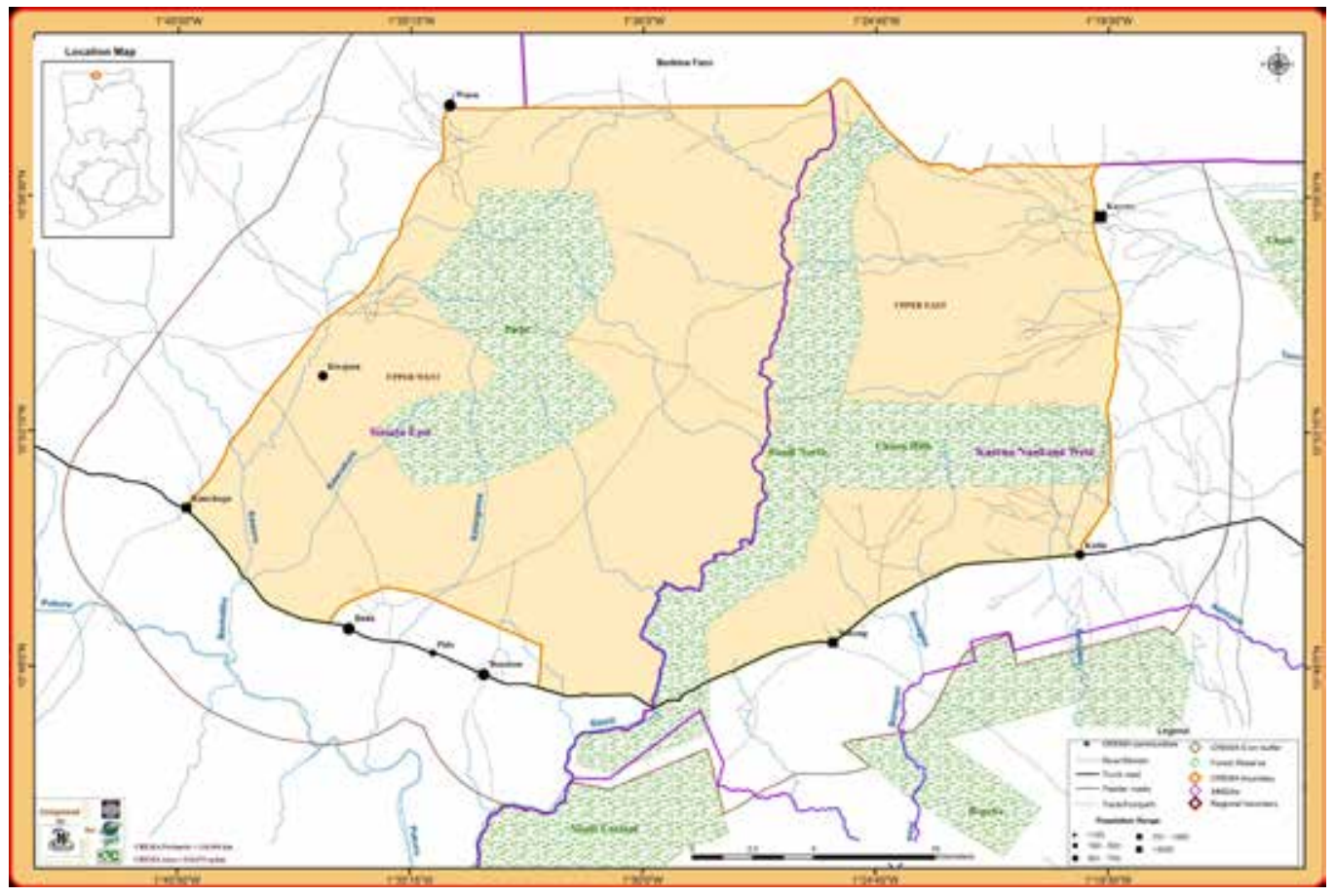

Figure 8.2 The Sanyiga Kasena Gavara Kara (SKGK) CREMA

Source: Wildlife Division of the Forestry Commission of Ghana

Eastern Corridor-implemented by the project (which ran from 2002 to 2008) to facilitate/enable the migration of wild animals from Burkina Faso to Ghana.

The WWC contains three official CREMAs, each with a certificate of devolution of authority and responsibility for natural resources management. They are distributed over four districts and two administrative regions. The Sanyiga Kasena Gavara Kara (SKGK) CREMA, shared between the Kassena Nakana West and Sissala East Districts, and the Builsa Yenning CREMA in the Builsa South District, are both located in Upper East Region. The Moagduri Wuntaluri Kuwosaasi CREMA in Mamprugu Moagduri District is located in the North East Region. ${ }^{2}$ Maps 8.2, 8.3 and 8.4 show the location of these CREMAs.

Each of these CREMAs is comprised of a number of communities that exploit the landscape's resources for their livelihoods, and contribute to the management of these resources through local governance bodies. Several villages and permanent farms have been set up along the WWC (Bouché 2007). The CREMAs are characterized as follows (Table 8.1).

2 The North East Region was part of the Northern Region until 2018, when the number of administrative regions in Ghana increased from 10 to 16 by splitting some large regions. The former Northern Region was split into three: the Northern, Savannah and North East Regions. 


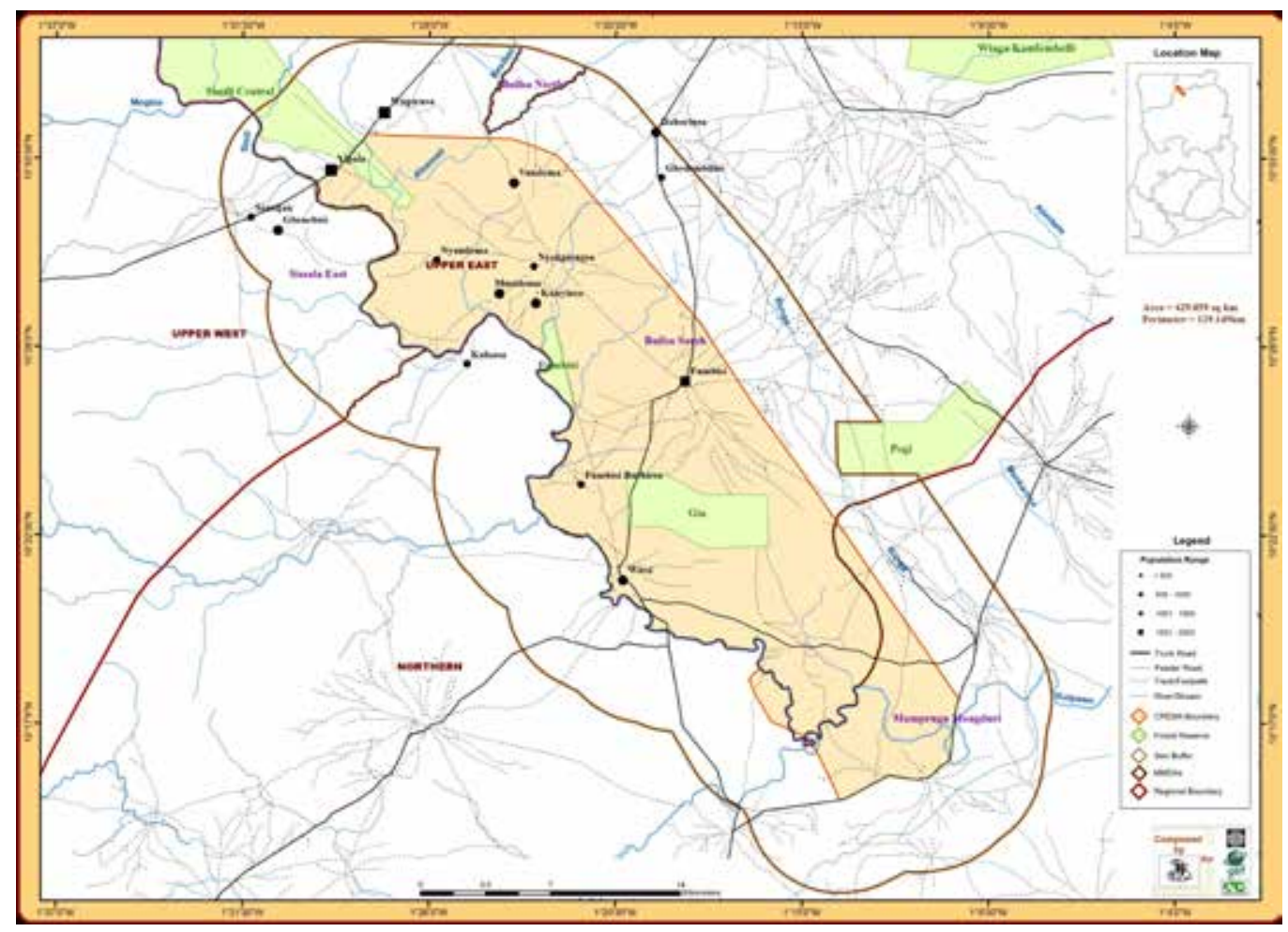

Figure 8.3 The Builsa Yenning CREMA

Source: Wildlife Division of the Forestry Commission of Ghana

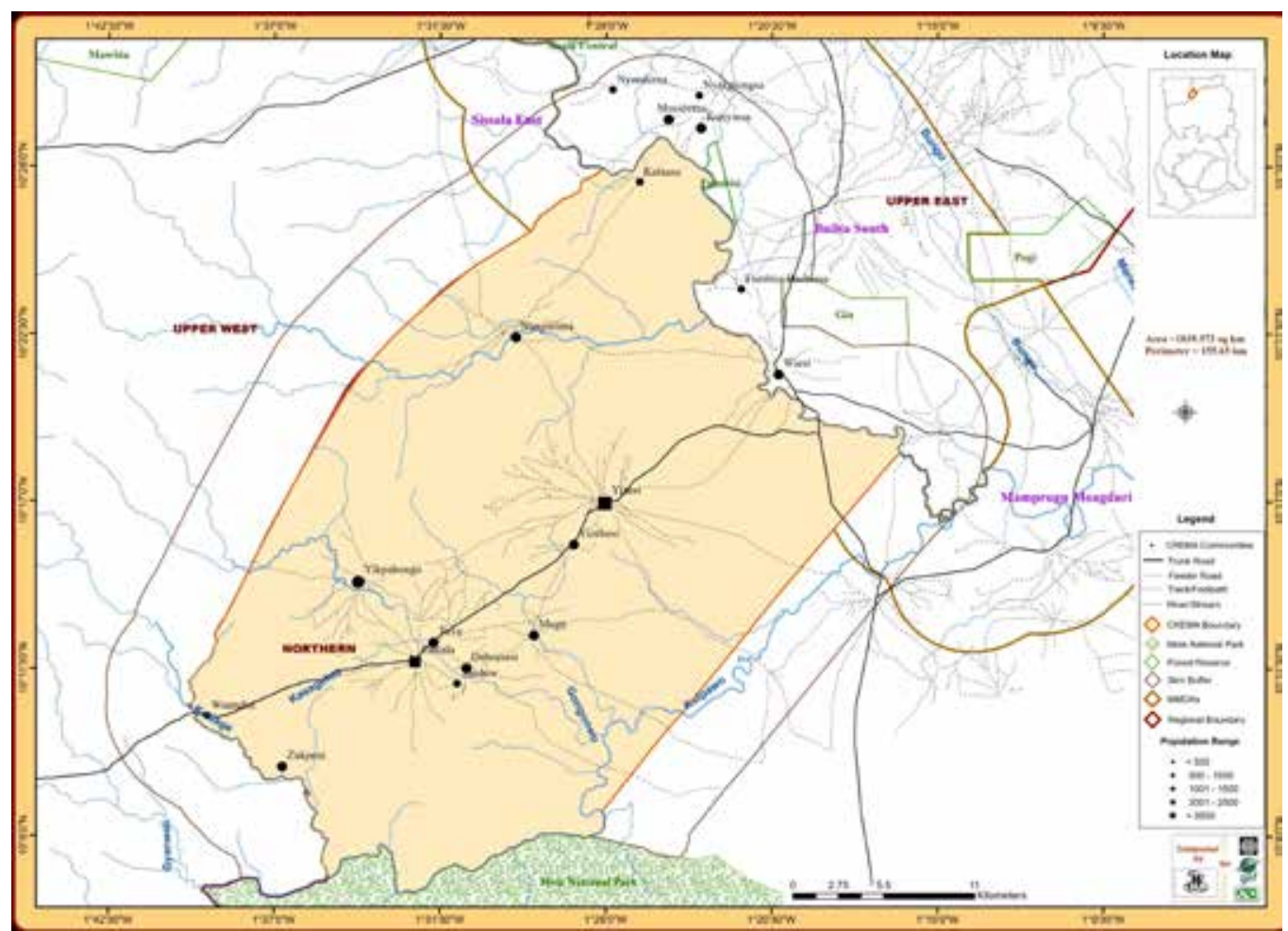

Figure 8.4 The Moagduri Wuntaluri Kuwosaasi CREMA

Source: Wildlife Division of the Forestry Commission of Ghana 
Table 8.1 Characteristics of CREMAS.

\begin{tabular}{|c|c|c|c|}
\hline Name of CREMA & Size & Villages & Geographical limits \\
\hline $\begin{array}{l}\text { Sanyiga Kasena Gavara } \\
\text { Kara (SKGK) }\end{array}$ & $587 \mathrm{~km}^{2}$ & $\begin{array}{l}\text { Katiu, Nakong and Kayoro in } \\
\text { Kasena Nankana West District; } \\
\text { and Basesam, Pido, Baliu, } \\
\text { Kunchoro, Kwapun and Wuru in } \\
\text { the Sissala East District }\end{array}$ & $\begin{array}{l}\text { Between longitudes } 1^{\circ} 18^{\prime} \\
00^{\prime \prime} \mathrm{W} \text { and } 1^{\circ} 39^{\prime} \circ 0^{\prime \prime} \mathrm{W}, \\
\text { and latitudes } 10^{\circ} 45^{\prime} 45^{\prime \prime} \\
\mathrm{N} \text { and } 11^{\circ} \circ 0^{\prime} 12^{\prime \prime} \mathrm{N}\end{array}$ \\
\hline Builsa Yenning & $430 \mathrm{~km}^{2}$ & $\begin{array}{l}\text { Gbedembilisi, Wiesi, Bachiesa, } \\
\text { Fumbisi, Kunyingsa, Musidema, } \\
\text { Vundema, Kalasa, Nyandema and } \\
\text { Nyankpiengsa }\end{array}$ & $\begin{array}{l}\text { Between longitudes } 1^{\circ} 10^{\prime} \\
30^{\prime \prime} \mathrm{W} \text { and } 1^{\circ} 32^{\prime} \circ 0^{\prime \prime} \mathrm{W}, \\
\text { and latitudes } 10^{\circ} 14^{\prime} 30^{\prime \prime} \\
\mathrm{N} \text { and } 10^{\circ} 34^{\prime} 25^{\prime \prime} \mathrm{N}\end{array}$ \\
\hline $\begin{array}{l}\text { Moagduri Wuntanluri } \\
\text { Kuwomsaasi (MWK) }\end{array}$ & $1,040 \mathrm{~km}^{2}$ & $\begin{array}{l}\text { Yezesi, Yezebisi, Tantala, Mugu, } \\
\text { Tandow, Dabozesi, Tuvuu, } \\
\text { Yikpabongo, Zukpeni, and } \\
\text { Wuntobri Nangruma }\end{array}$ & $\begin{array}{l}\text { Between longitudes } 1^{\circ} 17^{\prime} \\
00^{\prime \prime} \mathrm{W} \text { and } 1^{\circ} 39^{\prime} 45^{\prime \prime} \mathrm{W} \\
\text { and latitudes } 10^{\circ} 4^{\prime} \mathrm{N} \text { and } \\
10^{\circ} 28^{\prime} 30^{\prime \prime} \mathrm{N}\end{array}$ \\
\hline
\end{tabular}

Source: Mamprugu Moagduri District Assembly (2017)

\subsection{The biophysical context of Western Wildlife Corridor}

The WWC shares the same biophysical conditions that characterize the entire Northern Ghana region.

\subsubsection{Climate}

Northern Ghana has a tropical climate, with only one rainy season and one dry season. The rainy season is from April to October, when the monsoon is a humid wind. The average annual rainfall is around $900 \mathrm{~mm}$ in Bolgatanga to $1,100 \mathrm{~mm}$ in Mole National Park, but its distribution in time and space is unpredictable (Braimoh and Vlek 2005; Bouché 2007). The dry season is marked by the harmattan, a dry wind from the Sahara, and lasts from December to March. During this period, the days are very hot and the nights are cool. The average annual temperature is about $27^{\circ} \mathrm{C}$, with extremes of $10^{\circ} \mathrm{C}$ and $40^{\circ} \mathrm{C}$ (Wilson 1993; Bouché 2007).

\subsubsection{Soil, relief and hydrography}

As a whole, Ghana is a country of low plateaus. In the northern and south-eastern parts, altitudes do not exceed $500 \mathrm{~m}$. Specifically in the WWC, the altitude varies between $120 \mathrm{~m}$ and $490 \mathrm{~m}$ (Bouché 2007). In terms of hydrological networks, Northern Ghana is crossed by the Black Volta and White Volta Rivers, which join to form the Volta River that flows southward. Its waters have been retained in the country's south-east to create the Akosombo hydro-electric dam, thus creating Lake Volta, $550 \mathrm{~km}$ long and with a surface area of $8,502 \mathrm{~km}^{2}$.

Lake Volta is one of the largest artificial lakes in the world. However it is affected by recurrent droughts and a decrease in rainfall, which induce a progressive decrease of its water level. ${ }^{3}$

3 http://www.atlas-monde.net/afrique/ghana/ 
The soils in Northern Ghana are characterized by a layer of iron sandstone, which has developed from sandstone materials. Plant roots develop with difficulty at shallow depths. Generally sandy and not very acidic, the soils in the study area are very poor in organic matter, nitrogen and phosphorus (Braimoh and Vlek 2005).

\subsubsection{Ecological context: fauna and flora}

Northern Ghana covers an area of $97,702 \mathrm{~km}^{2}$ or 41 percent of the national territory.

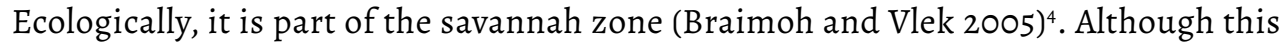
area is the driest part of the country, due to its proximity to the Sahara Desert, it has rich and varied ecosystems. Dominated by a Guinean savannah, it is characterized by grasslands and both open and closed woodlands (Braimoh and Vlek 2005). The area is considered to be one of the most important wildlife sanctuaries in Ghana, with species such as the elephant (Loxodonta africana), roan antelope (Hippotragus equinus), patas monkey (Erythrocebus patas), baboon (Papio anubis), green monkey (Cercopithecus aethiops), many reptiles and amphibians and numerous resident and migratory birds (Owusu-Ansah 2018). The woody species encountered are mainly Vitellaria paradoxa, Combretum spp., Acacia spp., Anogeissus leiocarpa, Afzelia africana, Burkea africana, Isoberlinia doka, Terminalia spp., Adansonia digitata, Boscia senegalensis, Calotropis procera, Lannea microcarpa, Parkia biglobosa, Pterocarpus erinaceus, etc. forming most of the woody savannas. Forest galleries border the main rivers and host species such as Danielia oliveri, Terminalia spp., Anogeissus leiocarpa and Khaya senegalensis (Bouché 2007; Owusu-Ansah 2018).

The main nature reserves located in Northern Ghana are:

- Gbele Game Production Reserve and Bird Sanctuary $\left(565.4 \mathrm{~km}^{2}\right)$ : established in 1975 by the Sissala East District Assembly in collaboration with the Wildlife Division of the Forestry Commission. It partly covers the districts of Wa, Nadowli and Sissala East. The Gbele Reserve is located $61 \mathrm{~km}$ from the town of Tumu (Sissala East District) and $89 \mathrm{~km}$ from the town of Wa (Wa District) in the Upper West Region (Yahaya and Venkateswar 2016);

- Mole National Park (4,840 km2), the largest reserve in Ghana, is located in Damango in the West Gonja District of the Savannah Region of Ghana. The park was originally established as a hunting reserve by Kwame Nkrumah (Ghana's first president) in 1958 and became a national park in 1971 (Apagrimchang 2018);

- Forest reserves: Northern Ghana has several forest reserves. Of Ghana's 280 forest reserves (Husseini et al. 2015) 57 are located in the Northern Savannah zone, of which 22 are shared between the Northern, Savannah and North-East regions, 19 in the Upper East region and 16 in the Upper West region (IUCN 2014). These include, among others, the Red Volta West, Red Volta East, Gambaga scarp West, Gambaga scarp East, Yakombo, Damongo scarp, Tamale Waterworks, Sinsanblegbini, Daka Headwaters and Kenikeni forest reserves. (Anderson et al. 2006; Husseini and Issifu 2015).

4 Ghana has six agro-ecological zones from south to north: the high rainforest zone in the southwest and the coastal savanna zone in the south and southeast; the semi deciduous forest zone; the forest-savanna transitional zone; the Guinea savanna zone; and the Sudan savanna zone (Germer and Sauerborn, 2008). 
The Eastern and Western wildlife corridors were established on the basis of these wildlife and forest reserves, with the aim of preserving the wildlife and plant biodiversity that inhabits these areas, and with a view to improving the livelihoods of local communities (Bouché 2007).

\subsubsection{Main environmental challenges: land degradation, deforestation and water scarcity}

Savannah landscapes such as the WWC are seen as multifunctional areas that can contribute toward reducing rural poverty, supporting the local economy and achieving local, national and international objectives for maintaining biological diversity (IUCN 2012). Natural resources are essential for improving the livelihoods of the world's poor people, 75 percent of whom live in rural areas and depend on natural resources to make a living (Anderson et al. 2006). However, the conservation and sustainable use of natural ecosystems are subject to numerous pressures related to livestock, agriculture and forest resource exploitation, resulting in severe degradation (Barlow et al. 2018).

The main constraints undermining Ghana's natural resource base include land degradation, deforestation, inappropriate agricultural practices, forest fires, unsustainable harvest (World Bank 2009) and mining activities (Kwame 2014). The northern savannah zone additionally suffers from demographic pressure, agricultural expansion, livestock pressure, and constant removal of trees and shrubs without adequate replacement (World Bank 2009; Marchetta 2011).

In Northern Ghana, water is scarce due to the few water courses that flow there, and decreased rainfall due to climate change. Combined with insufficient irrigation systems and the inadequacy of existing hydraulic structures (dams and artificial dugouts for agriculture), this leads to difficulties for agricultural and pastoral production (Marchetta 2011).

Interviews conducted during the scoping study with local communities and institutional actors operating in the study area revealed that the main problems they face in relation to natural resources are bush fires, illegal logging - particularly of rosewood (Box 8.1) charcoal production (a profitable activity for many young people), poaching of wildlife, gold panning, agricultural extension into forest reserves, and pastoralism by Fulani herders.

The forest administration is understaffed, creating a problem for efficiency of the Forestry Commission throughout the national territory. Northern Ghana is not spared from these difficulties, which adversely affect the remaining forest reserves and corridors. Moreover, the natural resource governance sector is often confronted with challenging situations, such as corruption (Ameyaw et al. 2015).

Political interference in natural resource governance is also a major constraint: some administrative and/or traditional authorities use their power to pursue their own commercial interests. They interfere in resource allocation issues in stumpage procedures, and in sanctions against offenders (Ameyaw et al. 2015). In this context, the enforcement of legal measures to protect the integrity of natural ecosystems becomes very difficult. Our interviews revealed that some village chiefs authorize logging in their communities, despite legal prohibitions. Because of their status as "traditional chiefs", they have a certain influence that protects them from prosecution. 


\section{Box 8.1 Rosewood between local community livelihoods and export product}

African rosewood (Pterocarpus erinaceus) is a plant species found in the northern part of Ghana, predominantly in the forest-savanna, Sudanese savannah and Guinean savannah transitional ecological zones. It is exploited by local communities for firewood and charcoal production, but also for the manufacture of musical instruments such as the xylophone. In addition, the leaves are used for cattle fodder, and the branches are used in the construction of houses.

Interest in this multi-purpose plant is likely to expand, due to the strong demand expressed by China, a major export market for rosewood since $2004 / 2005$. Ghana has become one of the main suppliers of rosewood to China, leading to excessive exploitation of the species as of 2010. As of 2014 it has been the second-largest supplier of rosewood in Africa (after Nigeria) to China and the fourth largest in the world. This will lead to an exponential increase in illegal logging, violation of national laws and regulations for timber exploitation and trade, and endangerment fragile landscapes in savannah ecological zones that harbour the rosewood, such as the Western Wildlife Corridor. Illegal operators armed with chainsaws, as well as fraudulent rosewood merchants, have reportedly besieged the northern regions of Ghana, cutting all the rosewood they can find ${ }^{a}$. This strong pressure constitutes a threat to natural resources and the conservation of biodiversity, and a constraint on improving the livelihoods of local communities.

Note:

a https://www.modernghana.com/news/455161/rosewood-face-risk-of-extinction-in-northernghana.html.

Source: Dumenu \& Bandoh (2016) and Abdul-Rahaman et al. (2016).

If no action is taken, all these difficulties could, in the long-term, lead to the destruction or even disappearance of emblematic ecosystems such as the Mole National Park and other nature reserves that contribute to the formation of the WWC.

\subsubsection{Development challenges related to climate change}

At the national and regional levels, constraints related to social, economic and environmental governance hinder Ghana's development and could negatively affect the implementation of integrated landscape approaches. Brown and Crawford's (2008) analyzes of the impact of climate change on the economic stability of Ghana and Burkina Faso show that there are five main challenges to be considered in Ghana. These are addressed in the following sub-sections.

\section{The North-South divide}

Ghana is characterized by a pronounced social divide. Poverty is concentrated in the northern part of the country, particularly in rural areas, while the southern regions are experiencing better socio-economic development. In addition, the North is not as well served as the South in terms of public and government services, and the rural North has 


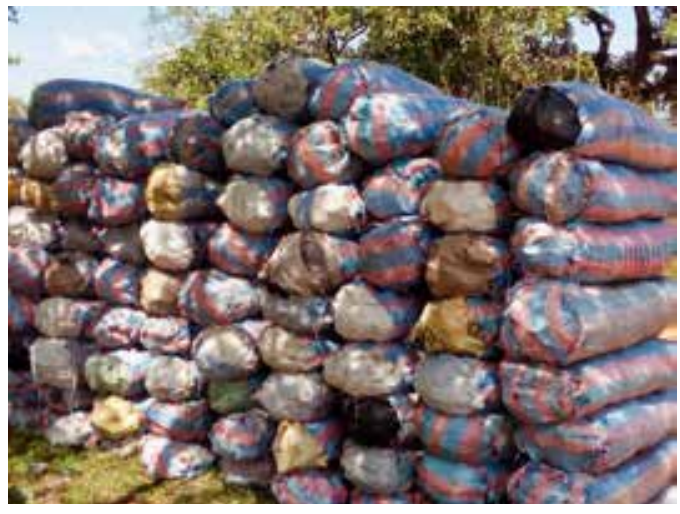

Figure 8.5 Bags of charcoal for sale at the outskirts of the Mole National Park.

Photo: Eric R.C. Bayala.

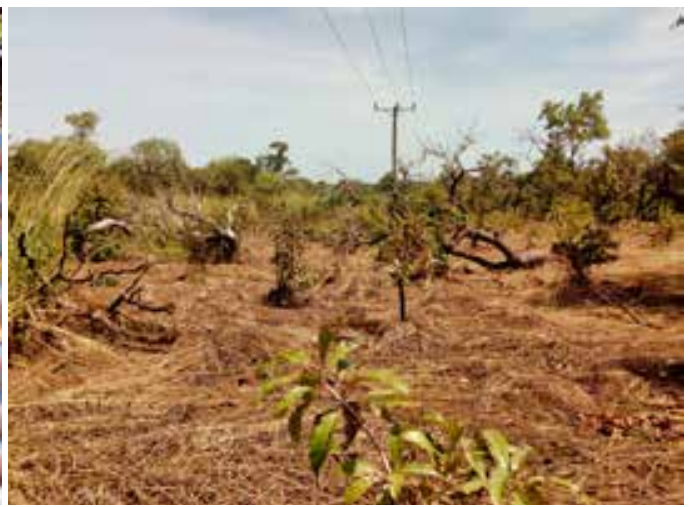

Figure 8.6 Clearing of new farms in Northern Ghana (CREMA of Murungu-Mognoré).

Photo: Eric R.C. Bayala.

long suffered from climate variability. Correlated with population growth, the demand for water in the North is increasing rapidly. Indeed, it appears that the demand for irrigation water in the dry regions of the North could increase twelvefold by 2050 due to climate change and population growth. This will be a significant development challenge that the government will have to face.

\section{The allocation of water between energy in the South and agriculture in the North}

The North-South divide would also play out in the allocation of water resources between the different regions. The trade-off between the use of water for agriculture in the North and its use for hydropower generation in the South remains a crucial issue.

\section{Management of regional water sources}

Climate change, declining rainfall and runoff could lead to regional tensions between Burkina Faso and Ghana over the sharing of water from the Volta River. The river, which serves six riparian countries, first crosses Burkina Faso before reaching Ghana, and together these two countries make up 85 per cent of the catchment area. To avoid future conflicts that could arise over water sharing, the six riparian countries (Burkina Faso, Ghana, Togo, Benin, Mali and Côte d'Ivoire) have come together to create a mechanism for managing the basin. This should prevent a number of disasters such as the floods that displaced about 285,000 people in Northern Ghana in September 2007 , following the opening of the gates of the Bagré dam in Burkina Faso to release surplus water (Brown and Crawford 2008).

\section{Economic stability and the structure of the economy}

Ghana's economy is strongly linked to the production of cocoa, which is mainly produced in the humid forest zone by rural communities for whom it represents an important source of income. This crop, for which Ghana is among the world's leading producers, contributes 3.4 percent to Gross Domestic Product (GDP) (Läderach et al. 2013). However, according to some analysts, Ghana's climate could be unsuitable for growing 
cocoa by 2080 . This would fundamentally change the Ghanaian economy and affect economic stability in unforeseen ways. However, other more optimistic scenarios reveal the fact that although climate change will have a negative impact on cocoa growing in Ghana, some areas such as the Kwahu Plateau in the south of the country will see an increase in production (Läderach et al. 2013; Schroth et al. 2016).

\section{Instability at the borders}

Conflicts caused by the impacts of climate change beyond Ghana's borders could lead to waves of human displacement and migration across borders. This, in turn, could lead to regional economic disruptions, problems of social coexistence between refugees and local communities, etc.

\subsubsection{Configuration of the Western Wildlife Corridor landscape}

The Western Wildlife Corridor is characterized by a sub-landscape formed by the CREMAs of Builsa Yenning and Moagduri Wuntaluri Kuwosaasi, and a micro-landscape formed by the CREMA of Sanyiga Kasena Gavara Kara. These two entities (sub-landscape and micro-landscape) are in turn composed of natural spaces, and spaces shaped by human activity. In this respect, the scoping study identified the following land uses: swidden agriculture, fallow, agroforest (parklands), rangeland, and small-scale cash crop gardens and plantations (cashew, citrus, mangos). In terms of management regimes, the landscape encompasses the wildlife corridor, forest and wildlife reserves, the national park, and CREMAs.

\subsection{Socioeconomic context and livelihoods}

The vast majority of the rural population in northern Ghana is affected by extreme poverty, with some of the highest rates in the country (Abdul-Moomin et al. 2016). Agriculture is the main livelihood activity, employing about 80 percent of the population and is mainly rainfed and dependent on soil fertility. The main crops grown are cereals (maize, sorghum, millet), legumes (soybeans, groundnuts and cowpeas), yam and cotton (Owusu-Ansah 2018). However, this activity is carried out primarily on small farms averaging about $\mathrm{I}$ ha in size. The decline in soil fertility resulting from continuous cropping and monoculture has led to reduced yields of some crops such as maize, sorghum and groundnuts (Braimoh and Vlek 2005).

In addition to agriculture and petty trade (food processing and weaving), local communities in the study site, in common with other communities in northern Ghana, earn a living from hunting, charcoal production, gold mining, livestock raising and the exploitation of timber and non-timber forest products, displaying a large dependence on natural resources (Marchetta 2011). Savannah woodlands are a source of medicinal plants; the main source of medicines for communities living there. In addition, the woodlands provide roofing thatch, fence posts, and food items such as bushmeat and fruit. ${ }^{5}$ As such, the ecosystems of Northern Ghana contribute significantly to people's

5 https://www.thegef.org/project/northern-savanna-biodiversity-conservation-nsbc-project. 
living conditions. The savannah woodlands contribute to up to $70 \%$ of Ghana's firewood and charcoal, and constitute the main source of livelihood for about $80 \%$ of charcoal producers (Obiri et al. 2014)

In Northern Ghana, women control non-timber forest products, such as shea (Vitellaria paradoxa) nuts, néré (Parkia biglobosa) fruit, baobab (Adansonia digitata) fruit and tamarind (Tamarindus indica). These are harvested for food, health and fodder needs; but above all, these provide women with an income. Some of these products are further processed, such as shea nuts that are transformed into butter, baobab fruit into biscuits, tamarind fruit into syrup, etc. In addition, the collection of firewood and charcoal production are economic activities in which women are engaged (Tetteh et al. 2011).

In summary, the landscapes of Northern Ghana offer a variety of livelihood sources and as such, are a source of socio-economic development, despite the challenges faced.

\subsection{Landscape governance}

Governance is a concept considered as a collective process, both formal and informal, on which decision-making processes and public regulatory and institutional frameworks depend (Maindo et al. 2015). In other words, governance is a participatory and decentralized exercise of power (Pitseys 2010). In Ghana, natural resource governance reforms have been aimed at involving local populations in the management of natural resources (Agyare et al. 2015), creating a dynamic collaboration between conservation stakeholders and landscape users. This is how the model of resource governance through CREMAs was developed.

\subsubsection{The CREMA system ${ }^{6}$}

The CREMA system is an innovative mechanism set up by Ghana's Forestry Commission through its Wildlife Division and partners to engage local communities in the governance and management of natural resources, notably near wildlife reserves and national parks. It represents a profound change in the national policy for the governance of natural resources, which allows local populations to govern the CREMA and benefit in kind or in cash from the forest and wildlife resources that it provides. The CREMA system has been in place in Ghana for almost 20 years; initially, going through a pilot phase and later scaled up, with a legal and institutional framework in place, allowing the Wildlife Division to transfer authority and responsibility for wildlife to rural communities.

\section{The CREMA implementation process}

Establishing a CREMA is a process that can be time-consuming (three to five years). It starts with the identification of a geographical area endowed with natural resources, where local communities have organized themselves for resource conservation. This is

6 Information in this section is based on: Wildlife Division, 2000; Agyare, 2013; Asare et al. 2013; Baruah et al., 2016; Foli et al., 2018; Murray et al., 2019. 


\section{Box 8.2 Shea: an under-valued source of income}

The production of shea butter is the main source of livelihood for more than 900,000 rural women in northern Ghana. Generally excluded from access to land, women have engaged in activities such as collecting shea nuts and processing these into butter. This activity, which they practice freely, is recognized as a traditional activity. Even if they benefit least from the final value of the product, the production of shea butter remains a life-saving income-generating activity for rural women, as it helps reduce their economic vulnerability. ${ }^{a}$

Shea has the potential to contribute to poverty reduction in rural areas, but little attention is paid to it in terms of creating a processing and marketing industry (AbdulMoomin et al. 2016). More than 60 percent of the shea nuts available in Northern Ghana are not harvested, and thus rot in the bush. However, increasing shea production and improving the processing rate of the nuts into butter, accompanied by the restructuring of the shea market, could create a rural transformation dynamic capable of reducing endemic poverty in northern Ghana (Laube 2015).

Note:

a https://www.inclusivebusiness.net/node/4037.

followed by a series of consultations and exchanges between the various stakeholders (NGOs, Wildlife Division representatives, community leaders) to assess the eligibility of the geographical entity proposed as a CREMA. Eligibility criteria include the structure and level of organization of the community, existing land tenure systems, land-use practices, and the uses made of landscape resources. Where a positive evaluation is made, and if the community leaders agree to engage in the CREMA process, a series of studies of the area would be conducted under the auspices of the Wildlife Division to establish the baseline in terms of land use, natural ecosystems, socio-economics, ethnography, etc. Once this prerequisite is completed, implementing agencies organize awareness and capacity building sessions as a prelude to the establishment of management structures.

\section{Local management/governance structures}

The first entity to be created is the Community Resource Management Committee (CRMC), mandatory for each community or group of communities. A CRMC usually consists of 5-13 people (men and women) appointed or elected in a village-wide meeting. Their role is to assist in planning and implementation of the CREMA activities. This committee serves as an intermediary between the community and the CREMA Executive Committee (CEC). Together with traditional chiefs, the CRMCs are responsible for drafting the CREMA "constitution", which is then submitted for

7 In the context of CREMA, a constitution is a social contract that establishes the organizational structure, defines the "community" and its purpose, and sets out the basic rules and regulations by which everyone should abide (Asare et al. 2013) and deforestation rates have increased in recent years. Mitigation initiatives such as REDD+ are widely considered as potentially efficient ways to generate emission reductions (or removals) 
review and adoption by all stakeholders (traditional authorities, Wildlife Division representatives, NGOs, CRMCs).

The CEC is the supreme body that directs and supervises decision-making, the design of CREMA development plans, and the definition of benefit-sharing arrangements. It is also responsible for clearly specifying the physical limits of the CREMA. It is comprised of CRMC members, including resource persons from the district, the Wildlife Division and NGOs. Thus, the CRMC ensures implementation of activities and respect for management rules in their respective community territories, and report to the CEC.

The CEC, with support of the Wildlife Division, traditional authorities, and District Assembly, should verify the alignment of CREMA rules and regulations with national and district laws. Those rules and regulations are then submitted to the District Assembly for formalization. Conclusion of the CREMA creation process is marked with an inauguration ceremony following the receipt of a devolution certificate issued by the Ministry of Lands and Natural Resources.

This was the process through which six CREMAs have been established in the WWC area: Moagduri Wuntanluri Kuwomsaasi; Sanyiga Kasena Gavara Kara; Builsa Yenning; Sissala-Kasena Fraah; BulKawe; and Chakali Sungmaaluu. To date, only the first three CREMAs have obtained a certificate of devolution and are operational.

\subsection{Multi-stakeholder platforms: opportunities and challenges for the implementation of landscape approaches}

\subsubsection{Preliminary stakeholder mapping}

Through the scoping study, we identified several types of actors intervening in Northern Ghana's landscapes, particularly in the study area. These were grouped into three main categories according to their interests (see Table 8.2). These stakeholders participate in one way or another in the governance of the CREMA in which they are involved.

\subsubsection{Existing multi-stakeholder platforms}

Multi-stakeholder platforms provide a framework for dialogue, consultation, compromise, and decision-making on conservation and development priorities as essential elements of landscape governance (Kusters et al. 2018; Ros-Tonen Reed et al. 2018). The platforms facilitate processes in which stakeholders from various sectors collaborate and jointly plan actions to achieve a common objective. The objective of multi-stakeholder processes is to promote better decision-making by ensuring that all relevant perspectives are considered at all stages of dialogue and consensus building (Warner 2007). Multi-stakeholder platforms are therefore essential for the implementation of integrated landscape approaches (ILAs), and thus, for the development of a concerted, participatory and adaptive landscape governance process. 
In the WWC, we identified the following main platforms during the scoping study:

\section{The Community Resource Management Committee (CRMC)}

This is the CREMA governance body at the local level and closest to the communities. At each CREMA constituent community, a CRMC exists to bring together community interest groups and to facilitate exchanges and decision-making at this level. These interest groups include hunters, youth groups, NTFP actors (shea and baobab), women's groups (for savings and loans), tindamba ${ }^{8}$, chiefs and others, depending on what exists in a particular community. One or two people represents each interest group at the CMRC, demonstrating how it offers an example of a local multi-stakeholder platform.

The number of CRMCs depends on the number of communities within the WWC. For example, Sanyiga Kasena Gavara Kara CREMA is composed of nine communities and therefore has nine CRMCs. The CREMAs of Builsa Yenning and Moagduri Wuntanluri Kuwomsaasi each have 10; hence, the total of 29 CRMCs in the WWC.

\section{The CREMA Executive Committee (CEC)}

The CEC is the second local multi-stakeholder platform, but unlike the CRMC, it operates at the CREMA level. Thus, in each of the CREMAs constituting the WWC, there is one $\mathrm{CEC}$, resulting in a total of three CECs in the Corridor.

The CEC brings together the various members of the CRMCs (considered as primary members), as well as traditional authority(ies), district representatives and institutions concerned with CREMA governance (secondary members). Where decisions are reached by vote, only the principal members are entitled to vote. The CEC lead team has five members, including at least two women, elected as president, secretary, organizer and treasurer. The CEC members are elected by the CREMA membership. CEC functions are determined by its statutes.

\section{The District Planning Coordinating Unit (DPCU)}

This platform operates at district level and provides a framework for exchanges and development planning between district officials and those of all decentralized government structures, as well as civil society organizations and NGOs in the district. At the WWC level, there are four DPCUs, as the Corridor spans four districts. However, our study interviews revealed that the DPCUs are not very active due to political and logistical constraints.

\section{The Sustainable Land and Water Management Project Learning Workshop Platform}

This platform was created within the framework of the Sustainable Land and Water Management project, funded by the World Bank and implemented in the Northern Savannah Ecological Zone. Its main purpose is to facilitate project actors exchanging ideas

8 Tindamba (singular: tindana) are landowning families descendent from the first settlers in an area, who hold land in custody for other community members and, as such, are allodial title holders of the land under their (customary) jurisdiction (Abdulai and Ndekugri 2007). 
Table 8.2 Preliminary stakeholder inventory in the study area.

\begin{tabular}{|c|c|c|}
\hline Actor type & Interest & Entities \\
\hline Institutional actors & $\begin{array}{l}\text { Their main interest is to ensure the } \\
\text { conservation of natural resources } \\
\text { and the preservation of biological } \\
\text { diversity. This is achieved through } \\
\text { research, awareness-raising, } \\
\text { capacity building and support for } \\
\text { implementation of conservation } \\
\text { actions. These actors intervene at the } \\
\text { national level. }\end{array}$ & $\begin{array}{l}\text { Forestry administration: } \\
\text { Forestry Commission (notably, the } \\
\text { Wildlife Division; Mole National Park } \\
\text { management; Forest Services Division); } \\
\text { Environmental Protection Agency } \\
\text { - Ministry of Food and Agriculture: } \\
\text { Water Resources Commission } \\
\text { District Agricultural Offices } \\
\text { - Universities and research centres: } \\
\text { Forestry Research Institute of Ghana } \\
\text { (FORIG); University for Development } \\
\text { Studies (UDS), Faculty of Natural } \\
\text { Resources and Environment } \\
\text { - Local authorities: District assemblies }\end{array}$ \\
\hline $\begin{array}{l}\text { NGOs and private } \\
\text { sector }\end{array}$ & $\begin{array}{l}\text { They support implementation of } \\
\text { the national policy on conservation } \\
\text { of natural resources. To this end, } \\
\text { they develop projects to preserve } \\
\text { biodiversity, improve livelihoods, } \\
\text { and raise public awareness of } \\
\text { environmental issues. NGOs are } \\
\text { non-profit organizations, whereas } \\
\text { the private sector is in search of } \\
\text { profit. }\end{array}$ & $\begin{array}{l}\text { NGOs: } \\
\text { A Rocha Ghana; Coalition for the } \\
\text { Development of Western Corridor of } \\
\text { Northern Region (Northcode); TreeAid } \\
\text { Ghana } \\
\text { - Private sector: } \\
\text { Savannah Fruits Company (SFC) }\end{array}$ \\
\hline Local actors & $\begin{array}{l}\text { Their main interest is to improve } \\
\text { their livelihoods through the } \\
\text { exploitation of natural resources. }\end{array}$ & $\begin{array}{l}\text { - Local communities } \\
\text { - Fulani (Fulbe) herdsmen }\end{array}$ \\
\hline
\end{tabular}

around the project objectives, sharing experiences and identifying new orientations for the project. It is therefore a platform designed for project follow-up.

However, with its multi-regional scope and the great diversity of its stakeholders, this platform could also serve as a framework for exchanges on other themes, such as the governance of multifunctional landscapes. Indeed, this platform brings together key institutions such as the Forestry Commission (Wildlife Division), the Environmental Protection Agency (EPA), and the Ministry of Food and Agriculture (MOFA). It could be an asset for the management of the WWC landscapes.

In short, the WWC benefits from a number of multi-stakeholder platforms distributed at the village, CREMA and regional levels. If properly utilized, these bodies could lead to more effective conservation of biodiversity in the CREMAs, and thus, to better governance of the WWC. Moreover, the existence of multi-stakeholder platforms is already a good basis for the implementation of landscape approaches. Indeed, the integrated landscape approach and multi-stakeholder platform concepts are intimately linked, such that proponents of ILAs suggest these platforms offer entry points for the implementation of a landscape approach (Ros-Tonen et al. 2018). ILAs generally aim to strengthen landscape governance through the establishment of multi-stakeholder platforms (Kusters et al. 2018). 


\subsubsection{Opportunities for the implementation of landscape approaches}

Several opportunities exist in the WWC for implementation of landscape approaches. From the analysis of data from field observations, interviews and literature, the following key points emerge:

- Several environmental NGOs are active in Northern Ghana (see Table 8.1), particularly in the WWC. Their presence is a financial and technical asset for the functioning of the multi-stakeholder process. These, NGOs could provide opportunities for financing projects falling within the framework of natural resource management, and hence, the CREMAs. In the technical field, the interventions of these NGOs related to sensitization and capacity building of local populations on environmental issues constitute a definite advantage for the implementation of a landscape approach. This aligns with Principle 10 of the landscape approach (strengthened stakeholder capacity) (Sayer et al. 2013).

- Collaboration between various stakeholders involved in the WWC provides an advantage for the implementation of landscape approaches and is a key objective of the Ten Principles framework. This enhances Principle 6 to achieve a negotiated and transparent change logic (Sayer et al. 2013).

- Interviews with institutional actors show that they have a good understanding of the landscape approach and are convinced of its potential for improving landscape governance. This would facilitate their engagement in a multi-stakeholder process for landscape governance, including those of the WWC.

- As the WWC landscape is organized in CREMAs, with governance structures such as CRMCs and CECs, this facilitates the stakeholder consultation process at several scales: village, CREMA, and region/sub-region (Principle 3 of landscape approaches on multiple scales). There is also a plurality and diversity of stakeholders engaged in the governance of the WWC landscape (Principle 5 of landscape approaches on multiple stakeholders) (Sayer et al. 2013).

\subsubsection{Challenges to the implementation of landscape approaches}

Landscape approaches have emerged as a form of landscape governance based on negotiating trade-offs between biodiversity conservation and local development (Reed et al. 2017). However, their implementation requires a number of prerequisites that can sometimes be a constraint, or even a challenge. In the WWC zone, the main constraints or challenges include the following.

\section{Financial constraints}

Today, the CREMAs of the WWC are barely active due to a lack of financial and logistical support necessary to make the governance bodies work. Committee meetings, including in the CRMC and CEC, are difficult to organize, as are community patrols to monitor natural resources. Interviewees said the CREMAs only function effectively when external projects are implemented; the end of a project also marks the end of the CREMA operations.

Thus, financial constraints appear to be a major challenge to the proper functioning of the CREMAs, and the implementation of landscape approaches. Creation of a national fund to support the long-term development of the CREMAs would greatly benefit landscape governance. 


\section{A lack of a solid multi-stakeholder platform}

At the level of the WWC, there are four types of multi-stakeholder platforms. However, these operate sporadically or are temporary (project-related). Moreover, even if there are multi-stakeholder platforms, they are often dedicated to only a portion of the actors affected by or affecting landscape governance. Yet, with landscape approaches, all key stakeholders must be brought together around the table for exchanges, negotiations and decision-making. Therefore, the establishment of a solid multi-stakeholder platform, based on long-term sustainable funding, with the capacity to convene all the key stakeholders in landscape governance, is a necessity for the implementation of a landscape approach in the context of the WWC.

\section{Conflicts between pastoral and agricultural communities}

In Northern Ghana, pastoralism is mainly practiced by Fulani herders. This community of nomadic pastoralists is strongly stigmatized by the other actors in the landscape with whom they sometimes maintain conflictual social relations. Some communities, particularly farmers who do not own livestock, are hostile to their presence in the same landscape (Tonah 2006). During interviews, the Fulani were always cited as a danger, threatening the sustainability of natural ecosystems because of the damage caused by their livestock (trampling of riverbanks, forest degradation, and crop destruction). The latter is the most frequent cause of conflicts between farmers and herders in Northern Ghana, and a serious hindrance to multi-stakeholder collaboration. The Fulani are also marginalized from natural resource governance processes - an exclusion that constitutes a major constraint to the development of landscape approaches, for which inclusion and collaboration between all the main actors in the landscape are fundamental principles.

\subsection{Conclusion}

The Western Wildlife Corridor in Northern Ghana is an area characterized by savanna ecosystems, with the presence of bush and woodland savannas, as well as gallery forests. This part of the country, despite the enormous pressure on natural resources, contains a rich biodiversity of flora and fauna relevant for local livelihoods. At the same time, Northern Ghana is marked by a problematic socio-economic and climatic context, with high poverty rate. This leads the local population to be highly dependent on natural resources. Hence the strong pressure on natural ecosystems, leading to landscape degradation and fragmentation. In addition, the WWC faces constraints linked to the governance of the CREMAs of which it consists. Among these, conflicts between landscape users, the misfunctioning of management bodies, the absence of a solid multi-stakeholder platform to facilitate collaboration and concerted decision-making between all key landscape stakeholders remain issues that threaten the sustainability of ecosystems in the WWC.

Although these constraints also put limits to the implementation of integrated landscape approaches, there are certainly opportunities to improve the governance of this landscape through such approaches. The organization of the landscape in CREMAs, the 
existence of platforms (CRMCs and CECs), and the presence of environmental NGOs in the area could provide a good basis for setting up a governance mechanism that favours consultation in decision-making, negotiation of compromises, and collaboration between all the key actors of the landscape, around an inclusive and sustainable multistakeholder platform. This is the essence of implementing landscape approaches.

\section{References}

Abdulai RT and Ndekugri IE. 2007. Customary landholding institutions and housing development in urban centres of Ghana: Case Studies of Kumasi and Wa. Habitat International 31(2): 257-267.

Abdul-Moomin A, Issahaku A. and Motin B. 2016. The Shea Industry and Rural Livelihoods among Women in the Wa Municipality, Ghana. Journal of Social Science Studies 3(2): 40-56. http://doi.org/10.5296/jsss.v3i2.8706.

Abdul-Rahaman I, Kabanda J. and Braimah MM. 2016. Desertification of the savanna: illegal logging of rosewood, causes and effects on the people of Kabonwule, Northern Region. Saudi Journal of Humanities and Social Sciences 1(3): 48-54. https://doi. org/10.21276/sjhss.2016.1.2.3.

Agyare A. 2013. Polycentric Governance and Social-Ecological Performance of Community Resource Management Areas in Ghana. PhD thesis, University of Victoria, Canada. https://doi.org/10.1017/CBO9781107415324.004.

Agyare A, Murray G, Dearden P and Rollins R. 2015. Conservation in context: Variability in desired and perceived outcomes of community based natural resources governance in Ghana. Society and Natural Resources 28(9): 975-994. https://doi.org/10.1080/089419 20.2015.1042127.

Ameyaw J, Arts B and Wals A. 2015. Challenges to responsible forest governance in Ghana and its implications for professional education. Forest Policy and Economics 62: 78-87. https://doi.org/10.1016/j.forpol.2015.07.011.

Anderson J, Benjamin C, Campbell B and Tiveau D. 2006. Forests, poverty and equity in Africa: New perspectives on policy and practice, International Forestry Review 8(1): 4453. 2006. https://doi.org/10.1505/ifor.8.1.44.

Apagrimchang AA. 2018. The woes of the forest of Northern Ghana, a national challenge. Should the charcoal industry be banned? Modern Ghana 28-01-2018. https://www. modernghana.com/news/831002/the-woes-of-the-forest-of-northernghana-a-nation.html.

Asare RA, Kyei A and Mason JJ. 2013. The community resource management area mechanism: A strategy to manage african forest resources for REDD+. Philosophical Transactions of the Royal Society B: Biological Sciences 368: 20120311. https://doi. org/10.1098/rstb.2012.0311.

Barlow J, França F, Gardner TA, Hicks CC, Lennox, GD, Berenguer E, Castello L, Economo EP, Ferreira J and Guénard B. 2018. The future of hyperdiverse tropical ecosystems. Nature 559(7715): 517-526. https://doi.org/10.1038/s41586-018-0301-1. 
Baruah M, Bobtoya S, Mbile P and Walters G. 2016. Governance of restoration and institutions: Working with Ghana's Community Resource Management Areas. World Development Perspectives 3: 38-41. https://doi.org/10.1016/j.wdp.2016.11.008.

Bouché P. 2007. Northern Ghana elephant survey. Pachyderm 42(42): 58-69. http://hdl. handle.net/2268/91445.

Braimoh AK and Vlek PLG. 2005. Land-cover change trajectories in northern Ghana. Environmental Management 36(3): 356-373. https://doi.org/10.1007/s00267-004-0283-7.

Brown O. and Crawford A. 2008. Climate change: A new threat to stability in West Africa? Evidence from Ghana and Burkina Faso. African Security Review 17(3): 39-57. https://doi.org/10.1080/10246029.2008.9627482.

Clay N. 2016. Producing hybrid forests in the Congo Basin: A political ecology of the landscape approach to conservation. Geoforum 76:130-141. https://doi.org/10.1016/j. geoforum.2016.09.008.

Dimobe K. 2017. Dynamique, séquestration de carbone et modèles de variation des savanes soudaniennes du burkina Faso et du Ghana (Afrique de l'ouest). Doctoral Dissertation, Université Ouaga, Ouagadougou, Burkina Faso.

Dumenu WK and Bandoh WN. 2016. Exploitation of African rosewood (Pterocarpus erinaceus) in Ghana: A situation analysis. Ghana J. Forestry 32: 1-15.

Foley JA, Ramankutty N, Brauman KA, Cassidy ES, Gerber JS, Johnston M, Mueller ND, O'Connell CO, Ray DK, West PC, et al. 2011. Solutions for a cultivated planet. Nature 478(7369): 337-342. https://doi.org/10.1038/nature10452.

Foli S, Ros-Tonen MAF, Reed J and Sunderland T. 2018. Natural resource management schemes as entry points for integrated landscape approaches: Evidence from Ghana and Burkina Faso. Environmental Management 62(1): 82-97. https://doi.org/10.1007/ s00267-017-0866-8.

Germer J and Sauerborn J. 2008. Estimation of the impact of oil palm plantation establishment on greenhouse gas balance. Environment, Development and Sustainability 10(6): 697-716. https://doi.org/10.1007/s10668-006-9080-1.

Godfray HCJ, Beddington JR, Crute IR, Haddad L, Lawrence D, Muir JF, Pretty J, Robinson S, Thomas SM and Toulmin C. 2010. Food security: The challenge of feeding 9 billion people. Science 327(5967): 812-818. https://doi.org/10.1126/science.1185383.

Green KE. 2016. A political ecology of scaling: Struggles over power, land and authority. Geoforum 74: 88-97. https://doi.org/10.1016/j.geoforum.2016.05.007.

Husseini R and Issifu H. 2015. Natural forest reserves in the northern region of Ghana: Description and management status. Research journali's Journal of Forestry 2(6): 1-15.

IUCN 2012. Livelihoods and Landscapes Strategy. Results and reflections. Gland, Switzerland: International Union for Conservation of Nature (IUCN).

IUCN 2014. Assessing Forest Reserve Conditions in Ghana through Crown Cover Mapping. Technical Report, (July): 1-8. Available at: https:/www.iucn.org/sites/ $\mathrm{dev} /$ files/import/downloads/mapping_ghana_forest_reserve_condition___pre_ publication_report_draft___july_2014.pdf.

IUCN 2017. The CREMA concept Upscaling Community Resource Management Areas as a Delivery Mechanism for REDD+ Implementation in Ghana International Union For 
Conservation of Nature. https://www.iucn.org/sites/dev/files/content/documents/ upscaling_community_resource_management_-_ghana.pdf. (June): 1-6.

Kusters K, Buck, L, de Graaf M, Minang P, van Oosten C and Zagt R. 2018. Participatory planning, monitoring and evaluation of multi-stakeholder platforms in integrated landscape initiatives. Environmental Management 62(1): 170-181. https://doi. org/10.1007/s00267-017-0847-y.

Kwame BF. 2014. The economic cost of environmental degradation: A case study of agricultural land degradation in Ghana. SSRN Electronic Journal, (January 2014). https://doi.org/10.2139/ssrn.2534429.

Läderach P, Martinez-Valle A, Schroth G and Castro N. 2013. Predicting the future climatic suitability for cocoa farming of the world's leading producer countries, Ghana and Côte d'Ivoire. Climatic Change 119(3-4): 841-854. https://doi.org/10.1007/ s10584-013-0774-8.

Laube W. 2015. Global shea nut commodity chains and poverty eradication in Northern Ghana: Myth or reality ? UDS International Journal of Development [UDSIJD] 2(1): 128-147. http://udsspace.uds.edu.gh/handle/123456789/456

Lindsay A. 2018. Social learning as an adaptive measure to prepare for climate change impacts on water provision in Peru. Journal of Environmental Studies and Sciences 8(4): 477-487. https://doi.org/10.1007/s13412-017-0464-3.

Maindo A, Tulonde JL and Amuri F. 2015. Guide de bonne gouvernance forestière APVFLEGT: Exploitation et commerce légaux du bois, une affaire de tous en Province Orientale, RD Congo, Tropenbos International RD Congo. https://www.tropenbos.org/ file.php/1940/forest_governance_tbi_fao-flegt.pdf.

Mamprugu Moagduri District Assembly. 2017. Community Resource Management Areas (CREMAs) Bylaw. https://ghalii.org/gh/LGB No.12.pdf.

Marchetta F. 2011. On the move: livelihood strategies in Northern Ghana. https://halshs. archives-ouvertes.fr/halshs-00591137.

Murray G, Agyare A, Dearden P and Rollins R. 2018. Devolution, coordination, and community-based natural resource management in Ghana's community resource management areas. African Geographical Review 38(4): 296-309. https://doi.org/10.1080 /19376812.2018.1426022.

Obiri BD, Nunoo I, Obeng E, Owusu FW and Marfo E. 2014. The charcoal industry in Ghana: An alternative livelihood option for displaced illegal chainsaw lumber producer. Wageningen, the Netherlands: Tropenbos International. https://www. tropenbos.org/file.php/1681/3-charcoal.pdf

Ouko EM. 2018. Contextualising integrated conservation and development projects: Restoring the lost "harambee" link in Kenya. Geoforum 92: 81-91. https://doi. org/10.1016/j.geoforum.2018.04.002.

Owusu-Ansa N. 2018. Assessing how collaborative resource management impacts victims' perspectives on wildlife crop raids. Journal of Natural Resources and Development 8: 115-124.

Pitseys J. 2010. Le concept de gouvernance. Revue Interdisciplinaire d'Études Juridiques 65(2): 207-228. https://doi.org/10.3917/riej.065.0207 
Reed J, Van Vianen J, Deakin EL, Barlow J and Sunderland T. 2016. Integrated landscape approaches to managing social and environmental issues in the tropics: Learning from the past to guide the future. Global Change Biology 22(7): 2540-2554. https://doi. org/10.1111/gcb.13284.

Reed J, Van Vianen J, Barlow J and Sunderland T. 2017. Have integrated landscape approaches reconciled societal and environmental issues in the tropics. Land Use Policy 63: 481-492. https://doi.org/10.1016/j.landusepol.2017.02.021.

Ros-Tonen MAF, Reed J and Sunderland T. 2018. From synergy to complexity: The trend toward integrated value chain and landscape governance. Environmental Management 62(1): 1-14. https://doi.org/10.1007/s00267-018-1055-0.

Sayer J, Sunderland J, Ghazoul J, Pfund J-L, Sheil D, Meijaard E, Venter M, Boedhihartono KA, Day M, Garcia C, et al. 2013. Ten principles for a landscape approach to reconciling agriculture, conservation, and other competing land uses. Proceedings of the National Academy of Sciences of the United States of America 110(21): 8349-8356. https://doi.org/10.1073/pnas.1210595110.

Schroth G, Läderach P, Martinez-Valle AI, Bunn C and Jassogne L. 2016. Vulnerability to climate change of cocoa in West Africa: Patterns, opportunities and limits to adaptation. Science of the Total Environment 556: 231-241. https://doi.org/10.1016/j. scitotenv.2016.03.024

Tetteh AB, Atosina AM, Adongo AA. 2011. Charcoal production in Gushegu District, Northern Region, Ghana: Lessons for sustainable forest management. International Journal of Environmental Sciences 1(7): 1944-1953.

Tonah S. 2006. Migration and farmer-herder conflicts in Ghana's Volta Basin. Canadian Journal of African Studies / Revue canadienne des études africaines 40(1): 152-178. https:// doi.org/10.1080/00083968.2006.10751339.

Tscharntke T, Clough Y, Wanger TC, Jackson L, Motzke I, Perfecto I, Vandermeer J and Whitbread A. 2012. Global food security, biodiversity conservation and the future of agricultural intensification. Biological Conservation 151(1): 53-59. https://doi. org/10.1016/j.biocon.2012.01.068.

Warner J, ed. 2007. Multi-Stakeholder Platforms for Integrated Water Management. Ashgate Studies in Environmental Policy and Practice. Aldenshot: Ashgate Publishing Limited.

Wildlife Division (WD) 2000. Wildlife Division policy for collaborative community based wildlife management. http://www.fcghana.org/library.php?id=19.

Wilson VJ. 1993. Zoological survey in Mole National Park. Final Report. North-Western Ghana part 1 large mammals. Forest Resource Management Programme/ Game and Wildlife Dept/IUCN project 9786_Accra Ghana: 124.

World Bank. 2009. Implementation completion and results report. Northern Savanna biodiversity conservation project. 102(SUPPL. 1). https://doi. org/10.1179/136485908X337463.

Yahaya AK and Venkateswar C. 2016. Are modern institutions effective in the conservation of the forest flora of Gbele resource reserve in the Upper West Region of Ghana? International Research Journal of Environmental Sciences 5(3)(March): 42-53. Available at: www.isca.in, www.isca.me. 


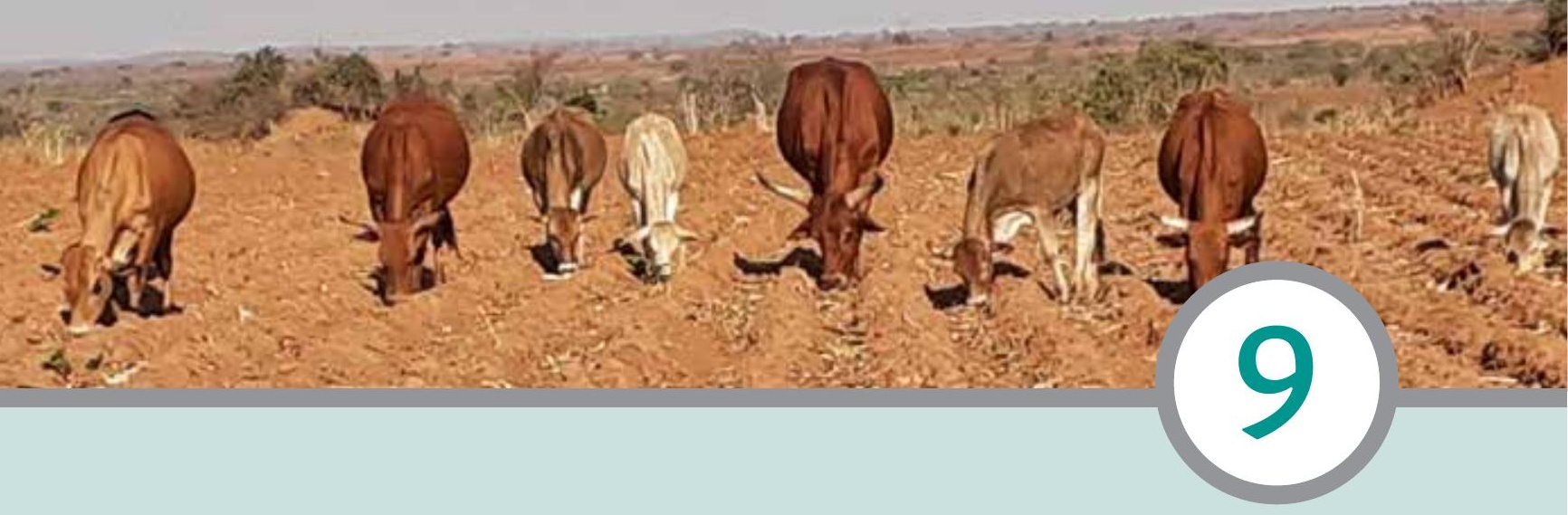

\section{Understanding landscape dynamics}

\section{A case study from Kalomo District}

Kaala B Moombe, Freddie S Siangulube, Bravedo M Mwaanga, Tiza I Mfuni,

Malaika P Yanou, Davison J Gumbo, Rays C Mwansa and Gilbert Juunza

\subsection{Introduction and background}

The dictum "Our Wealth is Maize and Cattle" is a literal translation of the ChiTonga adage "Buvwubi Bwesu Buli Mu Ng'ombe a Mapopwe"(KTC 2018; SZI 2019), and aptly describes the identity of those who live in the Kalomo District. Viewed also as the Farmers' Nest, these statements summarize the heterogeneity and dynamics of the Kalomo District landscape and resonate with the social-economic profile of the district. The long-term strategic direction of the district is to realize economic diversification, underpinned by export-oriented agriculture, tourism and improved natural resource development and management. These sectors have the potential to spur growth and poverty reduction for the district. However, there are a number of challenges in key sectors, centered on water scarcity, unplanned settlement, land degradation and a general uncoordinated approach to addressing local problems. Climate change, planning and a lack of coordination among stakeholders have also contributed to the severity of the problems. 


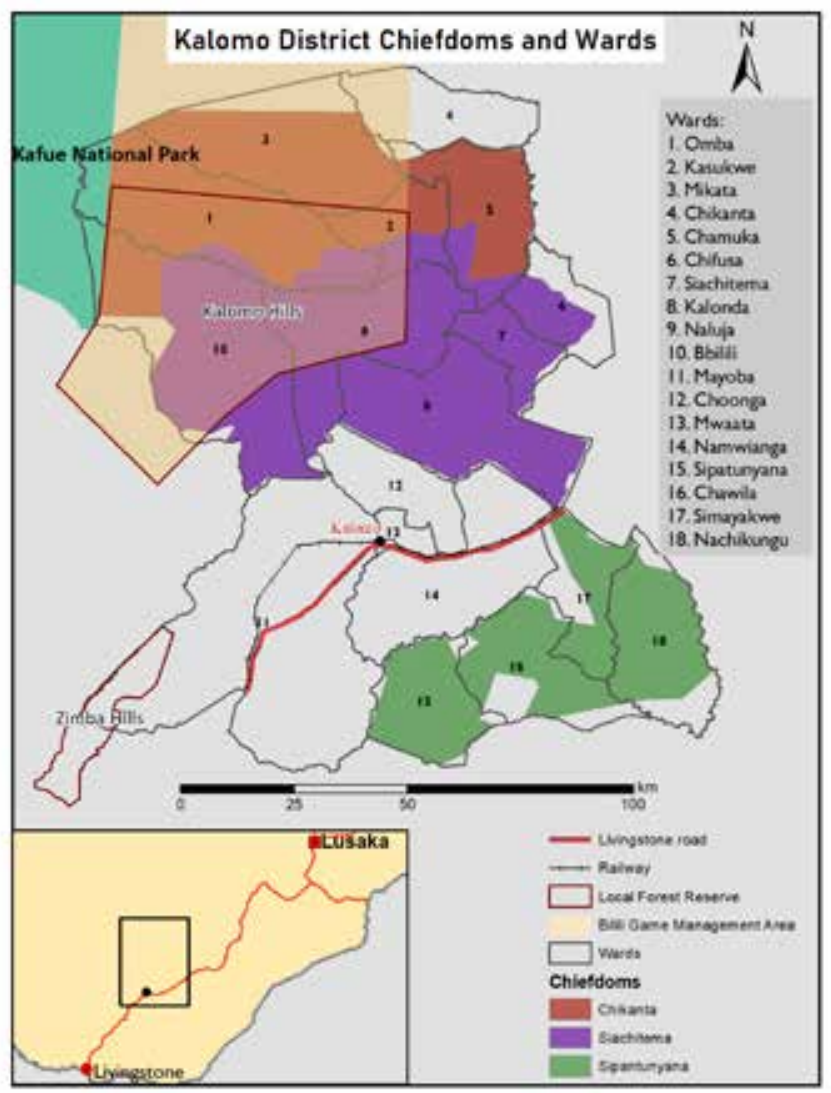

Figure 9.1 Location and administrative map of Kalomo District.

\subsubsection{Kalomo District in brief}

The total area of the district is $8074.84^{1} \mathrm{~km}^{2}$, which is located in one of Zambia's tourism corridors $^{2}$ along the T1 road. Kalomo District lies about $340 \mathrm{~km}$ from Lusaka and 120 $\mathrm{km}$ from Livingstone and is the third-largest district in the Southern Province (Figure 9.1). The administrative units for Kalomo are comprised of two political constituencies (Dundumwezi and Kalomo Central, 18 wards, and three chiefdoms, namely Chikanta, Siachitema and Sipatunyana (Chinene 2006; CSO 2011; KTC 2018).

The focus of this chapter is on characterizing the Farmers' Nest by highlighting its historical, socio-economic, and biophysical contexts (Section 9.2). The state and customary organizational and institutional setup of the district is presented and briefly analyzed, covering resource tenure, and governance structures and systems (Section 9.3). Section 9.4 covers the challenges, opportunities and options for landscape approaches and reflects on further research aspirations for the COLANDS initiative.

1 Cf. CSO (2011, 45): 15,000 km² before Zimba became a district.

2 Attractions include the associated Old Administrator's house, wildlife in the Game Management Area and Game Ranches, camping sites (e.g. the Dundumwezi camp), Bbilili hot springs, Kalundu Mound, Isamu Pati and different traditional ceremonies. The cultural or heritage-associated ceremonies include Musamu Muyumu, Chuungu Manzi Abila (associated with the hot springs). 


\section{The Farmers' Nest as the focus landscape}

The exploration for a suitable landscape where the COLANDS initiative could be implemented began with a comparison and review of information (written and oral) on the biophysical and social elements of landscapes in North-Western and Southern provinces of Zambia. Notwithstanding similarities, the preliminary review of the two provinces pointed to the Southern Province, where four candidate districts were eventually considered and scrutinized further. These are Choma, Kazungula, Zimba and Kalomo Districts (Figure 9.2).

The search processes included a combination of stakeholder engagement and consultations in the form of workshops, meetings, and field visits conducted within and outside candidate landscapes ${ }^{3}$ (districts). Such engagements spanned several social, economic and political factors found at district and village levels within the three districts, which determined the district and villages selected for the COLANDS Initiative. The factors that guided the choice of the district while bearing in mind the salient principles of landscape approaches upon which the COLANDS initiative is based are as follows:

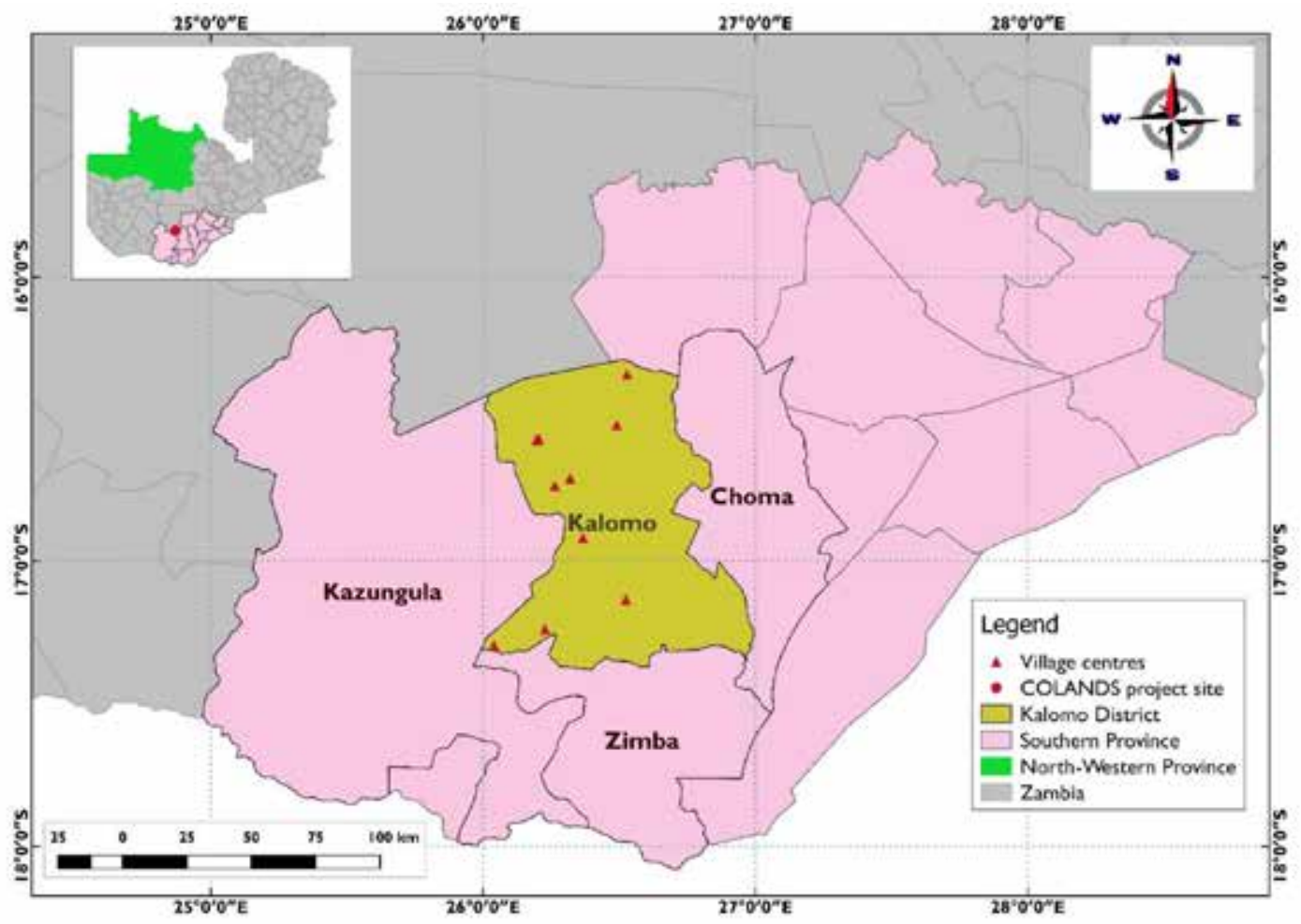

Figure 9.2 Initial candidate districts for the COLANDS initiative.

3 Inception Workshop (18-22 June 2018), CIFOR, Bogor Campus, Indonesia (for Kalomo District); Generative Interviews Training Programme (10-12 July 2019) for Village-Based Research Assistants, Zuus Lodge, Kalomo District (for nine study villages). 
- Landscape heterogeneity and dynamics

The social and biophysical diversity of a landscape is shaped by the history, migration and ethnic composition, and by physical and cultural attributes. The Kafue and Zambezi watersheds as well as Miombo and Mopane vegetation types dominate the biophysical components of the three candidate districts. The cultural land facets such as villages and shrines, which are some of the oldest symbols of political and social significance (Colson 1948) and landscape governance, characterize the areas. These landscape elements influence social practices, and, in some cases, they form the basis for an assortment of claims and counter claims by different livelihood sectors.

- Multiple stakeholders and platforms

It is important for the study district to have a mix of state and non-state actors dealing with social, economic and biophysical elements of the landscape. The private sector entities should be involved in wildlife, game ranches, livestock and agro-input supply, value chains and markets. The traditional state actors on both state land (forest reserves, national parks, etc.) and customary land (game management areas (GMAs), sacred groves, etc.) should include active local governance of resources. This may be in the form of a district council working hand in hand with the district administration (in the ministry of Local Government), line ministries and traditional leaders (chiefs and village headmen and headwomen). Bridging institutions, such as non-governmental and research organizations can be added to give diversity and to offer complementarity to avenues for engagement at various governance levels.

- History of engagement with landscape approaches The district chosen ought to have a well-documented and oral history of the implementation of past and current policy interventions. Such district features would proffer useful lessons for the COLANDS initiative as a way of presenting landscape change or an evolution trajectory. Furthermore, it could present opportunities for the examination of the ten landscape principles as articulated by Sayer et al. (2013) and the associated theory-practice gaps.

- Internal and external drivers of change Current environmental, socioeconomic and institutional contexts drive landscape evolution and dynamics in Kalomo, Zimba, Kazungula and Choma. The drivers of landscape change in these districts are many and varied. The most prominent are population growth, agricultural expansion, declining land quality, widespread deforestation and climate change. It is difficult to separate one challenge from the other, especially since anthropogenic activities have heavily degraded protected areas (PAs) (e.g. forests reserves, GMAs and cultural shrines) and have reduced the availability of and access to safe water sources through the siltation of surface water bodies such as dams and rivers/streams. Currently, organizational and institutional coordination at district level is limited, and has been further worsened by limited extension and law enforcement services. Heritage resources and sites are not being maintained, let alone managed (Chinene 2006; Mbanga et al. 2019; Umar 2019; Moombe 20204).

4 Discussions during the Twin Cave Theory of Change Workshop (16 February-20 February 2020) at Twin Cave Lodge organized by CIFOR confirmed that these landscape matters are still of concern (Moombe (2020). 


\section{- Accessibility/security/logistics}

All four candidate districts (for example, Kalomo) are accessible throughout the year despite the low coverage and poor condition of roads and transport networks (Tembo 2016), especially in rural areas. There have been no notable nor ongoing incidences of armed conflicts, either political or religious.

- Expected constraints, enabling conditions and applicability for scaling up

The expected key constraint in executing the COLANDS initiative hinges on weak institutional coordination within and among the actors. Therefore, of immense value to the intervention would be a vibrant hub of commercial and subsistence agriculture practitioners that could offer significant levels of stakeholder interactions.

Unfortunately, as with most district councils in Zambia, suitable platforms in the four candidate districts have not been identified, especially against a background of weak coordination. Thus, the current application of a suite of requisite institutional frameworks and guidelines (ROZ, 2002; GRZ, 2014; GRZ, 2015; GRZ, n.d.; URPA 2015; GRZ, 2016; GRZ, 2018) on decentralization, climate change, chiefs, urban and regional planning, $\mathrm{REDD}+{ }^{5}$, forestry (including community forestry) and those relating to wood fuel has not taken hold. There is a whole list of projects whose lessons could be included in the interrogation of the applicability of the landscape approach (LA) principles (Box 9.1) and these can be added to the first generation of social forestry programs of the late 1980 s in the province or country. Integrating lessons from these and the COLANDS initiative could provide a robust framework for assessing scaling-up options.

The above considerations for suitability of the COLANDS initiative, especially the multiple stakeholders and platforms and the history of engagement with landscape approaches, favored Kalomo District. For example, some of the interventions such as soil conservation (Haggblade and Tembo $2003^{6}$ ), the improved farmers' programs of

\section{Box 9.1 Some key projects/initiatives (see also Chapter 3).}

For Zambia, critical programs with relevant hallmark experiences and lessons to be hybridized with the COLANDS initiative include: the Decentralized Forest and other Natural Resources Management Project (DFRNMP), Strengthening Management Effectiveness and Generating Multiple Environmental Benefits within and around the Greater Kafue National Park and West Lunga National Park (GEF V), the Promoting Climate Resilient Community Based Regeneration of Indigenous Forests in Zambia Project, and the Zambia Integrated Forest Landscape Project (ZIFLP).

5 Reducing Emissions from Deforestation and forest Degradation.

6 A Swedish-funded Soil Conservation and Fertility Enhancement (SCAFE) project began in 1985 to promote a wide range of erosion control measures such as bunding, contour tillage, and vetiver grasses; and soil fertility enhancement techniques. The latter included crop residue management, green manures, cover crops, mulching, improved fallows, and conservation tillage. It later changed its name to the Land Management and Conservation Farming (LMCF) project. 
1936, Community-Based Natural Resource Management and Sustainable Agriculture (CONASA) (Manning 20117) and SCRIKA ${ }^{8}$ that have been implemented in Kalomo District are important in informing the COLANDS initiative.

\section{Selection criteria for study sites}

In all the three chiefdoms in Kalomo District, consideration was given for the selection of villages for the COLANDS initiative research activities along what is perceived as the state-chiefdom power continuum, i.e. following a gradient from customary to state land (Kalomo Hills Local Forest Reserve No. P.13 or KFR). As for the district, a qualitative aggregation of the considerations or factors outlined here resulted in choosing 10 study villages ${ }^{9}$ (see Appendix 9A: Selected characteristics of the selected villages). Three villages were selected in each of the Siachitema and Sipatunyana chiefdoms and four in Chikanta chiefdom: one around the chiefdom palace (perceived as the center of traditional power), another village somewhere in-between (buffer zone) the palace village and the KFR, and the third one in the KFR. The fourth village in Chikanta is in a cultural landscape in a sacred grove locally referred to as malende. The villages participating in the COLANDS initiative represent a demographic mix of cultural practices, powers and leadership capacities. This diversity is due to various social-biophysical historical backgrounds and development-induced displacements. Tracing the evolutionary dynamics from earlier landscape events could reveal valuable lessons for LAs.

\subsection{Characterizing the "Land of Maize and Cattle"}

\subsubsection{Historical context of Kalomo}

Kalomo town is a pre-Independence railway settlement with a strong colonial footprint, as its early development is associated with railway line construction that reached the present site in 1905 and was the first administrative capital for North-Western Rhodesia (NWR) from 1902 to 1907. Kalomo town was a subdistrict of Batoka District, established in 1900/1901. It was selected and opened in 1899 because of its pleasant weather (NAZ, KSB 3/1). Later, Livingstone proved to be a healthier location than Kalomo (whose

7 CONASA was funded by the United States Agency for International Development USAID and implemented in the district from early 2001 until 2005 by a consortium of organizations that included CARE, the Wildlife Conservation Society (WCS) and the African Wildlife Foundation (AWF). The aim of the project was to improve the livelihood security of people living within the project area, and to increase the sustainable production of natural resources (Manning 2011).

8 Strengthening Climate Resilience in the Kafue Subbasin project was funded by the World Bank and implemented from 2015 until 2019 using mostly a livelihoods and integrated conservation and development approach.

9 This took place during the Generative Interviews Training Programme (10-12 July 2019) for Village-Based Research Assistants, Zuus Lodge, Kalomo District (for nine study villages). The training focused on how to conduct a social survey on the multifunctional uses of the Kalomo, associated changes, institutions and visions about the landscapes. 
residents suffered from malaria and fever attacks) for the settler government and so assumed the capital status of NWR in September 1907 (NAZ, KSP 3/1; Nchito 2010; Nchito 2013).

Before colonial rule, the primary land use in the Plateau Tonga (where Kalomo lies) was shifting cultivation using primarily hand tools. Once raids by the Lozi, Kololo and Ndebele peoples began (circa 1800), activities such as cropping and cattle production were dislocated and reduced (Dixon-Fyle 1976; Murphy 2003; Thomson and Bennet 2005). Under colonial rule, as with many of the countries of southern Africa, land was alienated from the indigenous Plateau Tonga for occupation by European settlers (Commonwealth Secretariat 1979; Anderson and Grove 1987) and these farmers competed with indigenous maize farmers. The change in African farming in the late 1920s, aided by the adoption and increasing use of the plough and draft oxen, and increasing crop yields and competition in the market caused such settlers to demand the imposition of marketing controls (Vickery 1985). The widespread use of the animal-drawn plow heralded the beginning of a new threat in the form of soil erosion and land degradation, especially in areas where soil and water conservation measures were disregarded (Beinart 1984). The plow spurred agricultural expansion into even fragile ecosystems such as stream banks and wetlands. This context created tension between African peoples and settler immigrants. In response, the government introduced agrarian and land-use policy measures (Table 9.1).

\section{Table 9.1 Prominent policies to manage the African-immigrant settler production} systems

\begin{tabular}{|c|c|c|}
\hline Year & Policy, actions, measures & Purpose \\
\hline 1906 & $\begin{array}{l}\text { Movement of local people from ancestral } \\
\text { areas to less fertile ones }\end{array}$ & $\begin{array}{l}\text { Accommodate the construction of the railway, and } \\
\text { provide land for the settler immigrants producing } \\
\text { maize and cattle for the Congo market }\end{array}$ \\
\hline 1928 & Native Reserve Policy (NRP) & $\begin{array}{l}\text { Make it easier for the immigrant farmers to } \\
\text { produce for the market }\end{array}$ \\
\hline 1935 & Maize Control Board (MCB) & $\begin{array}{l}\text { Control to increase African production and protect } \\
\text { the immigrant farmer from competition }{ }^{\mathrm{a}}\end{array}$ \\
\hline 1936 & $\begin{array}{l}\text { Maize Control Policy (MCP), Land (soil) } \\
\text { Conservation Extension Schemes }\end{array}$ & $\begin{array}{l}\text { Protect settler farmers, control and rehabilitate } \\
\text { deteriorating land (also applied to native farming } \\
\text { lands) }\end{array}$ \\
\hline 1945 & Land Usage Survey (LUS) & $\begin{array}{l}\text { Introduce differential pricing to motivate farmers } \\
\text { to practice conservation agriculture with bonuses } \\
\text { to those who met satisfactory levels }\end{array}$ \\
\hline 1946 & Improved Farming Scheme (IFS) & Check overcultivation among the Plateau Tonga \\
\hline 1949 & Natural Resources Board (NRB) & $\begin{array}{l}\text { Engage farmers in conservation schemes } \\
\text { management through conservation committees }\end{array}$ \\
\hline
\end{tabular}

Note:

a Maize Control Acts of 1935 to 1955. 
In addition to these measures, the colonial administration established schemes such as the Improved Farming Scheme (IFS) aimed at creating a new cadre of African farmers. This was regarded with suspicion because it developed a small group of farmers, who were seen as privileged. However, they also resisted the scheme because of the hard work needed to improve the plots and inadequate compensation. Most farmers did not see the need for contour ridges and grass strips on their lands, and hefty fines were imposed on those who failed to observe the rules (Dixon-Fyle 1977; Stocking 1985). To most people, the conservation measures became symbols of oppression and were one of the many reasons for contestation. In response to these policies, African farmers created farmer associations and resisted some of the policies, which became strong bedrocks for entities fighting for independence, such as the 1948 Northern Rhodesia African Congress (NRAC). The extent to which the optimum parts of such policies continued into the postIndependence period is unclear, but we note that riverine gardens have been opened and human-wildlife conflicts around water points have increased, while the destruction of the crops of people who have moved into the interior of the bush have intensified. Soil erosion and deforestation have continued unabated; aspects that may be beyond the power of local-level institutions such as village headmen and headwomen. Over time, the ChiTonga culture and practices were affected and eroded, as were the taboos that helped with conservation work such as rainmaking. The cutting and removal of spiritual trees such as Parinari curatellifolia, have opened up the natural resources to disrespect and loss (Thomson and Bennet 2005).

\subsubsection{Biophysical context of Kalomo}

\section{Climate}

Falling in agro-ecological zone II of the country's climate classification, the Plateau Tonga on which the Kalomo District sits, experiences cool and dry (May-August), hot and dry (September-November) and warm and wet (December-April) seasons (DixonFyle 1976; GRZ 2004). Kalomo is one of the coolest districts in Zambia. The mean annual temperature is $20^{\circ} \mathrm{C}$. The temperature ranges from as low as $2{ }^{\circ} \mathrm{C}$ to as high as $40^{\circ} \mathrm{C}$ in the warm wet season. The rainfall is highly variable, ranging between 800 and $1200 \mathrm{~mm}$ in the higher altitude areas and $<800 \mathrm{~mm}$ in some lower parts (GRZ 2004; Kalinda et al. 2010; Somanje et al. 2017; KTC 2018). The rainfall days and amounts from 2004 to 2010 show a general decline (Figure 9.3). The average amount is 616.7 $\mathrm{mm}$ (range: $141.2-946.5 \mathrm{~mm}$ ) over an average number of 50 rainfall days (range: $27-69$ days). Previously, November-March/April was the main period for rains (Roberts 1976). However, dry periods over the period December-March/April is now commonplace.

The extent to which these climatic changes have affected livelihoods and food production has been severe, but the changes have not affected maize production in the district as the government and non-government organizations (NGOs) have stepped up agricultural input support.

\section{Vegetation}

Kalomo is covered by vegetation associated with dry forests and woodlands. The most prominent vegetation type is Miombo forest which is dominated by trees from the 
Kalomo District: Rainfall Amount, mm [2004-2018]

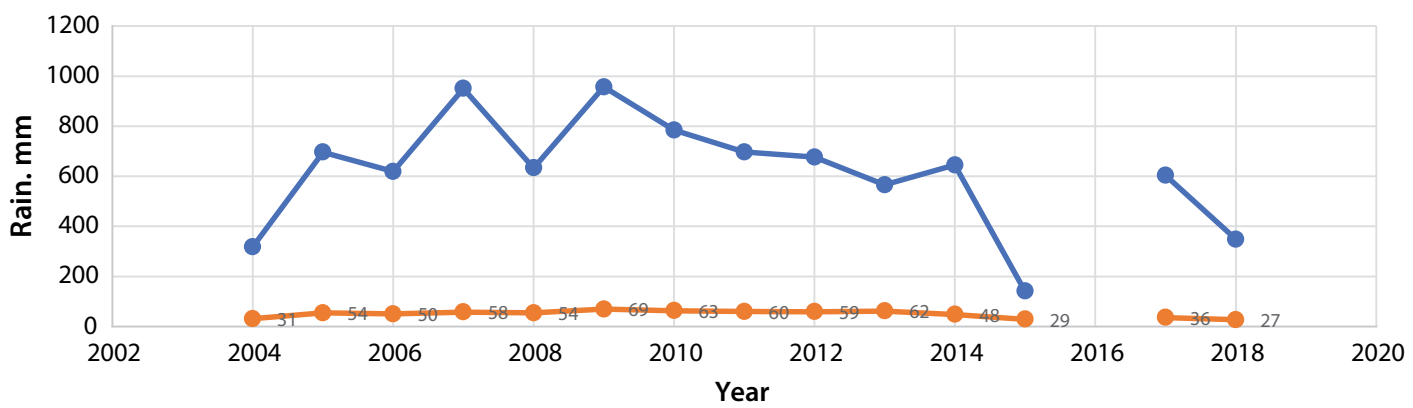

$\longrightarrow$ Amount of Rain $(\mathrm{mm}) \quad \longrightarrow$ Rain Days

Figure 9.3 Rainfall amounts in Kalomo District (15-year period).

Source: Based on Kalomo Town Council data (KTC 2018)

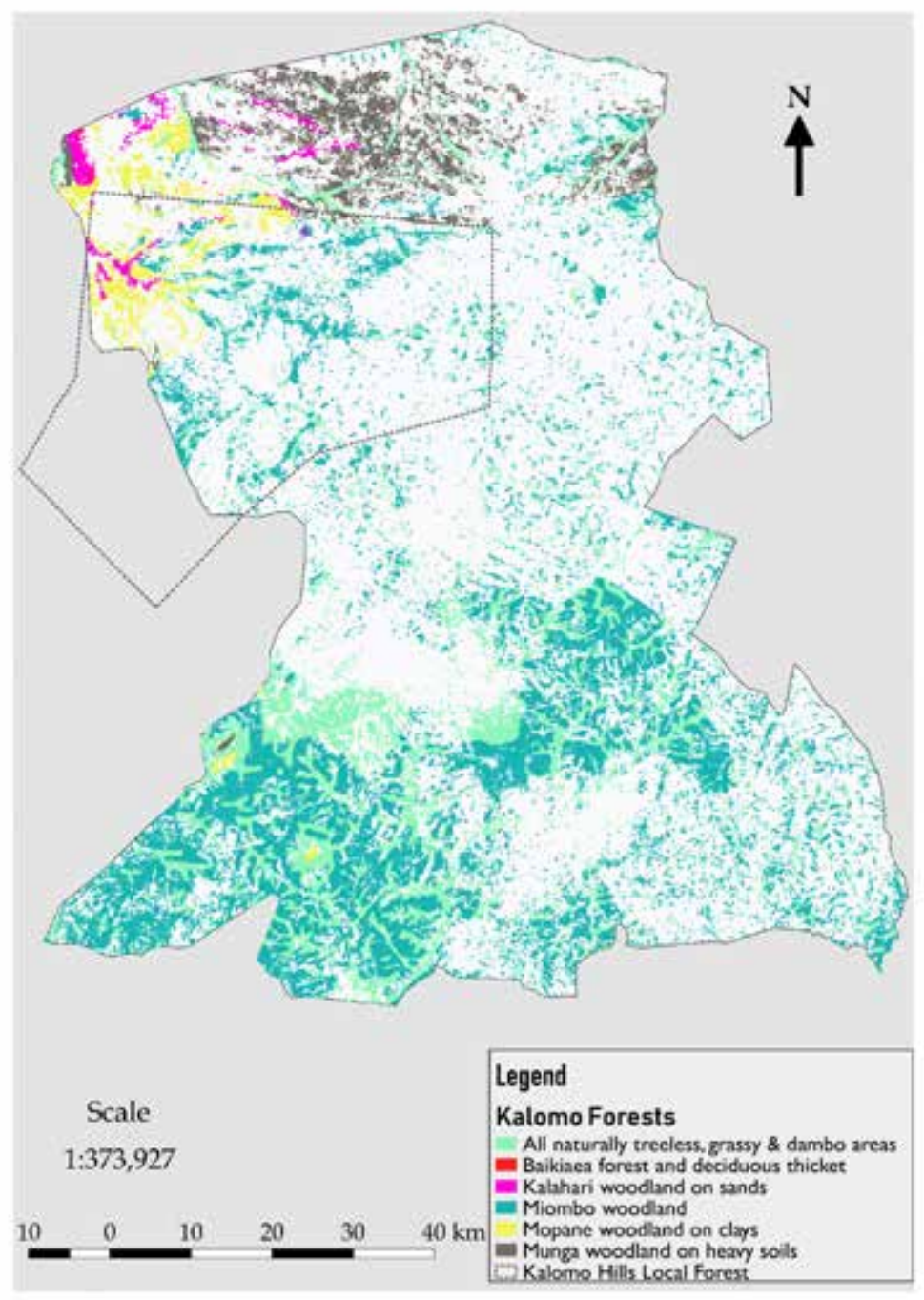

Figure 9.4 Kalomo vegetation. 
genera Brachystegia, Julbernardia, Isoberlinia and other leguminous trees with a welldeveloped grass layer. The woodland has undergone significant transformation in the last three decades. Most Miombo forest is secondary regrowth because of extensive cultivation in the past. In the west, Miombo woodlands have invaded into the Kalahari, forming Miombo/Kalahari woodlands (Dixon-Fyle 1976; Forestry Department 1976; Roberts 1976; Bäumle et al. 2007; Mbanga et al. 2019).

\section{Topography, soils and hydrology}

The district lies on a high plateau, referred to as the Batoka or Tonga ${ }^{10}$ Plateau at an altitude of between 1220 and 1830 meters above sea level (Fagan 1963 ${ }^{11}$; Roberts 1988), consisting of a soft undulating plain with a peak at its center. In terms of topography, Kalomo District can be divided into the plateau, the eastern escarpment, the southern Zambezi Basin and the Western Plains. In general, the district has sandy loam soils with scattered Kalahari sands and clay loam (ESDAC n.d.; Roberts 1976; KTC 2018) (Table 9.2).

The general drainage pattern in Kalomo District is toward the south to the Zambezi River. There are a few perennial rivers in the district. Kalomo River is the most noticeable (length of ca. $250 \mathrm{~km}$ ) with a drainage catchment of $6636 \mathrm{~km}^{2}$ which forms part of the Zambezi Basin. Other major rivers are the Sichikwenkwe, Mweemba, Kanyameza, Nanzhila and Luezi (Walsh 1950; Roberts 1976; Chinene 2006; KTC 2018). Although rarely used for water supply purposes because they are considered sacred places, groups of perennial hot springs, e.g. the Bbilili hot springs also exist (Bäumle et al. 2007).

Table 9.2 Soil features of Kalomo topographical zones.

\begin{tabular}{|c|c|}
\hline Part & Soil Features \\
\hline Plateau & Sandvelt soils overlaying a complex granite batholith \\
\hline Eastern escarpment & $\begin{array}{l}\text { Ferric Luvisol with Orthic/Xanthic Ferrasol, moderately leached reddish to } \\
\text { brownish clayey to loamy soils, derived from acid rocks on Miombo vegetation }\end{array}$ \\
\hline $\begin{array}{l}\text { Southern Zambezi } \\
\text { Basin }\end{array}$ & Brown sandy loams which mix progressively with the Kalahari sands \\
\hline Western Plains & $\begin{array}{l}\text { Dystric Gleysol with Humic Gleysol, hydromorphic sand soils, very poorly drained } \\
\text { in large dambos, nutritionally deficient grassy in carbonate-rich geology and } \\
\text { poorly sorted sandy silts, seasonally waterlogged depressions }\end{array}$ \\
\hline Northern parts & $\begin{array}{l}\text { Low and flat areas making them susceptible to summer floods, some limestone- } \\
\text { derived soils overlaying dolomitic limestone at the edge of the Kafue Basin }\end{array}$ \\
\hline
\end{tabular}

Source: Bäumle et al. (2007); Chinene (2006); von der Heyden and New (2003); KTC (2018)

10 Linguistically, the term 'Tonga' has been used to describe a group within the Central Bantu Zone which includes the Tonga, Lenje, We, Ila, Totela and other groups (Dixon-Fyle 1976).

11 This is $4000 \mathrm{ft}(1219.2 \mathrm{~m})$ above sea level. 


\subsubsection{Socio-economic context}

\section{Demography}

The population of the Southern Province has been on the increase with growth rates of $2.7 \%$ per annum between 2011 and 2013 due to, among other factors, improved access to health facilities, immigration and an increase in economic activities (CSO 2012). As of 2013, Kalomo District has a population of 395,471 which is projected to be 697,023 people by 2035 (CSO 2012). At present there are close to 44,728 households holding 258,570 people (female: $51.4 \%$, male: $48.6 \%$ ) at a density of 17.2 persons per $\mathrm{km}^{2}$. Comparatively, in 1963, a year before Independence, the population was 75,884 people. The total human population in the nine villages in the area where the COLANDS initiative is being implemented is approximately 6707, ranging from 152 to 1785 people per village. The average number of households per village is 160.3 (CSO, 2012; Moombe and Gumbo 2019).

\section{Migration and settlement patterns}

Kalomo exhibits a mix of people, including early white farmer settlers and local livestock herders. Migration in the district dates to pre-colonial times. Ethnically, the early migrants were Batonga, a Bantu ethnic group of southern Zambia, neighboring northern Zimbabwe, and to a lesser extent, Mozambique. The Batonga people settled in the area in the early $17^{\text {th }}$ century (Cliggett 2000). The history of the settlement patterns of the Tonga people of Kalomo is similar to the rest of Southern Province. They started as a society preyed on by powerful African neighbors such as the Lozi and Ndebele tribes who coveted their cattle during the mid-1800s. In response, they developed a highly dispersed pattern of settlement, which was easier to defend (Roberts 1976). At that time, the Tonga villages were a collection of huts spread over many kilometers and very few significantly large clusters developed. Tonga people also contended with early colonialism. The arrival of European foreign influence further disrupted the spatial organization of settlements on the Tonga Plateau, disturbing the indigenous economy and introducing urbanization (Nchito 2013).

There has been more recent migration in the Kalomo landscape. In a sample of nine villages, there is an average of 15 (range 3-54) migrants per village (Moombe and Gumbo 2019). For instance, Siankwembo, one of the oldest known villages in KFR, migrated from west of northern Rhodesia (Namwala areas) due to wars and, over time, were relegated to infertile land margins and eventually forced to settle in the forest reserve areas. ${ }^{12}$ Similarly, people in Nkandazovu, one of the villages in KFR, migrated from the Gwembe area during the construction of the Kariba dam (1955-1959). This is referred to in the Zambian development literature as Gwembe-Tonga Development Project, a compensation scheme. This project was funded by the government and World Bank and is a typical example of a conservation-development conflict, as it legitimatized settlements in a protected area. 
Generally, there are now more than 50 villages in KFR, compared with only five (i.e. Siankwembo, Siantambo, Sinyolo, Simapungula and Sande) in 1951 (Wadhams 1951). Currently, there are around 57,000 people, including about 12,000 farmers, accessing goods and services from the KFR. About 34,000 of these people reside in the reserve itself, compared with only about 300 adults from the five widely scattered villages at the time of its declaration (Wadhams 1951; ROZ, 1982; Mwansa 2018; Mbanga et al. 2019). Occupation in the KFR (both legal and illegal) is about $47.2-70 \%$ of the area. ${ }^{13}$ Agriculture, especially the expansion of crop fields (77.5\%), has contributed most significantly to forest degradation in the reserve. Fifty percent of the 220,000 (i.e. 111,000) tonnes of maize produced by Kalomo District comes from the KFR and its periphery. Settlements develop as a result of urban-rural migration and demand for services such as biomass energy, education, health facilities, communication, infrastructure and dams (Cooma 2018; Mwansa 2018). These activities have led to forest-cover change by $2 \%$ per annum from 1984 to 2018 , which is equivalent to 2836 ha per annum. Consequently, shrubs and grassland have replaced forests in some places (Mbanga et al. 2019).

\subsubsection{Landscape mosaics}

\section{Watershed and forest landscapes}

Kalomo landscape is part of the Kafue and the Zambezi Basin river systems. The former is approximately $42 \%$ of the total land area. The latter system drains the remaining $58 \%$ of Kalomo (MIGA 2013). The Nanzhila sub catchment is the largest of the lower Kafue and is approximately $7134 \mathrm{~km}^{2}$, with an estimated discharge of $308 \mathrm{~m}^{3} / \mathrm{s}$. All the other tributaries in the district are seasonal, transporting sporadic runoff during the rainy season (Bäumle et al. 2007; Chanda et al. 2019).

Dambos (shallow seasonal wetlands) account for $36.4 \%$ of total district land cover and serve as animal grazing and small-scale agriculture areas due to their ability to retain moisture during most of the dry season (Roberts 1988; Kadohira and Samui 2002). Croplands that include seasonal and abandoned fallow areas cover about $35.8 \%$ of the district land. The forest mosaics cover $23.2 \%$ (Forestry Department 2016), equivalent to 181,000 ha. The mosaics result from the widespread practice of farming and animal grazing. More than $50 \%$ of the forest area is under private tenure through commercial farms.

Bare ground is about $4.0 \%$ of total land cover in the district (which includes rural and urban settlements, infrastructure and agricultural lands). Water bodies (dam reservoirs, rivers, dambos and other water pools) constitute the smallest part of land cover in Kalomo (0.2\%). Figures $9.5 \mathrm{~A}$ and B show the distribution of land cover, use and forest distribution.

Kalomo District has two forest reserves: Kalomo Hills Local Forest Reserve No. P.13 (KFR) and Zimba Hills Local Forest Reserve No. P.10 (ZFR). Administratively, Zimba Hills Local Forest has been left to be managed by Zimba District because of its proximity. It is not discussed further here. 


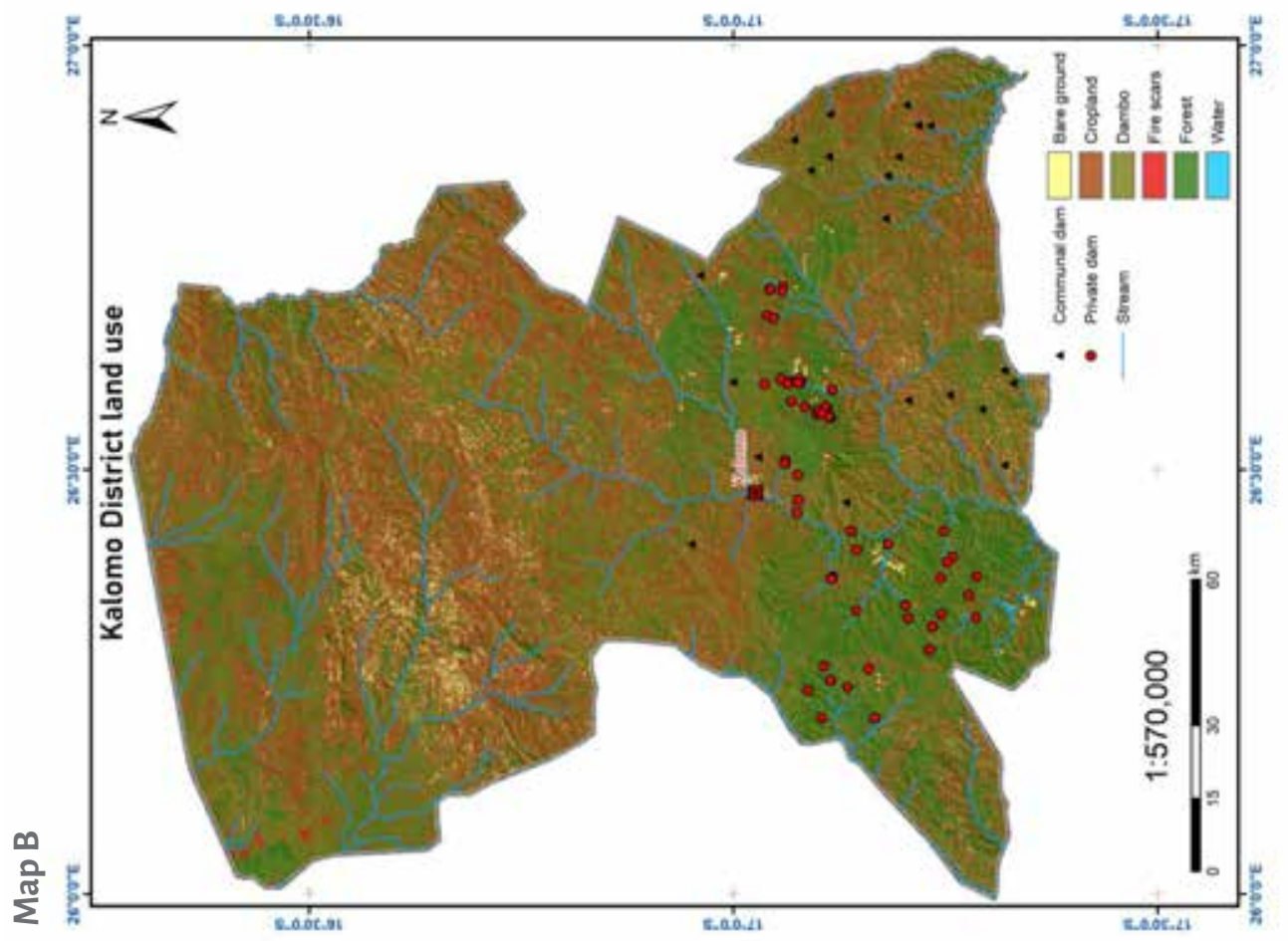

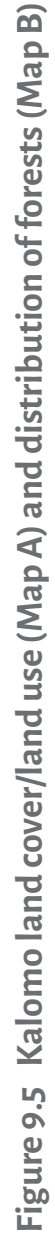


Table 9.3 Kalomo Hills Local Forest Reserve land cover

\begin{tabular}{|l|r|r|r|r|r|r|}
\hline & Cropland & \multicolumn{1}{|c|}{ Dambo } & \multicolumn{1}{|c|}{ Forest } & Water & Bare ground & Total \\
\hline $\mathrm{Ha}$ & $84,377.61$ & $52,464.80$ & $40,255.28$ & 22.11 & $6,330.99$ & $183,450.79$ \\
\hline \% Cover & 45.99 & 28.60 & 21.94 & 0.01 & 3.45 & \\
\hline
\end{tabular}

Source: Authors

\section{Table 9.4 Livestock distribution in Kalomo District}

\begin{tabular}{|l|c|}
\hline Livestock & \% of Total \\
\hline Poultry & 55.2 \\
\hline Cattle & 27.6 \\
\hline Goats & 13.8 \\
\hline Sheep & 1.9 \\
\hline Pigs & 1.3 \\
\hline Donkeys & 0.2 \\
\hline Total & 100.0 \\
\hline
\end{tabular}

Source: KTC (2018)

Kalomo Hills Local Forest Reserve No. P.13 (KFR), declared as such in 1952, is one of the state reserves in Kalomo. Since its declaration, its boundary has been altered legally three times, in 1970, 1975 and 1987. The reserve is partly in theChikanta and partly in the Siachitema chiefdoms in Dundumwezi Constituency, covering Bbilili, Naluja, Omba and Kasukwe Wards.

Its land cover and vegetation are like those in the rest of the district but differently configured (Table 9.3). Riparian, Miombo, Mopane and Kalahari woodlands/forests compose and predominate vegetation in the reserve. Munga and Savanna woodlands also occur in patches.

The reserve is a water and soil conservation area, being a headwater of significant rivers in the district (Wadhams $1951^{14}$ ). As of 2020, the reserve covers approximately 162,200 ha and encroachments are on-going.

\section{Agricultural landscapes: Livelihoods and land use pressure}

Kalomo is referred to as the 'Farmer's Nest' because of the commercial, medium- to small-scale livestock and crop farming enterprises that exist there. Sales of crops, livestock and fisheries products, as well as fruits and vegetables, contribute about $50 \%$ of local household incomes, with contributions of $34.4 \%, 9 \%$ and $7.8 \%$ from crops, livestock and fisheries, and fruits and vegetables, respectively. Alternative incomes include

14 Wadhams (1951) Reservation proposal No. S-4 Kalomo Hills to form the KPFA. Minute No. 829/R/12 by the Provincial Forestry Officer, Southern Province, Livingstone to the Chief Conservator of Forests, Ndola. 
the collection of natural products (wild fruits, mushrooms and honey) and the sale of fuelwood, charcoal and handicrafts (Kalinda et al. 2010).

Livestock production consists of traditional (indigenous) (50\%) and commercial (50\%) methods, with a total population of 411,765 animals. This population gives a cattle/capita of 0.44 . Besides cattle, people rear goats, sheep, poultry and pigs too (KTC 2018). Table 9.4 shows that poultry leads in number.

In the nine villages within the project working area, an average of 730 cattle per village were noted. These stock numbers create grazing conflicts in some villages, such as Mubombo Ulilanyama, which has local bylaws that restrict the number of cattle per household. It is not clear how much the range has improved due to these new arrangements. The poultry numbers range from 102 to 2801 per village, with an average of 1760 . The average number of chickens is 906 per village (Moombe and Gumbo 2019; pers. comm. with headmen during Validation Workshop 2029) for the nine villages within this study.

Kalomo produces approximately 14 tonnes of fish per year and aquaculture is expanding in the district. As of 2020 , there were 102 fish farmers, owning at least 174 fishponds (Fisheries Department ${ }^{15}$ ) with a total water surface area of $5820 \mathrm{~m}^{2}$. The expansion and contribution to food and nutrition security could be attributed to an enabling policy environment and the provision of inputs (KTC 2018).

Crop production in the district is carried out at subsistence level, complemented by limited semi-commercial and commercial farming. Major crops grown are maize (Zea mays), groundnuts (Arachis hypogeae), cotton (Gossypium hirsutum), tobacco (Nicotiana tabacum), sunflowers (Helianthus annuus), cowpeas (Vigna unguiculata), sweet potatoes (Ipomoea batatas), wheat (Triticum aestivum), soybeans (Glycine max) and various vegetables (Kalinda et al. 2010; KTC 2018). Maize is the primary staple crop and occupies $61 \%$ of the cultivated area. Both landraces and hybrid maize varieties are cultivated. The distribution of land area among crops in the district is indigenous maize varieties (25\%), groundnuts (26\%) and hybrid maize (30\%). Due to climate change, erratic rainfall and issues pertaining to the procurement of inputs, a general decline in maize production has been noted in the district from 2009 to 2018 . The average cropped area is about 3 ha per household. Figure 9.6 shows the general decline in maize production quantity in the district from 2009 to 2018 .

Gender plays a critical role in food production in the Kalomo landscape. In general, i ha of land supports on average two individuals, with female-headed households having smaller farm sizes of 3-5 ha of land. About $66 \%$ of men have access to land that is more than 5 ha (Kalinda et al. 2010). This social order has implications for the implementation of LAs in terms of participation and decision-making. 
Maize Production; 2010-2018 (Metric Tonnes)

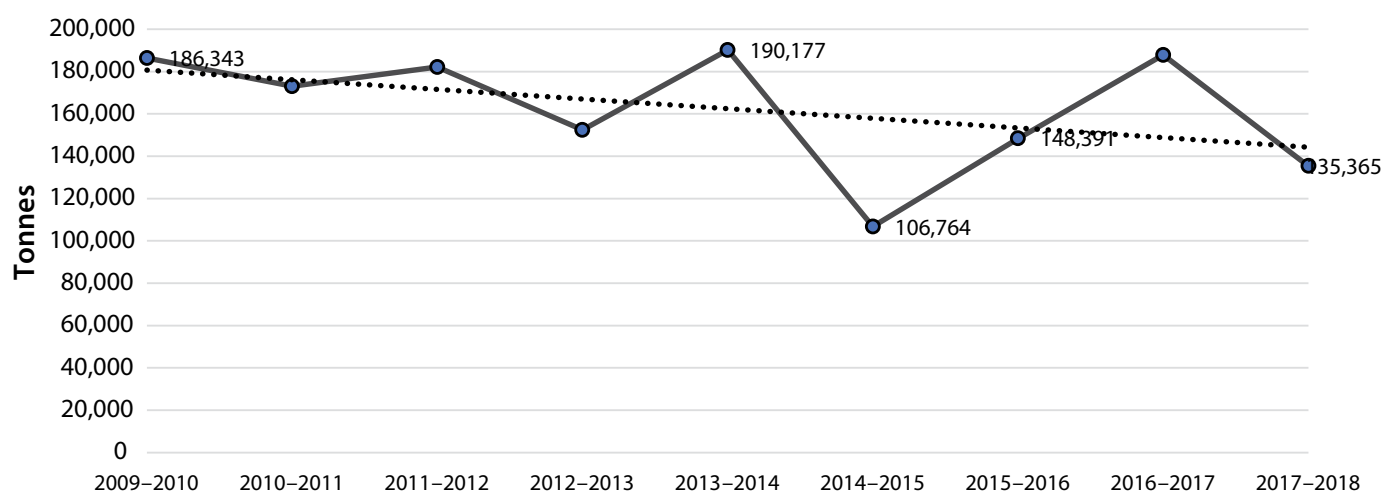

Farming Season, Year

Figure 9.6 Maize production in Kalomo District in metric tonnes (2010-2018).

Source: Based on KTC (2018)

\section{Infrastructure development}

Physical capital includes the basic infrastructure and producer goods needed to support livelihoods. Among the essentials for sustainable livelihoods are: affordable transport; secure shelter and buildings; adequate water supply and sanitation; clean, affordable energy; and access to information and means of communication). For Kalomo, the common and valuable physical assets comprise bicycles (73.3\%), radios (67.1\%), cattle (63\%) and farming tools. For housing or dwellings, the predominant type (73\%) is a brick house with grass thatched roof (Kalinda et al. 2010). There has been a gradual movement away from pole and thatch, which may signal an increased cutting down of trees for brick burning, which is contributing to tree loss.

Water is a scarce commodity in the Kalomo District, but with 178 dams, and an estimated average of 201,689 $\mathrm{m}^{3}$ dam capacity at full supply level (Water Resources Department, Kalomo, $2012^{16}$ ), some attempts to address the issue are in place. For example, between 1950 and 2019, an average of two dams were constructed every year. Available data ${ }^{17}$ shows that 112 are privately owned, 55 are communal and one is owned by a church. ${ }^{18}$ The construction of the dams was funded by entities comprising private (121), government (45), NGOs (6) and community (3). Three dams are in Chikanta, 137 in Sipatunyana and 38 in Siachitema chiefdom. The water in the dam reservoirs is used for animal watering, fish farming, irrigation and township supply.

Further infrastructure in the district comprises the railway and all-weather urban and rural roads that connect the district to the regional transportation networks; the

16 Based on data for 143 (of the 180) dams. Source: Excel sheet of Kalomo dams, and ward statistics was obtained from the Water Resources Department, Kalomo. Dated 2012.

17 Data are missing for nine dams.

18 Data on classification for the other dams is not available. 
electricity grid (Zambia Electricity Supply Corporation, Rural Electrification Authority) including in the Dimbwe, Kalomo Rural Resettlement and Chikanta areas; state and private mobile, internet, television and radio telecommunication networks and services; and solar, biogas fuel and efficient energy-saving stoves. Although inadequate, this infrastructure is essential for economic and social development. For example, more investment is needed in alternative energy sources to reduce the use of wood fuel (KTC 2018). The telecommunications industry has improved information dissemination to the population in the district (KTC 2018), and could be valuable for COLANDS's engagement and outreach activities. Infrastructure development could also provide thematic and spatial areas for entry into piloting LA through dialogue, as these are centers of social struggles. Energy consumption places considerable pressure on the environment, e.g. wood fuel and charcoal demand contributes directly to forest degradation (KTC 2018).

\subsection{Governance system at national, district and lower levels}

\subsubsection{State governance system}

Zambia is pursuing a decentralized governance system that devolves decision-making responsibilities to district and subdistrict governance organs. Statutory and customary components are the two overlapping decision-making organs in Kalomo District, which the Constitution and other relevant legislations support. The statutory system consists of the political and administrative systems through formal government institutions administered by entities at national and district levels. The customary

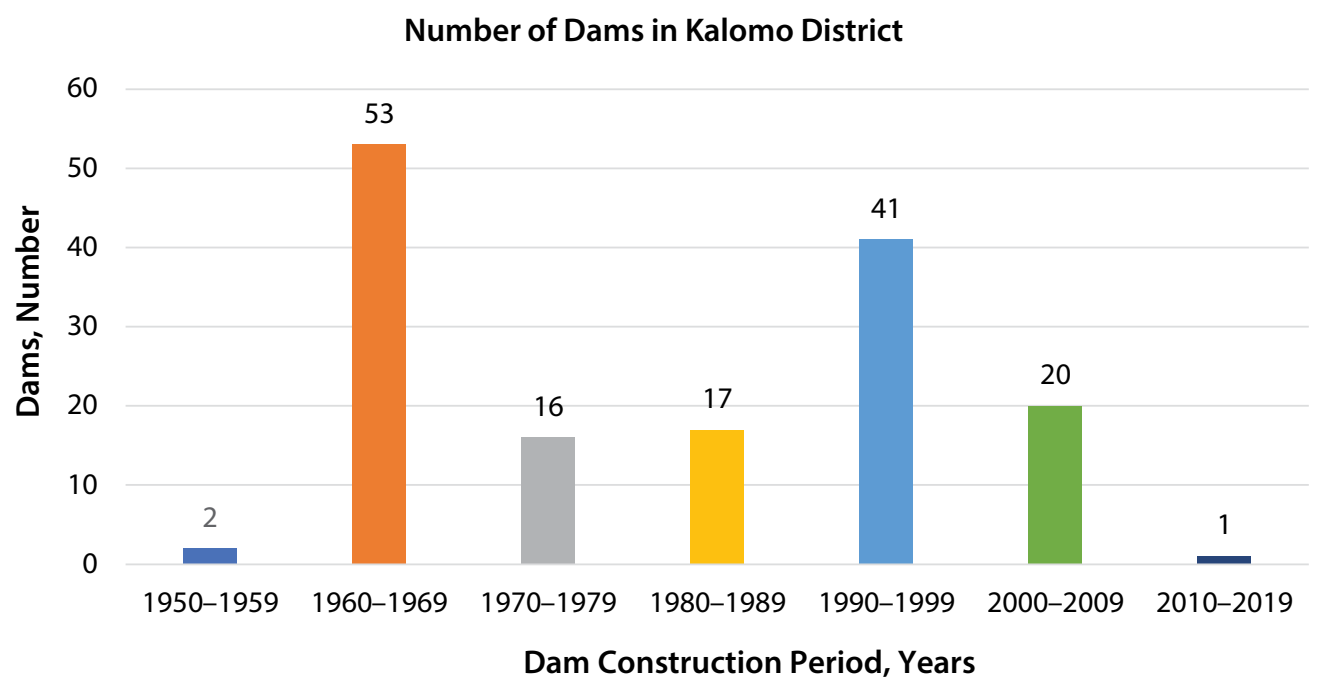

Figure 9.7 Dam distribution by the period of construction.

Source: based on data for the Department of Water Resource management Managem District (see Chapter 7); Kalomo_Dams_Kalomo District Wards_Water_Statistics_08 February 2012 
governance systems exist at subdistrict level, i.e. chiefdom level. The customary system involves interpretations of bylaws, indigenous local rules and regulations. Both statutory and customary components of governance have often demonstrated overlaps in the responsibilities in the management of natural resources and decision-making. The overlapping jurisdictional responsibilities of these components of governance have implications for the implementation of integrated landscape approaches (ILAs) in Kalomo.

Members of Parliament (MPs) represent political-spatial constituencies at the national level in legal and policy formulations in the National Assembly. At the sub-district level, elected councillors who link with the MP represent the local communities in lobbying development programs. Councillors are key persons in the governance chain as they are linked to all centers of decision-making, such as village development committees and district council chambers. Ideally, councillors are members of the more politicized Community Development Fund (CDF) committee, a platform that decides on the allocation of resources to local-level development initiatives. In 2019, Kalomo had 18 wards councillors and three chiefs. The former do not attend any District Development Coordinating Committee (DDCC) meetings, but only the CDF committee and council meetings.

The administrative functions of the district are superintended by the District Administration (DA) office. The DA's office coordinates all activities of government departments, planning units and other line ministries through the DDCC. It is mandatory for NGOs, as members of the cluster sub-committees of the DDCC, to report to the DDCC on activities in which they are involved. In the recent restructured DDCC, chiefs are members of these district platforms and represent the interests of the chief's councils and Village Development Committees (VDCs). One of the chiefs, with the support of the Chiefs and Traditional Affairs Officer, represents the chiefs in the DDCC. These two sub-governance systems (political and statutory) are linked through procedures outlined in government functions.

\subsubsection{Customary governance system}

The Chiefs Act (GRZ, 1965) and Registration and Development of Villages Act (GRZ, 1971) provide for the engagement of customary institutions in the country's governance systems The Chiefs Act makes provision for the recognition, appointment and functions of chiefs by the President on condition that the person is entitled to hold the office under customary law. Tonga communities found in the three chiefdoms in the COLANDS area are matrilineal, where inheritance follows the female lineage of the previous chief's clan. Thus, through an inheritance system, chiefs are selected to rule for a lifetime unless there are certain extenuating circumstances. Customary land is controlled by the chiefs and their headmen, but act with the consent of their people (van Loenen 1999). Customary communities are organized based on villages in a chiefdom and under the jurisdiction of chiefs, e.g. Siachitema, Sipatunyana and Chikanta for Kalomo in the case of the working areas of COLANDS. In the royal lineage governance structure and system, the Chiefs' Royal Establishment or Governance Councils, Development Trust, and several committees (Executive, Land, Traditional, Zonal) at various levels support the 
Table 9.5 Chiefdom hierarchical governance structure and key functions: The case of Kalomo District.

\begin{tabular}{|c|c|c|c|c|c|}
\hline Level & \multicolumn{5}{|c|}{ Chiefdom } \\
\hline & Sipatunyana & \multicolumn{2}{|l|}{ Siachitema } & \multicolumn{2}{|l|}{ Chikanta } \\
\hline 1 & $\begin{array}{l}\text { HRH Chief } \\
\text { Sipatunyana }\end{array}$ & \multicolumn{2}{|c|}{ HRH Senior Chief Siachitema } & \multicolumn{2}{|c|}{$\begin{array}{l}\text { HRH Chief Chikanta (+ The Chikanta } \\
\text { Royal Governance Council, CRGC) }\end{array}$} \\
\hline 2 & $\begin{array}{l}\text { Royal } \\
\text { Establishment } \\
\text { Council (RECO) }\end{array}$ & \multicolumn{2}{|c|}{$\begin{array}{l}\text { Executive Committee (Royal } \\
\text { Council) }\end{array}$} & \multicolumn{2}{|c|}{$\begin{array}{l}\text { Chikanta Royal Governance Council } \\
\text { (CRGC) }\end{array}$} \\
\hline 3 & Lands Committee & & & & $\begin{array}{l}\text { Chikanta } \\
\text { Development Trust } \\
\text { (CDT) (registered } \\
\text { with Registrar of } \\
\text { Societies) }\end{array}$ \\
\hline 4 & $\begin{array}{l}\text { Senior Headmen } \\
\text { and Chairpersons } \\
\text { of Settlements }\end{array}$ & \multicolumn{2}{|c|}{ Senior Headmen } & $\begin{array}{l}\text { Senior } \\
\text { Headmen } \\
\text { (Zonal Level) }\end{array}$ & \\
\hline 5 & Headmen & \multicolumn{2}{|l|}{ Headmen } & $\begin{array}{l}\text { Village } \\
\text { Headperson }\end{array}$ & \\
\hline 6 & & $\begin{array}{l}\text { Chitumbi } \\
\text { Traditional } \\
\text { Court }\end{array}$ & $\begin{array}{l}\text { (Maanzi Abila } \\
\text { Traditional } \\
\text { Committee) }\end{array}$ & $\begin{array}{l}\text { Zone } \\
\text { Committee } \\
\text { (23 Zones) }\end{array}$ & \\
\hline 6 & Village Committees & $\begin{array}{l}\text { Village } \\
\text { Committees }\end{array}$ & & $\begin{array}{l}\text { Village } \\
\text { Committee }\end{array}$ & \\
\hline \multirow[t]{3}{*}{7} & Subjects & Subjects & & Subjects & \\
\hline & \multicolumn{5}{|c|}{ Roles, Responsibilities } \\
\hline & $\begin{array}{l}\text { The Royal } \\
\text { Establishment: } \\
\text { Chooses a chief, } \\
\text { provides counsel, } \\
\text { resolves disputes, } \\
\text { composed of } 3 \\
\text { people. } \\
\text { The Lands } \\
\text { Committee: } \\
\text { Responsible for } \\
\text { allocating land in } \\
\text { settlements and } \\
\text { verifying vacant } \\
\text { plots, composed of } \\
10 \text { members, there } \\
\text { are } 12 \text { chairpersons } \\
\text { (not village head } \\
\text { persons); in the } \\
\text { settlements, there } \\
\text { are } 130 \text { headmen. }\end{array}$ & \multicolumn{2}{|c|}{$\begin{array}{l}\text { The Executive Committee: Chooses } \\
\text { a chief, provides counsel to his royal } \\
\text { highness, composed of } 11 \text { persons } \\
\text { (10 are head persons). } \\
\text { Chitumbi Traditional Court: } \\
\text { Resolves disputes, composed of } 10 \\
\text { persons (of whom } 9 \text { are headmen). } \\
\text { Maanzi Abila Committee: } \\
\text { Organizes the Maanzi Abila } \\
\text { Traditional Ceremony, composed of } \\
12 \text { members. The chiefdom has } 215 \\
\text { village ( } 27 \text { are senior) headmen. }\end{array}$} & \multicolumn{2}{|c|}{$\begin{array}{l}\text { CRGC: Chooses, provides counsel } \\
\text { and makes recommendations to the } \\
\text { chief. Examines policies/proposals; } \\
25 \text { members in this committee } \\
\text { ( } 21 \text { headmen, } 4 \text { village committee } \\
\text { members). } \\
\text { CDT: Oversees development activities } \\
\text { and programs, managed by a } \\
\text { 10-person committee, all villages have } \\
\text { village committees that work with } \\
\text { and assist the headman. Chiefdom } \\
\text { has } 330 \text { villages and head persons (of } \\
\text { which } 30 \text { are senior headmen). }\end{array}$} \\
\hline
\end{tabular}


chiefs (Table 9.5). Trusts serve as links with the external partners such as government, NGOs and others. Chiefdoms are subdivided into zones that are led by senior headmen ${ }^{19}$ in charge of several other headmen. Each village headman is supported by an elected village committee that also functions as a local-level platform for decision-making. In some villages, the Council of Elders supports the village headmen and traditional courts that help in resolving conflicts.

Chiefs provide overall leadership for the chiefdom and discharge the traditional functions of their office under customary law but within the confines of the Constitution or any written law. Every chief is required to preserve the public peace in his/her area (GRZ 1965). Besides, a chief ensures that all headmen duly perform their duties in his/ her chiefdom. Chiefs also ensure that the village productivity committees (VPCs) are established and are functioning effectively, and that they report to the VPCs and ward development committees (WDCs) the decisions reached in the House of Chiefs affecting or concerning their people. Generally, each VPC is to do all such things as may be necessary or desirable for the establishment, promotion and development of facilities for the betterment and happiness of the villagers socially, culturally, economically and politically and to create awareness among the villagers toward those ends. Since 1964, the role and authority of the traditional institutions have been gradually diluted, although these institutions continue to have a significant role in resource mobilization for development (KTC 2018).

Although all headmen in Kalomo District appear to have equal power and responsibilities, the reality is different. Those selected based on clans and who have been in the area much longer, wield more influence and enjoy more privileges of choice of better and more productive land for settlement, agriculture and grazing than those not based on clans. The clan-based headmen may have some connections with the traditional royal clans or 'ruling class' and are very influential. 'Governance convenience,' where the chief aims to improve management efficiency at the local level and reduce the size of villages, is the basis for the selection of the non-clan headmen. Observations in the study area indicate that most headmen who have settled in marginal areas and forest reserves are either 'immigrants' or are not directly related to the 'traditional ruling class'. These headmen may be selected regardless of the origin of an individual vying for leadership. In all cases, the headmen's tenure is similar to that of the chief where one can serve for a lifetime unless the Council of Elders, the chief or the general village members wish to remove such a headman for gross misconduct. Village committees are elected every year or after two years, depending on the village, and may be re-elected for several terms.

\subsubsection{Entry point for landscape governance and preliminary stakeholder analysis}

The preliminary stakeholder analysis for the Kalomo District reveals key institutions in the governance of the landscape. The existing executive, legislative, and judiciary government framework and structures serve as the entry points for landscape 


\section{Box 9.2 Organizations represented in the implementation of the COLANDS initiative in Kalomo District}

1) The executive (e.g. DC Office, Forestry, Agriculture, Water, Social Welfare, the Office of the President, Fisheries, Chiefs and Traditional Affairs, Agriculture Information Services, District Council, Chiefs and Headmen. In partnership with NGOs such as World Vision International, Care International, Community Based Natural Resources Management Forum (CBNRMF), Community Resources Boards (CRB) Association); 2) the legislature (e.g. National Assembly Office in Kalomo is a member of the COLANDS Consultative Working Group, chiefs/headmen); and 3) the judiciary (chiefs and headmen through the local courts).

governance under the COLANDS initiative. The coordination and actual implementation include the public and private sectors, NGOs as well as customary/rural community organizations and institutions across sectors of development. For example, participation in the COLANDS initiative so far has included organizations representing the entities listed in Box 9.2.

The government structures have served as entry channels with the advantage that they form part of the broader governance scheme (outlined in the Seventh National Development Plan (2017-2021) (7NDP). However, modifications to suit project aims may be needed. For example, the consultative working group serves to review, validate and provide information to the COLANDS initiative. This multidisciplinary group draws wisdom from the formal government structures.

\subsection{Challenges, opportunities and options for landscape approach implementation}

Several challenges in implementing a landscape approach exist as tabulated in Table 9.6. The major themes are sector-based priorities, actions and engagement models, policy incoherence, isolation of the private sector in natural resources management programs, cultural barriers and contestation over rights to resources.

\subsubsection{Legal framework for LA}

Over the years, the government has shown its commitment to a landscape approach through the development of several land use policy adjustments as well as in its 7NDP (Central Statistical Office (CSO) n.d.; see also Chapter 7).

\subsubsection{Reflections from field events}

The various stakeholder perspectives captured during field events help reflect ideas on landscapes, especially the centrality of biological diversity and ecosystem integrity, the value of ILAs in Kalomo, sharing roles, change detection and associated impacts as 
Table 9.6 Key challenges to the implementation of landscape approaches in Kalomo.

\begin{tabular}{|c|c|c|c|}
\hline \multirow{2}{*}{$\begin{array}{l}\text { Institutional } \\
\text { category }\end{array}$} & \multicolumn{3}{|c|}{ Land tenure category } \\
\hline & State & Customary & Private \\
\hline \multirow[t]{2}{*}{ Policy } & \multicolumn{3}{|c|}{$\begin{array}{l}\text { Weak and segmented linkages and capacity, coordination, networking, and } \\
\text { consultations among stakeholders and interest groups (state, customary, private) }\end{array}$} \\
\hline & $\begin{array}{l}\text { Enabling policies in one at } \\
\text { the expense of another sector. } \\
\text { Sector-based planning and } \\
\text { management of natural } \\
\text { resources, differences in } \\
\text { extension models and mandates, } \\
\text { institution-based interpretation } \\
\text { of roles; mismatch between local- } \\
\text { level aspirations and provisions } \\
\text { of projects support }\end{array}$ & \multicolumn{2}{|l|}{$\begin{array}{l}\text { 'Preliminary' issues } \\
\text { (e.g. boundary conflicts) } \\
\text { that may need to be } \\
\text { addressed before } \\
\text { implementation }\end{array}$} \\
\hline Legislation & $\begin{array}{l}\text { Incoherence in policy guidance } \\
\text { in some cases (refer to } 7.4 .2 \text { ); } \\
\text { weak recognition of customary } \\
\text { land tenure system }\end{array}$ & \multicolumn{2}{|l|}{$\begin{array}{l}\text { Absence of structures } \\
\text { provided by the law to } \\
\text { manage landscapes } \\
\text { (VPC, WDCs) }\end{array}$} \\
\hline Technical & $\begin{array}{l}\text { Inward-looking or internal } \\
\text { capacity development that } \\
\text { creates conflicts of interest }\end{array}$ & & \\
\hline \multirow[t]{2}{*}{ Governance } & $\begin{array}{l}\text { Land tenure recognition } \\
\text { and public provision of land } \\
\text { information; inadequate } \\
\text { monitoring of landscapes }\end{array}$ & $\begin{array}{l}\text { Contested role of } \\
\text { traditional authorities } \\
\text { in tenure systems }\end{array}$ & \\
\hline & \multicolumn{3}{|c|}{$\begin{array}{l}\text { Inconsistent management of conflicts in the realm of } \\
\text { conservation versus development (e.g. KFR) }\end{array}$} \\
\hline Environmental & $\begin{array}{l}\text { Culture of illegal access to } \\
\text { resources }\end{array}$ & & $\begin{array}{l}\text { A lack of private sector } \\
\text { involvement in natural } \\
\text { resources management } \\
\text { initiatives }\end{array}$ \\
\hline $\begin{array}{l}\text { Social, cultural, } \\
\text { economic }\end{array}$ & Low budgetary allocation & $\begin{array}{l}\text { Cultural barriers to } \\
\text { adoption of technologies } \\
\text { (e.g. conservation } \\
\text { agriculture); conflicts } \\
\text { between Western } \\
\text { (Christian) and } \\
\text { traditional religious and } \\
\text { other belief systems and } \\
\text { values }\end{array}$ & \\
\hline & $\begin{array}{l}\text { Limited financial capacity of the a } \\
\text { priorities and conceptualization o } \\
\text { resources }\end{array}$ & $\begin{array}{l}\text { tors (state, customary, priv } \\
\text { threats, contestations over }\end{array}$ & $\begin{array}{l}\text { ate), differences in } \\
\text { a bundle of powers over }\end{array}$ \\
\hline
\end{tabular}

Source: Chilesjhe (2005); Kalinda et al. (2010); Vinya et al. (2011); Mulolwa et al. (2016); Gumbo and Moombe (2018); Mbanga (2019); Umar (2019); Moombe and Gumbo (2020); pers. obs. Freddie Siangulube 
well as how to factor these into project management and landscape governance. The stakeholders saw ILAs as a pathway to addressing land-use issues (conflict resolution) in the district. Clarification of stakeholder roles calls for facilitating empowerment and knowledge sharing, making it an all-encompassing consultative facility. The heterogeneity of landscapes result in spatial and temporal overlaps, which is based on a history of access and utilization. This calls for critical matching and valorization of the social and biophysical elements. A critical question in this respect is: What are the landscapes of Kalomo, and what are their values and capabilities? Government departments (including MPs, councillors and other leaders) work together to integrate knowledge systems, management approaches and context and to implement ILA within existing planning and coordination frameworks in the district. There could be issues of resistance to change, power and mandates, and recognition of chiefs. How far do these issues affect willingness and attitudes toward collaboration and cooperation? There is a need to consider the farmer-technocrat, technocrat-technocrat, technocrat-chief and chief-chief interfaces.

\subsubsection{Methods to engage stakeholders in dialogue processes to envision future landscape trajectories}

The organizing principle must be triangulation/validation through the application of multiple methods. The value of mixed methods and methodologies for landscape approaches may be in revealing historical trend analysis, scenario building/forecasting and theory of change (see Chapter 6). A cocktail of established methodologies can be applied here, for example in the multi-stakeholder platforms. Such a mix of methods helps us to understand better how the landscapes have evolved, how different actors or actor groups envision the landscape in the future, as well as how actors think they can get from the baseline situation to the desired future.

\subsubsection{Further action: outreach, project implementation and research}

Among the key actions could be:

- creating more buy-in or socializing the COLANDS initiative (themes, baseline information, sharing/feedback), and social network analyses;

- developing governance systems and processes (i.e. methods, tools, platforms, performance evaluation);

- undertaking research in landscape evolution (including analysis of past policy interventions that have shaped the landscapes), restoration (charcoal or sustainable feedstock supply), governance, local or indigenous adaptive knowledge stock take, co-production and application (access analysis and LA framework for assessing contestation in Kalomo);

- contributing to filling in research-policy-society gaps.

\section{Conclusion}

The Farmers' Nest, i.e. Kalomo District, is under siege from long-term changes in weather, accelerating forest loss and unplanned settlements and villages as well as 
declining soil fertility. Grazing is becoming increasingly scarce suggesting that there may be conflicts around cattle and grazing land and the institutions that manage them. Kalomo District represents fertile ground for exploring ILA approaches in the near future.

The district has its own share of history of land use and change - biophysical and social which has not only shaped the landscape but also may explain the present state of the land. There is an underlying history of struggles and accommodation against a background of powerful chiefs and other institutions, but a rapidly deteriorating state of the land. While the traditional land management systems have remained largely intact, their capacity to address the new challenges of the land can be questioned, as evidenced by the loss of sacred lands to other land uses. The situation has been exacerbated by weak district coordination, which has allowed institutions to work in an unimpressive isolation mode - a perfect recipe for failure in resource management. With the challenges of charcoal production, limited grazing land and more demand for land on which to grow crops to fulfil the "maize and livestock" idiom, the reality is of great concern. But then, we wonder if these concerns are shared. ILAs offer an opportunity for dialogue and for the development of consensus and a shared way forward.

\section{References}

Anderson D and Grove R, eds. 1987. Conservation in Africa: People, Policies, and Practice. Cambridge: Cambridge University Press.

Bäumle R, Neukum C, Nkhoma J and Silembo O. 2007. The Groundwater Resources of Southern Province, Zambia (Phase 1) Volume 1. Technical Report. 1 (Phase 1).

Beinart B. 1984. Soil erosion, conservationism and ideas about development: A Southern African exploration, 1900-1960. Journal of Southern African Studies 11(1): 52-83.

[CCDSP] Chikanta Chiefdom Development Strategic Plan 2012-2016. USAID/President's Emergency Plan for AIDS Relief (PEPFAR)/Support to the HIV/AIDS Response Zambia (SHARe II) Project: GHH-1-02-07-00059.

Chanda D, Gilbert Juunza G, Mbanga T, Rays Mwansa R and Mwaanga B. 2019. Estimation of Streamflow for Nanzhila River in Kalomo and Forest Degradation Assessment. Unpublished.

Chinene VR. 2006. Kalomo District Southern Province: Environmental Policy Situation Analysis Report. Republic of Zambia. Ministry of Tourism Environment and Natural Resources.

Cliggett L. 2000. Social components of migration: Experiences from Southern Province, Zambia. Human Organization 59: 125-35.

Chileshe, RA. 2005. Land tenure and rural livelihoods in Zambia: Case studies of Kamena and St . Joseph. PhD Thesis. University of Western Cape.

Colson E. 1948. Rain-shrines of the Plateau Tonga of Northern Rhodesia. Africa 18(4): $272-83$.

Cooma B. 2018. Is Zambia Violating the Rights of Internally Displaced Persons? DRC Refugees fleeing into Zambia. https:/www.africablogging.org/is-zambia-violating-the-rights-ofinternally-displaced-persons/.

Commonwealth Secretariat. 1979. Report of the Regional Appropriate Technology Coordinators' Meeting, held In Lusaka, Zambia in June 1979. 
CSO. n.d. Crop Forecast Survey (CFS). Lusaka: CSO.

CSO. 1963. 1963 Final report of the May June 1963 census of Africans. 1963, 41. Lusaka: Rhodesia and Nyasaland, Ministry of Finance.

CSO. 2011. 2010 Census of Population and Housing Preliminary Population Figures. Republic of Zambia.

CSO. 2012. 2010 Census of Population and Housing. Population Summary Report. March 2012. Lusaka: Republic of Zambia.

Dixon-Fyle M. 1977. Agricultural improvement and political protest on the Tonga Plateau, Northern Rhodesia. The Journal of African History 18(4): 579-96.

Dixon-Fyle MR. 1976. Politics and Agrarian Change among the Plateau Tonga of Northern Rhodesia: 1924-63 [PhD thesis]. London: University of London. https://eprints.soas. ac.uk/29318/1/10731413.pdf.

[ESDAC] Joint Research Centre European Soil Data Centre. n.d. Soil map of Zambia. ESDAC, European Commission. Accessed 13 October 2020. https://esdac.jrc. ec.europa.eu/ESDB_Archive/EuDASM/Africa/images/maps/download/afr_zm20011_ so.jpg.

Fagan BM. 1963. The Kalomo/Choma Iron Age project (1960-1963): Preliminary report. South African Archaeological Society 18(69): 3-19.

Forestry Department. 2016. Ministry of Lands Natural Resources and Environmental Protection, Integrated Land Use Assessment Phase II - Technical Paper 1, Classification of Forests in Zambia. Classification of Forests in Zambia. Integrated Land Use Assessment Phase II - Technical Paper 1. Lusaka: Ministry of Lands Natural Resources and Environmental Protection/Food and Agricultural Organization of the United Nations, Ministry of Foreign Affairs Finland. Zambia http://zmb-nfms.org/ iluaii/images/technical_docs/1.-CLASSIFICATION-OF-ZAMBIAN-FORESTS.pdf.

GRZ. 1971. Laws of Zambia. The Registration and Development of Villages Act Chapter 289 of The Laws of Zambia. Ministry of Legal Affairs, Government of the Republic of Zambia

GRZ. 1965. Laws of Zambia. Chapter 287 of The Laws of Zambia. Ministry of Legal Affairs, Government of the Republic of Zambia.

GRZ. 2014. National Forestry Policy of 2014. Lusaka: Ministry of Lands, Natural Resources and Environmental Protection.

GRZ. 2015. The Forests Act No. 4 of 14 August 2015: 81-140. Lusaka: Ministry of Lands, Natural Resources and Environmental Protection.

GRZ. 2016. The National Climate Change Policy of 2016.

GRZ. 2018. The Regulations for community forestry (Statutory Instruments No. 11 of 2018 or SI11/2018).

GRZ.n.d. National Strategy to Reducing Emissions from Deforestation and forest Degradation. Lusaka: Ministry of Lands, Natural Resources and Environmental Protection.

Gumbo DJ and Moombe KB. 2018. COLANDS inception workshop report. Unpublished. Haggblade S and Tembo G. 2003. Conservation farming in Zambia. EPTD Discussion Paper No. 108, 3(108): 113. 
Kadohira M and Samui K. 2002. Traditional cattle farmers in Monze district of Zambia. Journal of African Studies 2002(61): 73-8. https://doi.org/10.11619/africa1964.2002.61_73.

Kalinda T, Tembo G, Kuntashula E, Langyintuo A, Mwangi W and La Rovere R. 2010. Characterization of Maize Producing Households in Monze and Kalomo Districts in Zambia. 1-55. https://repository.cimmyt.org/handle/10883/1093 Accessed Online: $5^{\text {th }}$ April 2020

[KTC] Kalomo Town Council. 2018. Kalomo Town Council Strategic Plan: 2018-2021. p. 50. Kalomo Town: KTC.

Manning IPA. 2011. Wildlife conservation in Zambia and the Landsafe Customary Commons. PhD thesis, University of Pretoria, Pretoria. http://hdl.handle. net $/ 2263 / 25570$.

Mbanga TM, Mulenga MC and Membele G. 2019. Monitoring Forest Cover Change in Kalomo Hills Local Forest Using Remote Sensing and GIS: 1984-2018. Unpublished.

Moombe KB. 2020. Theory of Change Workshop Report, Kalomo, Zambia. Unpublished. Moombe KB and Gumbo DJ. 2019. Validation Workshop. Village Headmen and Village Secretaries. Zuus Lodge, Kalomo District, Southern Province. 14-17 June 2019. FN_ C171019.

Mulolwa A, Mfune O, Shakachite O, Phiri D, Mubanga D, Umar BB, Nsombo P, Mukonde E, Phiri D and Kalinda TK. 2016. Land Governance Assessment. Zambia Country Report. Draft Version 1.1.

Multilateral Investment Guarantee Agency (MIGA). 2013. Environmental and Social Review Summary; Silverlands Ranching Limited. World Bank. https://www.miga.org/sites/ default/files/archive/Documents/ESRS_Zambia_SZL_final.pdf. Accessed Online: $5^{\text {th }}$ April 2020.

Murphy EP, ed. 2003. A History of the Jesuits in Zambia. A Mission Becomes a Province. Nairobi: Paulines Publications Africa.

Nchito WSS. 2013. The Growth and Functions of Small Urban Centres in Zambia: A Case Study of Mazabuka and Kalomo. PhD Thesis. Lusaka: University of Zambia.

Nchito WS. 2010. Migratory patterns in small towns: The cases of Mazabuka and Kalomo in Zambia. Environment and Urbanization 22(1983): 91-105. https://doi. org/10.1177/0956247810362846.

Roberts A. 1976. A History of Zambia. London: Cox and Wyman Limited.

Roberts N. 1988. Dambos in development: Management of a fragile ecological resource. Journal of Biogeography 15(1): 141-48.

ROZ. 1982. A Report of the Commission of Inquiry into land Matters in Southern Province.

ROZ. 2002. The National Decentralisation Policy. Towards Empowering the People. Lusaka: Office of the President/Cabinet Office.

Sayer J, Sunderland T, Ghazoul J, Pfund JL, Sheil D, Meijaard E, Venter V, Boedhihartono AK, Day D, Claude Garcia C et al. 2013. Ten principles for a landscape approach to reconciling agriculture, conservation, and other competing land uses. Proceedings of the National Academy of Sciences of the United States of America 110(21): 8349-56. https:// doi.org/10.1073/pnas.1210595110. 
Somanje AN, Crespo O and Zinyengere N. 2017. Chapter 5 - Conservation agriculture among farmers in Kalomo, Zambia : Potential for productivity under climate change. In Zinyengere N, Theodory TF, Gebreyes M and Speranza CI, eds. Beyond Agricultural Impacts. Academic Press. 77-99. https://doi.org/10.1016/B978-0-12-812624-0.00005-3.

Stocking M. 1985. Soil Conservation Policy in Colonial Africa, Agricultural History Vol. 59, No. 2, The History of Soil and Water Conservation: A Symposium (Apr., 1985).

[SZI] SMART Zambia Institute. 2019. https://www.sou.gov.zm/expo/?page_id=741.

Tembo T. 17 February 2016. ZICTA approves 5 tower sites in Kalomo. Zambia Daily Mail Limited. http://www.daily-mail.co.zm/zicta-approves-5-tower-sites-kalomo/

[URPA] The Urban and Regional Planning No. 3 of 2015. Lusaka: Government Printer.

Thomson E and Bennet O. 2005. Our gods never helped us again. The Tonga people describe resettlement and its aftermath. Oral Testimony Programme. Panos Southern Africa.

Umar BB. 2019. Integrated landscape approach: Identifying key practices, instruments, threats and opportunities for conservation of biodiversity and natural resources management in Kalomo District. Unpublished Report prepared for the Center for International Forest Research (CIFOR).

Van Loenen B. 1999. Land Tenure in Zambia. University of Maine, Department of Spatial Information Engineering. http://citeseerx.ist.psu.edu/viewdoc/download?doi=10.1.1. 460.7561\&rep $=$ repi\&type $=$ pdf.

Vickery KP. 1985. Saving settlers: Maize Control in Northern Rhodesia. Journal of Southern African Studies 11(2): 212-34.

Vinya R, Syampungani S, Kasumu E, Monder C and Kasubika R. 2011. Preliminary Study on the Drivers of Deforestation and Potential for REDD+ in Zambia. A consultancy report prepared for Forestry Department and FAO under the national UN-REDD+ Programme Ministry of Lands \& Natural Resources. Lusaka, Zambia.

von der Heyden CJ and New MG. 2003. The role of a dambo in the hydrology of a catchment and the river network downstream. Hydrology and Earth System Sciences, 7(3):339-57. https://doi.org/10.5194/hess-7-339-2003

Wadhams JO. 1951. Reservation proposal No. S-4 Kalomo Hills to form the Kalomo Protected Forest Area. Minute No. 829/R/12 by the Provincial Forestry Officer Southern Province, Livingstone to Chief Conservator of Forests, Ndola.

Walsh GEK. 1950. Kalomo, Livingstone District, Tour report No. 3 of 1950. Annexure A. Kalomo Tour reports 1950. SEC2/1031. File No. N/0836/1. National Archives of Zambia. 


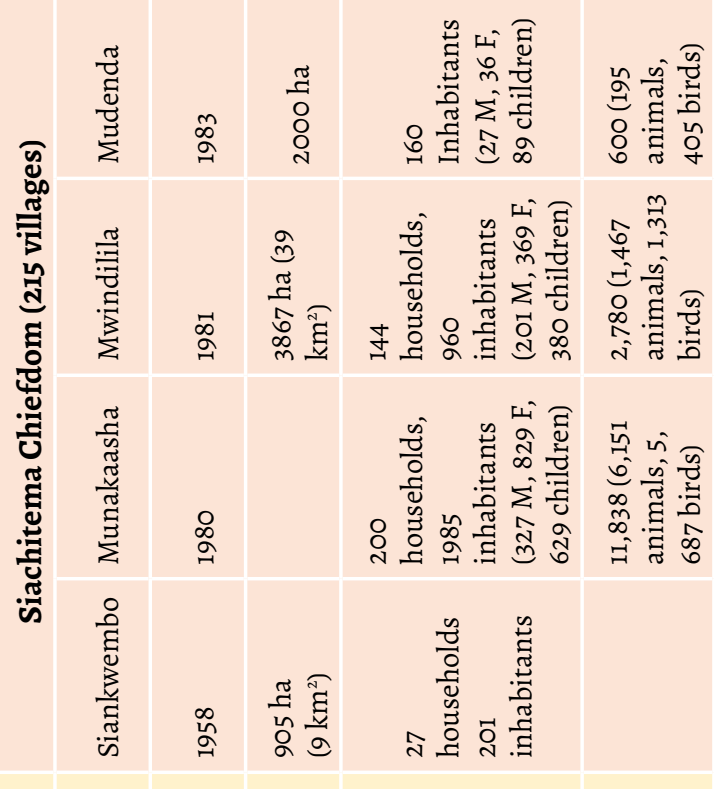

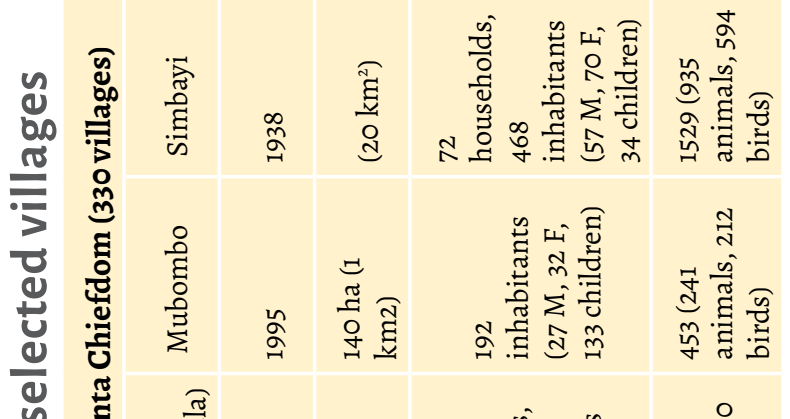

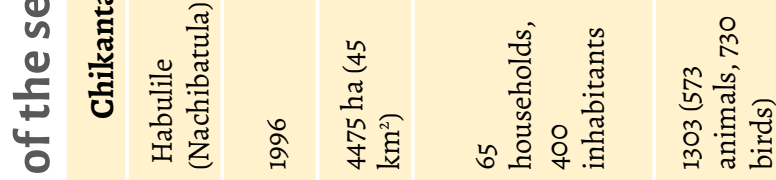

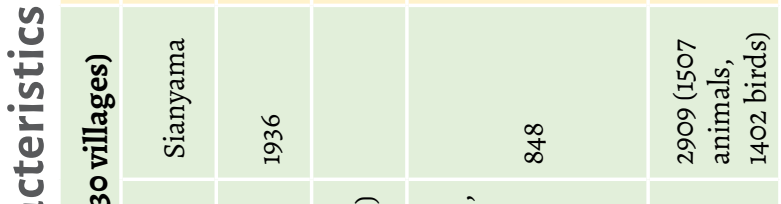

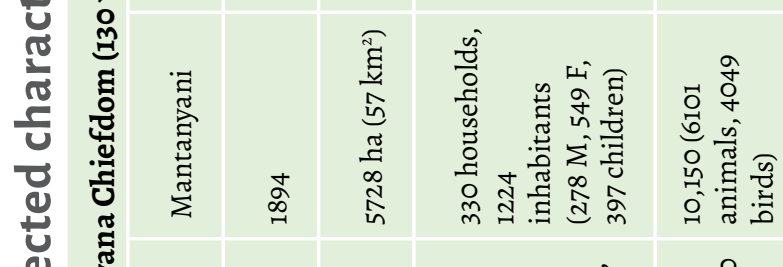

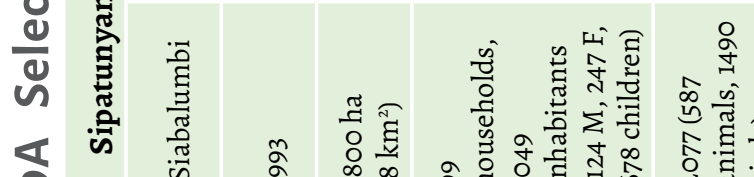

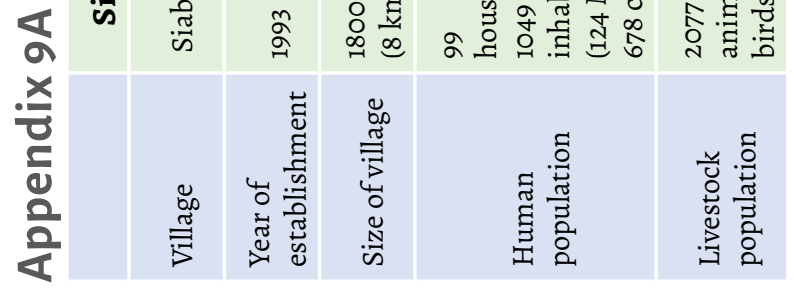




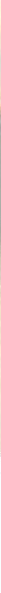

\section{Kapuas Hulu}

\section{A background analysis to implementing integrated landscape approaches in Indonesia}

Augusta M. Anandi, Elizabeth L Yuliani, Moira Moeliono, Yves Laumonier and

Sari Narulita

\section{Introduction}

This chapter focuses on the study area for the Collaborating to Operationalize Landscape Approaches for Nature, Development and Sustainability (COLANDS) initiative in Indonesia.

COLANDS in Indonesia has embraced Integrated Landscape Approaches (ILA) as a holistic approach to integrate and bridge multiple interests and demands (Reed et al. 2014). The approach was designed on the basis of models and concepts that emerged from the conservation community in an effort to balance nature and biodiversity protection with the development needs of the people who live within, or in proximity to, conservation areas (Reed et al. 2016; Sayer et al. 2013).

ILA principles emphasize the importance of collaboration at all levels and scales to facilitate stakeholders' negotiation of conservation-development trade-offs (Sayer et al. 2013). Acknowledging that trade-offs are the norm (Sunderland et al. 2008), ILAs aim to draw out conflicting objectives and seek more equitable alternative futures such that there are 'more winners and less losers' (Sayer et al. 2015). Utilizing ILA principles, COLANDS - which also includes initiatives in Ghana and Zambia (Chapters 8 and 9) aims to bridge stakeholder objectives across multiple sectors. 
The selected area of interest, Kapuas Hulu regency ${ }^{1}$, is located in Indonesia's West Kalimantan Province, and is one of the last areas in Indonesia with large areas of forest, which are mostly designated as protected areas. To strengthen this conservation role, Regency Regulation (peraturan daerah or, for short, perda) no. 20/2015 stipulates Kapuas Hulu as a 'conservation regency'2 to show the government's commitment and special attention to its conservation efforts. At the same time, it is confronted by rapid industrial plantation development expanding from the west of the province (Laumonier et al. 2020a).

Kapuas Hulu covers an area of 3,116,300 ha, administratively divided into 23 sub-districts (kecamatan). ${ }^{3}$ Each sub-district covers several villages and is led by a sub-district head (Camat). Kapuas Hulu has a population of 263,207 people of various cultural and religious backgrounds (BPS-Kapuas Hulu Regency, 2020). Socio-economic development is largely dependent on the primary and secondary sectors (i.e. extraction and transformation of natural resources) with the agriculture, forestry and fisheries sector and the construction industry being the two largest contributors. Each sector added about $22 \%$ to the annual GDP in the years between 2016 and 2019 (BPS-Kapuas Hulu Regency, 2020). Manufacturing is another important economic sector, contributing $11 \%$ to the economy (BPS-Kapuas Hulu Regency 2020).

Despite ongoing deforestation, approximately two-thirds of forest and associated biodiversity remains mostly intact. Regency spatial planning for 2014-2034 (RTRW Kabupaten) states that approximately $53 \%$ of the total land is allocated as protected areas $^{4}$ which include two national parks: Betung Kerihun $(816,693 \mathrm{ha})^{5}$ and Danau Sentarum (127,393 ha). ${ }^{6}$ In addition to national parks, a state forest area of about 461,470 ha includes protected forests and customary forests (KPHP Model Kapuas Hulu, 2015). Kapuas Hulu is also one of the Kalimantan regencies that belongs to the 23 million hectares-large 'Heart of Borneo' landscape initiative, which ecologically connects forest landscapes across Malaysia, Brunei Darussalam and Indonesia.

The crux of the issue appears as the interests of development and of conservation have an almost similar priority in the study area. Stakeholders have different agendas

1 Regency (kabupaten) is a second-level administrative division of Indonesia, directly administrated under a province. Both regency and city are at the same level, having their own local government and legislative bodies. Under law 32/2004, local governments now play a greater role in administering their areas.

2 Initially in May 2003 the Head of Regency declared Kapuas Hulu as a Conservation Regency, through Bupati Decree No.144/2003. The Perda no 20/2015 elevates the status of Conservation Regency. Perda, based on the Indonesia's national legislation, needs consensus from the Regional House of People's Representatives (DPRD), therefore is stronger than a Bupati decree. A Bupati decree can be replaced by a new Bupati.

3 Sub-district is the third-level administrative subdivision, below regency or municipality. The local term kecamatan is used in the majority of Indonesian areas, except in Papua, West Papua (district) and the Special Region of Yogyakarta (kapanewon and kemantren).

4 Protected forest based on Government Regulation 47/1997 on National Spatial Plan article 10. Protected forests are areas that provide protection for their subordinate areas; and areas that include local protected areas; nature reserve areas; nature conservation areas; cultural heritage areas; areas prone to natural disasters; and other protected areas.

5 Based on Ministerial Decree SK 3073/Menhut-II/KUH/2014.

6 Based on Ministerial Decree SK 4815/Menhut-II/KUH/2014. 
and interests to fulfil. This chapter will discuss the challenges in the field and the opportunities that exist in realizing a balance of development and conservation in harmony with the welfare of local communities.

For the Indonesian sites, we focus on two sub-watersheds of the larger Kapuas Basin, i.e. the Labian-Leboyan sub-watershed in the corridor area between Betung Kerihun and Danau Sentarum national parks; and the Seriang sub-watershed. In these sites we study the landscape-scale and governance challenges, with the aim to identify the potential to bridge and reconcile conservation and development interests across different stakeholders and jurisdictions.

\subsection{The study area}

COLANDS Indonesia has focussed on Labian-Leboyan and Seriang, the two subwatersheds of the main Kapuas watershed in the area. The interconnectedness of upstream and downstream activities in the watershed influences livelihood sustainability, biodiversity and the environmental stability of the entire Kapuas Hulu landscape.

Upstream, the dominant population is comprised of three main Dayak ethnicities; Iban, Embaloh, and Kantuk. The three live around the hilly area adjacent to Betung Kerihun National Park (BKNP). Their livelihoods rely on cultivation, such as swidden dry paddy fields, rubber farming, and the hunting and gathering of forest products (Colfer et al. 2000). Downstream, specifically within and adjacent to the Danau Sentarum National Park (DSNP), the area is dominated by Malay communities that rely on fisheries for their own consumption and for their livelihoods through commercial trade (Dudley 2000; Giesen and Aglionby 2000).

These sub-watersheds are located about $200 \mathrm{~km}$ from the regency capital city, Putussibau, and about $700 \mathrm{~km}$ to $800 \mathrm{~km}$ from Pontianak, the provincial capital. Each river and watershed covers several regencies, sub-districts and villages. The LabianLeboyan River starts north of the Mensiau village of Batang Lupar sub-district and flows through four villages until it reaches the most downstream village, the Malay village of Nanga Leboyan of Selimbau sub-district where the river blends into the lake in the eastern of DSNP. The Seriang River goes from the Seriang village of Badau sub-district to Pulau Majang farther downstream, and ends in the lake at the west of DSNP. Both rivers stream across the lakes leading into the Kapuas River, contributing to the largest watershed in West Kalimantan. During the wet season, the Danau Sentarum Basin functions as a water catchment where the overflow from the two rivers feeds the lake that streams further into the Kapuas River (Giesen 1987; Harwell 2010) (Figure 10.1).

Comparisons between the two sub-watershed land cover made between 2010 and 2019 showed significant differences between them. While one sub-watershed remained unchanged, the other experienced substantial forest clearing for agro-industrial expansion, development of infrastructure and growth of community agricultural plots. Government bodies, communities and NGOs have made several efforts to keep the remaining forest intact and to conserve biodiversity, while improving the wellbeing of 


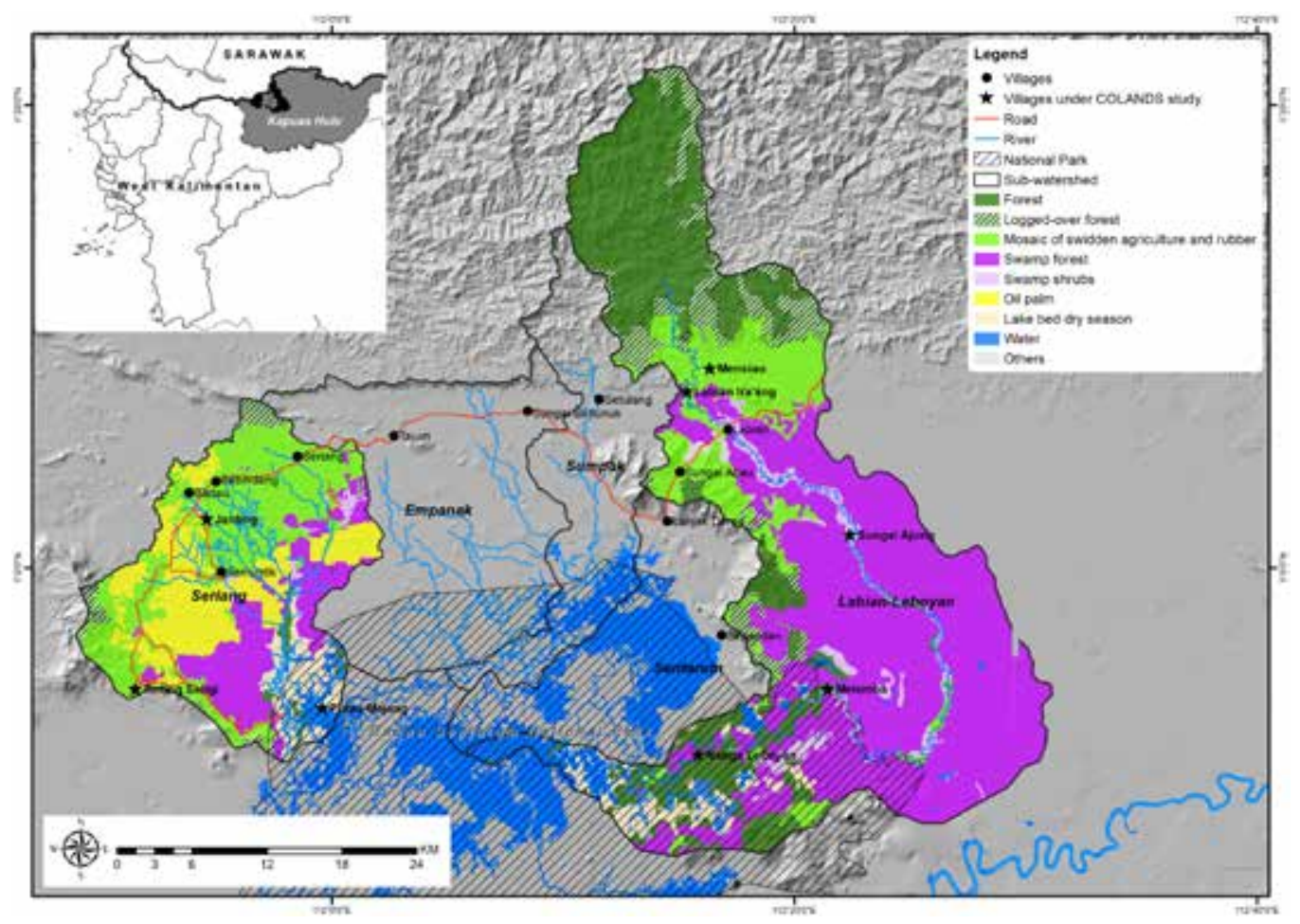

Figure 10.1. Situation map, vegetation and study sites in the sub-watersheds Labian-Leboyan and Seriang

Source: Laumonier et al. $2020 \mathrm{~b}$

local communities. Initiatives include establishment of village forests (Hutan Desa), ${ }^{7}$ development of alternative livelihoods through agricultural assistance, community empowerment, and multi-stakeholder forums for community development and environmental protection. However, several challenges remain, such as complex tenure arrangements and overlapping jurisdictions and responsibilities.

Advocating for a holistic approach toward integrated landscape governance requires facing the complexities that arise from a diverse range of actors, land uses and interests. ILAs therefore focus on managing for an adaptive capacity and applying an iterative process to address the inherent complexity within the system (Freeman et al. 2015). Thus, working at the watershed level is practical in order to identify and reach stakeholders - both at village and related regency levels.

There are a number of reasons for selecting the area. The first is because of its location in a major conservation area with the two sub-watersheds near the BKNP, the DSNP downstream, and the corridor between the two national parks. In the spatial planning

7 Village Forest (Hutan Desa/HD) is one of the Indonesian Social Forestry schemes, together with four other schemes: Community Forestry (Hutan Kemasyarakatan/HKm), Community Plantation Forest (Hutan Tanaman Rakyat/HTR), Customary Forest (Hutan Adat/HA) and Forestry Partnership (Kemitraan Kehutanan) (http://pkps. menlhk.go.id/). 
document, one location falls within the sub-district of Batang Lupar, which is almost entirely designated as conservation and protection area; the other in Selimbau and Badau, almost all of which are designated as 'land for other purposes'.

Second, governance in the two sub-watersheds has an impact on the larger landscape; that is, the regency and the main Kapuas watershed. The two sub-watersheds are indirectly connected to the Kapuas Basin, home to the longest river in Indonesia (Giesen 1987). Third, swamp forest in the Seriang sub-watershed is under pressure from expanding large-scale oil palm plantations. In spatial planning documents, a large part of the area is allocated for "other land use"; i.e. areas designated for agro-industries, agropolitan ${ }^{8}$ approaches and minapolitan ${ }^{9}$ approaches for both large-scale and community agricultural use.

Seriang, in the Badau sub-district administration area, is designated for oil palm plantation development. It is also close to one border post (PLBN or Pos Lintas Batas) designated to become an official Malaysia-Indonesia international entry port. Dry port development, an inland terminal for agricultural produce, is planned there to support the trans-shipment or logistics for large-scale industries such as oil palm. One impact of this development may be the transformation of the traditional mosaic landscape of swidden, fallows and watershed protection areas to a mono-culture oil palm plantation.

The Labian-Leboyan and Seriang landscapes have unique geomorphologies, from tropical mountainous range in BKNP to wetlands and peat in the DSNP Basin. This fluvio-lacustrine basin is flooded during wet seasons as excess water from interconnecting rivers fills some 80 lakes. These lakes partially or fully drain during dry periods (Anshari et al. 2001). Within the wetlands, several hills rise up to $120 \mathrm{~m}$ and $370 \mathrm{~m}$, and the whole basin is surrounded by mountainous, steep and dissected ranges up to $2000 \mathrm{~m}$ (Giesen and Aglionby 2000).

Within the study site, there are various types of vegetation, influenced by the topographical differences. The surrounding hills are the domain of the Dipterocarp rain forests (Whitmore 1984), the unique southeast Asian rain forest rich with many commercialized hardwood species (Ashton 1988), and that provide crucial canopy structure for orang-utan, and other wildlife habitat (Caldecott and Miles 2005). Part of the wetlands is a very old tropical peatland (Anshari et al. 2004; Manuri et al. 2014). The wetlands are dominated by various freshwater and peat swamp forests, including stunted forests (Giessen 2000), which are adapted to high fluctuations of inundation throughout the year.

Overall, the climate is equatorial. The mean annual temperature is $27.2^{\circ} \mathrm{C}$ (lowest monthly mean $22.1^{\circ} \mathrm{C}$ and highest $31.9^{\circ} \mathrm{C}$ ), for a mean annual precipitation of $4,154 \mathrm{~mm}$ (driest annual mean 2,673 mm, wettest 5,550 mm) (www.worldclim.org 2018) with an annual average varying between 120 and 310 rainy days. The wet season lasts from November to April, the dry season from May to September. Mostly during El Niño periods, the area regularly faces seasonal droughts.

8 The agropolitan approach is used in an area to strengthen agriculture, animal husbandry and fresh-water fish production.

9 Minapolitan is an area for economic development in marine and salt-water fisheries. 


\subsection{Landscape challenges}

\subsubsection{Environmental challenges}

The study area faces several environmental challenges. First, the Seriang landscape experienced high levels of deforestation during the past ten years. About 11,500 ha one-quarter of the total area $(44,000 \mathrm{ha})$ - has been converted to oil palm plantations since 2000 (Laumonier et al. 2020b). In Labian-Leboyan, land clearing also occurs, but at a slower rate compared with Seriang. For generations, local residents have used swidden agriculture for upland paddy fields, and there are a number of established plots for individual oil palm plantations (Anandi pers. obs. 2020). Furthermore, fragmented forest and peatland conversion along the Labian-Leboyan corridor, due to human activities such as road networks, livelihoods, and settlements, threaten the habitats of endangered wildlife, particularly the Bornean orang-utan (Pongo pygmaeus) (Prayogo et al. 2016; Russon et al. 2001; Wulffraat et al. 2014).

Second, declining water quality and water that appears muddy due to sedimentation, have plagued the two sub-watersheds. This is primarily due to water pollution from fish poisoning and the use of agriculture chemicals (pesticides), which has become a growing concern to the DSNP area where it causes deterioration in fish habitat (Giesen and Aglionby 2000; Heri et al. 2010; Roslinda et al. 2012). Traditionally, the Dayak communities upstream have fished for their own consumption, using a particular tree (tuba or tubai langkong - Barringtonia sarcostachys) whose root bark is crushed to release a toxin and then tossed in the water. The poison causes a temporary numbing effect on the fish, without impacting the overall water quality. However, over time, the use of natural roots became less attractive for fishers and chemical poisons are now used instead. Chemical poison is easier to access and affects more fish in a short period of time (Giesen and Aglionby 2000; Heri et al. 2010; personal interviews with fishermen at Tinting Seligi, Nanga Leboyan and a farmer at Labian village between 2019 and 2020). Sedimentation from oil-palm plantations also has a negative impact on water quality (Muhyidin 2017), as does the swidden agriculture in the upstream area (Labrière et al. 2015), which has a negative effect on the hydrology of the sub-watersheds (Lusiana et al. 2008). Some community members are concerned by erosion and sediment-loaded water due to the swidden cultivation upstream - especially dry paddy fields along the riverbanks (interviews with head of village Labian Iraang August 2019; mid-age woman in Labian Iraang March 2020).

Third, poor waste management in the downstream area has led to increased garbage disposal in the Danau Sentarum Lake; notably, plastic trash (G. Hartono Danau Sentarum and Betung Kerihun national park officer February 2020).

\subsubsection{Social challenges: multiple stakeholders with competing claims and agendas}

Entrenched power struggles exist between communities in the two sub-watersheds, based on territorial claims and competition over natural resources, exacerbated by new demands from government and corporations. Building social cohesion and enhancing 
efforts to better balance conservation and livelihood interests is therefore needed. Customary leaders play an important role in this respect. In the current administrative structure, villages consist of several hamlets, which are defined and organized based on a longhouse or fisher group working area. In addition to the head of village and the village administration, it is important to engage with the customary leaders in the hamlets. However, competing claims over natural resources and territories exist even within a longhouse. Despite kinship, it is common to find competition and differences of interests among households (Wadley and Eilenberg 2005). This social challenge related to competing territorial claims is also addressed in Section 10.2.4 on landscape governance challenges.

\subsubsection{Economic challenges}

About 60 percent of economic activity in Kapuas Hulu regency is related to agriculture (including oil palm plantations), forestry, hunting and fisheries (BPS-Kapuas Hulu Regency, 2018, 2020). In both Seriang and Labian-Leboyan, subsistence livelihoods are characterized by fisheries and hunting, and dryland farming of crops such as rice, cassava, maize, and vegetables (BPS-Kapuas Hulu Regency 2019b; Shantiko et al. 2013; Sunkar and Santosa 2018). Rice harvesting is primarily for subsistence, while other products such as rubber, fruits, tengkawang (illipe nut), and pepper (Shantiko et al. 2013) offer sources of income. Rubber and pepper are important cash crops; hence, the value attached to maintaining their cultivation. Despite this, low market prices have made these crops less attractive in the past two years (Anandi, pers. obs. 2019 and 2020). For example, rubber fetches only IDR 6000-7000/kg (less than USD 0.50) and a massive decline has been reported in pepper prices since 2018 , to about IDR $24,000 / \mathrm{kg}$ (USD 1.50) from $120,000 / \mathrm{kg}$ (USD 8).

In Seriang, oil palm plantations have significantly changed the pattern of economic activities in the communities, providing an important source of household income (Leonald and Rowland 2016; Shantiko et al. 2013). Employment opportunities are increasing, particularly for paid employment, while the plantations also provide a boost to entrepreneurial activities such as shopkeeping (Muhyidin 2017). Nonetheless, the majority of the oil-palm labor force work as daily laborers (BHL-buruh harian lepas) due to their low levels of education. ${ }^{10}$ Usually, employment for local people is limited to low-level jobs, sometimes even invisible to the official employer, as in the case of 'kernel helpers'. ${ }^{11}$ A daily plantation laborer earns a wage of about IDR126,000/day or the equivalent of USD 10/day for 25 working days in a month (interviews, head of village Tinting Seligi and head of village Seriang, August 2019).

Compared to Labian-Leboyan, Seriang has better infrastructure, with a paved road network to the centre of the sub-district capital and markets in Badau (BPS-Kapuas Hulu Regency 2019a). The telecommunications network is also well developed (BPSKapuas Hulu Regency 2019a) which is helpful for communities trading their produce.

10 In Kapuas Hulu, a high number of employed workers had only a basic education, having left school after a primary education (year 1-6) (BPS-Kapuas Hulu Regency, 2018).

11 A kernet helper is a person hired by the harvester to help achieve the company's daily quota. The harvester will share the daily salary with the helper. 
However, due to unstable prices for agricultural commodities other than oil palm, many households in the Seriang sub-watershed combine their income from their own farms with wage labor at the plantations (Leonald and Rowland 2016; Anandi, pers. obs. 2019).

The Labian-Leboyan sub-watershed faces several economic challenges as access to telecommunication and transportation is very limited and basic. Four villages upstream are somewhat more accessible by gravel road; however, this road is damaged and access is difficult (BPS-Kapuas Hulu Regency 2019b; Anandi, pers. obs. 2020). Two villages downstream, which are located along the lake, can be reached by a speed boat during the wet season and by motorbikes during the dry season. However, the telecommunications network is weak, adding to the challenges faced by local people in selling their produce. Many upstream communities, therefore, rely on middlemen who regularly buy the produce in the villages to re-sell in Lanjak, Badau, Sintang, or Pontianak (interviews with community members in four villages between February and March, 2020). This puts farmers at a severe disadvantage, leaving them with little power to negotiate better prices, and allowing the middlemen to profit from the low prices they pay to the farmers.

Moving downstream to the Danau Sentarum, fishing is the main source of income for communities. Cash generation peaks during the dry season, when water levels fall and fish become trapped in smaller bodies of water, making them much easier to catch. During this "fish harvest" time, the lake area becomes crowded with permanent fishermen as well as seasonal fishers, mostly from outside of the lake area (Roslinda et al. 2012). These seasonal fishers come from nearby areas such as Selimbau, Suhaid and Lanjak (Heri et al. 2010). A problem arises during the wet season, when many fishers rear the Giant Snakehead fish (Channa micropletes, locally called Toman), which has an adverse impact on the overall ecosystem in Danau Sentarum due to its heavy consumption of smaller fish (Heri et al. 2010). It is a relatively lucrative venture, as the fish can mature in about twenty months. Based on an average of three cages, each with about 2,000 Toman, a farmer can make profit of about IDR 150 million (USD 10,250) in one harvest period.

Finally, employment opportunities in Malaysia and Brunei Darussalam remain an attractive source of income. After completing high school, both men and women will often go abroad to work as daily laborers (Shantiko et al. 2013; Wadley and Eilenberg 2005) albeit illegally, receiving a monthly salary of about MYR 1,500-3,000 (USD 350 to USD 700) ${ }^{12}$ (interviews with several community members in Melemba, Labian Iraang, and Mensiau, between February to March, 2020). Particularly in Dayak villages in both sub-watersheds, about half the population lives abroad while the elderly, women and children remain at home. Women in the economically active age (15 years to 60 years) maintain the household and work on the family farm, cultivating crops and selling the harvest for their income (BPS-Kapuas Hulu Regency 2018).

This presents an additional challenge for project implementation, including the COLANDS initiative. Women in these circumstances have little additional time to actively engage in a project or initiative, leaving interventions to focus instead

12 MYR (Malaysian Ringgit) is equivalent to 0.33 Bruneian dollar (BND). The USD equivalent of 1 MYR is 0.23 (Currency Converter, 9 June 2020). 
on individuals who are willing and able to commit time and have authority in the community. This, in turn, leads to the exclusion of women and other marginalized people, causing distrust toward the project implementers and among community members.

\subsubsection{Governance challenges}

\section{Complex tenure arrangements}

The major governance challenge in Kapuas Hulu concerns the co-existence of customary and government land tenure. Law No. 5/1990 on Conservation of Natural Resources and Their Ecosystems, and No. 41/1999 Forestry Law, regulate access to conservation and forest areas, and set restrictions on human and development activities. Both laws acknowledge the presence of Indigenous peoples and their customary land, and prohibit individual land ownership within conservation and forest areas. Communities living within forest areas have been struggling to adjust to these regulations.

Part of the customary arrangements concern historic agreements on "designated" community territory with Dayak sub-ethnicities, such as the Iban, Embaloh, Kantuk, and Malay groups (Sada et al. 2019). In the Dayak communities, each territory is led by a Temenggong (customary leader). The Temenggong institution was created by the Dutch in the $18^{\text {th }}$ century (Eilenberg and Wadley 2009) and is still in use today. The current government administration refers to these territories as a sub-district (for Iban Temenggong Batang Lupar and Temenggong Badau) and sub-watershed (for Embaloh Temenggong Benua Labian).

The Embaloh people are considered the first settlers in Labian-Leboyan. In the $19^{\text {th }}$ century, the Iban community migrated from the border area between Sarawak and Kalimantan to the current Labian-Leboyan area to take advantage of better livelihood opportunities. Within the same period, the Malay communities also started to migrate as temporary fishers in the same area. The Embaloh made agreements with the Iban and Malay regarding the location of settlements, rent and the utilization of land and natural resources for their livelihoods. It was, however, prohibited to sell land (Iban hamlet customary leader, Kanisius Kanai, interview March 2020; Temenggong Tamambaloh Labian Antonius Pameang, interview March 2020). These agreements were made verbally and only a few customary elders are aware of these unwritten arrangements.

Customary arrangements govern and regulate the utilization of forest land for livelihood, cultural and social purposes. The Dayak communities are organized around a longhouse, divided into compartments that each host a family (Sada et al. 2019). Each longhouse is connected to a territorial area and employs a customary governance system that regulates access to sacred and cultivation areas (Shantiko et al. 2013; Yuliani et al. 2018). There are individual and communal forms of land ownership, mostly marked by trees, a river, and other geographical features. Through time, longhouse members may migrate and establish new territories, yet ownership rights in the previous longhouse remain and are passed down to family members who decide to settle within the longhouse. This keeps existing territories intact, while new community territories continue to spread. 
The Dayak and Malay concepts of land and resource territory are passed down through generations. The Dayak, for example, consider both a communal forest garden with durian and other fruit trees within their former longhouse area (Tembawai in Iban and Belen Sau in Embaloh) and old cultivation areas (Damun in Iban and Belen Uma in Embaloh) as valuable. Similarly, the Malays value the concept of working areas for fishers and honey farmers. The majority of Malay communities rely on two main livelihoods: fisheries and honey collectors during the off-season for fishing, which forms part of their identity. Initially, a working area was formed by a group of fishers with good working relationships that have selected an area to fish. The selected area would be considered as "owned" by the working group (about 10-15 members) for harvest during fish season. This area was seen as a temporary area to stay (periau) where each fisher of the group builds a temporary house to visit seasonally, but over time, families began to settle there permanently. More recently, the group working area has grown to include 20 to 50 households. The area became a hamlet, where each household has a strong family kinship with the early group of fishers. Such communities in each hamlet have detailed and up-to-date regulations at both hamlet and village level. Every three years, all members of the hamlet fisher family gather to discuss area regulations related to fishing, as well as the rights and responsibilities, and the types of sanctions for rulebreakers. This is an open, iterative forum where regulations are flexibly adapted, based on experience, needs and community consensus. These regulations are shared with other hamlets and neighboring villages to ensure they are respected (personal interview with the Nanga Leboyan customary leader, Semangit head of fishers, and an elderly women in Semangit, February 2020).

In the past, within the periau area, fishers also practiced semi-natural beekeeping for additional income. A beekeeping technique was applied called tikung, in which a board was installed in typical wetland low-lying trees such as "putat" (Barringtonia acutangula) one of many tree species dominating the wetland that attracts bees (de Jong 2000). The beekeeper owns the tree and it is passed down based on kinship. At present, a periau refers to an area of beekeeping that is managed by a group of beekeeping farmers (Ginting 2017; Roslinda et al. 2012). Every hamlet has a periau, and each with its own set of regulations. There are approximately 37 periau within the DSNP area that have joined associations (Aliansi Organis Indonesia, 2012; personal interview with Suryadi, head of Periau for Semangit hamlet, February 2020).

Other than the customary arrangements mentioned above, a village concept is the most recent governance arrangement. Statutory village boundaries suggest clarity concerning borders and serve to resolve related conflicts. However, the formal concept of village that was primarily developed in the 1970s based on the situation in Java, therefore is different from the Dayak and Malay traditional concepts. In statutory terms, the village is the smallest government unit and led by the village head. A 'village' is a legal community unit that has the authority to govern and manage government affairs, local community interests based on community initiatives, original rights, and/or traditional rights (Village Law No. 6/2014). Each village within the study site consists of two or four hamlets. A hamlet (kampung) may refer to a longhouse territory for the Dayak customary groups (Iban, Embaloh, Kantuk), or a fishing working area, where each has its own customary governance arrangements. Commonly, villagers primarily identify themselves 
by their hamlet rather than the village (Anandi, pers. obs. 2020). Due to their history, the customary areas of Dayak communities in particular were scattered over many places. As described previously, such scattering continues due to families separating and settling in various locations, while maintaining ownership rights in their hamlet of origin. As a result, customary areas do not align with statutory village boundaries and many customary areas are located in different villages.

Although village demarcation processes provide clarity for administrative village boundaries, this demarcation also causes a blurring of customary and statutory governance arrangements and boundaries that a landscape approach may overcome. This approach could bring neighboring villages together and help communicate communal land tenure arrangements and links to the initial territorial areas. The establishment of village boundaries and the existing practice of customary territories calls for open communication, and clear and accurate information sharing among stakeholders across all sectors in the landscape.

\section{Overlapping jurisdictions}

Implementing landscape approaches requires recognizing the various centres of decision-making, and the jurisdictions, duties, responsibilities and authority of governance institutions from national to village level. Overlapping jurisdictions are challenging in forest governance as they complicate communications and decisionmaking due to its multiple layers of roles and bureaucracies (Li 2007; Moeliono et al. 2017; Wollenberg et al. 2009). Forest and land governance in Indonesia has been structured through centralization policies during the New Order era - decentralization ${ }^{13}$ and re-centralization policies ${ }^{14}$ have resulted in a continuous tug-of-war over power and authority (Myers et al. 2016; Sahide et al. 2016).

Table 10.1 lists the various agencies in the two sub-watersheds; their jurisdictions and governance responsibilities; and the legal basis for their roles. The Ministry of Environment and Forestry (MoEF) holds most of the authority, albeit distributed over several agencies with distinct responsibilities, namely the Watershed Management Authority $\left(\mathrm{BPDAS}^{15}\right)$, the Protected Forest Management Unit $\left(\mathrm{KPH}^{16}\right)$ and National Park management office (Balai $\mathrm{TN}^{17}$ ). Within the MoEF, each agency reports to a different directorate that has various mandates and responsibilities on the ground. There are nine such directorates, including Forestry and Environmental Planning; Conservation of Natural Resources and Ecosystems; Watershed and Protection Forest Management; and Sustainable Production Forest Management.

13 Law 22/1999 and the revised version Law 32/2004 on Local Government wherein the central government gives the authority to the local government, highlighting the importance of democracy, community participation, equality and justice.

14 Law 23/2014 on Local Government has shifted authority over forest resources management from regency to province level.

15 BPDAS = Balai Pengelolaan Daerah Aliran Sungai (Watershed Management Authority).

$16 \mathrm{KPH}=$ Kesatuan Pengelolaan Hutan (Forest Management Unit).

$17 \mathrm{TN}=$ Taman nasional (National Park). 
Responsibility for management of land for other purposes (APL/Area Peruntukan Lain) rests with several agencies led by regional development planning boards (BAPPEDA ${ }^{18}$ ) at provincial and regency levels. Another key actor at regency level is the Village Community Empowerment Agency (DPMD), which supports and supervises village development. Important actors at lower levels include the heads of sub-district and village officials. From a jurisdictional point of view, the distribution of responsibilities results in various approaches toward the development of each area. BAPPEDA, as the lead agency at regency level, oversees the landscape from a spatial planning perspective. It is responsible for coordinating the spatial land-use planning (RTRW ${ }^{19}$ ) where it addresses the allocation of areas for agriculture, water management, conservation and other land uses, based on national targets $\left(\mathrm{RPJMN}^{20}\right)$ (Interview with officers from Provincial BAPPEDA, February 2020).

The Watershed Management Agency (BPDAS) is responsible for managing the watershed, including securing the connection between upstream and downstream areas and overall watershed quality through activities such as rehabilitation and reforestation along the riverbanks (interview with a head of department of BPDAS, February 2020). $\mathrm{BPDAS}$ is also responsible for the management of the protected forest $(\mathrm{HL}=$ hutan lindung) area.

The National Park management office manages the designated national park areas, including human populations, nature, and wildlife therein. To this end, it applies a zoning system for the park area that regulates accessibility and restrictions. A longterm (ten year) and short-term (five year) management planning document serves as a guideline for operations.

The Forest Management Unit (FMU) works within state forests only. Similar to the National Park management office, the FMU applies a planning document and categorizes its working area based on a blocking system to indicate restricted areas and areas that are accessible for community activities. For example, a strict conservation area is designated as a 'core block' (blok inti); there is also a 'block for utilization' area (blok pemanfaatan), and a 'special' designated block (blok khusus) (Direktorat Wilayah Pengelolaan dan Penyiapan Areal Pemanfaatan Kawasan Hutan, 2012). At the same time, Law 6/2014 pertaining to villages stipulates that a village has the autonomy to manage its community and land area. Each village is allocated annual funding of close to IDR I Billion (USD 70,000) that can be used for village development, disaster preparedness, conservation, and supporting community livelihoods and well-being. Based on this law, the head of village has a stronger decision-making power regarding village development and projects and the financing thereof, compared to the National Park management office, FMU, BPDAS, and the regency government.

Based on customary territorial land governance arrangements, household and community properties may extend beyond village boundaries and into forest and 


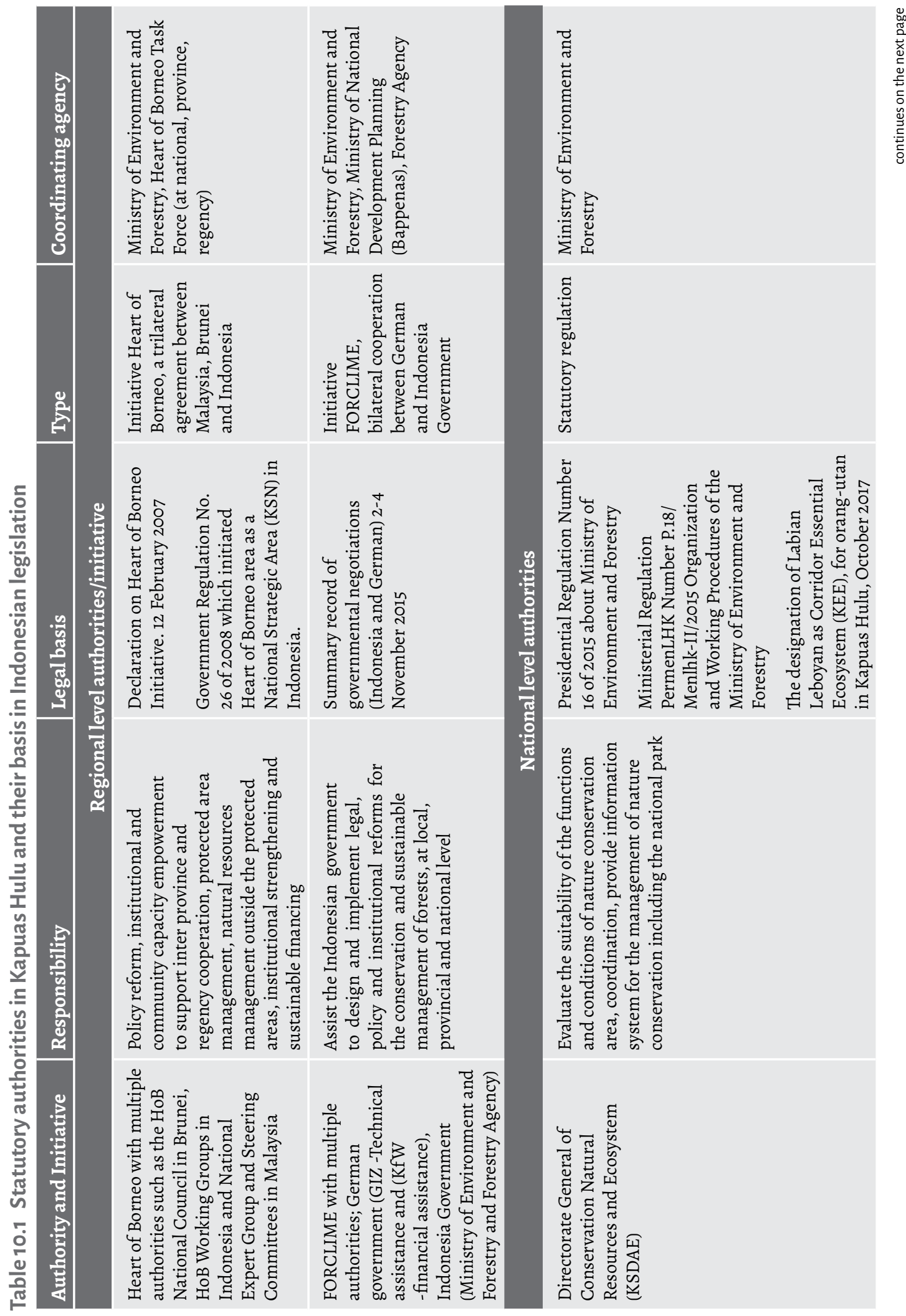




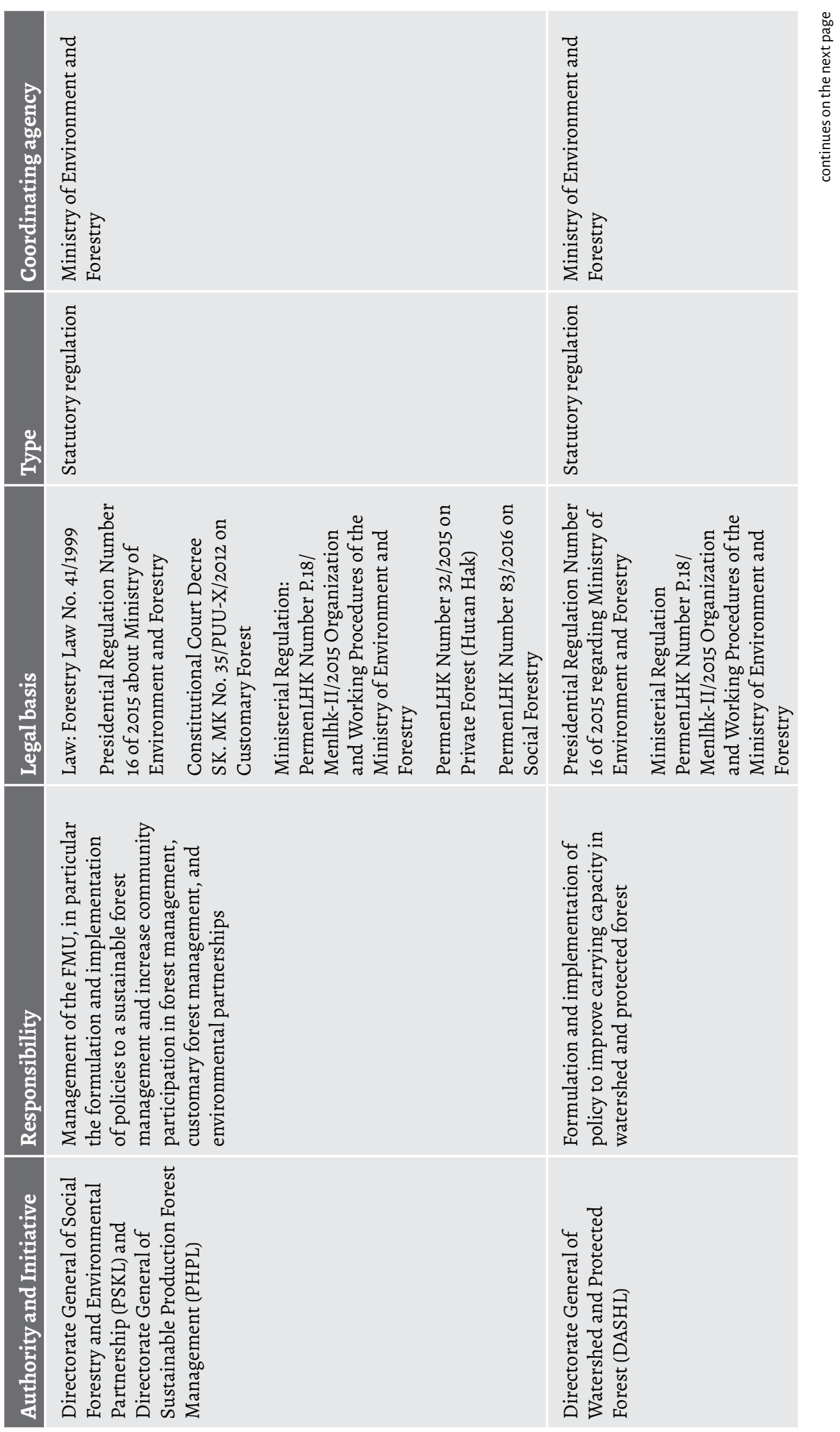




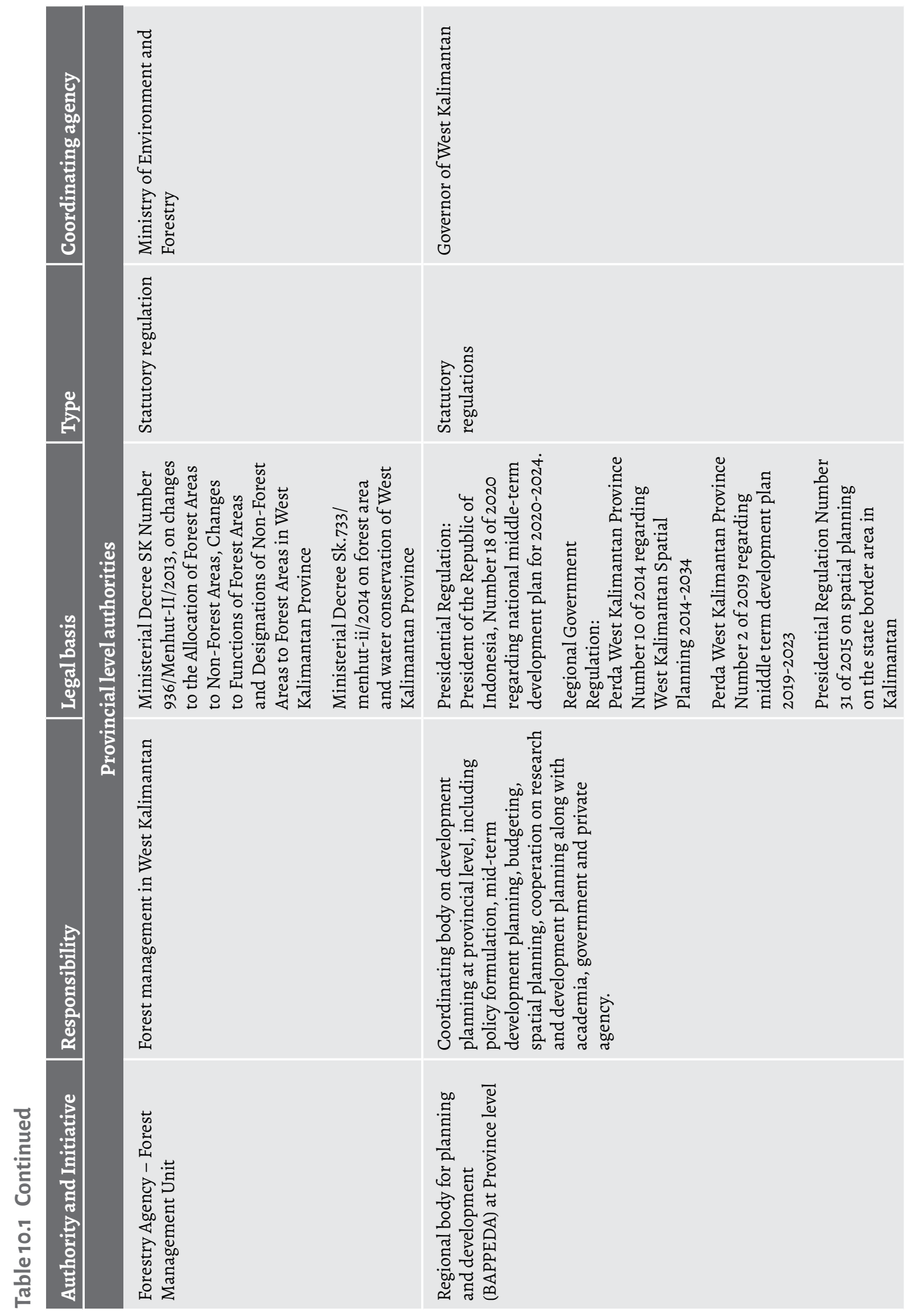




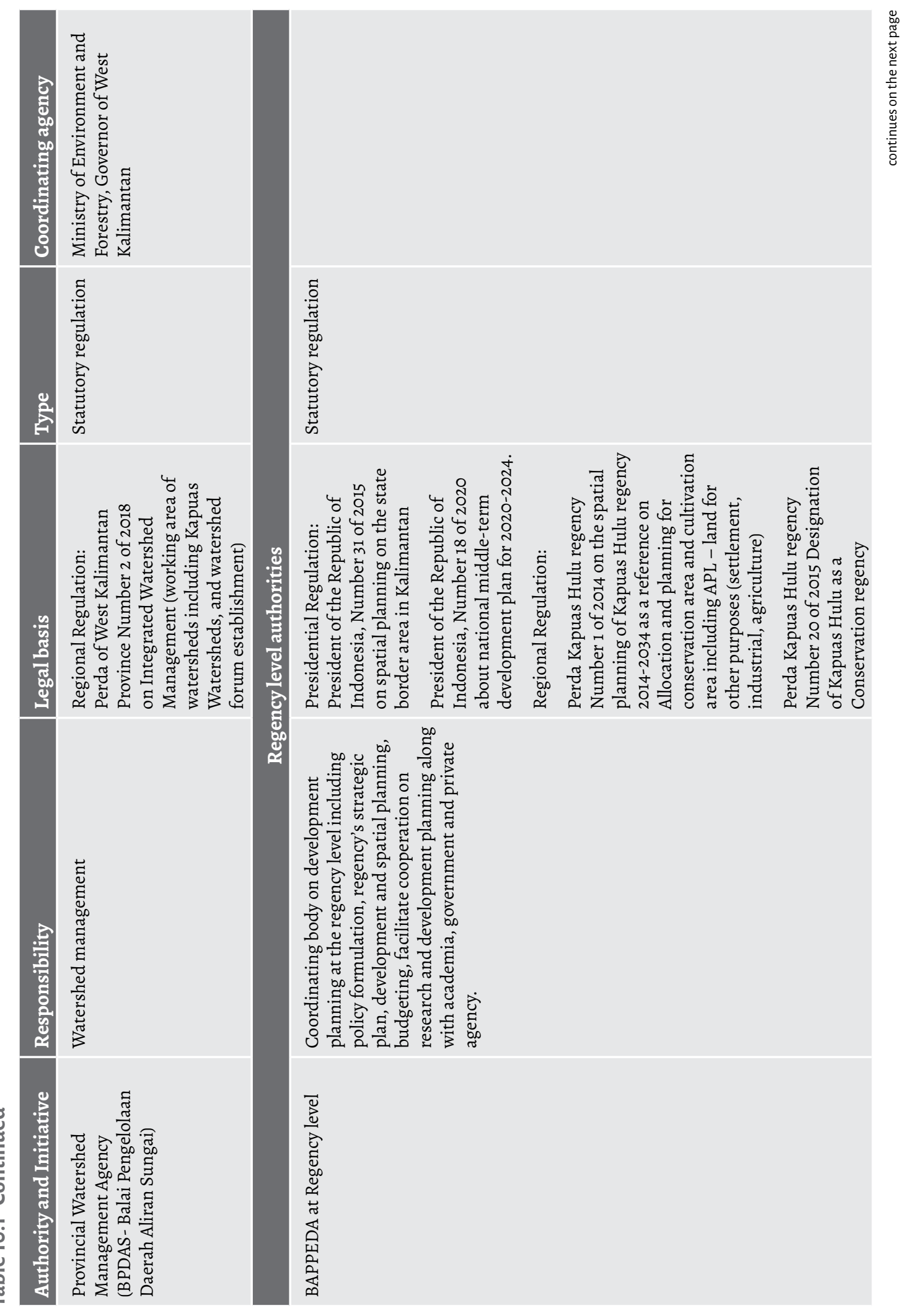



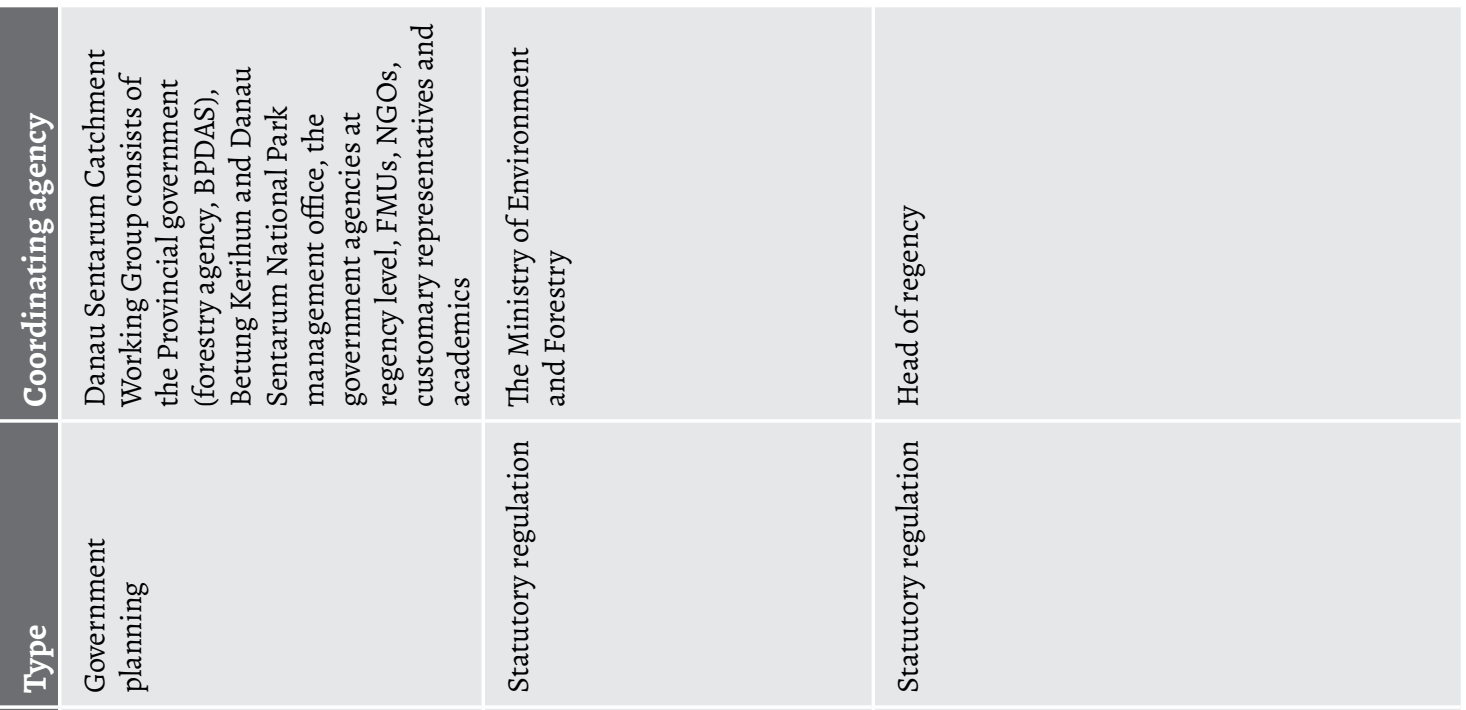

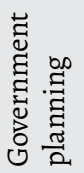

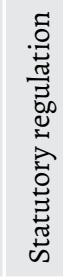
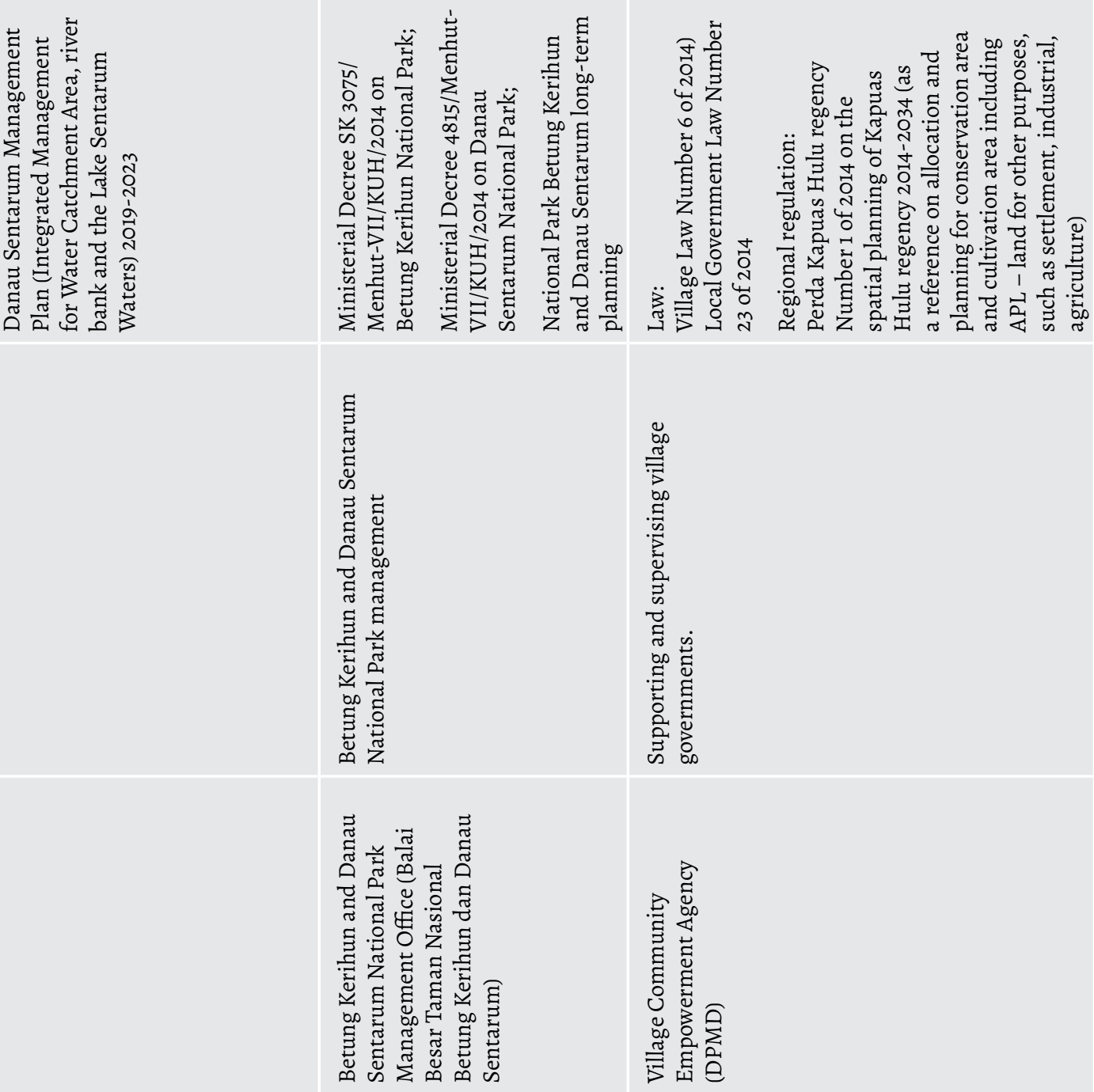


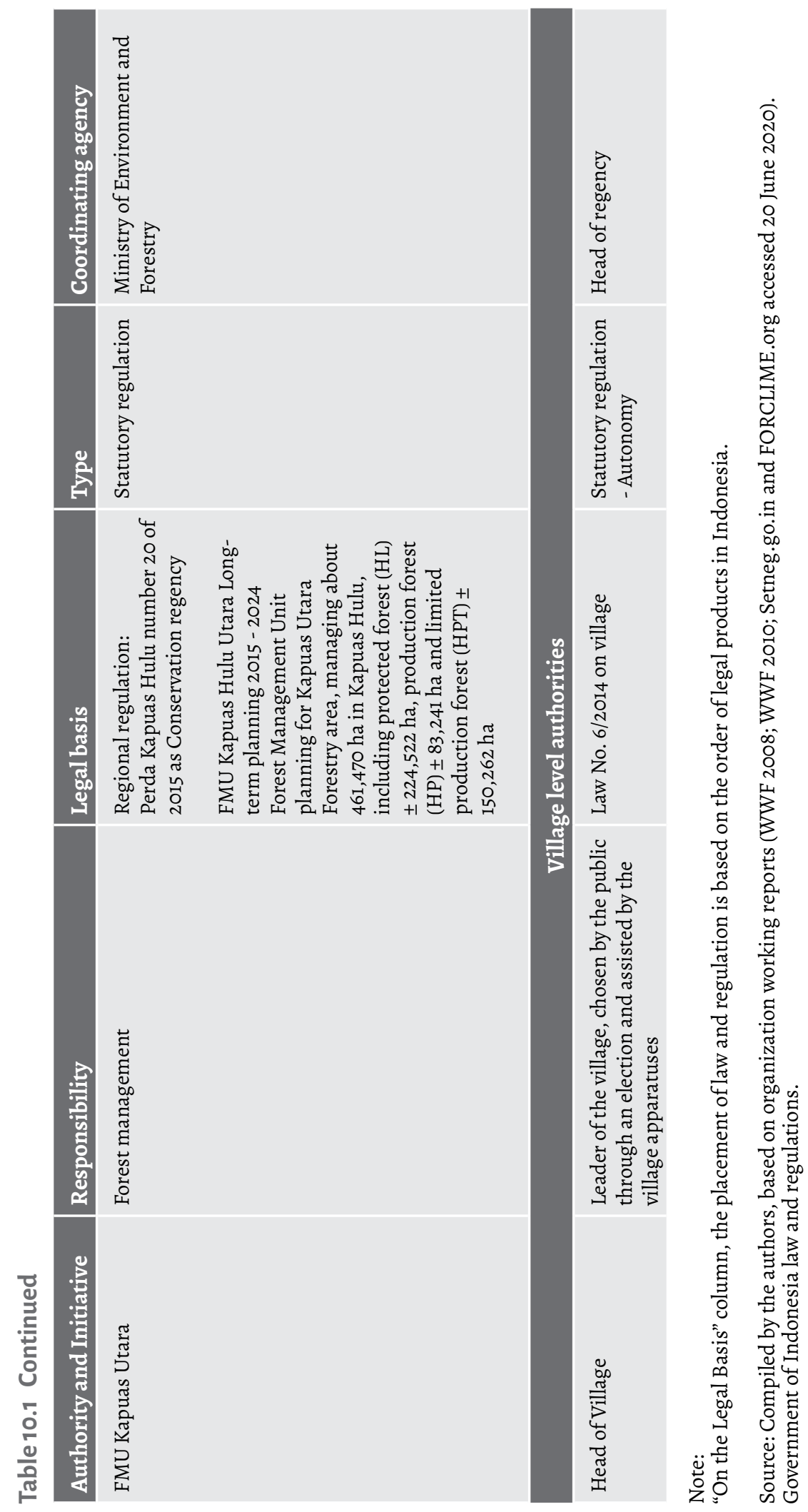


conservation areas (FMUs and national parks). However, this is not the case for oil palm plantations. Much of the plantation areas were converted from forest areas, which were previously allocated to logging concessions. Consequently, the forest area that is available for communal activities and cultural traditions has gradually diminished due to expansion of oil palm plantations.

A key conservation initiative has been developed outside conservation and forest areas. In October 2017, the Directorate General of Conservation Natural Resources and Ecosystem (KSDAE) designated Labian-Leboyan as an Ecosystem Essential Area (KEE) for orang-utan habitat. The protocol of collaboration on managing the KEE was signed by KSDAE, TNBKDS, the Provincial Forestry Agency, BAPPEDA of Kapuas Hulu Regency and WWF (Hadrian 2017; Hakim 2017). This is the first KEE initiative for supporting the orang-utan conservation in Indonesia. The KEE designation is applied for conservation and environmental protection purposes outside conservation areas. The KEE designation requires committed stakeholders and budgetary consistency (Anandi pers. obs.). Without KEE, this respective area is allocated for other development purposes. On a legal basis, the existing perda in this conservation regency should strengthen the KEE operation that will engage a wider range of stakeholders to achieve balanced development and conservation goals. However, to align with the regency development planning and budget allocation, the KEE must be translated into the specific planning document, perda on Regency Strategic Area (Kawasan Strategis Kabupaten known as KSK). Therefore, to be operationally validated, the final legal form of KEE in this situation is 'Perda on KSK Koridor'.

There are several essential requirements to develop KSK, such as reference to the RTRWK ${ }^{21}$ Kapuas Hulu, synchronization with national standards for detailed mapping, and later validation by the KSDAE and the ATR/BPN (Anandi pers. obs. and personal interview with ATR/BPN director of spatial planning development and regional space utilization, September 2018). KSK formulation is under BAPPEDA of Kapuas Hulu Regency responsibility, and is partially funded by the WWF. At the time of writing, status of the KSK was under development and was awaiting detailed mapping activities (personal interview with BAPPEDA officer of Kapuas Hulu Regency, August 2019). As a result, the KEE operational status was uncertain.

Due to myriad regulations and jurisdictions, implementing an integrated landscape approach is challenging. As demonstrated here, the agencies concerned have various responsibilities that represent different approaches and activities in their area of jurisdiction. This may present challenges to the continuation of ILA initiatives beyond the duration of COLANDS activities. The growing number of NGOs, public-private and private initiatives in the focus area are addressed in the next section. These add further to this complexity.

\subsection{Growing numbers of interventions, but better coordination and synergy required}

\subsubsection{Bilateral cooperation}


The Forest and Climate Change program (FORCLIME), a major initiative, was implemented between 2012 and 2020 . A collaboration between the governments of Indonesia and Germany, the program aims to support the FMU in reducing greenhouse gas emissions, managing protected areas and building capacity to achieve those ends. ${ }^{22}$ Since 2015 , this has been associated with sub-projects in several villages in the Batang Lupar sub-district, such as village forest management, village boundary demarcation, GPS training, agriculture and farming. The project was expected to conclude by mid-2020 and in a series of interviews with village administrators and youths from the project sites in March 2020, concerns were expressed over how to continue the initiatives. Interviewees said, "We were not sure how to sustain the activities after the project ends. There might have been some guidance but it was not clear for us. Without guidance that we understand, we are worried that the activities might stop once the project ends." Concerns were expressed that the program could join numerous other small projects within the sub-watershed that were not sustained.

\subsubsection{NGO activities}

NGO assistance in Labian-Leboyan and Seriang began in mid-1990s with the Wetlands International Indonesia program's conservation research in Danau Sentarum. Since then, more NGOs - including the World Wide Fund for Nature (WWF), Riak Bumi, Diantama, and Forina - have implemented conservation initiatives in both the subwatershed, including WWF activities concerning orang-utan protection. Over time, NGO projects are significantly declining in Seriang, and increasing focus in Labian Leboyan. However, other NGO initiatives with limited time frames began to implement projects, WWF activities also slowed in Labian-Leboyan. In 2019, WWF closed its branch office in Batang Lupar, which had coordinated many initiatives along the LabianLeboyan River. Prominent NGOs that remain active in the sub-watershed, as of time of writing, include WWF, Riak Bumi, and Kompakh. There are also two recent projects in the scoping phase Forest Investment Program (FIP-1) funded by the Asian Development Bank (ADB); and the Non-Timber Forest Products Exchange Program (NTFP-EP).

For interventions in national parks and state forests, each NGO needs permission and coordination with the Betung Kerihun Danau Sentarum National Park Management Office and the FMU. Interventions mostly focus on support for alternative livelihoods in the communities (horticulture, rubber gardens, NTFP commodity processing, ecotourism); capacity building in village planning; and village forest management. One of the dominant activities of the NGOs is stimulating agricultural production of such commodities as rubber, coffee and kratom (Mitragyna speciosa) - tree leaves used as a stimulant, either chewed or brewed in tea. However, several challenges impede the sustainability of such interventions. Although coffee and kratom are promoted, most farmers have prioritized rubber, which communities have traditionally cultivated. Yet, government agencies provide limited marketing support for rubber, and some farmers have not seen any direct income benefits because of low latex prices (IDR 6,500-7,000/ $\mathrm{kg}$ or USD 0.50 cents $/ \mathrm{kg}$ ) (Interviews with farmers in three villages, February-March 2020). Furthermore, although such initiatives are ideally coordinated with the regency 
government (specifically, the Agriculture and Food Crops Agency) and the communities, in practice, each NGO works independently with the communities in its working area. This means that communities become dependent on the NGO to facilitate marketing, technologies and compensation for their work in the above mentioned nurseries. Hence, when project funding ends, the activity is not well embedded in the local economy and the institutional environment.

Some NGOs have embarked on kratom production as an alternative livelihood and established nurseries and distributed seedlings. Kratom is a native evergreen tree used by the Dayak as a form of traditional medicine. It is a pioneer species confined to waterlogged areas and riverbanks, is easily grown in those conditions, and offers good market and economic value (dried flakes are valued at IDR $25,000 / \mathrm{kg}$ or USD $1.50 / \mathrm{kg}$, and dried leaves, IDR 5,000-7,000/kg or USD 0.50 cents $/ \mathrm{kg}$ ). However, inconsistent and changing laws concerning this commodity have caused confusion among farmers and governance agencies (Oxtora 2019; Rezkisari 2019). National regulation classifies kratom as both a forestry species and an illegal commodity due to its opioid receptor characteristics. This creates uncertainty about whether it can be planted within conservation and state forests, creating challenges for farmers.

Several NGO programs stimulate activities such as ecotourism, production of traditional crafts, and processing of non-timber forest products. Some of these programs use a common approach to reach beneficiaries by forming working groups and farmer groups (kelompok tani) with the intention to empower the targeted groups and a long-term aim that the groups' knowledge and efforts will benefit wider communities. The target groups include women, groups of farmers, and youths. This may not always be the most desirable approach - despite the close kin relationships within a village or hamlet - as not everyone has the same level of commitment and conflicts may therefore arise.

NGOs have played a key role in establishing forums in Kapuas Hulu for coordination and collaboration at the landscape scale. For example, the National Park management office collaborated with BAPPEDA of Kapuas Hulu Regency and other government agencies to establish the Cagar Biosfer forum in early 2020, with 80 members from government, NGOs, the private sector and customary representatives. Other examples include the trilateral 'Heart of Borneo' task force, between Indonesia, Malaysia, and Brunei Darussalam governments, which was facilitated by WWF Indonesia; and the LabianLeboyan forum organized at the watershed level by WWF and BAPPEDA of Kapuas Hulu Regency. These fora were mainly created and funded by donors and NGOs, with the commitment of government agencies from regency to regional levels. However, most participants are the same, educated people that already have networks organized among themselves. Engagement of local communities in such collaborations and platforms is rare.

Moreover, such forums are highly dependent on donor funding. The Labian-Leboyan forum, for instance, was established in 2007 but has been idle since 2009 and was reactivated only from 2016-2018 with financing from the Tropical Forest Conservation Act (TFCA) program. The latter involves the governments of Indonesia and the United States, in collaboration with The Nature Conservancy (TNC), WWF Indonesia and Indonesian Biodiversity Foundation (KEHATI) Foundation to stimulate the conservation, protection, 
restoration, and sustainable use of tropical forests in Berau (East Kalimantan), Kapuas Hulu and the Heart of Borneo. ${ }^{23}$ According to interviews with community members in four villages, these NGO initiatives have empowered villagers to voice their opinions, deal with outsiders, defend customary rights, become active in an organization, and work on administrative processes such as writing and submitting proposals; and designing rules and regulations (interview with Erwanto, February 2020; Asmoro, February 2020; women in Melemba village, February 2020; women in Mensiau village, March 2020). Yet, as seen above, their initiatives need to be better embedded in the local contexts for improved coordination and sustained effects.

\subsubsection{Public-private partnerships}

The Forest Honey Bee Collectors' Association in Lake Sentarum (APDS), which markets wild honey with organic certification, started in 2002 with the support of NGOs, notably Wetlands International and Riak Bumi (Aliansi Organis Indonesia 2012). From a total of 37 Periau in Kapuas Hulu, there are 13 Periau that joined the APDS. It has continued to function independently through the work of villagers living around the national park, particularly from Leboyan and Semangit (Selimbau sub-district). APDS members are also active fishers and engage with APDS not only to provide them with additional income from honey, but also with the ability to negotiate, market, develop organizational skills and attain product standardization. Since 2015 , the DSNP supports the APDS committee members in marketing and training in certified production. The APDS has also led to another community initiative, namely the establishment of the Tourism Management Association KPP ${ }^{24}$ Semujan Dorsata. Established in 2016, this initiative works closely with National Park management office and private tourism agencies to develop their business.

Eco-tourism is increasingly popular at the community level. KPP Kaban Mayas in downstream Labian-Leboyan is a community-based eco-tourism initiative established by WWF in 2010. KPP Kaban Mayas, in an Iban village, has instilled its ecotourism plan into the village's 20 -year spatial plan. The neighbouring village, a Malay community, followed suit by establishing KPP Semujan Dorsata in 2016. Located within the Danau Sentarum National Park area, group members proactively seek information and collaboration with DSNP officers related to potential tourism destinations. However, despite the proximity between villages, these groups work at a hamlet level, and independently seek support from external market actors (interview with KPP members in two villages, Erwanto, February 2020; Ferry, February 2002; Asmoro, February 2020).

\subsubsection{Private sector initiatives}

The private sector has affected landscapes, as well as social and political dynamics in Kapuas Hulu. During the Soeharto (Suharto) presidency (1967-1998), the national government allocated state forest areas to large-scale timber concessions. Many of these

23 Penabulu:https://penabulufoundation.org/en/tfca-kalimantan-strengthening-institutional-capacityprogram-program-management-and-financial-management-of-tfca-kalimantan-partners/, accessed 14 June 2020.

$24 \mathrm{KPP}=$ Kelompok Pengelola Pariwisata (Tourism Management Association). 
were given to people with close ties to the president, and to military personnel, with the intention of securing the border area. Large-scale timber logging by private companies such as PT Yamaker and PT Landjak Deras began in the 1980 s and were booming between 2000 and 2004 (Eilenberg 2012) during a brief period when decentralization allowed the regency to issue small-scale logging permits. Conflicts with some local communities started when companies preferred to hire migrant labor. However, for some other communities, employment in the concessions provided cash income, while road building to the concessions improved transportation access. With almost no government attention to the border communities, some of the timber businessmen built trust relationships with the communities through the customary leaders by providing support with cash, entrepreneurship, work opportunities and road building (Eilenberg 2012).

In 2005 , the national government declared a moratorium on new logging concessions (Eilenberg 2012, 2016), and at the same time, promoted oil palm plantations to improve the development of the border area (Hasudungan 2018). As a result, the logging areas - particularly the forest production areas that were cleared, as well as the community fallow areas - were downgraded to non-forest cultivation area (APL), much of which was designated for oil palm plantations. PT Sinar Mas, the most prominent plantation in Kapuas Hulu, began its operations in 2007 (Direktorat Jenderal Industri Agro 2011). Since then, plantations have expanded rapidly.

Land-use conflicts occur in many areas that are designated for oil palm. In the Seriang sub-watershed, particularly the Badau sub-district, private firms approach the community in various ways. During the early logging concession period, the common practice for appropriating community land was through repeated village visits, building relationships with local regency officers and customary elites, promoting the company agenda and making promises (Hasudungan, 2018; Yuliani et al. 2020). Some companies would hire village leaders as community representatives (Hasudungan, 2018). However, their decision-making and negotiation power vis-à-vis the oil palm companies has been generally weak and highly reliant on facilitation by the regency government. More recently, companies have tried to gain legitimacy through social investments in health and education. Through such investments, they aim to strengthen their relationships with local communities and alleviate land tenure conflicts, thus paving the way for their business operations (ibid).

There is no concrete collaboration between the private sector, government, local society, and NGOs in the context of landscape-scale initiatives. Individual relations with those in power, such as the regency head, still play a significant role in the private sector's support and presence. Personal relationships also influence the private sector's willingness to contribute to a government or community program. TNBKDS personnel, for example, approached fishing enthusiasts for support in fundraising to obtain wild Arowana (Asian bonytongue, Schlerophages formosus ${ }^{25}$ fish stock released in the

25 Arowana is an endemic species which almost extinct in the wild due to its expensive price. As expensive as IDR 875 million (USD 59,000). https://wartakota.tribunnews.com/2019/06/23/heboh-ikan-arwana-super-red-kapuashulu-kalbar-terjual-senilai-rp-875-juta-di-china. 
"protected community lake" in Melemba village (Interview with G. Hartono, Danau Sentarum and Betung Kerihun national park officer, February 2020).

In summary, this section shows the challenges in bridging conservation and development objectives among communities, NGOs, governments, and private sectors. Despite the many attempts to build multi-sectoral platforms to promote coordination, many of the initiatives by outsiders remain isolated projects. There have been no significant changes made in private-sector engagement with conservation initiatives since the "New Order" era of President Suharto. Yet engaging the private sector is a necessary step that can lead to an improved landscape governance (Sayer et al. 2015).

The APDS, KPPs, and the national park staff rigorously build networks with the private sector. Although collaboration exists in the study area, it happens on a small scale. Existing collaboration with the private sector was build over time after a consistent relationship, both formal and informally. Engaging private actors requires a continuous, clear, and transparent approach to communicating interest and purpose between actors. Informal communication also plays a significant role in establishing cooperation and collaboration as suggested by the ten principles for ILAs (Sayer et al. 2013). Implementing ILAs in a broader context will help in strengthening the network (Riggs et al. 2018) that has been established. ILAs provide a platform for actors to communicate openly, horizontally, and vertically. Information sharing can thus reach a wider network, and stakeholders will be able to identify similar interests. As a result, ILAs can bridge conservation and development goals and scale up collaboration (Langston et al. 2019; Reed et al. 2020) beyond the private sector. It is also important to note, as shown in this chapter, that despite the importance of the formal setting and legal context in setting geographical boundaries, informal connections and communication are essential, allowing individual actors to fluidly share information and opinions.

\subsection{The way forward}

The environmental, social and economic challenges facing the Kapuas Hulu landscape require concerted efforts to implement an ILA. However, the complexity of tenure and governance arrangements poses a challenge. The regency spatial planning agency has allocated areas for development, cultivation, and conservation where each priority is mandated to particular agencies. National, provincial, regency and village authorities operate in the landscape with different conservation and development approaches and overlapping jurisdictions, responsibilities and budgets. The addition of illcoordinated bilateral, NGO, public-private and private initiatives further complicates the institutional landscape.

We identified several established forums that are already well known among the local government, users groups, and the local communities in our landscape. We recognize some forums' weaknesses and strengths, which helped us understand how ILA principles can further engage and empower these forums to be more effective, linked, and collaborative. Supporting the existing forums will allow us to reach out to the 
communities and groups they represent, and hopefully open the door to building the trust to work together on landscape management.

The work of NGOs and their past and present initiatives have had a positive impact on community empowerment; not only financially, but also in terms of enhancing capacity. Such community-based conservation-development initiatives can be promising entry points for the operationalization and implementation of a landscape approach (Foli et al. 2018), but these must be strengthened and scaled up to sub-district or sub-watershed level. In parallel, existing discussion platforms could play a role in facilitating the necessary links between community, governmental and civic actors in the landscape for collaboration and mutual support.

\section{References}

Aliansi Organis Indonesia (AOI) 2012. Madu hutan organis Sentarum: Sebuah upaya komunitas periau untuk pelestarian hutan dan membangunkan kemandirian ekonomi (Sentarum organic wild honey: an effort by the Periau community to conserve forest and develop economic independence) Bogor: http://aoi.ngo/web/. AOI.

Anshari G, Kershaw AP and van der Kaars S. 2001. A late Pleistocene and Holocene pollen and charcoal record from peat swamp forest, Lake Sentarum wildlife reserve, West Kalimantan, Indonesia. Palaeogeography, Palaeoclimatology, Palaeoecology 173(3-4): 213-228. https://doi.org/10.1016/S0031-0182(01)00246-2.

Anshari G, Kershaw AP, van der Kaars S and Jacobsen G. 2004. Environmental change and peatland forest dynamics in the Lake Sentarum area, West Kalimantan, Indonesia. Journal of Quaternary Science 19(7): 637-655. https://doi.org/10.1002/jqs.879.

Ashton PS. 1988. Dipterocarp biology as a window to the understanding of tropical forest structure. Annual Review of Ecology and Systematics 19(1): 347-370.

Basuki TM, van Laake PE, Skidmore AK and Hussin YA. 2009. Allometric equations for estimating the above-ground biomass in tropical lowland Dipterocarp forests. Forest Ecology and Management 257(8): 1684-1694. https://doi.org/10.1016/j. forec0.2009.01.027.

BPS-Kapuas Hulu Regency. 2018. Employment Statistics of Kapuas Hulu Regency, Kapuas Hulu.

BPS-Kapuas Hulu Regency. 2019a. Badau sub-district in figures 2019, Kapuas Hulu.

BPS-Kapuas Hulu Regency. 2019b. Kecamatan Batang Lupar Dalam Angka 2019. https://doi. org/1102001.6108.210.

BPS - Kapuas Hulu Regency. 2020. Kapuas Hulu Regency in Figures 2020, Kapuas Hulu.

Caldecott J and Miles L. 2005. World atlas of great apes and their conservation. In Caldecott,J and Miles L. (eds.) Prepared at the UNEP World Conservation Monitoring Centre. Berkeley: University of California Press.

Colfer CJP, Salim A, Wadley RL and Dudley RG. 2000. Understanding patterns of resource use and consumption: A prelude to co-management. Borneo Research Bulletin 31: $29-38$. 
de Jong W. 2000. Micro-differences in local resource management: The case of honey in West Kalimantan, Indonesia. Human Ecology 28: 631-639.

Direktorat Jenderal Industri Agro. 2011. Sinar Mas Grup Bangun Dua Pabrik CPO, retrieved 5 May 2020. http://www.kemenperin.go.id/artikel/1217/Sinar-Mas-GrupBangun-Dua-Pabrik-CPO.

Direktorat Wilayah Pengelolaan dan Penyiapan Areal Pemanfaatan Kawasan Hutan. 2012. Petunjuk Teknis Tata Hutan dan Penyusunan Rencana Pengelolaan Hutan KPHL dan KPHP.

Dudley, RG. 2000. The fishery of Danau Sentarum. Borneo Research Bulletin 31: 261-306.

Eilenberg, M. 2012. The confession of a timber baron: patterns of patronage on the Indonesian-Malaysian border. Identities 19(2): 149-167. https://doi.org/10.1080/10702 89x.2012.672841.

Eilenberg M. 2016. A State of fragmentation: Enacting sovereignty and citizenship at the edge of the Indonesian state. Development and Change 47(6): 1338-1360. https://doi. org/10.1111/dech.12272.

Eilenberg M and Wadley, RL. 2009. Borderland livelihood strategies: The socio-economic significance of ethnicity in cross-border labour migration, West Kalimantan, Indonesia. Asia Pacific Viewpoint 50(1): 58-73. https://doi.org/10.1111/j.14678373.2009.01381.x.

Foli S, Ros-Tonen MAF, Reed J and Sunderland T. 2018. Natural resource management schemes as entry points for integrated landscape approaches: Evidence from Ghana and Burkina Faso. Environmental Management 62(1): 82-97. https://doi.org/10.1007/ s00267-017-0866-8.

Freeman OE, Duguma LA, and Minang, PA. 2015. Operationalizing the integrated landscape approach in practice. Ecology and Society 20(1). https://doi.org/10.5751/ES07175-200124.

Giesen W. 1987. Danau Sentarum Wildlife Reserve: Inventory, ecology, and management guidelines. Bogor, Indonesia: WWF.

Giesen W and Aglionby J. 2000. Introduction to Danau Sentarum National Park, West Kalimantan. Borneo Research Bulletin 31:5-28.

Ginting T. 2017. Valuasi ekonomi dan alternatif kebijakan pengelolaan kawasan taman nasional danau sentarum thasia ginting. Bogor Agricultural University (IPB).

Hadrian P. 2017. Kehidupan Orangutan di alam harusnya bebas ancaman. Mongabay. Retrieved 19 July 2020. https://www.mongabay.co.id/2017/12/04/kehidupanorangutan-di-alam-harusnya-bebas-ancaman/.

Hakim S. 2017. Pemerintah pusat tetapkan Kapuas Hulu sebagai kawasan ekosistem esensial. Tribun Pontianak. Retrieved 23 July 2020. https://pontianak.tribunnews. com/2017/10/20/pemerintah-pusat-tetapkan-kapuas-hulu-sebagai-kawasanekosistem-esensia.

Harwell EE. 2010. Fluid landscapes and contested boundaries in Danau Sentarum. Borneo Research Bulletin 41: 36-62.

Hasudungan A. 2018. Political Ecology of Palm Oil Development in the Kapuas Hulu District of West Kalimantan. PhD dissertation, University of Sydney. 
Heri V, Yuliani EL and Indriatmoko Y. 2010. Interacting threats and challenges in protecting Danau Sentarum, Borneo Research Bulletin 41:7 4-100.

KPHP Model Kapuas Hulu 2015. Rencana Pengelolaan Jangka Panjang 2015 - 2024 Kesatuan Kengelolaan Hutan Produksi Model Kabupaten Kapuas Hulu Provinsi Kalimantan Barat (Long-term management plan 2015-2024 Forest Management Unit Model Kapuas Hulu Regency of West Kalimantan Province). Kapuas Hulu Regency: The Government Agency of Agriculture and Forestry.

Langston JD, McIntyre R, Falconer K, Sunderland T, van Noordwijk M and Boedhihartono AK. 2019. Discourses mapped by Q-method show governance constraints motivate landscape approaches in Indonesia. PLoS ONE 14(1): 1-22. https://doi.org/10.1371/journal.pone.0211221.

Labrière N, Laumonier Y, Locatelli B, Vieilledent G and Comptour M. 2015. Ecosystem services and biodiversity in a rapidly transforming landscape in northern Borneo. PLoS ONE 10(10), e0140423.

Laumonier Y, Simamora T, Manurung A, Narulita S., Pribadi U, Simorangkir A and Shantiko B. 2020a. Sentinel landscapes initiative: Stocktake and baseline data analysis for future landscape management and monitoring in West Kalimantan. FTA Working Paper 5. Bogor, Indonesia: CIFOR.

Laumonier Y, Hadi DP, Pribadi UA, Narulita S. 2020b. Kapuas Hulu ecological vegetation map 1:50000, CIFOR. Available at: https://doi.org/10.17528/CIFOR/DATA.00202, Bogor, Indonesia.

Leonald L, and Rowland D. 2016. Drivers and effects of agrarian change in Kapuas Hulu Regency, West Kalimantan, Indonesia. In Deakin L, Kshatriya M and Sunderland $\mathrm{T}$ (eds.) Agrarian Change in Tropical Landscapes. 91-138. https://doi.org/10.17528/ cifor/005867. Bogor, Indonesia: CIFOR.

Li TM. 2007. Practices of assemblage and community forest management. Economy and Society 36(2): 263-293. https://doi.org/10.1080/03085140701254308.

Lusiana B, Widodo R, Mulyoutami E, Nugroho DA, and van Noordwijk M. 2008. Kajian kondisi hidrologis DAS Kapuas Hulu, Kabupaten Kapuas Hulu, Kalimantan Barat (World Agroforestry Center Working Paper No 60). Bogor.

Manuri S, Brack C, Nugroho NP, Hergoualc'h K, Novita N, Dotzauer H, ... Widyasari E. 2014. Tree biomass equations for tropical peat swamp forest ecosystems in Indonesia. Forest Ecology and Management 334: 241-253. https://doi.org/10.1016/j. forec0.2014.08.031.

Moeliono M, Thuy PT, Bong IW, Wong GY and Brockhaus M. 2017. Social forestry-why and for whom? A comparison of policies in Vietnam and Indonesia. Forest and Society 1(2): 78-97. https://doi.org/10.24259/fs.vii2.2484.

Muhyidin A. 2017. When the Forest is Depleted: Resource Governance in the Border Regions of Kapuas Hulu in West Kalimantan, Indonesia. ASEAN-Canada Research Partnership Working Paper Series No. 5. Singapore: RSIS.

Myers R, Sanders AJP, Larson AM, Prasti RD and Ravikumar A. 2016. Analyzing multilevel governance in Indonesia: Lessons for REDD+ from the study of landuse change in Central and West Kalimantan. CIFOR working paper 202. https://doi. org/10.17528/cifor/006058. 
Oxtora R. 2019. Bupati Kapuas Hulu minta regulasi jelas terkait Kratom (Kapuas Hulu regency head demanding a clear regulation on kratom). ANTARA News.com, 5 November 2019, retrieved July 18, 2020. https://www.antaranews.com/berita/1147664/ bupati-kapuas-hulu-minta-regulasi-jelas-terkait-kratom.

Prayogo H, Thohari, Machmud A, Solihin, Duryadi D, Prasetyo, ... Jito. 2016. Pemodelan kesesuaian habitat orangutan kalimantan (Pongo pygmaeus pygmaeus Linn, 1760) di koridor satwa Kapuas Hulu Kalimantan Barat. Journal Penelitian Hutan dan Konservasi Alam 13(2): 137-150.

Reed J, Deakin L, Sunderland T. 2014. What are 'integrated landscape approaches' and how effectively have they been implemented in the tropics: a systematic map protocol. Environmental Evidence 4(2): 1-7.

Reed J, Van Vianen J, Deakin EL, Barlow J, Sunderland T. 2016. Integrated landscape approaches to managing social and environmental issues in the tropics: Learning from the past to guide the future. Global Change Biology 22(7): 2540-2554. https://doi. org/10.1111/gcb.13284.

Reed J, Ickowitz A, Chervier C, Djoudi H, Moombe K, Ros-Tonen M ... Sunderland T. 2020. Integrated landscape approaches in the tropics: A brief stock-take. Land Use Policy 99: 104822. https://doi.org/10.1016/j.landusepol.2020.104822.

Rezkisari I. 2019. Tokoh adat minta presiden temui petani kratom (Customary leader inqury to the President to meet with the kratom farmers. Republika, retrieved 18 July 1 2020. https://nasional.republika.co.id/berita/qojcmm328/tokoh-adat-mintapresiden-temui-petani-kratom.

Roslinda E, Darusman D, Suharjito D, Nurrochmat DR. 2012. Stakeholders analysis on the management of Danau Sentarum National Park Kapuas Hulu Regency West Kalimantan Province. Jurnal Manajemen Hutan Tropika (Journal of Tropical Forest Management) 18(2): 78-85. https://doi.org/10.7226/jtfm.18.2.78.

Russon AE, Erman A and Dennis R. 2001. The population and distribution of orangutans (Pongo pygmaeus pygmaeus) in and around the Danau Sentarum Wildlife Reserve, West Kalimantan, Indonesia. Biological Conservation 97(1): 21-28, https://doi.org/10.1016/ S0006-3207(00)00087-2.

Sada C, Alas Y, Anshari M. 2019. Indigenous people of Borneo (Dayak): Development, social cultural perspective and its challenges. Cogent Arts and Humanities 6(1). https:// doi.org/10.1080/23311983.2019.1665936.

Sahide MAK, Supratman S, Maryudi A, Kim YS. and Giessen L. 2016. Decentralisation policy as recentralisation strategy: Forest management units and community forestry in Indonesia. International Forestry Review 18(1): 78-95, https://doi. org/10.1505/146554816818206168.

Sayer J, Margules C, Boedhihartono AK, Dale A, Sunderland T, Supriatna J, Saryanthi R. 2015. Landscape approaches: What are the pre-conditions for success? Sustainability Science 10(2): 345-355 . https://doi.org/10.1007/s11625-014-0281-5.

Sayer J, Sunderland T, Ghazoul J, Pfund JL, Sheil D, Meijaard E... Buck LE. 2013. Ten principles for a landscape approach to reconciling agriculture, conservation, and other competing land uses. Proceedings of the National Academy of Sciences of the United States of America 110(21): 8349-8356. https://doi.org/10.1073/pnas.1210595110. 
Shantiko B, Fripp E, Taufiqoh T, Heri T, Laumonier Y. 2013. Socio-economic considerations for land-use planning: The case of Kapuas Hulu, West Kalimantan. CIFOR Working Paper 120, 63 p. https://doi.org/10.17528/cifor/004349.

Sunderland TCH, Ehringhau C, Campbell BM. 2008. Conservation and development in tropical forest landscapes: A time to face the trade-offs? Environmental Conservation 34(4): 276-279. https://doi.org/10.1017/S0376892908004438.

Sunkar A, and Santosa Y. 2018. Biodiversity conservation at Betung Kerihun National Park: The positive role of customary law in mitigating a local community trust deficit. IOP Conference Series: Earth and Environmental Science 196: 012024. https://doi. org/10.1088/1755-1315/196/1/012024.

Wadley RL, and Eilenberg M. 2005. Autonomy, identity, and 'illegal' logging in the borderland of West Kalimantan, Indonesia. Asia Pacific Journal of Anthropology 6(1): 19-34. https://doi.org/10.1080/14442210500074853.

Whitmore TC. 1984. Tropical Rain Forests of the Far East. 2nd edn. Oxford: Clarendon.

Wollenberg E, Moeliono M, Limberg G. 2009. Riding the rapids: Synthesis and conclusion, In: Moeliono M, Wollenberg E and Limberg G, eds. The Decentralization of Forest Governance: Politics, Economics and the Fight for Control of Forests in Indonesian Borneo. London: Earthscan. 281-298.

WWF 2010. Financing the Heart of Borneo - A Partnership Approach to Economic Sustainability. http://awsassets.panda.org/downloads/financing_the_heart_of_ borneo_pdf.

WWF 2008. Heart of Borneo Indonesia. Secretariat of National Working Group Heart of Borneo. Directorate General of Forest Protection and Nature Conservation, Ministry of Forestry Republic Indonesia. http://heartofborneo.or.id/en/.

Wulffraat S, Faisal KF, Wedastra IBK, Shapiro A. 2014. The Environmental Status of the Heart of Borneo. WWF HoB Initiative.

Yuliani EL, Adnan H, Achdiawan R, Bakara D, Heri V, Sammy J... Sunderland T. 2018. The roles of traditional knowledge systems in orang-utan Pongo spp. and forest conservation: A case study of Danau Sentarum, West Kalimantan, Indonesia. Oryx 52(1): 156-165. https://doi.org/10.1017/S0030605316000636.

Yuliani EL, Jong EBP de, Knippenberg L, Bakara DO, Salim MA, Sunderland T. 2018. Keeping the land: Indigenous communities' struggle over land use and sustainable forest management in Kalimantan, Indonesia. Ecology and Society 23:49.

Yuliani EL, Groot WT de, Knippenberg L, Bakara DO. 2020. Forest or oil palm plantation? Interpretation of local responses to the oil palm promises in Kalimantan, Indonesia. Land Use Policy 96:104616. 


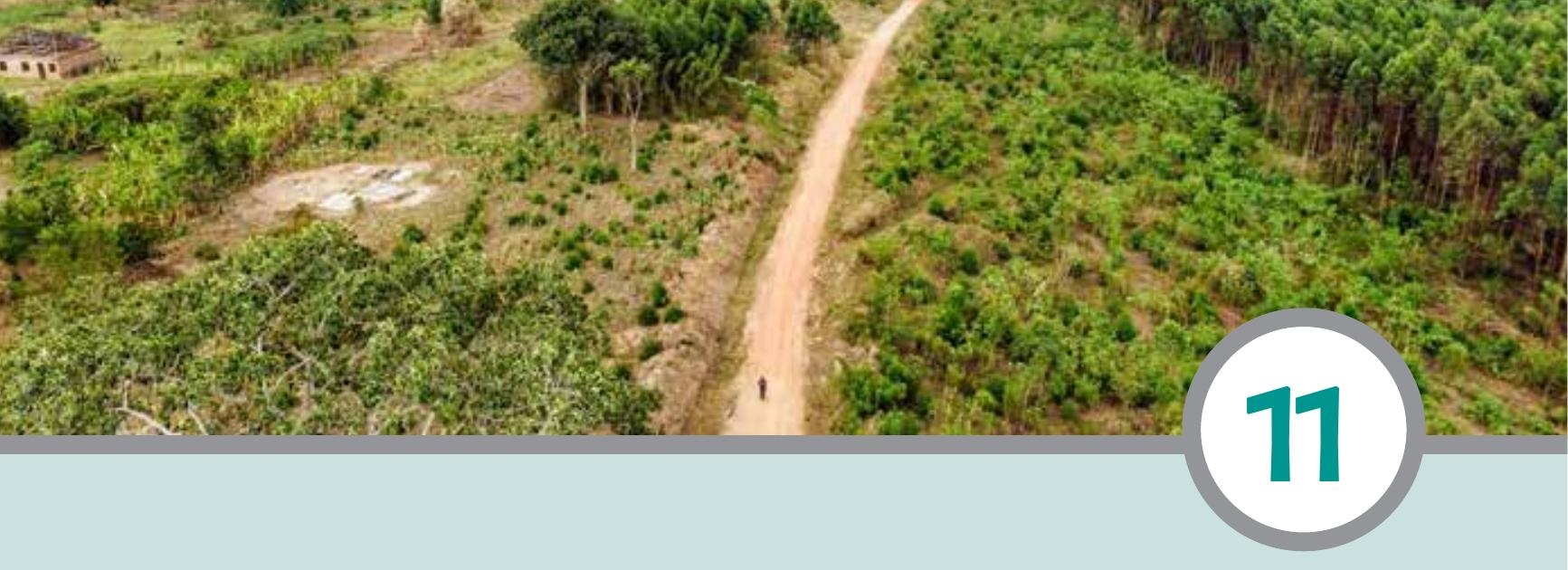

\section{Conclusion and the way forward}

Terry Sunderland, James Reed and Mirjam Ros-Tonen

Although the term "landscape approach" was initially coined by the conservation biologist Reed Noss in 1983, it was not until after the 1992 Rio Summit that the term gathered momentum in the conservation and development lexicon. The promise and potential of landscape approaches have been central tenets in the sustainable development discourse since then. Numerous institutions, including CIFOR, have integrated landscape approaches (ILA) within their research and development strategies. Moreover, the successful Global Landscapes Forum (GLF) has positioned the "landscape" centre stage politically, socially and environmentally, since it organized its first in a series of recurring events in parallel to the Conference of the Parties to the UNFCCC in Warsaw in 2013.

Scholars have made great progress in conceptual frameworks, theoretical approaches and broad philosophies related to spatial approaches to environmental governance and management, but how are we doing on implementation? In Chapter 2, we learnt that, in many respects, landscape approaches are well documented as a concept, but fall considerably short of actually providing clear and unambiguous examples of operationalization. To better understand the conditions under which landscape approaches function best, an element of trial and error is required. Yet, the poor record of reported case studies suggests there is currently limited learning from doing. The COLANDS initiative is an explicit attempt to address this gap by delivering robust monitoring and reporting of efforts in three tropical landscapes. 
One major concern in all three COLANDS landscapes is the loss of biodiversity (Chapter 3). Biodiversity is not only important for its intrinsic value, but also for the goods and services that it provides, particularly in complex, multi-functional landscapes (Grass et al. 2020). For example, the provision of ecosystem services is critical in supporting rural livelihoods and contributing to agricultural production (Reed et al. 2017). As we have seen, landscape simplification can lead to catastrophic impacts in biodiversity conservation and rural livelihoods (Rasmussen et al. 2019). The importance of forested landscapes for the livelihoods of its inhabitants is well illustrated by Newton et al. (2020), who estimate that 1.6 billion people live within $5 \mathrm{~km}$ of a forest. It is these, often contested, mosaic landscapes that directly provide food, shelter, clean water, and other goods and services to around a fifth of humanity (WWF 2020) and, indirectly, to many millions of others more.

Biodiversity loss is also slated as one of the main causes of zoonotic spill over, a highly pertinent issue at the current time of COVID-19 (Baudron and Liégeois 2020). Simplified landscapes do not have the environmental and economic resilience of more complex systems and, thus, exposure to zoonoses, and other environmental challenges, is increased. The origins of landscape approaches were rooted in the ecological and biological fields of scholarship (Lindenmayer et al. 2008), and it was the development of further principles to include more social issues that has given the framework a more developmental aspect (Sayer et al. 2013). However, landscape approaches today have arguably shifted away from the biophysical to an extent that we probably need to come full circle and bring back the element of biodiversity. Hence, the re-emphasis on measuring and monitoring biodiversity as described in Chapter 3.

The 'wicked problems' landscapes are facing clearly require multi-stakeholder dialogue. However, bringing stakeholders with different powers, capacities, needs and interests together inevitably brings challenges. Chapter 4 provides an evidence-based "toolkit" to overcome such challenges. Knowledge co-production, triple-loop learning and seeking consensus in multi-stakeholder platforms; promoting understanding of landscape dynamics through modeling, scenario building or joint development of a theory of change; and incentives for pro-conservation behaviour can all help to stimulate multistakeholder engagement in landscape approaches.

Another critical feature of operationalizing landscape approaches is a greater emphasis on monitoring and evaluation. Only then are we able to learn from the lessons of implementation. Chapter 5 highlights the importance of evaluation to assess the effectiveness and pathways to sustainable landscape approaches. It elaborates on the use of process analysis and impact evaluation to draw important lessons for the replication of landscape approaches in other contexts. It also argues for using theories of change to improve the quality and credibility of landscape approach evaluation and to decide on methods and data to be used. A theory of change has been developed for Zambia and we hope to complete those for the other two landscapes in the coming months. Further work will rely on the establishment of baselines using existing datasets, rather than undertaking resource-intensive primary research, thus allowing replicability elsewhere.

Over the past 10-15 years the research community has developed a suite of tools and methods to understand significant and more subtle changes in the socio-ecological 
systems in rural landscapes. These range from modeling (Sandker et al. 2009) to more participatory-based approaches (e.g. Endamana et al. 2010; Langston et al. 2019; Asubonteng et al. 2020). Chapter 6 presents an overview of some of these methods that can be used in implementing landscape approaches and their alignment with the ten principles (Sayer et al. 2013). While historical timelines help uncover past landscape dynamics, baseline studies give insight into the present, while forecasting helps identify future trends. It is anticipated that the $\mathrm{PhD}$ candidates involved in the COLANDS initiative will adopt and modify these methods in their ongoing studies to identify potential needs, opportunities and challenges in the three country landscapes.

The policy context in each of our three target countries is, without question, highly conducive for the implementation of landscape-scale initiatives. Chapter 7 highlights how the policy arena provides a framework for more integrated landscape approaches, theoretically breaking down sectorial barriers between agriculture and forestry. The CREMA in Ghana (Chapter 8), the CBNRM forum in Zambia (Chapter 9), and mushrooming community-based environment-development initiatives and discussion platforms in Indonesia (Chapter 10) provide promising entry points for the implementation of landscape approaches. However, the best policy framework, in common with landscape approaches, is only as good as its implementation, and we will continue to evaluate the policy context of the potential for sustainable landscapes for the duration of engagement by COLANDS.

Many of the COLANDS landscapes are managed, albeit informally, in a way that provides goods and services over the long term, and it is often external agencies that drive drastic change, and often conflict, as also described in the three country chapters (Chapters 8-10). Fundamentally, we can learn a great deal from those already living and working in mosaic landscapes and perhaps the "movement" aimed at supporting sustainable landscapes globally as aspired to by the GLF could, and should, be a more bottom-up process, building on the capacity and experience of local stakeholders, rather than one characterized by high-level panels and other putative talk-shops (Boedhihartono et al. 2018).

One early observation that is worth recording here is that we, as a team, have been frustrated by the lack of engagement by the private sector in our COLANDS initiative. Commercial farming plays an important role in the landscapes of both Zambia (cattle, maize) and Indonesia (oil palm), and private sector stakeholders have been repeatedly invited to stakeholder meetings and consultations, but rarely, if ever, show up. Donor agencies continue to advise that sustainable development is reliant on successful engagement with the private sector, but what recourse is there if they regard our initiatives as irrelevant (at best) or counter-productive to their own interests (at the very worst)? In this regard, in Ghana, where activities are delayed due to the change of country focus and subsequent lockdown, the situation seems to look somewhat more promising with the presence of the Savannah Fruits Company. This enterprise has 14 years of experience in collaborating with local cooperatives and civil society organizations to sustainably produce savannah fruits, while empowering women.

There are also expectations of projects to bring economic development. In both Zambia and Indonesia, we encountered expectations regarding the traditional delivery of 
development activities that local stakeholders perceive as a reward for engagement with our research. Building on the work of Sayer and Wells (2004), perhaps the reliance on external agencies for both biodiversity conservation and rural development has, in many instances, abrogated or minimalized the responsibility that national governments should have for such activities. It could be argued that by engaging as facilitators in our target landscapes, such roles and responsibilities would be more clearly defined. This would enhance a shift from project to process whereby engagement is continuous and not constrained by project funding cycles, donor intransigence and conservation and development fads (Redford et al. 2013). However, while we are aware that such a position is, from a purist research perspective, ideal, we also acknowledge that many of our stakeholders remain chronically poor and in need of support, particularly in the absence of government action. The issue of whether the COLANDS initiative should serve as an entry point for further rural development or more effective biodiversity conservation can be somewhat of a dilemma. However, the direction to go should be driven by the needs and aspirations of local stakeholders. This requires thinking "beyond the project" to such an extent that it represents a paradigm shift in the way we deliver "sustainable development". Instead of an interventionist project approach, we should see landscapescale interventions as facilitation processes that ignite the latent structures and multistakeholder platforms that are already in place.

But how do we manage trajectories of change? And whose responsibility is it to influence better outcomes in landscape governance and management? Decisions made in national capitals and beyond can have dramatic impacts on rural landscapes and livelihoods. Whether this involves the award of an oil-palm concession, a mining contract, or the gazettement of a new protected area, the benefits may be felt nationally, but the costs are often borne locally, with loss of access to land and resources. Again, local stakeholders have the most to lose from such changes.

There is evidence that landscape-scale implementation is considered widespread (e.g. Milder et al. 2014; Zanzanaini et al. 2017). Yet, the actions and objectives of such projects are diverse (Carmenta et al. 2020) and many projects that purport to work within the broader landscape are arguably more traditional Integrated Conservation and Development Projects (ICDPs), which have been found wanting in their ability to operate beyond the protected area. Reviewing 15 conservation projects in the Lower Mekong, Sunderland et al. (2013), for example, found that projects situated within landscapes do not necessarily work at the scale of the landscape. This might be inherent in the concept of "project" itself. Short-term engagement, a strong focus on law enforcement, the provision of alternative income-generating activities, and establishing parallel institutions outside of governmental structures characterize "the project" (Sayer and Wells, 2004). As such, it is no wonder that project approaches have had questionable outcomes. Sayer and Wells (2004) also refer to the "tyranny of the logframe", causing projects to be hamstrung from the outset by a rigid management framework and its pre-defined outputs and outcomes rather than allowing a more organic, and adaptive, approach to management and implementation.

Another major obstacle to long-term engagement that we have identified is the fact there are often issues far beyond the control of a single research or development 
initiative. When first proposing this project (as it was conceived in the first instance) to IKI, we had included Burkina Faso as a target country of interest primarily due to the long-term work by CIFOR and partners there over many years, as well as the expertise and experience of the research team (see Chapter 1). Unfortunately, the first year of implementation was hampered by increasing uncertainty surrounding the security situation in the country, driven primarily by increasingly militant anti-government militia. Finally, it was decided that it was not possible to safely work in Burkina Faso and hence, we were forced to identify an alternative site. Considering the biophysical as well as partial social similarity in both landscapes, the Western Wildlife Corridor in Northern Ghana was chosen (Chapter 8). This course of events shows that a process approach is fraught with unexpected turns and twists, and this calls for adaptability (principle 1) of an integrated landscape approach (Sayer et al. 2013; see also Chapters 1, 2 and 7) and moving beyond "lock-frames" (Gasper 1997).

And circumstances continue to change. Rapidly. At the time of writing (October 2020), the world is in an increasingly precipitous state. We are currently gripped by a pandemic that has, thus far, resulted in the deaths of over a million people and the concomitant lockdowns and social isolation have weakened the global economy to such as extent that the World Bank (2020) suggests we are entering a full-scale depression. The economic fall-out from the pandemic is predicted to affect developing and emerging economies more significantly than richer nations. As urban jobs are lost, there is often no other recourse for many, and in the absence of social welfare programs, people are returning to their rural homes. Many will be forced into itinerant agriculture and other forms of natural resource extraction. This will have a significant impact on rural landscapes demographically, with an influx of younger people back into the rural milieu, with both environmental and economic effects (Boillat and Zähringer 2020). As part of the COLANDS initiative, we will be monitoring these population dynamics and the resultant changes in our target landscapes. While the circumstances of such a research opportunity are indeed unfortunate, understanding such dynamics and resulting social and economic changes can inform the governance and management of rural landscapes under increasingly precarious and uncertain conditions, including the broader and more pervasive impacts of climate change.

It is due to the uncertainties associated with landscape dynamics that throughout this book we refer to COLANDS as an "initiative" rather than a project and speak of landscape approaches in the three target countries as a "process". We believe that successful landscape approaches should be thought of as a long-term commitment that focuses on a broader suite of issues than traditional sectorial projects, be it biodiversity conservation, human health, food security or rural development. As has been highlighted in this book, these are all inextricably interlinked and should be regarded as such (Diaz et al. 2019).

Unfortunately, the pandemic has limited our engagement in all three countries thus far and we would have hoped for more tangible, reportable "lessons learned" as we enter our third year of funding. However, we believe that this book represents a useful attempt at reporting our experiences of operationalizing landscape approaches in the three target countries. 


\section{References}

Asubonteng KO, Ros-Tonen MAF, Baud ISA and Pfeffer K 2020. Envisioning the future of mosaic landscapes: Actor perceptions in a mixed cocoa-oil palm area in Ghana. Journal of Environmental Management 1-19.https://doi.org/10.1007/s00267-020-01368-4.

Baudron F and Liégeois F. 2020. Fixing our global agricultural system to prevent the next COVID-19. Outlook on Agriculture 49: 111-118. https://doi.org/10.1177/0030727020931122.

Boedhihartono AK, Bongers F, Boot RGA, van Dijk J, Jeans H, van Kuijk M, Koster H, Reed J, Sayer J, Sunderland T, Turnhout E, van Vianen J and Zuidema PA. 2018. Conservation science and practice must engage with the realities of complex tropical landscapes. Tropical Conservation Science 11:194008291877957. https://doi. org/10.1177/1940082918779571.

Boillat and Zahringer. 2020. https://glp.earth/news-events/blog/covid-19-reversemigration-and-impact-land-systems.

Carmenta R, Coomes DA, DeClerck FA, Hart AK, Harvey CA, Milder J, ... EstradaCarmona N. 2020. Characterizing and evaluating integrated landscape initiatives. One Earth 2(2): 174-187.

Díaz S, Settele J, Brondízio E, Ngo H, Agard J, Arneth A, Balvanera P, Brauman K, Butchart S, Chan K. et al. 2019. Pervasive human-driven decline of life on Earth points to the need for transformative change. Science 366(6471):eaax3100.

Endamana D, Boedhihartono AK, Bokoto B, Defo L, Eyebe A, Ndikumagenge C, Nzooh Z, Ruiz-Perez M and Sayer JA. 2010. A framework for assessing conservation and development in a Congo Basin forest landscape. Tropical Conservation Science 3:262281. https://doi.org/10.1177/194008291000300303.

Gasper D. 1997. 'Logical frameworks' : A critical assessment managerial theory, pluralistic practice. Working Paper Series 264: 1-36.

Grass I, Kubitza C, Krishna VV, Grass I, Kubitza C, Krishna VV, Corre MD, Mußhoff O, Pütz P, Drescher J, Rembold K, Sulpin Ariyanti ES...Wolni M. 2020. Trade-offs between multifunctionality and profit in tropical smallholder landscapes. Nature Communications 11, 186. https://doi.org/10.1038/s41467-020-15013-5.

Langston JD, Riggs R, Kastanya A, Sayer J, Margules C and Boedhihartono AK. 2019. Science embedded in local forest landscape management improves benefit flows to society. Frontiers in Forests and Global Change 2: 1-13. https://doi.org/10.3389/ ffgc.2019.00003.

Lindenmayer D, Hobbs RJ, Montague-Drake R, Alexandra J, Bennett A, Burgman M, Cale P, Calhoun A, Cramer V, Cullen P, ...Zavaleta E. 2008. A checklist for ecological management of landscapes for conservation. Ecology Letters 11(1): 78-91. https://doi. org/10.1111/j.1461-0248.2007.01114.x.

Milder JC, Hart AK, Dobie P, Minai J and Zaleski C. 2014. Integrated landscape initiatives for African agriculture, development, and conservation: A region-wide assessment. World Development. 54:68-80. https://doi.org/10.1016/j.worlddev.2013.07.006.

Newton P, Kinzer AT, Miller DC, Oldekop JA and Agrawal A. 2020. The number and spatial distribution of forest-proximate people globally. One Earth 3(3):363-370. https://doi. org/10.1016/j.oneear.2020.08.016. 
Noss RF. 1983. A regional landscape approach to maintain diversity. BioScience 33(11): $700-706$.

Rasmussen LV, Fagan M, Ickowitz A, Wood SLR, Kennedy G, Powell B, Baudron F, Gergel S, Jung S, Smithwick E, Sunderland T, Wood S and Rhemtulla JM. 2019. Forest pattern, not just amount, influences dietary quality in five African countries. Global Food Security 25: 100331.

Redford KH, Padoch C and Sunderland T. 2013. Fads, funding, and forgetting in three decades of conservation. Conservation Biology 27(3): 437-438. https://doi.org/10.1111/ cobi.12071.

Reed J, van Vianen J, Foli S, Clendenning J, Yang K, MacDonald M, Petrokofsky G, Padoch C and Sunderland T. 2017. Trees for life: The ecosystem service contribution of trees to food production and livelihoods in the tropics. Forest Policy and Economics 84: 62-71. https://doi.org/10.1016/j.forpol.2017.01.012.

Sandker M, Campbell BM, Nzooh Z, Sunderland T, Amougou V, Defo L and Sayer J. 2009. Exploring the effectiveness of integrated conservation and development interventions in a Central African forest landscape. Biodiversity and Conservation 18: 2875-2892. https://doi.org/10.1007/s10531-009-9613-7.

Sayer J, Sunderland T, Ghazoul J, Pfund J-L, Sheil D, Meijaard E, Venter M, Boedhihartono AK, Day M, Garcia C, van Oosten C and Buck LE. 2013. Ten principles for a landscape approach to reconciling agriculture, conservation, and other competing land uses. Proceedings of the National Academy of Sciences of the USA 110: 8349-56. https://doi.org/10.1073/pnas.1210595110.

Sayer J and Wells MP. 2004. The pathology of projects. In McShane TO, Wells MP, eds. Getting biodiversity projects to work. Towards more effective conservation and development. New York: Columbia University Press. 35-48.

Sunderland TCH, Sayer JA and Hoang Minh-Ha, eds. 2013. Evidence-based conservation: Lessons from the Lower Mekong. London: Earthscan.

World Bank. 2020. Global economic prospects. Washington DC: The World Bank Group. WWF. 2020. Living planet report 2020. Gland: WWF.

Zanzanaini C, Thi Tran B, Singh S, Hart A, Milder J and DeClerck F. 2017. Integrated landscape initiatives for agriculture, livelihoods and ecosystem conservation: An assessment of experiences from South and Southeast Asia. Landscape and Urban Planning 165: 11-21. https://doi.org/10.1016/j.landurbplan.2017.03.010. 


\section{ISBN 978-602-387-138-4}

DOI: $10.17528 /$ cifor/007800

Poverty, food insecurity, biodiversity and habitat loss are persistent global challenges that are further exacerbated by the impacts of climate change. These challenges are particularly hard felt in the tropical landscapes of the global South where tensions between local socio-economic and international environmental commitments are pervasive. Due to the apparent failure of sectorial approaches to address such challenges, more holistic strategies are being increasingly promoted. Integrated landscape approaches are one such example; essentially a governance strategy that engages multiple stakeholders to reconcile societal and environmental objectives at the landscape scale to identify trade-offs and potential synergies for more sustainable and equitable land management. Integrated landscape approaches have been widely endorsed in the international and national policy arena, within academia, and in the discourse surrounding conservation and development funding. However, despite strong scientific theories and concepts, the implementation, and particularly evaluation and reporting, of integrated landscape approaches in the tropics remains poorly developed.

The COLANDS initiative represents an explicit attempt to contribute toward the evidence base by operationalizing integrated landscape approaches in Chana, Zambia and Indonesia. In this regard we aim to provide regular, honest reporting of progress. This book details the experiences of researchers engaged in these landscape-scale initiatives across the first two years of implementation.

With dedicated chapters on current progress, biodiversity, methods and evaluation the book provides useful tools and resources for research and implementation. Furthermore, we consider the complex socio-political challenges associated with landscape approaches with chapters focussed on how to effectively engaging stakeholders and understanding the national policy environment. We then provide profiles of the sites in each of the three countries and describe the historical context, current status and potential for more integrated landscape governance. This book explores the techniques and strategies that can be deployed to improve the governance and management of land and natural resources and better reconcile conservation and development objectives in tropical landscapes undergoing rapid change.

\begin{tabular}{|l|l|l|} 
RESEARCH & This research was carried out by CIFOR as part of the CGIAR Research Program on \\
PRGRAM on & $\begin{array}{l}\text { Forests, Trees and } \\
\text { Agroforestry }\end{array}$ & $\begin{array}{l}\text { Forests, Trees and Agroforestry (FTA). FTA is the world's largest research for development } \\
\text { program to enhancetherole of forests, trees and agroforestry in sustainable development } \\
\text { and food security and to address climate change. CIFOR leads FTA in partnership with } \\
\text { Bioversity International, CATIE, CIRAD, INBAR, ICRAF and TBI. } \\
\text { FTA's work is supported by the CCIAR Trust Fund: cgiar.org/funders/ }\end{array}$ \\
\hline
\end{tabular}

\section{cifor.org | cifor.org/colands}

